PNNL-24709, Rev. 2

\title{
Conceptual Model of lodine Behavior in the Subsurface at the Hanford Site
}

\section{September 2017}

\author{
MJ Truex \\ BD Lee \\ CD Johnson \\ NP Qafoku \\ JE Szecsody \\ JE Kyle \\ M Tfaily \\ MMV Snyder \\ KJ Cantrell \\ DL Saunders
}

\author{
AR Lawter \\ M Oostrom \\ G Tartakovsky \\ II Leavy \\ EM McElroy \\ D Appriou \\ R Sahajpal \\ MM Carroll \\ RK Chu \\ EA Cordova
}

\author{
GV Last \\ MH Lee \\ DI Kaplan \\ W Garcia \\ S Kerisit \\ O Qafoku \\ M Bowden \\ F Smith \\ JG Toyoda \\ AE Plymale
}




\title{
DISCLAIMER
}

This report was prepared as an account of work sponsored by an agency of the United States Government. Neither the United States Government nor any agency thereof, nor Battelle Memorial Institute, nor any of their employees, makes any warranty, express or implied, or assumes any legal liability or responsibility for the accuracy, completeness, or usefulness of any information, apparatus, product, or process disclosed, or represents that its use would not infringe privately owned rights. Reference herein to any specific commercial product, process, or service by trade name, trademark, manufacturer, or otherwise does not necessarily constitute or imply its endorsement, recommendation, or favoring by the United States Government or any agency thereof, or Battelle Memorial Institute. The views and opinions of authors expressed herein do not necessarily state or reflect those of the United States Government or any agency thereof.

\author{
PACIFIC NORTHWEST NATIONAL LABORATORY \\ operated by \\ BATTELLE \\ for the \\ UNITED STATES DEPARTMENT OF ENERGY \\ under Contract DE-AC05-76RL01830
}

Printed in the United States of America
Available to DOE and DOE contractors from the
Office of Scientific and Technical Information,
P.O. Box 62, Oak Ridge, TN 37831-0062;
ph: (865) 576-8401
fax: $(865)$ 576-5728
email: reports@adonis.osti.gov

Available to the public from the National Technical Information Service

5301 Shawnee Rd., Alexandria, VA 22312

ph: (800) 553-NTIS (6847)

email: orders@ntis.gov $<$ http://www.ntis.gov/about/form.aspx $>$

Online ordering: http://www.ntis.gov

This document was printed on recycled paper. 
PNNL-24709, Rev. 2

RPT-DVZ-AFRI-030, Rev. 2

\section{Conceptual Model of lodine Behavior in the Subsurface at the Hanford Site}

\author{
MJ Truex \\ BD Lee \\ CD Johnson \\ NP Qafoku \\ JE Szecsody \\ JE Kyle \\ M Tfaily \\ MMV Snyder \\ KJ Cantrell \\ DL Saunders
}

\author{
AR Lawter \\ M Oostrom \\ G Tartakovsky \\ II Leavy \\ EM McElroy \\ D Appriou \\ R Sahajpal \\ MM Carroll \\ RK Chu \\ EA Cordova
}

\author{
GV Last \\ MH Lee \\ DI Kaplan ${ }^{1}$ \\ W Garcia \\ S Kerisit \\ O Qafoku \\ M Bowden \\ F Smith \\ JG Toyoda \\ AE Plymale
}

September 2017

Prepared for

the U.S. Department of Energy

under Contract DE-AC05-76RL01830

Pacific Northwest National Laboratory

Richland, Washington 99352

\footnotetext{
${ }^{1}$ Savannah River National Laboratory, Aiken, South Carolina
} 
PNNL-24709, Rev. 2

RPT-DVZ-AFRI-030, Rev. 2

\section{Summary}

Isotopes of iodine were generated during plutonium production within the nine production reactors at the U.S. Department of Energy Hanford Site. The short half-life ${ }^{131}$ I that was released from the fuel into the atmosphere during the dissolution process (when the fuel was dissolved) in the Hanford Site 200 Area is no longer present at concentrations of concern in the environment. The long half-life ${ }^{129}$ I generated at the Hanford Site during reactor operations was (1) stored in single-shell and double-shell tanks, (2) discharged to liquid disposal sites (e.g., cribs and trenches), (3) released to the atmosphere during fuel reprocessing operations, or (4) captured by off-gas absorbent devices (silver reactors) at chemical separations plants (PUREX, B-Plant, T-Plant, and REDOX). Releases of ${ }^{129}$ I to the subsurface have resulted in several large, though dilute, plumes in the groundwater. There is also ${ }^{129} \mathrm{I}$ remaining in the vadose zone beneath disposal or leak locations. The fate and transport of ${ }^{129} \mathrm{I}$ in the environment and potential remediation technologies are currently being studied as part of environmental remediation activities at the Hanford Site. A conceptual model describing the nature and extent of subsurface contamination, factors that control plume behavior, and factors relevant to potential remediation processes is needed to support environmental remedy decisions. Because ${ }^{129} \mathrm{I}$ is an uncommon contaminant, relevant remediation experience and scientific literature are limited. In addition, its behavior in subsurface is different from that of other more common and important contaminants (e.g., U, Cr and Tc) in terms of sorption (adsorption and precipitation), and aqueous phase species transformation via redox reactions. Thus, the conceptual model also needs to both describe known contaminant and biogeochemical process information and identify aspects about which additional information is needed to effectively support remedy decisions.

There are three basic components of the conceptual model: Inputs, Source Flux to Groundwater, and Plume Behavior. Inputs include information about ${ }^{129}$ I discharges to the subsurface and other boundary conditions (e.g., recharge from precipitation) that influence ${ }^{129}$ I fate and transport. Information is available from several sources to define the important input parameters. The source flux to groundwater component identifies factors important to consider in defining the nature of sources to historical, current, and future groundwater plumes. This information is needed to provide a context for examining fate and transport and remediation of groundwater plumes, which are the risk driver for remediation activities. Some analyses have been completed to quantify potential source flux to the groundwater. However, additional evaluations using recently developed approaches will be needed to refine these estimates. Prediction of plume behavior associated with ${ }^{129}$ I fate and transport is needed for risk assessment and to support remedy decisions and remedy design and implementation. Recent information describing the relative quantity of three primary iodine chemical species present in the groundwater (iodide, iodate, and organic-iodine complexes) is pertinent to predicting plume behavior because each chemical species has different transport characteristics and may be subject to transformation reactions. The transformation reactions can change the relative quantity of chemical species, result in accumulation as a solid phase, or promote volatilization of iodine. Thus, transformation reactions are relevant to plume attenuation and for application of remediation technologies. Existing data describing iodine species transport properties and transformation reactions have been compiled. In addition, technical gaps were identified associated with the need to refine this information in support of future remedy decisions. Revision 1 of this document includes updates to the text and addition of descriptions of studies that were applied to address some of the data gaps identified in Revision 0 (see Change History, Rev. 1). Revision 2 of this document includes additions and updates to existing text, additions of new sections and subsections that describe studies that 
PNNL-24709, Rev. 2

RPT-DVZ-AFRI-030, Rev. 2

were conducted during FY17 to address data gaps identified in the previous revisions of this report (see Change History, Rev. 2).

Because there are uncertainties in the iodine species transport parameters and transformation reactions with respect to plume behavior at the Hanford Site, alternative conceptual models were developed based on outcomes of ongoing research. The first two alternatives describe scenarios with different iodine chemical species controlling the overall transport behavior of ${ }^{129} \mathrm{I}$ for a condition where no significant species transformation reactions are occurring. The other two alternatives describe scenarios where different types of transformation reactions are important. These alternative conceptual models provide a structure to guide development of studies that will help distinguish the alternative that best describes plume behavior as part of refining the iodine conceptual model for the Hanford Site and providing an appropriate technical basis for fate and transport analyses and remediation decisions. 
PNNL-24709, Rev. 2

RPT-DVZ-AFRI-030, Rev. 2

\section{Change History, Rev. 1}

Revision 1 of this document includes updates to the text and added descriptions of studies that were applied to address some of the data gaps identified in Revision 0. Descriptions of the changes are provided below.

Changes to Existing Sections

- The summary indicates that Revision 1 contains new information and updated text.

- Section 1.0 (introductory paragraph) was updated to indicate that Revision 1 contains new information and updated text.

- Section 2.1, Figure 5 was updated.

- Section 2.2, Figure 7 was updated.

- Section 2.3 was updated with new introductory text and new Sections 2.3.1 through 2.3.5 were added (as described below).

- Section 3.1 was updated by adding a new section to describe a vadose zone evaluation (Section 3.1.2, described below).

- Section 4.1 alternative conceptual model descriptions were updated to incorporate new information from the added experimental studies in Section 2.3.

- Section 4.2 data gaps descriptions were updated to incorporate new information from the added experimental studies in Section 2.3.

- Section 6.0 conclusions and recommendations were updated to incorporate new information from the added experimental studies in Section 2.3.

\section{Added Sections}

- Section 2.3.1 was added to describe the results of experiments to quantify sorption of iodine species. Previous literature information about iodine species sorption from Revision 0 was included in this new section.

- Section 2.3.2 was added to describe the results of experiments to evaluate microbial transformation of iodine species. Previous literature information about iodine species microbial transformation from Revision 0 was included in this new section.

- Section 2.3.3 was added to describe the results of experiments to evaluate transformation of iodine species in aquifer sediments. Previous literature information about iodine species transformation in sediments from Revision 0 was included in this new section.

- Section 2.3.4 was added to describe the results of scoping experiments to evaluate the organic compounds and potential associations of iodine with organic compounds in Hanford Site 200-UP-1 operable unit groundwater samples. Previous text providing context about organic-iodine species from Revision 0 was included in this new section. 
PNNL-24709, Rev. 2

RPT-DVZ-AFRI-030, Rev. 2

- Section 2.3.5 was added to describe the results of experiments to evaluate formation of precipitates incorporating iodate during calcite precipitation. Previous literature information about coprecipitation of iodate and calcite from Revision 0 was included in this new section.

- Section 3.1.2 was added to describe the results of a vadose zone modeling analysis of the ${ }^{129}$ I source areas for the 200-UP-1 operable unit.

- Section 5.0 was added to describe the quality assurance associated with information in this report. 
PNNL-24709, Rev. 2

RPT-DVZ-AFRI-030, Rev. 2

\section{Change History, Rev. 2}

Revision 2 of this document includes updates to the text and added descriptions of studies that were applied to address some of the data gaps identified in Revision 1. Descriptions of the changes are provided below.

Changes to Existing Sections

- The summary indicates that Revision 2 contains new information and updated text.

- Section 1.0 (introductory paragraph) was updated to indicate that Revision 2 contains new information and updated text.

- Section 1.2 was updated with text about iodine speciation on the Hanford Site and additional well data from the Hanford Site was added to this section.

- Section 2.3 was updated in the following ways:

Section 2.3.2 was updated by adding a paragraph and Figure 15 to describe additional work conducted involving iodate bioreduction by MR-1.

Section 2.3.4 was updated by removing text describing future work and moving the Rev. 1 additions into Section 2.3.4.1. Section 2.3.4.2 was added to include new work conducted in this area (as described below).

Section 2.3.5 was updated with revised text to further describe the calcite precipitation batch experiments, and Sections 2.3.5.1 to 2.3.5.3 were added (as described below).

Section 2.3.6 was added (as described below).

- Section 3.0, Figure 38, was added to show the current iodine plume map.

- Section 4.0 was updated to include findings of Revision 2.

- Section 5.0 was updated to include Revision 2 in applicable QA statements.

- Section 6.0 conclusions and recommendations were updated to incorporate new information from the added experimental studies and updated text throughout the report.

Added Sections

- Section 2.3.4.2 was added to describe the results of scoping experiments to evaluate the organic compounds and potential associations of iodine with organic compounds in Hanford Site 200-UP-1 operable unit groundwater samples. This section expands the work included in Revision 1, described in Section 2.3.4.1. Sections 2.3.4.1 and 2.3.4.2 both contain scoping work that is considered "For Information Only."

- Sections 2.3.5.1, 2.3.5.2, and 2.3.5.3 were added to describe stability testing of iodate-containing calcite, solid phase characterization of iodate-containing calcite, and additional scoping work conducted to further understanding of processes that hinder and/or improve iodine incorporation into calcite, respectively. The scoping work and solid phase characterization presented in these sections is For Information Only. 
PNNL-24709, Rev. 2

RPT-DVZ-AFRI-030, Rev. 2

- Section 2.3.6 was added to describe molecular dynamic modeling. The modeling work is considered For Information Only.

- A reference to Section 1.2 was added to Appendix A, Section A.1.1. 
PNNL-24709, Rev. 2

RPT-DVZ-AFRI-030, Rev. 2

\section{Acknowledgments}

This document was prepared by the Deep Vadose Zone - Applied Field Research Initiative at Pacific Northwest National Laboratory. Funding for this work was provided by the U.S. Department of Energy (DOE) Richland Operations Office. The Pacific Northwest National Laboratory is operated by Battelle Memorial Institute for the DOE under Contract DE-AC05-76RL01830. 
PNNL-24709, Rev. 2

RPT-DVZ-AFRI-030, Rev. 2

\section{Acronyms and Abbreviations}

\begin{tabular}{|c|c|}
\hline ABTS & 2,2'-azino-bis(3-ethylbenzothiazoline-6-sulphonic acid) \\
\hline AGW & artificial groundwater \\
\hline ASME & American Society of Mechanical Engineers \\
\hline $\mathrm{BBI}$ & Best Basis Inventory \\
\hline bls & below land surface \\
\hline bwt & below water table \\
\hline CAWSRP & Conducting Analytical Work in Support of Regulatory Programs \\
\hline CFB & Cytophaga-Flexibacter-Bacteriodes \\
\hline CFR & Code of Federal Regulations \\
\hline DOC & dissolved organic carbon \\
\hline DOE & U.S. Department of Energy \\
\hline DPMAS & direct-polarization magic-angle spinning \\
\hline DVZ & Deep Vadose Zone \\
\hline DVZ-AFRI & Deep Vadose Zone - Applied Field Research Initiative \\
\hline DWS & drinking water standard \\
\hline EDS & energy dispersive $\mathrm{X}$-ray spectroscopy \\
\hline EXAFS & extended X-ray absorption fine structure spectra \\
\hline $\mathrm{E}_{\mathrm{h}}$ & oxidation/reduction potential \\
\hline ESL & Environmental Sciences Laboratory \\
\hline FIB & focused ion beam \\
\hline FIO & For Information Only \\
\hline FTICR & Fourier transform ion cyclotron resonance \\
\hline FY & fiscal year \\
\hline HASQARD & Hanford Analytical Services Quality Assurance Requirements Document \\
\hline HDI & PNNL’s “How Do I...” \\
\hline ID & identification (number or name) \\
\hline $\mathrm{K}_{\mathrm{d}}$ & linear equilibrium adsorption coefficient \\
\hline LMCO & laccase-like multicopper oxidase \\
\hline MS & mass spectrometer \\
\hline MTBE & methyl tert-butyl ether \\
\hline NanoSIMS & nanoscale secondary ion mass spectroscopy \\
\hline NMR & nuclear magnetic resonance \\
\hline NOM & natural organic matter \\
\hline NQA & Nuclear Quality Assurance \\
\hline OC & organic carbon \\
\hline $\mathrm{OM}$ & organic matter \\
\hline
\end{tabular}


PNNL-24709, Rev. 2

RPT-DVZ-AFRI-030, Rev. 2

$\begin{array}{ll}\text { Organo-I } & \text { organo-iodine } \\ \text { OU } & \text { operable unit } \\ \text { pH } & \text { negative of the base 10 logarithm of the hydrogen ion activity in solution } \\ \text { PNNL } & \text { Pacific Northwest National Laboratory } \\ \text { QA } & \text { quality assurance } \\ \text { SAM } & \text { s-adenosyl-l-methionine } \\ \text { SEM } & \text { scanning electron microscope } \\ \text { SOM } & \text { soil organic matter } \\ \text { SRS } & \text { Savannah River Site } \\ \text { TEM/SAED } & \text { transmission electron microscope/selected area electron diffraction } \\ \text { TI } & \text { total iodine } \\ \text { VK } & \text { van Krevelen } \\ \text { VL } & \text { (Hanford) Virtual Library } \\ \text { WMA } & \text { Waste Management Area } \\ \text { XANES } & \text { X-ray absorption near-edge structure } \\ \text { XRD } & \text { X-ray diffraction }\end{array}$




\section{Contents}

Summary . .iii

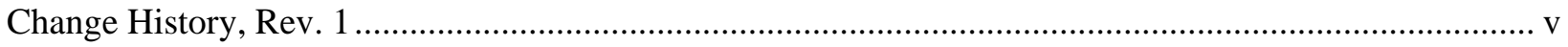

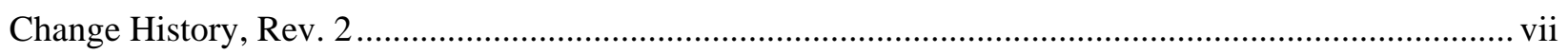

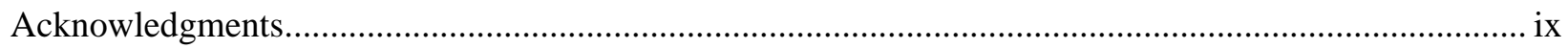

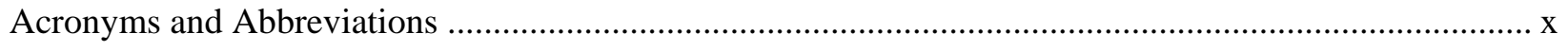

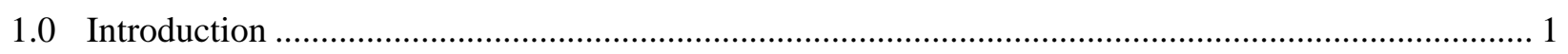

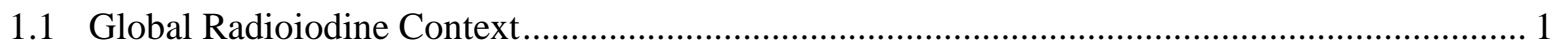

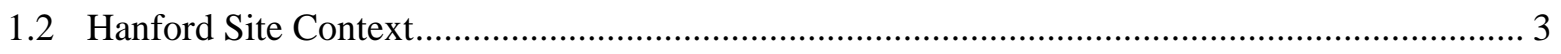

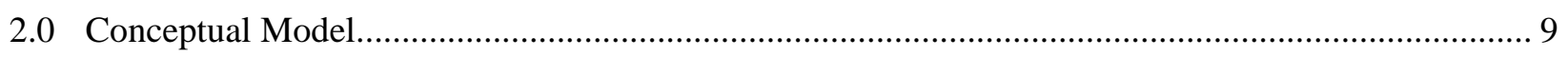

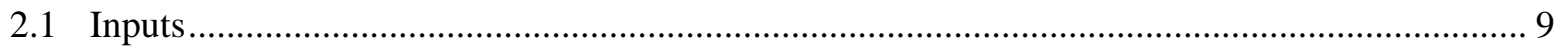

2.2 Source Flux to Groundwater …....................................................................................... 14

2.3 Plume Behavior: Controlling Features and Processes........................................................ 16

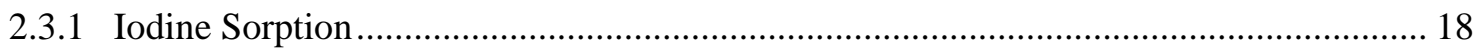

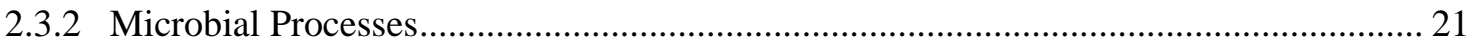

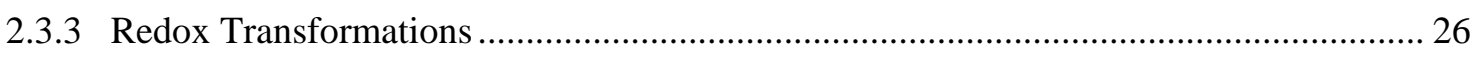

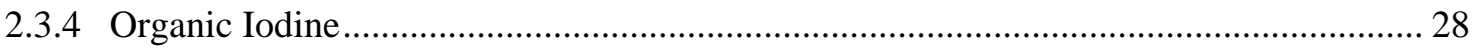

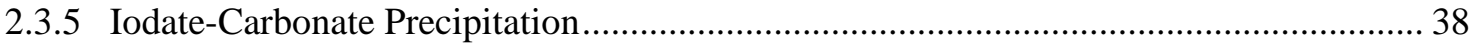

2.3.6 Ab Initio Molecular Dynamics Simulation of Iodate incorporation into Calcite ............ 49

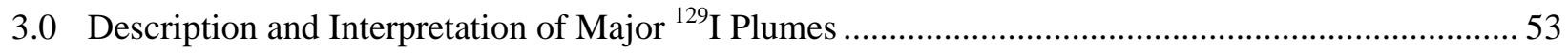

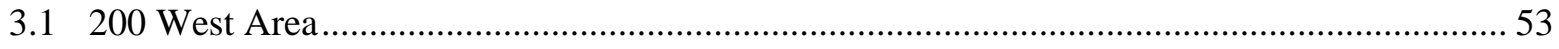

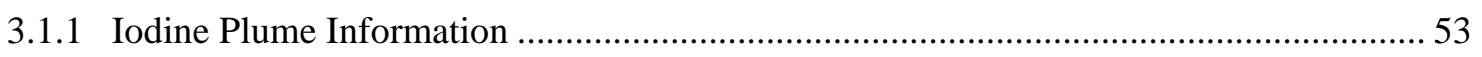

3.1.2 200-UP-1 Operable Unit Plume Vadose Zone Source Evaluation.................................. 59

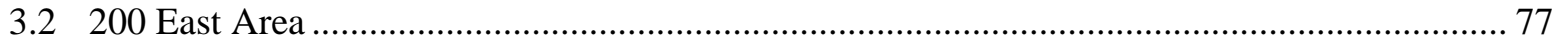

4.0 Alternative Conceptual Models for Future Plume Behavior ......................................................... 82

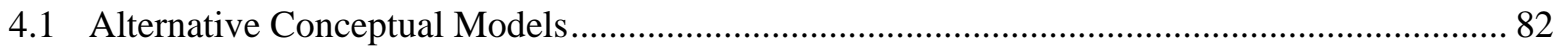

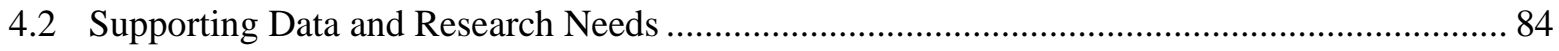

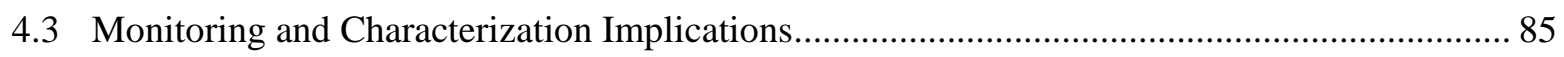

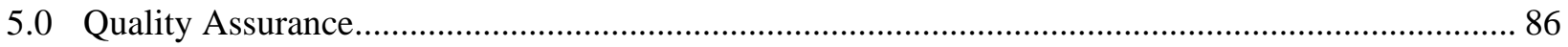

6.0 Brief Summary of Recent Findings, Recommendations and Conclusions ....................................... 88

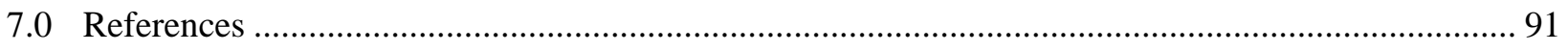

Appendix A Summary of Current Biogeochemical Process Information ................................................ A.1

Appendix B 200-UP-1 Operable Unit ${ }^{129}$ I Disposal Site Information ..................................................1 
PNNL-24709, Rev. 2

RPT-DVZ-AFRI-030, Rev. 2

\section{Figures}

Figure 1. Global iodine cycle, showing natural and anthropogenic sources of iodine isotopes and cycling of multiple iodine species in the environment.

Figure 2. ${ }^{129}$ I and other contaminant plumes associated with the 200 East and 200 West Areas on the Hanford Site. Figure adapted from DOE 2014.

Figure 3. System-level depiction of elements affecting iodine fate and transport......

Figure 4. Relative percentage of the total ${ }^{129}$ I inventory released to individual waste sites based on data from the Soil Inventory Model (Corbin et al. 2005) for sites with greater than $1 \%$ of the total (the 216-U-1/2 sites associated with part of the 200-UP-1 OU plume had less than $1 \%$ of the total).

Figure 5. Estimated total liquid waste disposal volumes for sites with greater than $1 \%$ of the disposed ${ }^{129}$ I inventory (Figure 4 ) with average annual disposal shown for sites having more than 1 year of disposal. Note that the 216-U-1/2 sites associated with part of the 200-UP-1 OU plume had less than $1 \%$ of the total and are, therefore, not shown here. Also, note the log-scale on the y-axis. Based on data from the Virtual Library, Effluent Volume to Soil Disposal Site module.

Figure 6. Calculated average ${ }^{129}$ I concentration for sites with greater than $1 \%$ of the disposed ${ }^{129} \mathrm{I}$ inventory (Figure 4). Note that the 216-U-1/2 sites associated with part of the 200-UP-1 OU plume had less than $1 \%$ of the total and are, therefore, not shown here. Also, note the logscale on the $\mathrm{y}$-axis and that the DWS is $1 \mathrm{pCi} / \mathrm{L}$ for ${ }^{129} \mathrm{I}$.

Figure 7. Total ${ }^{129}$ I inventory and relative number of soil column pore volumes of effluent received for sites with greater than $1 \%$ of the disposed ${ }^{129}$ I inventory (Figure 4 ). Note that the $216-\mathrm{U}-1 / 2$ sites associated with part of the 200-UP-1 OU plume had less than $1 \%$ of the total and are, therefore, not shown here. Also, note the log-scale on the y-axes.

Figure 8. Conceptual overview of subsurface biogeochemical processes that affect the fate and transport of iodine. The figure does not distinguish between ${ }^{129} \mathrm{I}$ and ${ }^{127} \mathrm{I}$ because these processes are the same for both isotopes. The three primary aqueous iodine species are iodate $\left(\mathrm{IO}_{3}^{-}\right)$, Organo-I, and iodide $\left(\mathrm{I}^{-}\right)$. Processes include biotic (Bacteria) transformations between iodine species as shown and potential transformations to other species, as illustrated in Figure 9. Iodate reduction may also occur abiotically (not shown) (e.g., by reactions with sediment-associated iron/manganese at the Hanford Site, see Section 2.3.1). Iodine species adsorb to sediment surfaces (e.g., on iron oxide deposits or phyllosilicates), with greater adsorption expected in fine-textured sediment zones (Fines). Natural organic matter may facilitate sorption and accumulation of iodine or, as a DOC, may form mobile Organo-I. Iodate may co-precipitate with calcium carbonate.

Figure 9. Biological transformations associated with iodine cycling in the environment. The blue ellipse represents predominantly aqueous-phase iodine species. The orange ellipse represents predominantly solid-phase species of iodine associated with organic compounds (Organo-I) or accumulated in microbial biomass (Microbe-I). Some types of Organo-I may also be mobile in the aqueous phase. The green ellipse represents predominantly gas-phase volatile Organo-I compounds. Figure 8 provides context for some of these processes within the subsurface biogeochemical environment.

Figure 10. Results of batch sorption experiments spiked with iodide showing no transformation to iodate. Iodide data also demonstrate minimal sorption to the sediments. 
Figure 11. Results of two replicate column sorption experiments with iodide in the column influent.

Figure 12. Results of batch experiments spiked with iodate showing iodate transformation to iodide. A $\mathrm{K}_{\mathrm{d}}$ value for iodate of $0.9 \mathrm{~mL} / \mathrm{g}$ was estimated from these data.

Figure 13. Results of three replicate column sorption experiments with iodate in the column influent.

Figure 14. Iodate (with associated increase in iodide concentration) and nitrate reduction by Agrobacterium DVZ35 in a growth media.

Figure 15. Iodate bioreduction by Shewanella oneidensis strain MR-1 (wild type) vs. no-cell controls, in anoxic M1 medium (phosphate-buffered at $\mathrm{pH} 7.0$ ), with lactate (20 mM) as electron donor.

Figure 16. Growth and ABTS oxidation by different Hanford bacterial isolates (A) and molecular iodine concentration over time for four microbial isolates (DVZ2, DVZ19, DVZ21, and DVZ24) as an indicator for iodide oxidation (B). Negative controls contained no bacteria. Positive controls contained an enzyme that oxidizes ABTS and iodide.

Figure 17. Organic compound classification by van Krevelen analysis based on their H/C and $\mathrm{O} / \mathrm{C}$ atomic ratios.

Figure 18. van Krevelen plot of organic compound data and assigned formula categories for (a) well C9416, (b) C9415, and (c) C9412.

Figure 19. van Krevelen diagram of the 8 standards used for the $\mathrm{KI}$ and $\mathrm{KIO}_{3}$ spiking experiments. The standards fall within the different regions of the diagram highlighting the structural differences.

Figure 20. (A) MS/MS of 4-iodopyrazole $\left(\mathrm{C}_{3} \mathrm{H}_{3} \mathrm{~N}_{2} \mathrm{I}\right)$ in negative ionization ([M-H] $)$. Fragmentation of the standard produced an $\mathrm{m} / \mathrm{z}$ 126.9048, the exact mass of iodide. (B) MS/MS of 4-iodo-6-phenylpyrimidine $\left(\mathrm{C}_{10} \mathrm{H}_{7} \mathrm{~N}_{2} \mathrm{I}\right)$ in positive ionization $\left([\mathrm{M}+\mathrm{H}]^{+}\right)$. The loss of IH produced the fragment $\mathrm{m} / \mathrm{z}$ 155.0609, the exact mass of the standard without iodine.

Figure 21. van Krevelen diagram of sediment and pore water OM. The van Krevelen diagram is a two dimensional (2D) scatter plot that has axes on the basis of the ratio of the number of major elements (e.g., H/C, O/C) in molecules.

Figure 22. Kendrick plot of all peaks observed in the $\mathrm{m} / \mathrm{z}$ 450-550 region before (full-orange) and after fragmentation (grey and blue)

Figure 23. Kendrick plot of (a) all peaks observed in the m/z 450-550 region before fragmentation, (b), and (c) zoom-in at specific regions of the Kendrick plot.

Figure 24. van Krevelen diagram of the assigned formulas of our potential iodate-containing organic compounds.

Figure 25. Iodate concentrations (measured as total iodine) over time for experiments when iodate was added in one of the calcite-forming solutions prior to their mixing. The calciteforming solutions had concentrations of (a) $0.1 \mathrm{M}$ or (b) $1 \mathrm{M}$. Initial iodate concentrations are shown in the legend. The first iodate measurement (time zero) was taken $4 \mathrm{~h}$ after mixing of the calcite-forming solutions (i.e., after precipitation of calcite occurred). Error bars reflect standard deviations from the mean (two replicates).

Figure 26. Iodate concentrations (measured as total iodine) over time for experiments when iodate was added in one of the calcite-forming solutions prior to their mixing (purple square) compared to the experiment when iodate was added $24 \mathrm{~h}$ after mixing of the calcite-forming solutions (turquoise diamond, late spike). The first iodate measurement (time zero) was taken $4 \mathrm{~h}$ after mixing of the calcite-forming solutions (i.e., after precipitation of calcite 
occurred) for the immediate-spike test (purple square). The time zero sample of the latespike experiment was taken prior to the addition of the iodate and the subsequent sample was taken $4 \mathrm{~h}$ later. The $0.1 \mathrm{M}$ calcite-forming solutions were used in both experiments. Added iodate concentrations are shown in the legend. Error bars reflect standard deviations from the mean (two replicates).

Figure 27. Vented poly bottle

Figure 28. Calcite solubility as a function of $\mathrm{pH}$ for calcite produced without iodine spikes (1M) and with $250 \mu \mathrm{g} / \mathrm{L}$ (7C) or $500 \mu \mathrm{g} / \mathrm{L}$ (9C) starting iodine concentrations (FIO).

Figure 29. XRD results for calcite samples produced with variable iodine and/or chromium spike concentrations (FIO).

Figure 30. "FIO” SEM images from calcite precipitated from $1 \mathrm{M} \mathrm{CaCl} 2$ and $\left.\left(\mathrm{NH}_{4}\right)_{2} \mathrm{CO}_{3}\right\urcorner$ with variable iodine and/or chromate spike concentrations. Top row: $50 \mu \mathrm{g} / \mathrm{L}$ iodate spike; middle row: $250 \mu \mathrm{g} / \mathrm{L}$ iodate spike added after precipitation ("late spike”); bottom row: $250 \mu \mathrm{g} / \mathrm{L}$ i iodate spike and an additional $500 \mu \mathrm{g} / \mathrm{L}$ chromate spike. Note that the scale of the SEM micrographs is approximate.

Figure 31. "FIO" TEM images and EDS spectra of a FIB-ed calcite sample that contained iodate showing that most likely iodate was present in locations close to the surface of calcite particles (Courtesy of Libor Kovarik, Environmental Molecular Sciences Laboratory (EMSL)

Figure 32. The preliminary, "FIO" nanoSIMS observations indicate that I was accumulated along crystal boundaries and was part of the crystal structure and not simply due to surface contamination (Courtesy of John Cliff, EMSL)......

Figure 33. Results of the scoping experiments showing that in the presence of a reducing agent used to immobilize co-contaminants such as Tc, calcite precipitation is not able to remove iodate from solution as efficiently as without the reducing agent present due to the reduction of iodate to iodide.

Figure 34. Experimental and calculated I K-edge EXAFS spectra (left) and corresponding Fourier transform magnitudes (right) for I in $\mathrm{NaIO}_{3}$ (top), $\mathrm{Ca}\left(\mathrm{IO}_{3}\right)_{2} \cdot \mathrm{nH}_{2} \mathrm{O}$ (middle), and $\mathrm{KIO}_{3}$ (bottom) for temperatures ranging from 8 to $200 \mathrm{~K}$. The experimental data are from Podder et al. (2017), Laurencin et al. (2014), and Yagi et al. (2001). The simulated supercell sizes are also shown in each case. All of the experimental and calculated data in this figure are FIO.

Figure 35. Atomistic models illustrating the incorporation of iodate at the carbonate position in calcite and charge compensation by sodium in the two nearest-neighbor positions (\#1 and \#2) and in a distant position (\#3). The corresponding atomic positions in pure calcite are also shown (\#0). Calcium atoms are shown in blue, oxygen in red, carbon in brown, iodine in purple, and sodium in yellow.

Figure 36. Atomistic models illustrating the incorporation of iodate at the carbonate position in calcite and charge compensation by hydrogen in the two nearest-neighbor positions (\#1 and \#2). Calcium atoms are shown in blue, oxygen in red, carbon in brown, iodine in purple, and hydrogen in white. The positions of the calcium vacancy are shown by green dotted circles.

Figure 37. ${ }^{129}$ I groundwater plumes emanating from the 200 West Area (adapted from DOE 2014).

Figure 38. Map of the iodine plume as of 5/1/2017. The open circles (Type 1 Control Point) to the east of the distal end of the plume are the hydraulic containment wells. The wells were completed in 2015, and have been in operation since at least the beginning of 2016 . 
Figure 39. ${ }^{129}$ I plume depictions over a 20-year period for the 200-UP-1 OU. Plume images were obtained using the Plume Status feature of the PHOENIX web-based data tool for the Hanford Site (http://phoenix.pnnl.gov/apps/plumes/index.html, accessed on 8/18/2015). Note that the set of wells used for plume contouring has varied over time. 56

Figure 40. Wells selected for plotting temporal data (yellow circles). Well locations are shown with a background of the $2013{ }^{129} \mathrm{I}$ plume contours, where light blue is 1 to $10 \mathrm{pCi} / \mathrm{L}$ and darker blue is greater than $10 \mathrm{pCi} / \mathrm{L}$. Image was obtained using the PHOENIX web-based data tool for the Hanford Site (http://phoenix.pnnl.gov/, accessed on 8/18/2015).

Figure 41. Temporal ${ }^{129}$ I concentration profiles in seven wells within the central portion of the 200-UP-1 OU. Data were obtained using the PHOENIX web-based data tool for the Hanford Site (http://phoenix.pnnl.gov/, accessed on 8/18/2015).

Figure 42. Predicted long-term ${ }^{129}$ I discharge across the water table emanating from the S-7 crib for various partition coefficient $\left(\mathrm{K}_{\mathrm{d}}\right)$ values.

Figure 43. Near-term predicted ${ }^{129} \mathrm{I}$ discharge across the water table emanating from the S-7 crib for various partition coefficient $\left(\mathrm{K}_{\mathrm{d}}\right)$ values.

Figure 44. ${ }^{129}$ I concentrations (pCi/L) for the Base Case at (a) 1965, (b) 2000, and (c) 2100.................. 63

Figure 45. Aqueous saturations for the Base Case at (a) 1965, (b) 2000, and (c) 2100.

Figure 46. Predicted normalized cumulative ${ }^{129}$ I discharge across the water table emanating from the S-7 crib for various partition coefficient $\left(\mathrm{K}_{\mathrm{d}}\right)$ values.

Figure 47. Near-term predicted normalized cumulative ${ }^{129}$ I discharge across the water table emanating from the S-7 crib for various partition coefficient $\left(\mathrm{K}_{\mathrm{d}}\right)$ values.

Figure 48. Predicted ${ }^{129}$ I discharge across the water table emanating from the S-7 crib for various $\mathrm{K}_{\mathrm{d}}$ values for various combinations partition coefficient $\left(\mathrm{K}_{\mathrm{d}}\right)$ and reaction rates $(k)$ values.

Figure 49. Predicted ${ }^{129}$ I groundwater concentrations at (a) 2000, (b) 2016, and (c) 2100 at various distances downstream of the footprint center of the S-7 crib for a $\mathrm{K}_{\mathrm{d}}=0 \mathrm{~mL} / \mathrm{g}$ (water table is at $z=0 \mathrm{~m}$ ).

Figure 50. Predicted ${ }^{129}$ I groundwater concentrations at (a) 2000, (b) 2016, and (c) 2100 at various distances downstream of the footprint center of the $\mathrm{S}-7$ crib for a $\mathrm{K}_{\mathrm{d}}=0.2 \mathrm{~mL} / \mathrm{g}$ (water table is at $z=0 \mathrm{~m}$ ).

Figure 51. Predicted ${ }^{129}$ I groundwater concentrations at (a) 2000, (b) 2016, and (c) 2100 at various distances downstream of the footprint center of the S-7 crib for a $\mathrm{K}_{\mathrm{d}}=0.5 \mathrm{~mL} / \mathrm{g}$ (water table is at $z=0 \mathrm{~m}$ ).

Figure 52. Predicted ${ }^{129}$ I groundwater concentrations at (a) 2000, (b) 2016, and (c) 2100 at various distances downstream of the footprint center of the S-7 crib for a $\mathrm{K}_{\mathrm{d}}=0 \mathrm{~mL} / \mathrm{g}$ and $k$ $=0.01 / \mathrm{yr}$ (water table is at $z=0 \mathrm{~m}$ ). .

Figure 53. Predicted ${ }^{129}$ I groundwater concentrations at (a) 2000, (b) 2016, and (c) 2100 at various distances downstream of the footprint center of the S-7 crib for a $\mathrm{K}_{\mathrm{d}}=0 \mathrm{~mL} / \mathrm{g}$ and $k$ $=0.1 / \mathrm{yr}$ (water table is at $z=0 \mathrm{~m}$ ).

Figure 54. Predicted ${ }^{129}$ I groundwater concentrations at (a) 2000, (b) 2016, and (c) 2100 at various distances downstream of the footprint center of the $S-7$ crib for a $K_{d}=0.2 \mathrm{~mL} / \mathrm{g}$ and $k=0.01 / \mathrm{yr}$ (water table is at $z=0 \mathrm{~m}$ ).

Figure 55. Predicted ${ }^{129}$ I groundwater concentrations at (a) 2000, (b) 2016, and (c) 2100 at various distances downstream of the footprint center of the $S-7$ crib for a $K_{d}=0.2 \mathrm{~mL} / \mathrm{g}$ and $k=0.1 / \mathrm{yr}$ (water table is at $z=0 \mathrm{~m}$ ). 
Figure 56. Predicted long-term ${ }^{129}$ I discharge across the water table emanating from the S-1/2 crib for various partition coefficient $\left(\mathrm{K}_{\mathrm{d}}\right)$ values. 75

Figure 57. Predicted normalized cumulative ${ }^{129} \mathrm{I}$ discharge across the water table emanating from the $\mathrm{S}-1 / 2$ crib for various partition coefficient $\left(\mathrm{K}_{\mathrm{d}}\right)$ values.

Figure 58. Predicted ${ }^{129}$ I discharge across the water table emanating from the S-1/2 crib for various $\mathrm{K}_{\mathrm{d}}$ values for various combinations partition coefficient $\left(\mathrm{K}_{\mathrm{d}}\right)$ and reaction rates $(k)$ values.

Figure 59. ${ }^{129}$ I groundwater contamination emanating from the 200 East Area (adapted from DOE 2014).

Figure 60. ${ }^{129}$ I plume depictions over a 20-year period for the 200-UP-1 OU. Plume images were obtained using the Plume Status feature of the PHOENIX web-based data tool for the Hanford Site (http://phoenix.pnnl.gov/apps/plumes/index.html, accessed on 8/18/2015).

Note that the wells used for plume contouring has varied over time.

Figure 61. Temporal ${ }^{129}$ I concentration profiles in nine 200-PO-1 OU wells for which concentrations were historically greater than $15 \mathrm{pCi} / \mathrm{L}$. Data were obtained using the PHOENIX web-based data tool for the Hanford Site (http://phoenix.pnnl.gov/, accessed on 8/18/2015)

\section{Tables}

Table 1. Major sources of ${ }^{129}$ I in the environment. 2

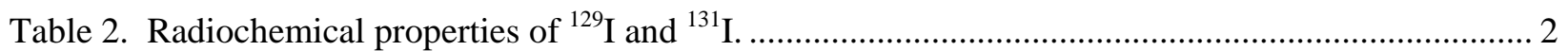

Table 3. Current estimates of ${ }^{129}$ I distribution at the Hanford Site. .......................................................... 4

Table 4. Chemistry and ${ }^{127}$ I speciation of filtered Hanford Site groundwater (Zhang et al. 2013)............. 7

Table 5. Iodine speciation in groundwater samples taken during drilling of monitoring well 299-W22-114 (ft bls = feet below land surface; ft bwt = feet below water table).

Table 6. Iodine speciation in groundwater samples from locations over the length of the 200-UP1

${ }^{129}$ I plume (ft bwt $=$ feet below water table).

Table 7. Categorization of waste sites based on potential impact to groundwater for three time intervals: up to year 2100, 2100-3100, and after 3100 (adapted from Truex and Carroll 2013). Sites with predicted groundwater concentrations less than the DWS are not shown ( 300 sites). Black text is for simulated results. Red text indicates values based on observed groundwater data.

Table 8. Co-contaminants in relative rank order based on the Soil Inventory Model inventories (Corbin et al. 2005).

Table 9. Iodide and iodate $K_{d}$ values for composite sediments recovered from 200 West Area borehole cores (Xu et al. 2015).

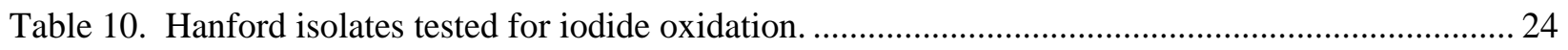

Table 11. Matrix of soil column experiments and summarized results. ................................................ 27

Table 12. Organic standards used in this study, both pre-bound with iodine and iodine free.

Table 13. Results from $\mathrm{KI}$ and $\mathrm{KIO}_{3}$ spiked organic standards experiment. Values in the table indicate the number of MS peaks identified to contain iodide $(\mathrm{m} / \mathrm{z} 126.905)$ and iodate $(\mathrm{m} / \mathrm{z}$ 174.889) 3 or 10 days after spiking. Values in parentheses identify the number of new 
PNNL-24709, Rev. 2

RPT-DVZ-AFRI-030, Rev. 2

Organo-I peaks identified after 10 days of spiking. Values in brackets in the iodate 10 day standards indicate the number of peaks identified to contain $\mathrm{m} / \mathrm{z} 126.905$, equal to that of iodide.

Table 14. Pore water and sediment sample locations from the Hanford Site (data presented here is FIO).

Table 15. FTICR-MS classification of compounds with assigned molecular formulas in the sediment and pore water. The numbers in the table represent \% relative abundances of FTICR MS class composition and compound classes, and the bottom row represents the total number of peaks observed in each sample.

Table 16. Final concentrations of iodine in $\mu \mathrm{g} \mathrm{I} / \mathrm{g}$ calcite for calcite tests described in Section 2.3.5. "Starting solution molarity" refers to the molarity of the calcium chloride and ammonium carbonate used to produce calcite, and additional variables are included in "other additions or info" column. Tests were conducted in duplicate; the average of two tests is included here with the standard deviation on the mean.

Table 17. Comparison of calculated $\mathrm{I}-\mathrm{O}$ bond lengths $(\AA)$ in $\mathrm{NaIO}_{3}$ and $\mathrm{Ca}\left(\mathrm{IO}_{3}\right)_{2}$ with $\mathrm{XRD}$ data. These data are from published sources (indicated by superscripts) or are FIO. ............................... 50

Table 18. Disposal characteristics of U1/U2, S-1/2, and S7 cribs....................................................... 59

Table 19. Partition coefficient $\left(\mathrm{K}_{\mathrm{d}}\right)$ and first-order reaction rate constant $(\mathrm{k})$ for the $\mathrm{S}-1 / 2$ and $\mathrm{S}-7$ simulations. 
PNNL-24709, Rev. 2

RPT-DVZ-AFRI-030, Rev. 2

\subsection{Introduction}

At the U.S. Department of Energy (DOE) Hanford Site, there are large dilute iodine-129 $\left({ }^{129} \mathrm{I}\right)$ groundwater plumes. A conceptual model describing the nature and extent of these plumes, factors that control plume behavior, and factors relevant to potential remediation processes is needed to support remedy decisions. Because ${ }^{129} \mathrm{I}$ is an uncommon contaminant, relevant remediation experience and scientific literature are limited. Thus, the conceptual model also needs to both describe known contaminant and biogeochemical process information and identify aspects about which additional information is needed to effectively support remedy decisions. Because there is an ongoing research program at the Hanford Site to address identified conceptual model gaps, it is anticipated that this conceptual model document will be updated periodically to represent the evolving state of knowledge for the ${ }^{129}$ I plumes. Revision 1 is the first update and includes some revisions to the document text and addition of descriptions of studies that were applied to address some of the data gaps identified in Revision 0 (see Change History, Rev. 1). Revision 2 of this document represents the second update and includes additional revisions to the document text, revisions and additions to existing sections of Revision 1, and additions of new sections with descriptions of experiments and data collected over FY17 to address conceptual model data gaps identified in the previous revisions of this report (see Change History, Rev. 2, page vii of this report).

\subsection{Global Radioiodine Context}

Radioiodine (i.e., radioactive isotopes of iodine) is produced primarily from neutron-induced fission of uranium and plutonium in nuclear reactors, but also is produced naturally in small quantities from spontaneous fission of natural uranium and by interaction of high-energy particles with xenon in the upper atmosphere (note that medical isotopes are not included in this document). Nuclear reactions form a variety of fission products, including 19 iodine isotopes (Kantelo et al. 1990). However, only the ${ }^{129} \mathrm{I}$ isotope is of long-term concern. Worldwide, chemical separation or reprocessing of nuclear fuel has resulted in the release of radioiodine into the environment. The ${ }^{129}$ I isotope has also been released to the environment by nuclear weapons testing (Muramatsu et al. 2004). The Hanford Site was one of the major contributors to worldwide release of the ${ }^{129} \mathrm{I}$ isotope to the environment (Table 1). Table 2 shows the radiochemical properties of ${ }^{129} \mathrm{I}$ and ${ }^{131} \mathrm{I}$ (an isotope of short-term concern).

Sources of ${ }^{129}$ I and ${ }^{127}$ I (stable, non-radioactive iodine) and the ways in which these species are introduced into the global iodine cycle must be considered to understand the fate of ${ }^{129} \mathrm{I}$ in the environment. Stable iodine is distributed in the environment in water and in other materials (Fehn 2012; Muramatsu and Wedepohl 1998; Muramatsu et al. 2004; Whitehead 1984, Kaplan et al., 2014). Solid sources of iodine in the environment include pelagic clays, shale, limestone, igneous rocks, algae, and gas hydrates. A large amount of iodine is sequestered in geological media and would not interact with the global (surface) iodine cycle. Fluid sources of iodine include seawater, freshwater, volcanic fluids, pore waters, and oil field brines associated with drilling. Igneous rocks, such as basalts, hold the least amount of iodine, by weight, along with freshwater and seawater. Some of the primary reservoirs for iodine are marine sediments and sedimentary rocks. By weight, algae (including seaweed) contain the highest amount of iodine. Volcanic and geothermal activity can release some iodine into the surface environment as volcanic fluids and in water. Likewise, the human pursuit of various energy sources has released iodine to the surface iodine cycle in brines from oil and natural gas production and from fracking 
PNNL-24709, Rev. 2

RPT-DVZ-AFRI-030, Rev. 2

(Harkness et al. 2015). The quantity of natural ${ }^{129} \mathrm{I}$ is quite small compared to the amount of natural ${ }^{127} \mathrm{I}$. Generation of ${ }^{129} \mathrm{I}$ as a byproduct of the nuclear energy industry and weapons testing is the largest anthropogenic source (Table 1).

Table 1. Major sources of ${ }^{129}$ I in the environment.

\begin{tabular}{|c|c|}
\hline Source & $\begin{array}{l}{ }^{129} \text { I Mass Released } \\
(\mathrm{kg})\end{array}$ \\
\hline Fuel reprocessing at La Hague (France) & $3800^{(a)}$ \\
\hline Fuel reprocessing Sellafield (UK) & $1400^{\text {(a) }}$ \\
\hline Hanford Site & $266^{(\mathrm{b})}$ \\
\hline Natural hydrosphere and atmosphere & $100^{\text {(c) }}$ \\
\hline Atmospheric weapons testing & $50^{(\mathrm{b})}$ \\
\hline Savannah River Site & $32^{(d)}$ \\
\hline Nevada Test Site underground nuclear testing & $10^{(\mathrm{b})}$ \\
\hline Chernobyl & $1-2^{(b)}$ \\
\hline Fukushima & $1.2^{(\mathrm{e})}$ \\
\hline $\begin{array}{l}\text { (a) Hou et al. } 2009 \\
\text { (b) Raisbeck and Yiou } 1999 \\
\text { (c) Bustad et al. } 1983 \\
\text { (d) Kantelo et al. } 1990 \\
\text { (e) Hou et al. } 2013\end{array}$ & \\
\hline
\end{tabular}

Table 2. Radiochemical properties of ${ }^{129} \mathrm{I}$ and ${ }^{131} \mathrm{I}$.

\begin{tabular}{|c|c|c|c|}
\hline Property & ${ }^{129} I$ & ${ }^{131} \mid$ & Reference \\
\hline Half-life & $1.57 \times 10^{7} y$ & $8.0252 \mathrm{~d}$ & KAPL 2010 \\
\hline Number of neutrons & 76 & 78 & KAPL 2010 \\
\hline Number of protons & 53 & 53 & KAPL 2010 \\
\hline $\begin{array}{l}\text { Main radiation emissions }{ }^{(a)} \\
\text { (energies and intensities [\%]) }\end{array}$ & $\begin{array}{c}\beta^{-} 0.15 \mathrm{MeV}(100 \%) \\
\gamma 39.6 \mathrm{keV}(7.5 \%)\end{array}$ & $\begin{array}{c}\beta^{-} 0.606 \mathrm{MeV}(90 \%) \\
\gamma 364.5 \mathrm{keV}(82 \%)\end{array}$ & $\begin{array}{l}\text { KAPL 2010; } \\
\text { NNDC } 2015\end{array}$ \\
\hline Decay reaction & ${ }_{53}^{129} \mathrm{I} \rightarrow \beta^{-}+{ }_{54}^{129} \mathrm{Xe}$ & ${ }_{53}^{131} \mid \rightarrow \beta^{-}+{ }_{54}^{131} \mathrm{Xe}$ & KAPL 2010 \\
\hline
\end{tabular}

(a) X-ray, electron, and minor beta/gamma emissions are not shown.

$\mathrm{KAPL}=$ Knolls Atomic Power Laboratory; NNDC $=$ National Nuclear Data Center

Sources and sinks of the global iodine cycle are divided into three primary pools: marine, terrestrial, and atmospheric (Figure 1). Sources of natural iodine (mostly ${ }^{127} \mathrm{I}$ ) are shown on the right of Figure 1, while anthropogenic sources (including ${ }^{129} \mathrm{I}$ and ${ }^{131} \mathrm{I}$ ) are shown on the left. Surface and atmospheric movement of iodine within the cycle occurs by deposition in rainfall, dry deposition (including uptake by plant leaves), volatilization, suspension of dust, suspension of marine aerosols, uptake by plant roots, decomposition of plants, runoff, irrigation, leaching, weathering, combustion of fossil fuels, nuclear fuel reprocessing, and weapons production. Iodine at the surface and in the atmosphere can also be affected by biogeochemical and solar processes that cause transformations between different iodine chemical species. Biogeochemical and physical processes relevant to subsurface fate and transport of ${ }^{129} \mathrm{I}$ contamination are presented in Section 2.0. 


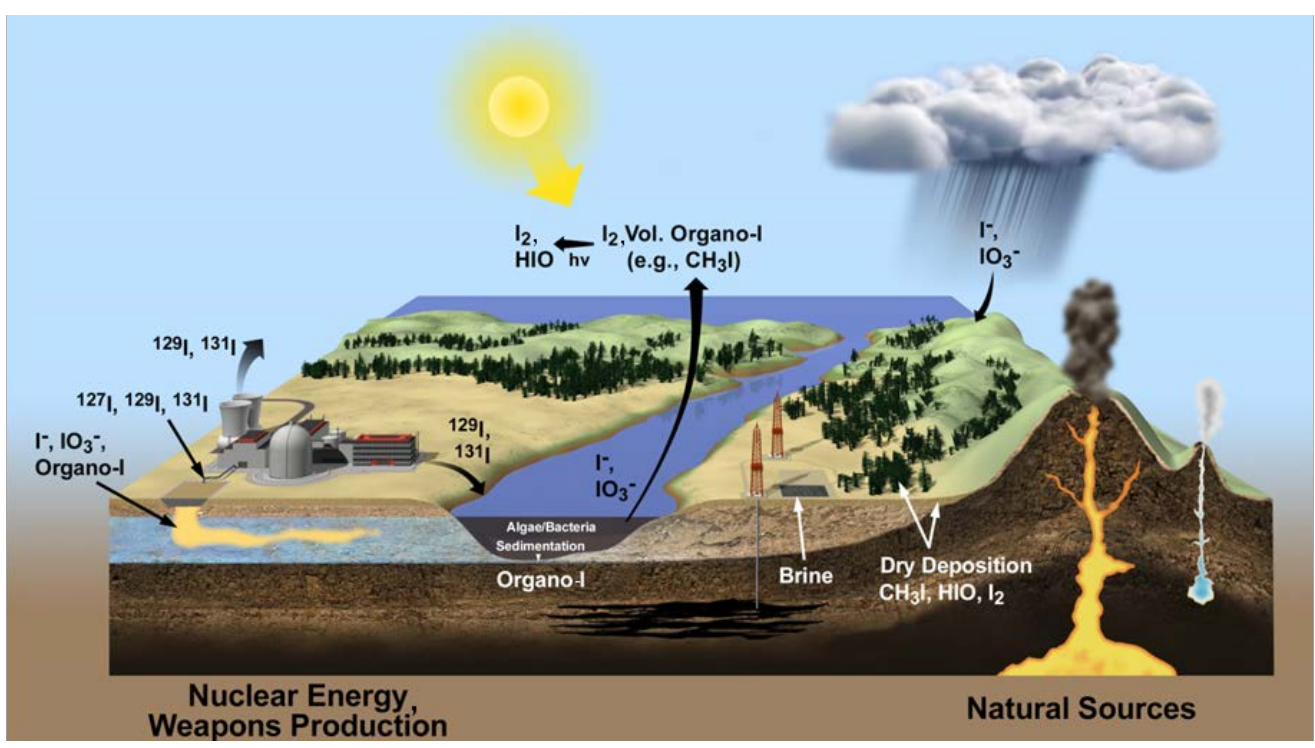

Figure 1. Global iodine cycle, showing natural and anthropogenic sources of iodine isotopes and cycling of multiple iodine species in the environment.

\subsection{Hanford Site Context}

In 1943, construction began on the first of nine nuclear reactors at the Hanford Site to produce plutonium for the development of atomic weapons for the Manhattan Project during World War II and throughout the Cold War. Over a production period lasting from 1944 to 1987, approximately 110,000 tons of nuclear fuel was processed (Gephart 2003). During the production period, billions of gallons of liquid nuclear waste and millions of tons of solid waste were produced. Isotopes of iodine were generated during plutonium production within the nine production reactors at the Hanford Site. The short half-life ${ }^{131}$ I released from the fuel into the atmosphere during the dissolution process (when the fuel was dissolved) in the Hanford Site 200 Area is no longer present at concentrations of concern in the environment.

Much of the contamination observed in groundwater at the Hanford Site, including iodine, resulted from planned releases of process liquid wastes and wastewater to the soil via discharge to engineered structures (cribs, trenches, ditches, ponds, leach fields, or injection wells). Unplanned releases of the same or similar waste materials resulted in contaminant discharges from tanks, pipelines, or other waste storage or conveyance components to the subsurface.

The total amount of ${ }^{129}$ I generated at the Hanford Site during reactor operations is well known: 49.4 Ci of ${ }^{129}$ I was produced during reactor operations according to ORIGEN2 fuel activity estimates (Watrous et al. 2002). However, the distribution of that well-defined inventory to storage or environmental releases is very uncertain. The inventory has been distributed among the following mechanisms:

- Stored in single-shell and double-shell tanks

- Discharged to liquid disposal sites (e.g., cribs and trenches)

- Released to the atmosphere during fuel reprocessing operations 
- Captured by off-gas absorbent devices (silver reactors) at chemical separations facilities (PUREX, B-Plant, T-Plant, and REDOX)

Table 3 summarizes current estimates for these mechanisms. This table does not include the ${ }^{129} \mathrm{I}$ inventory that may have been disposed at the Hanford Site from receipt of offsite waste.

Table 3. Current estimates of ${ }^{129}$ I distribution at the Hanford Site.

\begin{tabular}{|c|c|c|}
\hline${ }^{129}$ I Inventory Category & Estimate & Discussion and References \\
\hline $\begin{array}{l}\text { Total generated by } \\
\text { production reactors }\end{array}$ & $49.4 \mathrm{Ci}$ & $\begin{array}{l}\text { Based on calculation using the } 2002 \text { ORIGEN2 fuel activity } \\
\text { estimate (Watrous et al. 2002). This estimate is well known } \\
\text { and based on fuel irradiation histories. }\end{array}$ \\
\hline $\begin{array}{l}\text { Stored in single-shell } \\
\text { and double-shell tanks }\end{array}$ & $29.0 \mathrm{Ci}^{(\mathrm{a})}$ & $\begin{array}{l}\text { Best Basis Inventory (BBI) obtained from the Tank Waste } \\
\text { Information Network System (April 23, 2015) } \\
\text { (https://twins.labworks.org/twinsdata/default.htm). } \\
\text { Significant uncertainty remains with this estimate. }\end{array}$ \\
\hline $\begin{array}{l}\text { Discharged to liquid } \\
\text { disposal sites }\end{array}$ & $4.7 \mathrm{Ci}$ & $\begin{array}{l}\text { From Hanford's Soil Inventory Model (Corbin et al. 2005). } \\
\text { Uncertainty estimates were developed for individual waste } \\
\text { sites that ranged from } 20 \% \text { to almost } 400 \% \text {. }\end{array}$ \\
\hline $\begin{array}{l}\text { Released to the } \\
\text { atmosphere }\end{array}$ & Unknown & $\begin{array}{l}\text { Estimates of magnitude of these potential releases are not } \\
\text { available. This remains one of the main uncertainties } \\
\text { limiting development of a true mass balance for Hanford }{ }^{129} \mathrm{I} \text {. }\end{array}$ \\
\hline $\begin{array}{l}\text { Captured by off-gas } \\
\text { absorbent devices }\end{array}$ & Unknown & $\begin{array}{l}\text { Devices known as "silver reactors" were used to capture } \\
\text { iodine at chemical separations plants (PUREX, B-Plant, } \\
\text { T-Plant, and REDOX). The }{ }^{129} \text { I inventory captured in this } \\
\text { manner is not known. Some of these devices remain at the } \\
\text { canyon facilities and some are in solid waste burial grounds. }\end{array}$ \\
\hline
\end{tabular}

(a) The BBI underwent a significant update in 2004 (Higley et al. 2004), which reduced the tank inventory estimate from 48.2 to $31.8 \mathrm{Ci}$ based on improved models of separations processes. This change removed the previous conservative assumption that essentially all of the ${ }^{129}$ I sent to the separations plants exited those plants in waste streams sent to tank farms. Subsequent revisions to the BBI have replaced generic estimates for specific waste streams with sample-based estimates from the tanks.

Once ${ }^{129} \mathrm{I}$ and other mobile contaminants reach the aquifer, they spread, producing large-scale plumes (Figure 2). Three ${ }^{129}$ I plumes in groundwater originate in the Hanford Site Central Plateau (marked as the "Plateau Area Boundary" on Figure 2) and cover an area greater than $50 \mathrm{~km}^{2}$. In general, the plume emanating from the 200 East Area is larger because of differences in subsurface geology. The water table beneath the 200 East Area and extending to the Columbia River is within more-permeable sediments. In the 200 West Area, the water table is primarily within the lower permeability Ringold Formation. This results in faster groundwater flow and shorter travel times in the 200 East Area than in the 200 West Area (Freshley and Graham 1988). The largest ${ }^{129}$ I plume extends toward the southeast from the 200 East Area. A smaller arm of the plume has moved toward the northwest between Gable Mountain and Gable Butte. The largest ${ }^{129}$ I plume associated with the 200 West Area is in the 200-UP-1 operable unit (OU). 
PNNL-24709, Rev. 2

RPT-DVZ-AFRI-030, Rev. 2

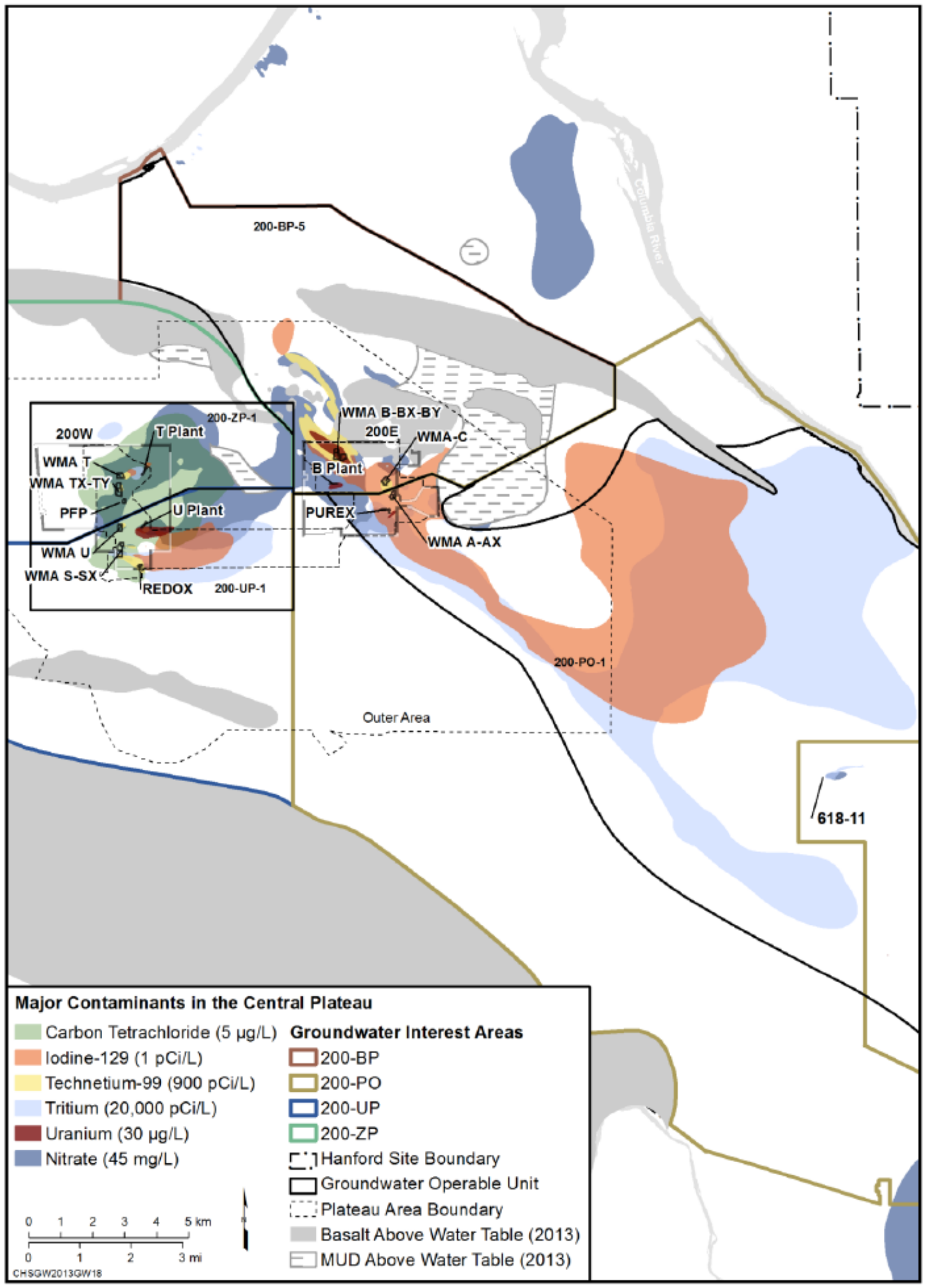

Figure 2. ${ }^{129}$ I and other contaminant plumes associated with the 200 East and 200 West Areas on the Hanford Site. Figure adapted from DOE 2014. 
PNNL-24709, Rev. 2

RPT-DVZ-AFRI-030, Rev. 2

The ${ }^{129}$ I plumes in the Hanford Site Central Plateau are very large and dilute. The lengths of the leading edges of the plumes are on the scale of kilometers. The ${ }^{129}$ I concentrations are all less than $50 \mathrm{pCi} / \mathrm{L}$, with most less than $10 \mathrm{pCi} / \mathrm{L}$, though above the drinking water standard (DWS) of $1 \mathrm{pCi} / \mathrm{L}$. Furthermore, natural stable iodine $\left({ }^{127} \mathrm{I}\right)$ is also present in the aquifer at much greater concentrations than ${ }^{129}$ I. The presence of ${ }^{127} \mathrm{I}$ is important because most remediation technologies are not specific for a particular iodine isotope (e.g., Kaplan et al. 2012). In addition, ${ }^{127} \mathrm{I}$ and ${ }^{129} \mathrm{I}$ have the same chemical behavior in the subsurface so that the presence of ${ }^{127}$ I will influence the biogeochemical processes for ${ }^{129}$ I.

In the past, iodide was assumed to be the dominant iodine species in Hanford groundwater based on a presumption that iodine was released as iodide, or because thermodynamic equilibrium with measured $\mathrm{E}_{\mathrm{h}}$ values in Hanford groundwater favor iodide formation. However, it is well known that $\mathrm{E}_{\mathrm{h}}$ measurements can be misleading (Lindberg and Runnells 1984; Stumm and Morgan 1996). Reasons for this include concentrations of redox elements that are too low to establish a Nernstian $\mathrm{E}_{\mathrm{h}}$ during potentiometric measurements and lack of equilibrium among some redox couples (slow reaction kinetics). If instead of using measured $E_{h}$ values, measured oxygen concentrations are used to constrain the $E_{h}$ of the system, it can be demonstrated that iodate $\left(\mathrm{IO}_{3}^{-}\right)$is the thermodynamically stable form of iodine in Hanford groundwater. At equilibrium, for $\mathrm{O}_{2}$ concentrations as low as $0.1 \mathrm{mg} / \mathrm{L}$, essentially all iodine will be in the form of iodate, with iodide concentrations being approximately nine orders of magnitude less than iodate.

In addition to the thermodynamic considerations discussed above, it is very likely that iodate was the dominant iodine species disposed to the vadose zone at Hanford. The best evidence to support this assertion is the work of Sakurai et al. (1989). In this work, iodine speciation was measured in simulated spent-fuel solutions that consisted of $10 \mathrm{mg} / \mathrm{L}$ iodide in 3.4 or $6.1 \mathrm{M} \mathrm{HNO}_{3}$, with either 50 or $250 \mathrm{~g} \mathrm{U} / \mathrm{L}$ and a suite of fission products. After addition of the iodide, the solution was maintained at $100{ }^{\circ} \mathrm{C}$ for 3 hours. Subsequently, iodine speciation was measured. The results of Sakurai et al. (1989) indicate that on average over $90 \%$ of the iodine added volatilized to $\mathrm{I}_{2}(\mathrm{~g})$. The remaining iodine in solution consisted of iodate, iodide, molecular iodine $\left(\mathrm{I}_{2}\right)$, organic iodine, and colloidal iodine. The average distribution of iodine species was as follows: $47.6 \%$ iodate, $3.2 \%$ iodide, $17.3 \%$ molecular iodine, $6.1 \%$ organic iodine, and $12.4 \%$ colloidal iodine. The average ratio of iodate to iodide in these solutions was 19.5 , very similar to that measured in Hanford groundwater (19.6) (see Table 4, Zhang et al. 2013). Colloidal iodine was attributed largely to palladium and silver iodides formed through precipitation with palladium and silver in the fission products. It is not expected that these colloidal species would be able to travel significant distances through the vadose zone because, depending on the size, the colloidal particles may interact with other larger particles and become immobile. $\mathrm{I}_{2}$ can form HOI in water, and both of these species can react with natural organic matter to form organo-iodine (Organo-I) compounds (Luther 2011). It is possible that reaction of $I_{2}$ disposed to the vadose zone interacting with organic matter in the vadose zone sediments is a significant source of the organic-iodine measured in Hanford groundwater.

Analysis of groundwater samples taken from numerous monitoring wells within the 200-ZP-1 OU in the 200 West Area presented by Zhang et al. (2013) show that, on average, about $70 \%$ of the iodine is present as $\mathrm{IO}_{3}^{-}$, about $26 \%$ is Organo-I, and a small amount (about 4\%) is $\mathrm{I}^{-}$(see Table 4). While ${ }^{129} \mathrm{I}$ was also evaluated in this study by Zhang et al., only iodate was detected when measuring radioactive ${ }^{129} \mathrm{I}$ species because of limits of analytical detection. One observation from this analysis was that the average iodate concentration for ${ }^{127} \mathrm{I}$ in the seven wells tested was $22.66 \mu \mathrm{g} / \mathrm{L}$, while ${ }^{129} \mathrm{I}$ averaged $0.096 \mu \mathrm{g} / \mathrm{L}$ 
PNNL-24709, Rev. 2

RPT-DVZ-AFRI-030, Rev. 2

(18.43 pCi/L). The observed iodine speciation is important input for evaluating the fate and transport of iodine in the subsurface.

Table 4. Chemistry and ${ }^{127}$ I speciation of filtered Hanford Site groundwater (Zhang et al. 2013).

\begin{tabular}{|c|c|c|c|c|c|c|c|c|c|c|c|c|}
\hline Well & $\mathrm{pH}$ & $\begin{array}{l}\text { Eh } \\
(\mathrm{mV})\end{array}$ & $\begin{array}{l}\text { DOC } \\
(\mu \mathrm{M})\end{array}$ & $\begin{array}{c}\mathrm{Ca} \\
(\mathrm{mg} / \mathrm{L})\end{array}$ & $\begin{array}{c}\mathrm{Si} \\
(\mathrm{mg} / \mathrm{L})\end{array}$ & $\begin{array}{l}\text { lodide } \\
(\mu \mathrm{g} / \mathrm{L})\end{array}$ & $\begin{array}{l}\text { lodate } \\
(\mu \mathrm{g} / \mathrm{L})\end{array}$ & $\begin{array}{c}\text { Organo I } \\
(\mu \mathrm{g} / \mathrm{L})\end{array}$ & $\begin{array}{l}\text { Total I } \\
(\mu \mathrm{g} / \mathrm{L})\end{array}$ & $\begin{array}{c}\text { lodide } \\
\text { (\%) }\end{array}$ & $\begin{array}{l}\text { lodate } \\
\text { (\%) }\end{array}$ & $\begin{array}{c}\text { Organo-I } \\
(\%)\end{array}$ \\
\hline 299-W14-11 & 7.7 & 250 & 50.2 & 59.4 & 7.5 & 0.35 & 59.50 & 15.18 & 75.03 & 0.5 & 79.3 & 20.2 \\
\hline 299-W14-13 & 7.7 & 249 & 63.0 & 81.9 & 7.4 & 0.33 & 42.72 & 17.01 & 60.05 & 0.6 & 71.1 & 28.3 \\
\hline 299-W14-15 & 7.9 & 220 & 25.5 & 35.4 & 5.6 & 0.43 & 32.63 & 5.66 & 38.72 & 1.1 & 84.3 & 14.6 \\
\hline 299-W11-43 & 7.6 & 150 & 37.2 & 78.8 & 7.0 & 0.36 & 6.66 & 2.76 & 9.78 & 3.7 & 68.1 & 28.3 \\
\hline 299-W11-88 & 7.8 & 321 & 15.6 & 22.1 & 15.0 & 0.17 & 7.08 & 2.08 & 9.33 & 1.8 & 75.9 & 22.3 \\
\hline 699-36-70B & 7.8 & 334 & 35.3 & 19.4 & 10.7 & 0.23 & 5.87 & 2.28 & 8.38 & 2.8 & 70.0 & 27.2 \\
\hline 699-38-70B & 7.8 & 125 & 21.5 & 29.7 & 8.9 & 1.38 & 4.18 & 3.68 & 9.24 & 15.0 & 45.2 & 39.8 \\
\hline Average & 7.8 & 236 & 35.5 & 49.5 & 8.9 & 0.46 & 22.66 & 6.95 & 30.08 & 3.6 & 70.6 & 25.8 \\
\hline
\end{tabular}

Recently, groundwater samples from the 200-UP-1 OU ${ }^{129}$ I plume were analyzed to determine ${ }^{127}$ I speciation across the length of the plume. Analysis was performed on seven samples from well 299-W22-114, each sample representing a discrete depth below the water table, and then three monitoring well samples (699-36-70A, 699-35-66A, and 699-36-66B). Speciation data for samples from 299-W22-114 are shown in Table 5. Nitrate and ${ }^{129}$ I data are also shown. With the exception of the sample from $7.59 \mathrm{ft}$ below the water table (bwt), iodate was the only ${ }^{127} \mathrm{I}$ species present in all other samples. The nitrate concentration from the shallowest sample is the highest and iodine speciation is $44.2 \%$ and $55.8 \%$ for iodate and iodide, respectively. Radioiodine was present at above the Environmental Protection Agency (EPA) National Primary Drinking Water Regulations (https://www.epa.gov/ground-water-and-drinking-water/national-primary-drinking-water-regulations ) standard of $1 \mathrm{pCi} / \mathrm{L}$ (based on 4 mrem/year) in samples ranging from 7.59 to $67.29 \mathrm{ft}$ below the water table.

Table 5. Iodine speciation in groundwater samples taken during drilling of monitoring well 299-W22-114 (ft bls = feet below land surface; ft bwt = feet below water table).

\begin{tabular}{|c|c|c|c|c|c|c|}
\hline $\begin{array}{l}\text { Depth } \\
\text { (ft bls) }\end{array}$ & $\begin{array}{c}\text { Depth } \\
\text { (ft bwt) }\end{array}$ & $\begin{array}{c}129 \mathrm{I} \\
(\mathrm{pCi} / \mathrm{L})\end{array}$ & $\begin{array}{c}127 \mathrm{I} \\
(\mu \mathrm{g} / \mathrm{L})\end{array}$ & $\begin{array}{l}\text { lodate } \\
(\mu \mathrm{g} / \mathrm{L})\end{array}$ & $\begin{array}{l}\text { lodide } \\
\text { ( } \mu \mathrm{g} / \mathrm{L})\end{array}$ & $\begin{array}{c}\mathrm{NO}_{3} \\
\text { (mg/L) }\end{array}$ \\
\hline 257.5 & 7.6 & 4.0 & 6.2 & 2.8 & 3.6 & 79.7 \\
\hline 284.0 & 34.1 & 1.7 & 13.6 & 17.8 & ND & 5.3 \\
\hline 317.2 & 67.3 & 1.5 & 11.0 & 14.5 & ND & 4.4 \\
\hline 347.6 & 97.7 & 0.3 & 13.0 & 17.1 & ND & 3.5 \\
\hline 377.6 & 127.7 & 0.5 & 13.2 & 17.6 & ND & 3.9 \\
\hline 427.5 & 177.6 & 0.3 & 16.1 & 21.8 & ND & 6.2 \\
\hline 447.2 & 197.3 & 0.05 & 17.1 & 22.4 & ND & 7.5 \\
\hline
\end{tabular}


PNNL-24709, Rev. 2

RPT-DVZ-AFRI-030, Rev. 2

Similar analyses were performed on groundwater samples from three existing monitoring wells to determine possible changes in speciation across the length of the iodine plume (Table 6). This type of data might be useful in determining whether the ratio of species changes as the plume expands, and might be an indicator of possible attenuation mechanisms occurring in the groundwater. During this sampling period, ${ }^{127} \mathrm{I}$ analysis and speciation was not performed for samples from monitoring well 299-W22-114, but nitrate and ${ }^{129}$ I values are reported. Again, these results indicated that iodate was the only species present in the 200-UP-1 ${ }^{129}$ I plume.

Table 6. Iodine speciation in groundwater samples from locations over the length of the 200-UP1

${ }^{129}$ I plume (ft bwt $=$ feet below water table).

\begin{tabular}{|c|c|c|c|c|c|c|}
\hline Well ID & $\begin{array}{c}\text { Depth } \\
\text { (ft bwt) }\end{array}$ & $\begin{array}{c}129 \mathrm{I} \\
(\mathrm{pCi} / \mathrm{L})\end{array}$ & $\begin{array}{c}127 \mathrm{I} \\
(\mu \mathrm{g} / \mathrm{L})\end{array}$ & $\begin{array}{l}\text { lodate } \\
\text { ( } \mu \mathrm{g} / \mathrm{L})\end{array}$ & $\begin{array}{l}\text { lodide } \\
\text { ( } \mu \mathrm{g} / \mathrm{L})\end{array}$ & $\begin{array}{c}\mathrm{NO}_{3} \\
(\mathrm{mg} / \mathrm{L})\end{array}$ \\
\hline 299-W22-114 & 7.6 & 4.0 & ND & ND & ND & 84.1 \\
\hline 699-36-70A & 34.1 & 8.0 & 10.1 & 13.0 & ND & 16.8 \\
\hline $699-35-66 A$ & 67.3 & 1.5 & 11.0 & 13.0 & ND & 24.3 \\
\hline 699-36-66B & 97.7 & 2.8 & 12.7 & 17.1 & ND & 53.1 \\
\hline
\end{tabular}


PNNL-24709, Rev. 2

RPT-DVZ-AFRI-030, Rev. 2

\subsection{Conceptual Model}

This section presents a conceptual model description, highlighting factors important to remediation technology evaluation for iodine contamination at the Hanford Site and information relevant to key elements of the conceptual model. As an overview, Figure 3 is a system-level depiction of elements affecting iodine fate and transport from waste sites in the Hanford Central Plateau. The following subsections summarize information about the three components of the conceptual model: Inputs, Source Flux to Groundwater, and Plume Behavior.

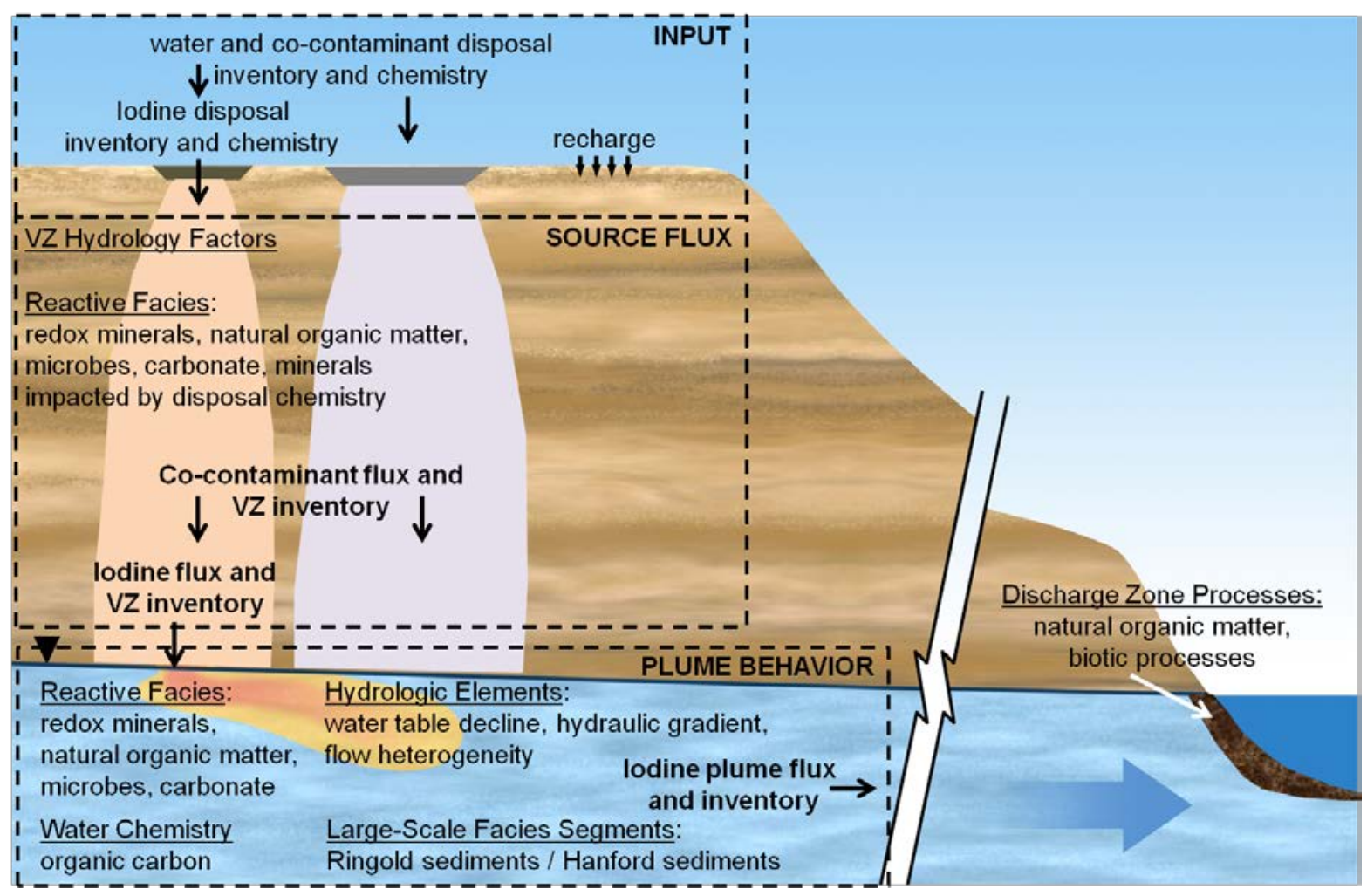

Figure 3. System-level depiction of elements affecting iodine fate and transport.

\subsection{Inputs}

Inputs (Figure 3) consist of waste disposal inventories, water disposal volumes, waste disposal chemistry, facility design (e.g., a specific retention trench versus a waste storage tank), and recharge. These items are discussed in turn below.

Corbin et al. (2005) indicate that a total of about 4.7 Ci of ${ }^{129} \mathrm{I}$ was released to waste sites at the Hanford Site. This inventory does not include the ${ }^{129}$ I inventory believed to be retained in underground storage tanks. Two of these sites (216-A-10 and 216-A-5 in the 200 East Area) received 1.7 and $1.0 \mathrm{Ci}$ of ${ }^{129} \mathrm{I}$ (accounting for $57 \%$ of the total ${ }^{129}$ I disposed or otherwise released to waste sites). Four other waste sites (216-S-7, 216-U-10, and 216-S-1\&2 in the 200 West Area and 216-A-6 in the 200 East Area) account for another $16 \%$ of the inventory, while 27 other sites account for another $18 \%$. Together, these 33 sites account for $91 \%$ of the ${ }^{129}$ I inventory released to the subsurface. Figure 4 shows the relative percent of the overall ${ }^{129}$ I inventory released at each of these 33 waste sites. 
PNNL-24709, Rev. 2

RPT-DVZ-AFRI-030, Rev. 2

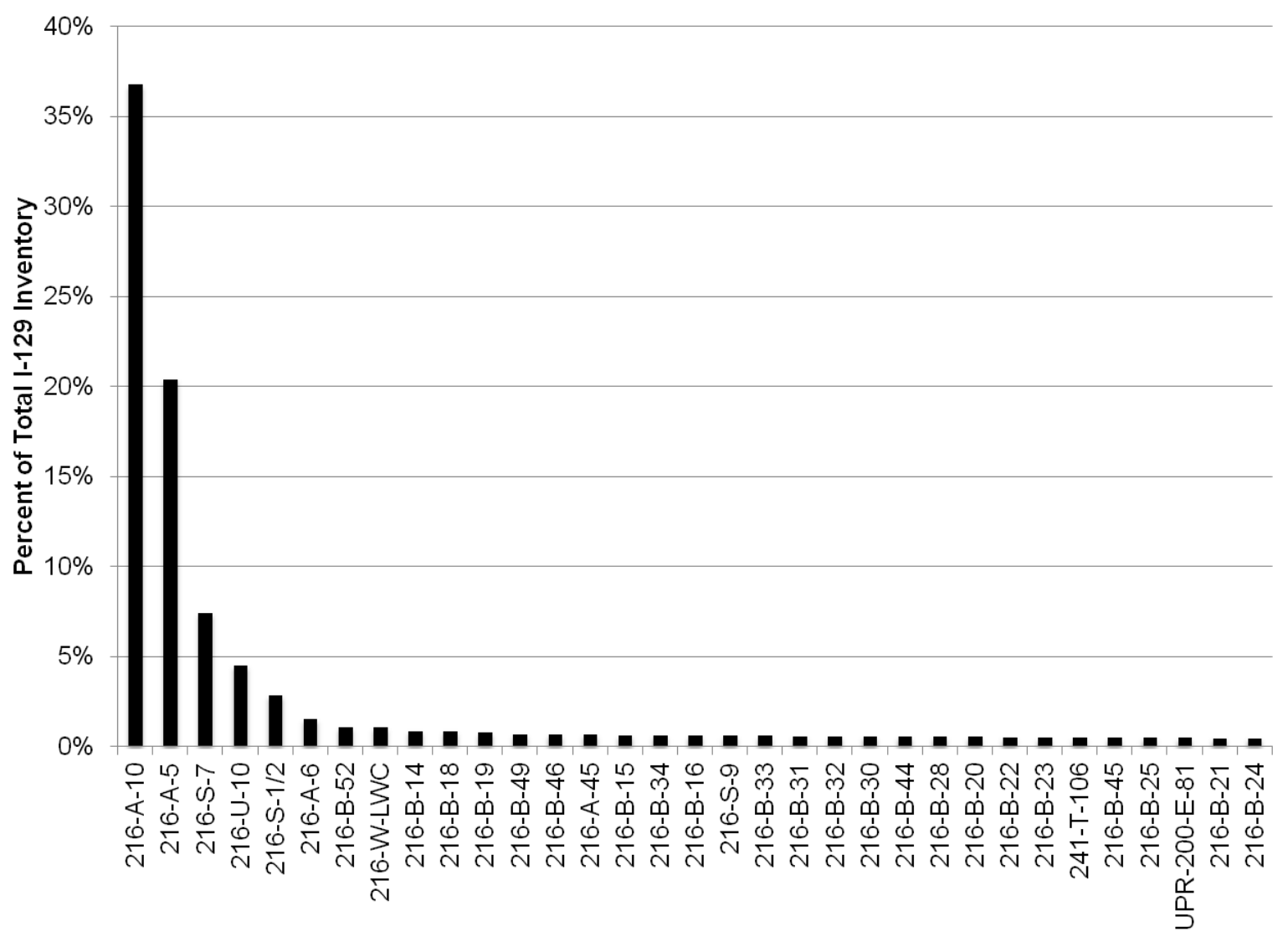

Figure 4. Relative percentage of the total ${ }^{129}$ I inventory released to individual waste sites based on data from the Soil Inventory Model (Corbin et al. 2005) for sites with greater than $1 \%$ of the total (the 216-U-1/2 sites associated with part of the 200-UP-1 OU plume had less than $1 \%$ of the total).

Truex and Carroll (2013) examined predicted groundwater concentrations from the System Assessment Capability (Eslinger et al. 2006). They used a DWS factor (the maximum predicted groundwater concentration divided by the DWS) to categorize sites based on their potential impact to groundwater relative to three different timeframes: up to the year 2100, up to the year 3100, and up to the year 12,000. Table 7 lists those sites with predicted groundwater concentrations exceeding the DWS for ${ }^{129}$ I (i.e., a DWS factor $>1$ ) and the relative timing of those concentrations. Sites relevant to the 200-UP-1 OU are highlighted in this table.

In addition to the inventory of ${ }^{129}$ I received by each facility, another important factor to consider is the volume of liquid disposal. The disposed liquid provides the primary driving force for initial distribution of contaminants in the subsurface, with large volumes generally leading to more extensive migration and in some cases, current breakthrough observed in the groundwater. Over the long term, recharge becomes a controlling factor in the flux of contaminants from the vadose zone to the groundwater.

Figure 5 shows the total and annual average disposal volumes for the 33 sites with the largest ${ }^{129} \mathrm{I}$ inventories (Figure 4). Many of these waste sites were either cribs (9) or trenches (13) that received process effluent for only a short amount of time ( $<1$ year). Figure 6 illustrates the average concentration of ${ }^{129}$ I received by each of the sites. 
PNNL-24709, Rev. 2

RPT-DVZ-AFRI-030, Rev. 2

Table 7. Categorization of waste sites based on potential impact to groundwater for three time intervals: up to year 2100, 2100-3100, and after 3100 (adapted from Truex and Carroll 2013). Sites with predicted groundwater concentrations less than the DWS are not shown ( 300 sites). Black text is for simulated results. Red text indicates values based on observed groundwater data.

\begin{tabular}{|c|c|c|c|c|}
\hline \multirow{2}{*}{ Site Name } & \multirow{2}{*}{ Site ID } & \multicolumn{3}{|c|}{${ }^{129}$ I DWS Factor ${ }^{(a)}$} \\
\hline & & Up to Year 2100 & $2100-3100$ & After $3100^{(b)}$ \\
\hline \multirow[t]{3}{*}{ REDOX Cribs } & $216-S-1 \& 2$ & $9(37)$ & 14 & 14 \\
\hline & $216-S-7$ & $82(37)$ & 30 & 11 \\
\hline & $216-S-9$ & - & - & 3 \\
\hline \multirow[t]{4}{*}{ S/SX Tank Farms } & $\begin{array}{l}\text { 241-SX-104, 108, } \\
\text { 109, 110, 111, } \\
112,113\end{array}$ & - & $1-10$ & $1-10$ \\
\hline & 241-SX-107 & - & 17 & - \\
\hline & 241-SX-108 & - & 53 & - \\
\hline & 241-SX-115 & - & 17 & - \\
\hline \multirow[t]{3}{*}{ T Tank Farm } & 241-T-101 & - & 1 & - \\
\hline & 241-T-103 & 1 & 2 & - \\
\hline & 241-T-106 & - & 57 & 1 \\
\hline $\begin{array}{l}\text { Solid Waste - } \\
\text { 200-ZP-1 }\end{array}$ & $218-W-4 B$ & - & - & 17 \\
\hline \multirow[t]{4}{*}{ TX/TY Tank Farms } & 241-TX-107 & 23 & 11 & - \\
\hline & 241-TY-101 & - & 2 & - \\
\hline & 241-TY-103 & - & 6 & - \\
\hline & 241-TY-105 & - & 2 & - \\
\hline \multirow[t]{4}{*}{ TX Trenches } & $216-\mathrm{T}-22$ & - & 2 & - \\
\hline & $216-\mathrm{T}-23$ & - & 2 & - \\
\hline & $216-\mathrm{T}-24$ & - & 2 & - \\
\hline & 216-T-25 & 6 & 2 & - \\
\hline $\begin{array}{l}\text { B, BX, BY Tank } \\
\text { Farms }\end{array}$ & 241-BX-102 & 4 & - & - \\
\hline BY Cribs & Multiple & 2 & - & - \\
\hline U Cribs & $216-U-1 / 2$ & 3 & - & - \\
\hline \multirow[t]{4}{*}{ U Tank Farm } & 241-U-101 & - & 3 & - \\
\hline & 241-U-104 & - & 10 & - \\
\hline & 241-U-110 & - & 2 & - \\
\hline & $241-U-112$ & - & 4 & - \\
\hline \multirow{2}{*}{$\begin{array}{l}\text { TY Cribs and } \\
\text { Vicinity }\end{array}$} & 216-T-18 & - & - & 3 \\
\hline & $216-\mathrm{T}-26$ & 8 & 2 & 2 \\
\hline A/AX Tank Farms & 241-A-103 & - & 7 & - \\
\hline BC Cribs & Multiple & - & - & $1-9$ \\
\hline BC Trenches & Multiple & - & - & $1-9$ \\
\hline Laundry Waste Crib & 216-W-LWC & 7 & 1 & - \\
\hline \multirow[t]{2}{*}{ PUREX Cribs } & $216-A-5$ & $6(9)$ & 3 & 2 \\
\hline & $216-A-10$ & $5(9)$ & 1 & - \\
\hline C Tank Farm & UPR-200-E-81 & - & - & 3 \\
\hline $\begin{array}{l}\text { (a) Maximum predicted } \\
\text { (b) Simulations were co }\end{array}$ & $\begin{array}{l}\text { undwater concentrat } \\
\text { cted through year } 12\end{array}$ & he DWS. On & equal & are shown \\
\hline
\end{tabular}




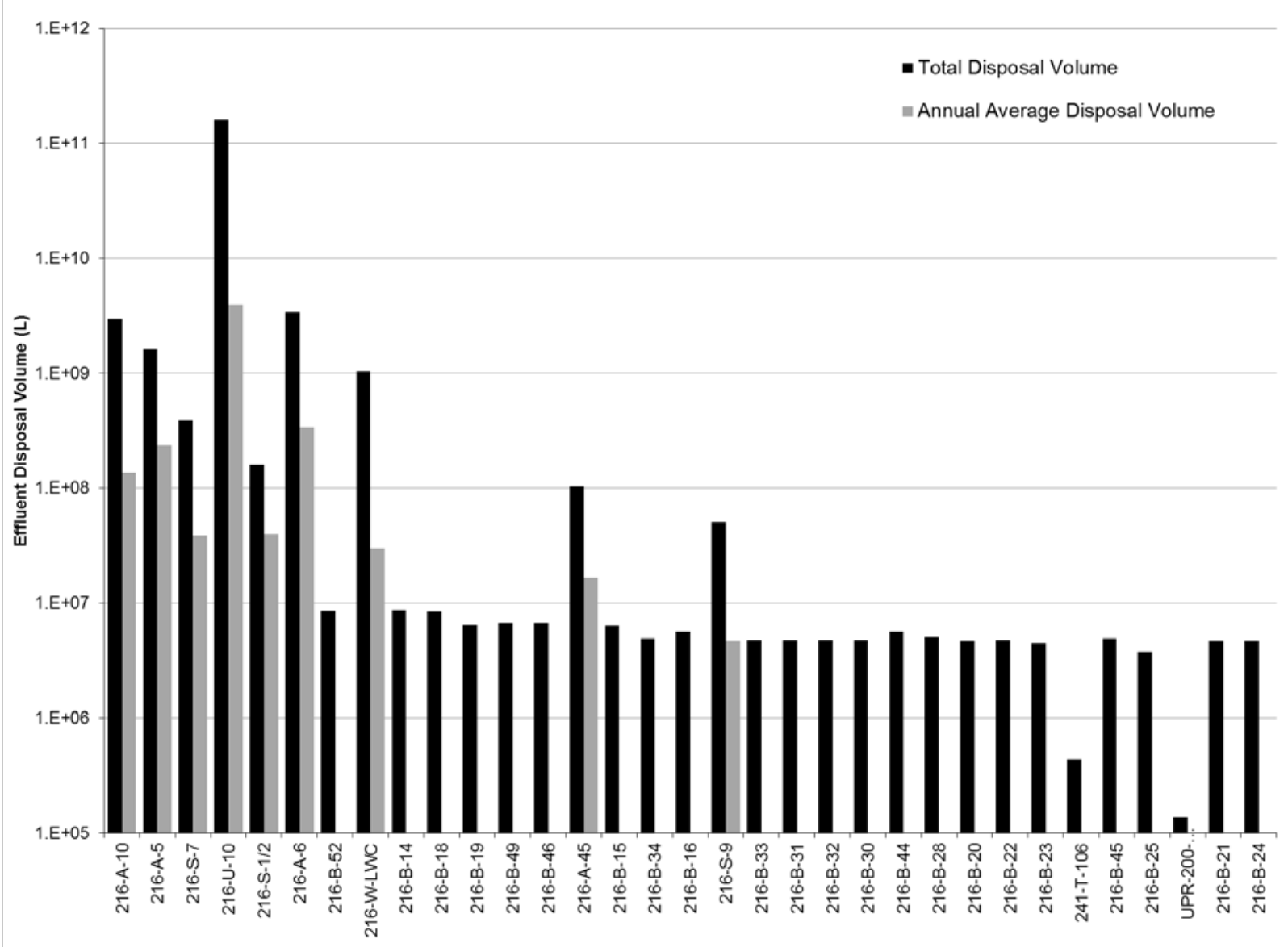

Figure 5. Estimated total liquid waste disposal volumes for sites with greater than $1 \%$ of the disposed ${ }^{129} \mathrm{I}$ inventory (Figure 4) with average annual disposal shown for sites having more than 1 year of disposal. Note that the 216-U-1/2 sites associated with part of the 200-UP-1 OU plume had less than $1 \%$ of the total and are, therefore, not shown here. Also, note the log-scale on the y-axis. Based on data from the Virtual Library, Effluent Volume to Soil Disposal Site module. 


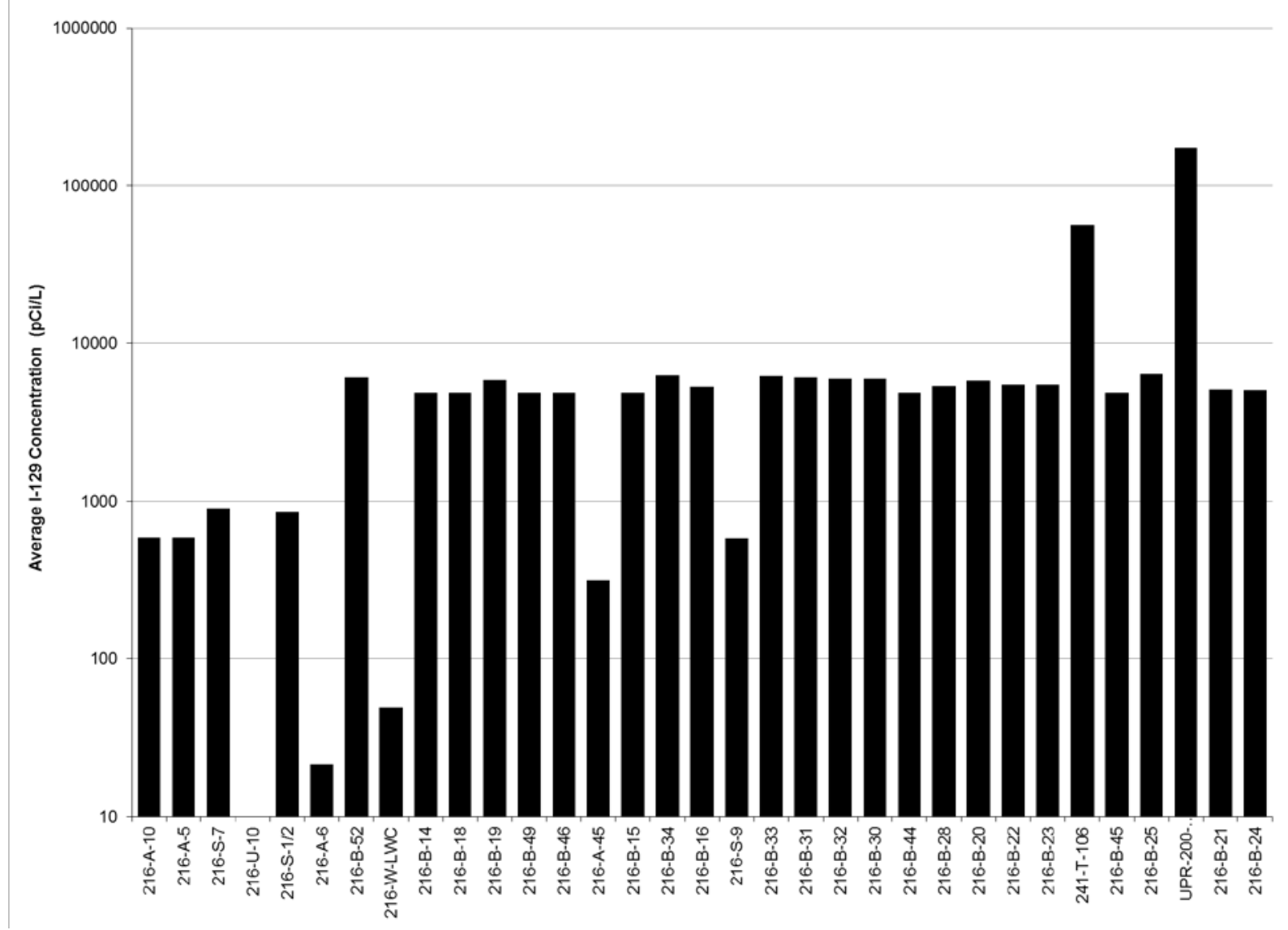

Figure 6. Calculated average ${ }^{129}$ I concentration for sites with greater than $1 \%$ of the disposed ${ }^{129} \mathrm{I}$ inventory (Figure 4). Note that the 216-U-1/2 sites associated with part of the 200-UP-1 OU plume had less than $1 \%$ of the total and are, therefore, not shown here. Also, note the log-scale on the $\mathrm{y}$-axis and that the DWS is $1 \mathrm{pCi} / \mathrm{L}$ for ${ }^{129} \mathrm{I}$.

The waste disposal chemistry can be important because the presence of co-contaminants can affect subsurface and remediation biogeochemistry. In addition, acidic or basic conditions in the disposed fluid can lead to neutralization reactions affecting contaminant fate and transport in the vadose zone, thereby influencing the contaminant flux to groundwater (Truex et al. 2014). Table 8 lists the co-contaminants for the major iodine disposal sites. Note that this assessment focused on waste disposal sites, but releases from waste storage tanks would have a unique chemistry that may need to be considered. 
PNNL-24709, Rev. 2

RPT-DVZ-AFRI-030, Rev. 2

Table 8. Co-contaminants in relative rank order based on the Soil Inventory Model inventories (Corbin et al. 2005).

\begin{tabular}{|c|c|}
\hline Disposal Facilities & $\begin{array}{l}\text { Dominant Chemicals } \\
\text { (in relative rank order by weight percent) }\end{array}$ \\
\hline $\begin{array}{l}\text { PUREX Cribs (216-A-10, 216-A-5, 216-A-6, and } \\
\text { 216-A-45) }\end{array}$ & $\begin{array}{l}\mathrm{NO}_{3}, \mathrm{CO}_{3}, \mathrm{Cl}, \mathrm{K}, \mathrm{Na}, \mathrm{PO}_{4}, \mathrm{SO}_{4}, \mathrm{Fe}, \mathrm{Ca}, \mathrm{U}-\mathrm{Total} \text {, } \\
\mathrm{Si} \text { (acidic except 216-A-6 is neutral/basic) }\end{array}$ \\
\hline $\begin{array}{l}\text { REDOX Cribs (216-S-7, 216-S-1\&2 and } \\
216-\mathrm{S}-9)\end{array}$ & $\mathrm{NO}_{3}, \mathrm{Na}, \mathrm{Al}, \mathrm{U}-$ Total (acidic) \\
\hline $\begin{array}{l}\text { BC Cribs (216-B-14, 216-B-15, 216-B-16, } \\
\text { 216-B-18, 216-B-19) }\end{array}$ & $\begin{array}{l}\mathrm{NO}_{3}, \mathrm{Na}, \mathrm{SO}_{4}, \mathrm{PO}_{4}, \mathrm{~F}, \mathrm{Cl}, \mathrm{K}, \mathrm{Si}, \mathrm{CO}_{3}, \mathrm{Cr}, \mathrm{Ca}, \mathrm{Ni} \text {, } \\
\mathrm{Fe}, \mathrm{Bi}, \mathrm{NO}_{2}, \mathrm{U} \text {-Total, } \mathrm{Zr}, \mathrm{Ag}, \mathrm{Hg}, \mathrm{NH}_{3} \text {, butanol } \\
\text { (neutral/basic) }\end{array}$ \\
\hline $\begin{array}{l}\text { BC Trenches (216-B-20, 216-B-21, 216-B-22, } \\
\text { 216-B-23, 216- B-24, 216-B-25, 216-B-28, } \\
\text { 216-B-30, 216-B-31, 216-B-32, 216-B-33, } \\
\text { 216-B-34, 216-B-52 }\end{array}$ & $\begin{array}{l}\mathrm{NO}_{3}, \mathrm{Na}, \mathrm{SO}_{4}, \mathrm{PO}_{4}, \mathrm{CO}_{3}, \mathrm{NO}_{2}, \mathrm{~F}, \mathrm{Cl}, \mathrm{K}, \mathrm{NH}_{3}, \mathrm{Si} \\
\mathrm{Al}, \mathrm{Cr}, \mathrm{Ca}, \mathrm{Ni}, \mathrm{Fe}, \mathrm{Bi}, \mathrm{U} \text {-Total (neutral/basic) }\end{array}$ \\
\hline $\begin{array}{l}\text { BY Cribs (216-B-44, 216-B-45, 216-B-46, } \\
216-\mathrm{B}-49)\end{array}$ & $\begin{array}{l}\mathrm{NO}_{3}, \mathrm{Na}, \mathrm{SO}_{4}, \mathrm{PO}_{4}, \mathrm{~F}, \mathrm{Cl}, \mathrm{K}, \mathrm{Si}, \mathrm{CO}_{3}, \mathrm{Cr}, \mathrm{Ca}, \mathrm{Ni} \\
\mathrm{Fe}, \mathrm{NO}_{2}, \mathrm{Ni}, \mathrm{Bi}, \mathrm{U} \text {-Total (neutral/basic) }\end{array}$ \\
\hline 216-U-10 Pond & $\begin{array}{l}\mathrm{CO}_{3}, \mathrm{NO}_{3}, \mathrm{SO}_{4}, \mathrm{~K}, \mathrm{NO}_{2}, \mathrm{Na}, \mathrm{Ca}, \mathrm{PO}_{4}, \mathrm{Si}, \mathrm{Cl}, \mathrm{TBP}, \\
\mathrm{NH}_{3}, \mathrm{Fe}, \mathrm{CCl}_{4}, \mathrm{~F}, \mathrm{Al}, \mathrm{Pb}, \mathrm{Cr}, \mathrm{U} \text {-Total }\end{array}$ \\
\hline Laundry Waste Crib (216-W-LWC) & $\begin{array}{l}\mathrm{Na}, \mathrm{PO}_{4}, \mathrm{Si}, \mathrm{Ca}, \mathrm{NH}_{3}, \mathrm{SO}_{4}, \mathrm{Cl}, \mathrm{K}, \mathrm{Fe}, \mathrm{Al}, \mathrm{NO}_{3}, \mathrm{~F} \\
\mathrm{~Pb}, \mathrm{Mn}, \mathrm{Ni}, \mathrm{Cr}, \mathrm{U} \text {-Total }\end{array}$ \\
\hline 241-T-106 (UPR-200-W-148) & $\begin{array}{l}\mathrm{Na}, \mathrm{NO}_{3}, \mathrm{NO}_{2}, \mathrm{Al}, \mathrm{CO}_{3}, \mathrm{SO}_{4}, \mathrm{Cl}, \mathrm{Cr}, \mathrm{K}, \mathrm{PO}_{4}, \mathrm{NH}_{3} \\
\mathrm{Fe}, \mathrm{Si}, \mathrm{Ca}, \mathrm{Ni}, \mathrm{F}, \mathrm{Pb}, \mathrm{U} \text {-Total }\end{array}$ \\
\hline UPR-200-E-81 & $\begin{array}{l}\mathrm{NO}_{3}, \mathrm{Na}, \mathrm{Al}, \mathrm{NO}_{2}, \mathrm{SO}_{4}, \mathrm{Cl}, \mathrm{CO}_{3}, \mathrm{Cr}, \mathrm{Ca}, \mathrm{Pb}, \mathrm{Fe} \\
\mathrm{K}, \mathrm{Ni} \text {, U-Total }\end{array}$ \\
\hline
\end{tabular}

Though not a waste site or contaminant input, recharge from precipitation is an important factor in transport of contaminants through the vadose zone. Recharge is the portion of water from precipitation that infiltrates into the ground and continues migrating downward toward the groundwater (recognizing that some water that infiltrates does not continue moving toward the groundwater because of processes like transpiration). Fayer and Keller (2007) reported long-term recharge rates ranging from $<0.01$ to $9.2 \mathrm{~cm} / \mathrm{yr}$ for various combinations of soil and surface vegetation conditions across the Hanford Site. For operational areas generally devoid of well-established shrub vegetation, the long-term drainage estimates are generally in the range of 0.8 to $9.2 \mathrm{~cm} / \mathrm{yr}$.

\subsection{Source Flux to Groundwater}

A combination of water disposal volume and rate, recharge, subsurface hydraulic properties, and contaminant transport characteristics (as influenced by vadose zone reactive facies and disposal chemistry) control the flux of contaminants through the vadose zone to the groundwater (Figure 3). Source flux may need to be considered in groundwater remediation if it is expected that the source flux will continue to contribute significantly to the groundwater plume.

This conceptual model evaluation does not examine source flux in detail. However, for context, Figure 7 shows the approximate number of soil column pore volumes of effluent received by each site (based on the waste site footprint and an estimated porosity of 35\%) relative to their total ${ }^{129}$ I inventory (information from Last et al. 2006a, b). While this assessment does not account for lateral spreading in 
the vadose zone, those sites that received more than one soil column pore volume are likely to have caused a near-term impact to groundwater (e.g., as demonstrated in the groundwater monitoring data for the 216-A-10 and 216-S-7 cribs). All sites would be expected to have some longer-term contaminant flux controlled by the recharge rate. However, those sites with a higher pore volume estimate may have contaminants deeper in the vadose zone and therefore may affect groundwater sooner than sites with a lower pore volume estimate. Additional information relevant to evaluating the source flux is provided by Truex and Carroll (2013).

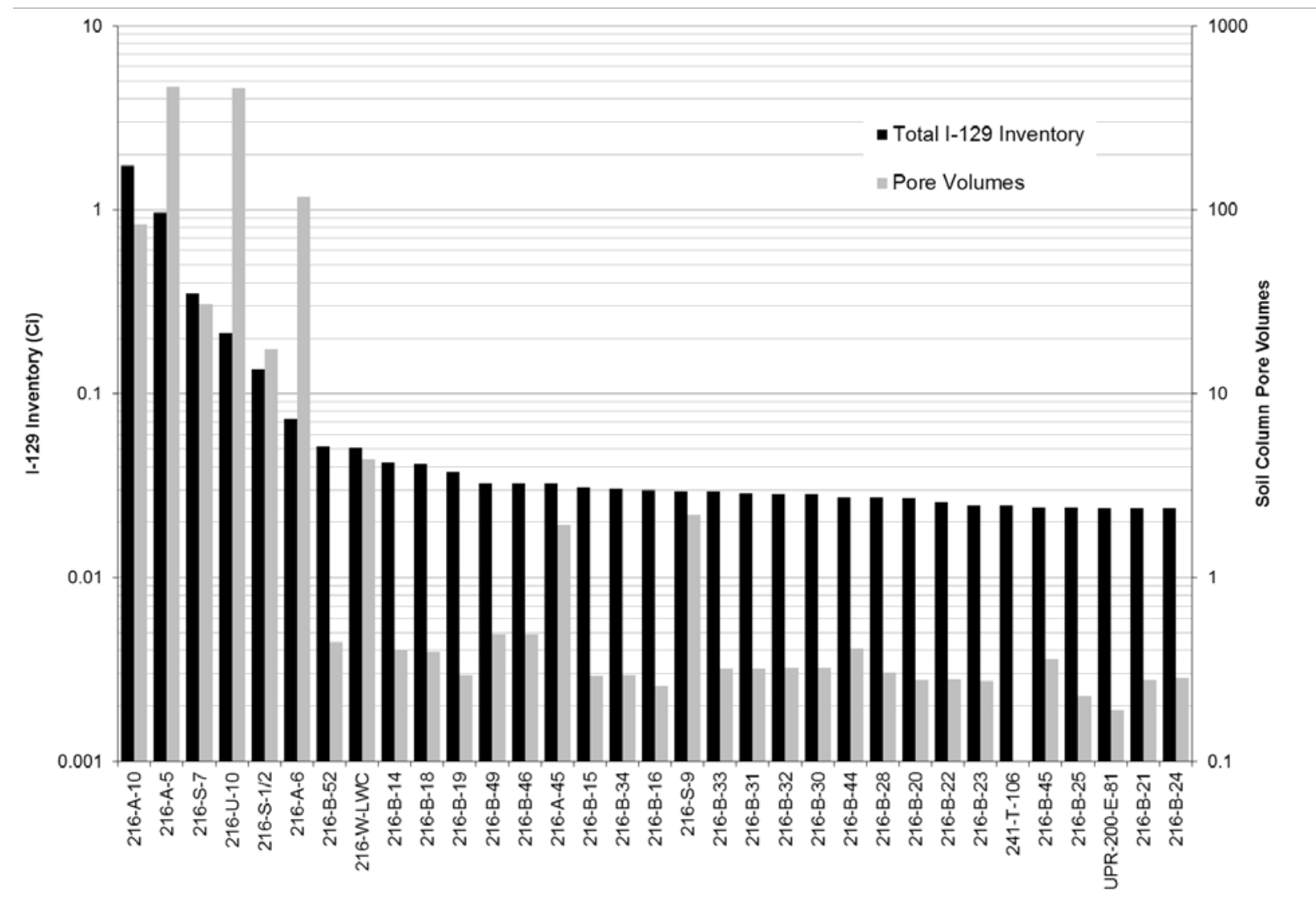

Figure 7. Total ${ }^{129}$ I inventory and relative number of soil column pore volumes of effluent received for sites with greater than $1 \%$ of the disposed ${ }^{129}$ I inventory (Figure 4). Note that the $216-\mathrm{U}-1 / 2$ sites associated with part of the 200-UP-1 OU plume had less than $1 \%$ of the total and are, therefore, not shown here. Also, note the log-scale on the y-axes.

Iodine speciation will affect the iodine source flux to the groundwater because different iodine species have different transport characteristics. Other than the hydrologic features and processes, the controlling features and processes for iodine transport in the vadose zone are the same as those in the groundwater and are presented in the next section. 


\subsection{Plume Behavior: Controlling Features and Processes}

Hydrologic features are important with respect to water movement in the subsurface and, therefore, affect iodine transport and plume behavior. In addition to the groundwater information in the annual report for the Hanford groundwater monitoring program (DOE 2014), information on subsurface flow and transport parameters has been compiled in a number of documents (e.g., DOE 2005, 2012a; Fayer and Keller 2007; Last et al. 2006a, 2009). However, iodine transport is also influenced by reactive facies related to reactions (e.g., oxidation/reduction transformations) and physical interactions (e.g., sorption). The general facies of importance are redox minerals, organic material, carbonate, and microorganisms. Water chemistry components such as dissolved organic matter and $\mathrm{pH}$ influence transformation reactions and transport. In addition, co-contaminants, such as nitrate or other compounds that participate in redox reactions, may influence iodine transformation reactions and sorption. Both ${ }^{129}$ I and ${ }^{127}$ I concentrations should be considered when evaluating plume behavior and reactive facies. ${ }^{127} \mathrm{I}$ and ${ }^{129} \mathrm{I}$ are found in Hanford Site groundwater at ${ }^{127} \mathrm{IO}_{3}{ }^{-} /{ }^{129} \mathrm{IO}_{3}{ }^{-}$ratios ranging from 100 to 300, indicating much higher ${ }^{127} \mathrm{I}$ concentrations in the groundwater. The source of ${ }^{127} \mathrm{I}$ is not known, but iodine commonly exists as a trace constituent of nitric acid. Therefore, the enormous volumes of nitric acid used during operations are a likely contributing source for the groundwater ${ }^{127} \mathrm{I}$.

Several observations from previous and ongoing field and laboratory studies of the iodine in groundwater at the Hanford Site provide context for evaluating processes controlling migration of the iodine plumes. First, analysis of groundwater samples from the 200 West Area (Zhang et al. 2013) showed a mix of iodine species present with, on average, about $70 \%$ of the iodine present as $\mathrm{IO}_{3}{ }^{-}$, about 26\% as Organo-I, and a small amount (about 4\%) as I-. In addition, sequential extraction of Hanford sediment samples (Xu et al. 2015) showed a significant fraction of iodine in sediment-associated phases in addition to aqueous and adsorbed phases. These previous studies have also observed iodate reduction and association of iodate with carbonate precipitates. Collectively, this information and the additional information reported herein demonstrate that iodine behavior in the subsurface is affected by transformations and sediment interactions. Thus, the conceptual model and related efforts to evaluate iodine fate and transport at Hanford need to include quantitative descriptions of such processes controlling plume behavior.

As shown in Figures 8 and 9, adsorption, transformations between species, associations with organic compounds, and precipitation are all important for iodine fate and transport. Figure 8 shows an overview of biogeochemical processes that can affect the fate of iodine in the subsurface. Categories of microbial mediated reactions are shown on Figure 9. Information about these and additional processes affecting the speciation and fate of iodine are summarized in the sections below. Appendix A contains additional information. 


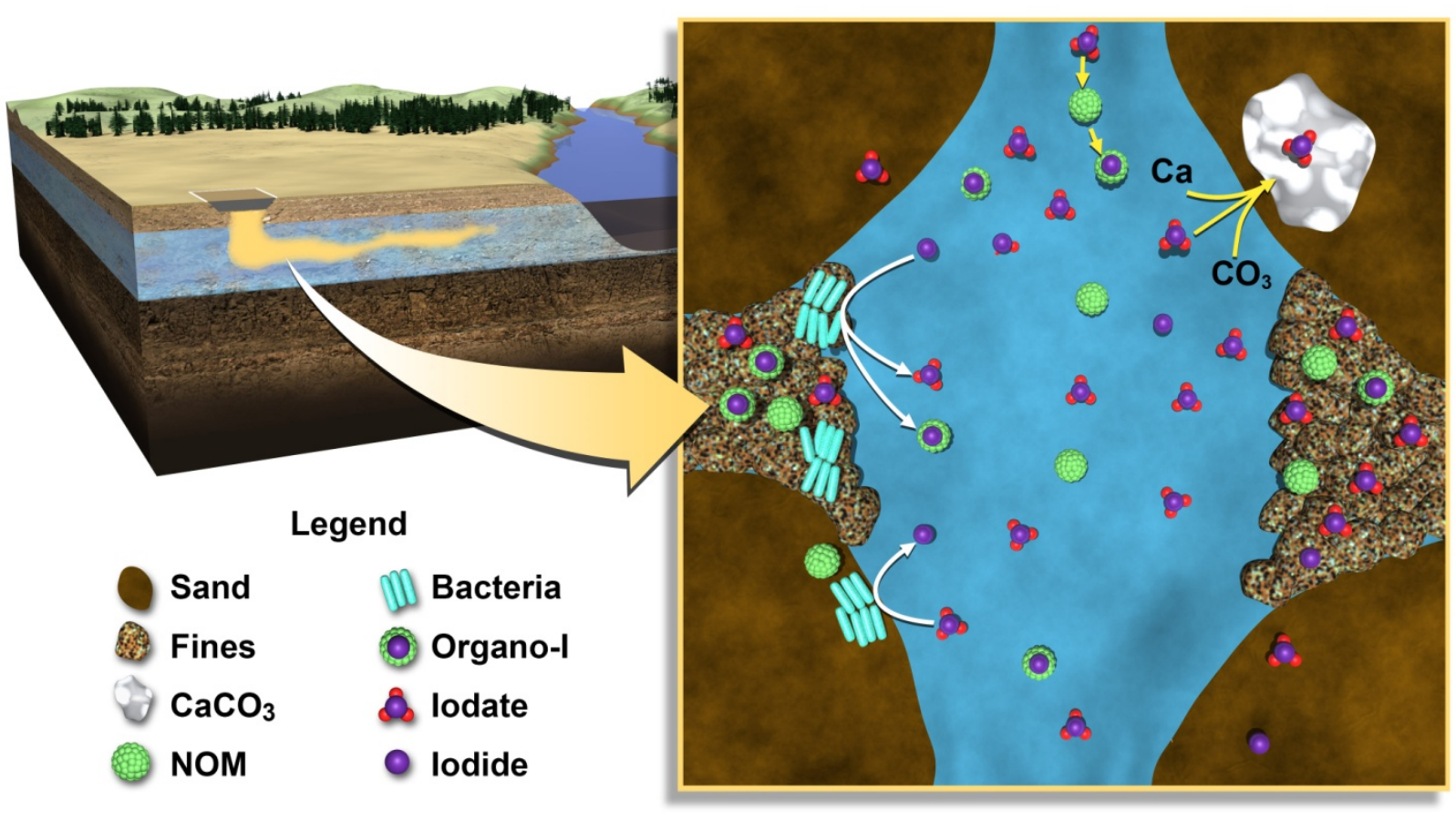

Figure 8. Conceptual overview of subsurface biogeochemical processes that affect the fate and transport of iodine. The figure does not distinguish between ${ }^{129} \mathrm{I}$ and ${ }^{127} \mathrm{I}$ because these processes are the same for both isotopes. The three primary aqueous iodine species are iodate $\left(\mathrm{IO}_{3}{ }^{-}\right)$, Organo-I, and iodide $\left(\mathrm{I}^{-}\right)$. Processes include biotic (Bacteria) transformations between iodine species as shown and potential transformations to other species, as illustrated in Figure 9. Iodate reduction may also occur abiotically (not shown) (e.g., by reactions with sediment-associated iron/manganese at the Hanford Site, see Section 2.3.1). Iodine species adsorb to sediment surfaces (e.g., on iron oxide deposits or phyllosilicates), with greater adsorption expected in fine-textured sediment zones (Fines). Natural organic matter may facilitate sorption and accumulation of iodine or, as a DOC, may form mobile Organo-I. Iodate may co-precipitate with calcium carbonate. 
PNNL-24709, Rev. 2

RPT-DVZ-AFRI-030, Rev. 2

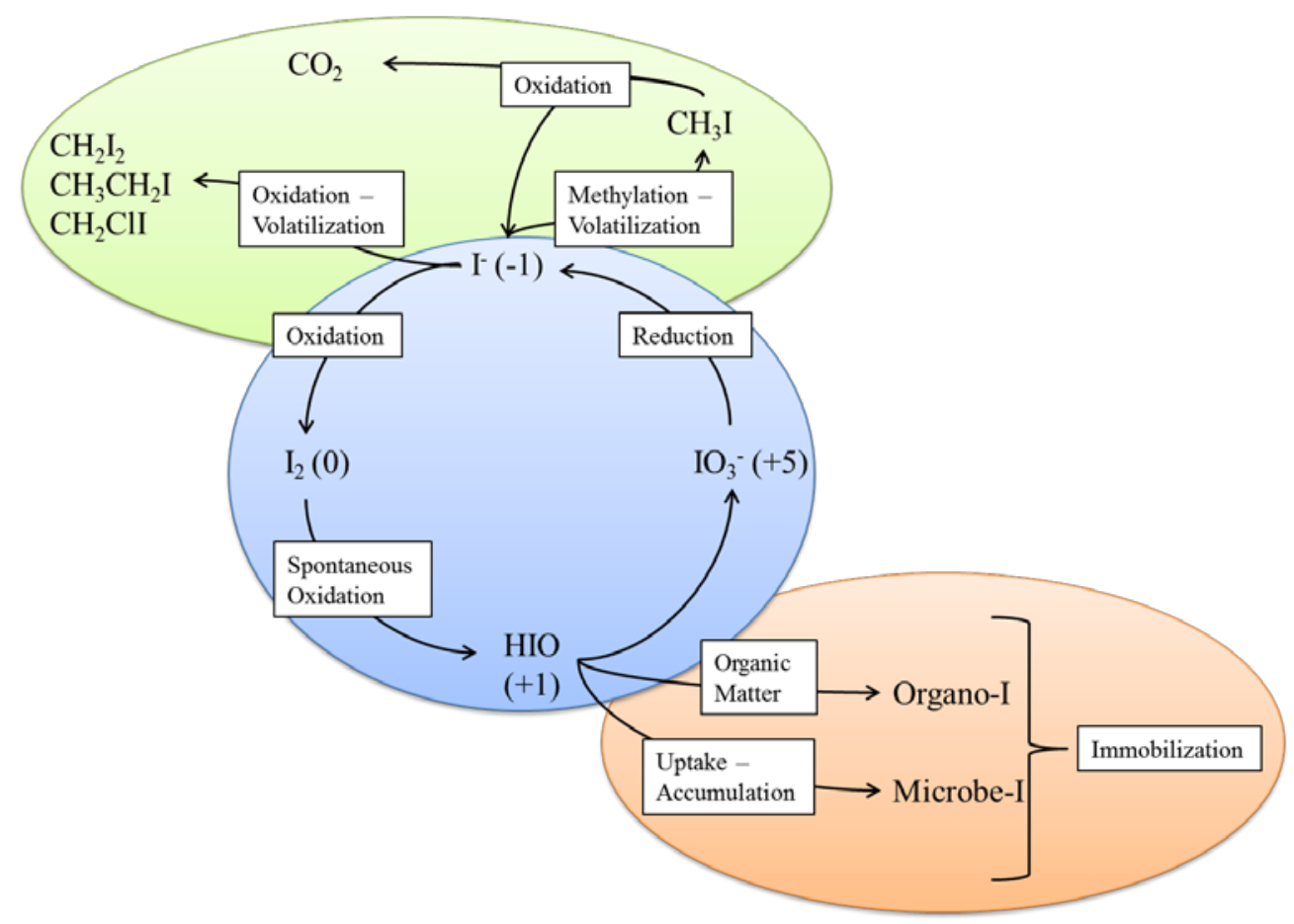

Figure 9. Biological transformations associated with iodine cycling in the environment. The blue ellipse represents predominantly aqueous-phase iodine species. The orange ellipse represents predominantly solid-phase species of iodine associated with organic compounds (Organo-I) or accumulated in microbial biomass (Microbe-I). Some types of Organo-I may also be mobile in the aqueous phase. The green ellipse represents predominantly gas-phase volatile Organo-I compounds. Figure 8 provides context for some of these processes within the subsurface biogeochemical environment.

\subsection{1 lodine Sorption}

Iodine adsorption is important to quantify for predicting iodine fate and transport. Iodine is generally characterized as a mobile contaminant in groundwater, and the observed large plumes at the Hanford Site are consistent with this generalization. However, iodine transport behavior differs for each species. Studies of sorption were conducted for iodide and iodate to Ringold sediments obtained from borehole C9483 (depth interval 387-388 ft bgs), located downgradient of the ${ }^{129} \mathrm{I}$ plume in the 200-UP-1 OU. Adsorption was measured in batch experiments at different soil/water ratios and also during breakthrough in 1-D soil columns.

For iodide, batch sorption experiments in oxic groundwater spiked with $50 \mu \mathrm{g} / \mathrm{L}$ iodide for a range of sediment/water ratios showed very little sorption $\left(\mathrm{K}_{\mathrm{d}}<0.01 \mathrm{~mL} / \mathrm{g}\right)$ over a time scale of $46 \mathrm{~h}$ (Figure 10). In two soil-column experiments, $\mathrm{K}_{\mathrm{d}}$ values of 0.07 and $0.10 \mathrm{~mL} / \mathrm{g}$ (retardation factors of 1.3 and 1.5, respectively) were calculated from the lag in breakthrough of the injected concentration of $100 \mu \mathrm{g} / \mathrm{L}$ iodide (Figure 11). No oxidation of iodide to iodate was observed during these studies (see also Section 2.3.3). 
PNNL-24709, Rev. 2

RPT-DVZ-AFRI-030, Rev. 2

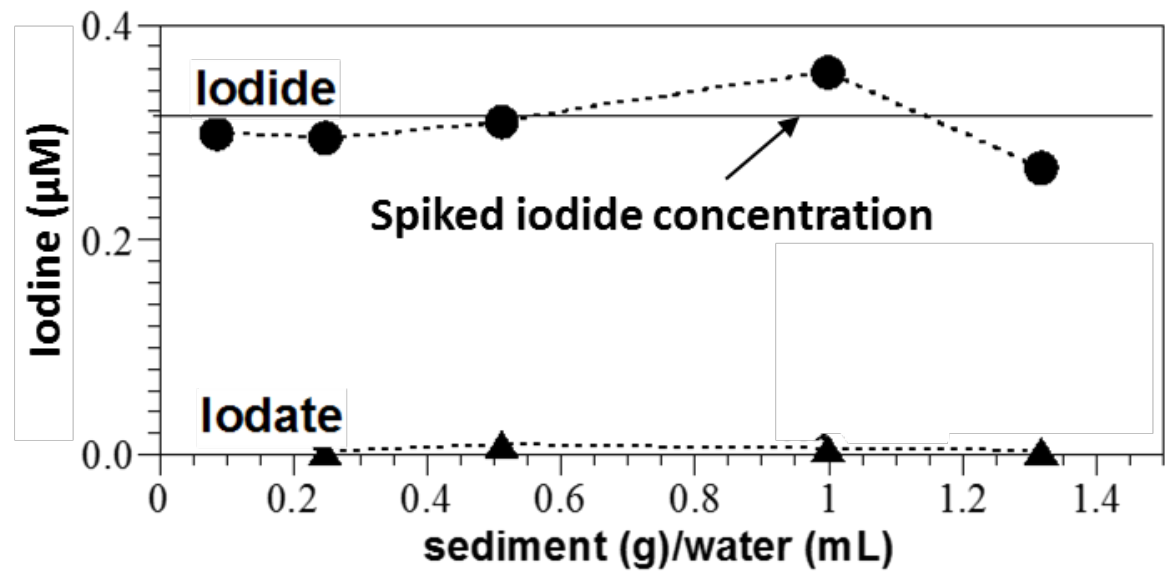

Figure 10. Results of batch sorption experiments spiked with iodide showing no transformation to iodate. Iodide data also demonstrate minimal sorption to the sediments.

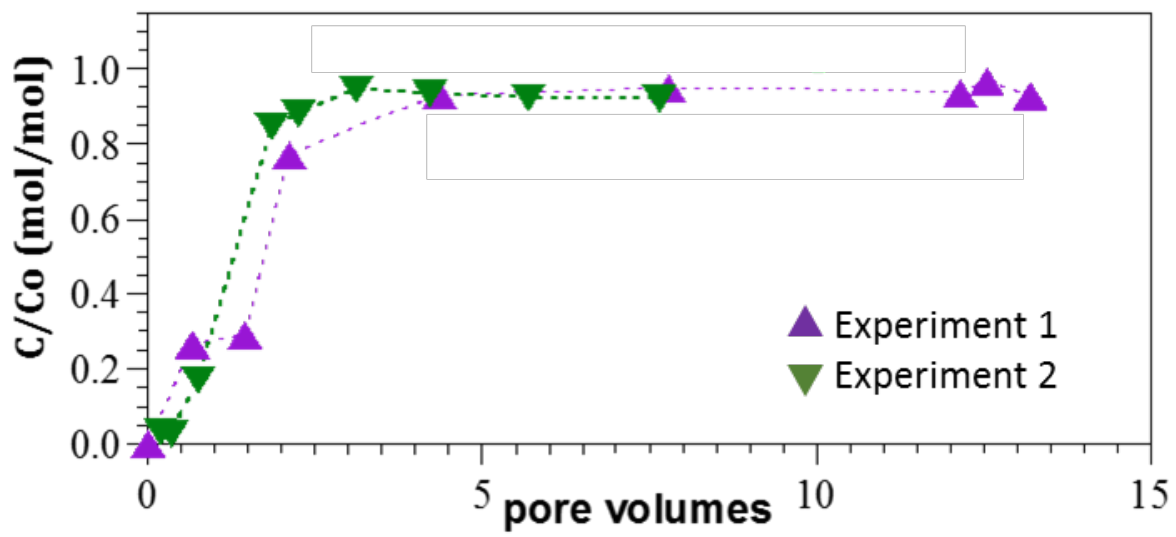

Figure 11. Results of two replicate column sorption experiments with iodide in the column influent.

Iodate sorption was difficult to measure due to relatively rapid biotic/abiotic iodate reduction to iodide that occurred in the sediment (see also Section 2.3.3). Thus, limited batch experimental data could be used to quantify sorption. From batch studies of iodate transformation and sorption in oxic groundwater spiked with $50 \mu \mathrm{g} / \mathrm{L}$ iodide for a range of sediment/water ratio, a $\mathrm{K}_{\mathrm{d}}$ of $0.9 \mathrm{~mL} / \mathrm{g}$ was estimated over a time scale of $46 \mathrm{~h}$ (Figure 12). Iodate sorption was estimated from the lag in breakthrough of the injected concentration of $100 \mu \mathrm{g} / \mathrm{L}$ iodate in three soil-column experiments (Figure 13). These experiments resulted in estimated $K_{d}$ values of 0.3 to $1.2 \mathrm{~mL} / \mathrm{g}$ (retardation factors of 2.4 to 6.2 , respectively). 
PNNL-24709, Rev. 2

RPT-DVZ-AFRI-030, Rev. 2

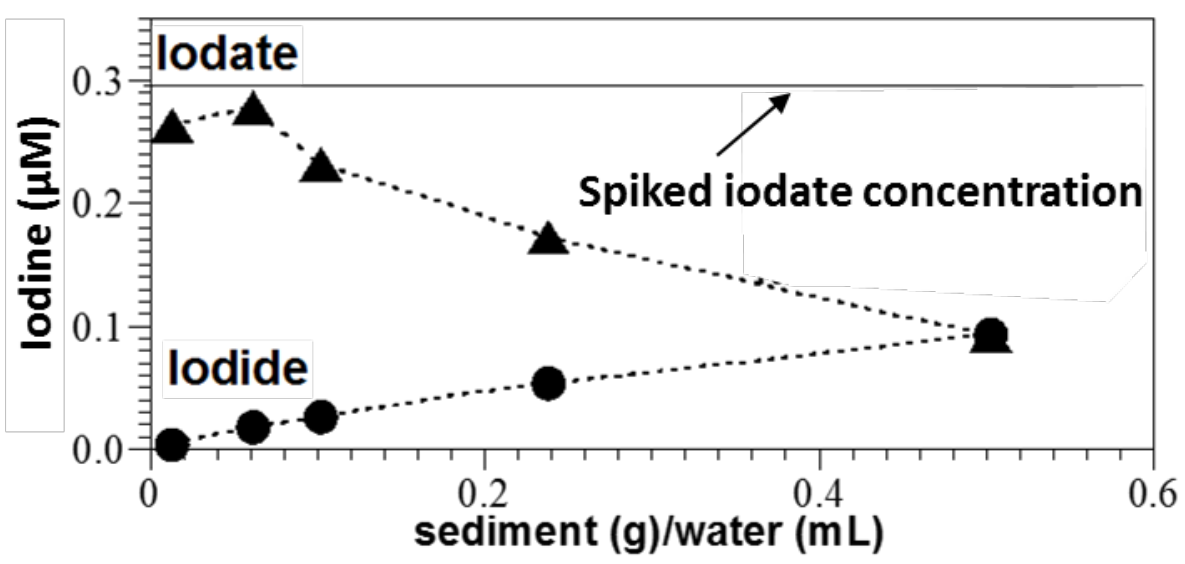

Figure 12. Results of batch experiments spiked with iodate showing iodate transformation to iodide. A $K_{d}$ value for iodate of $0.9 \mathrm{~mL} / \mathrm{g}$ was estimated from these data.

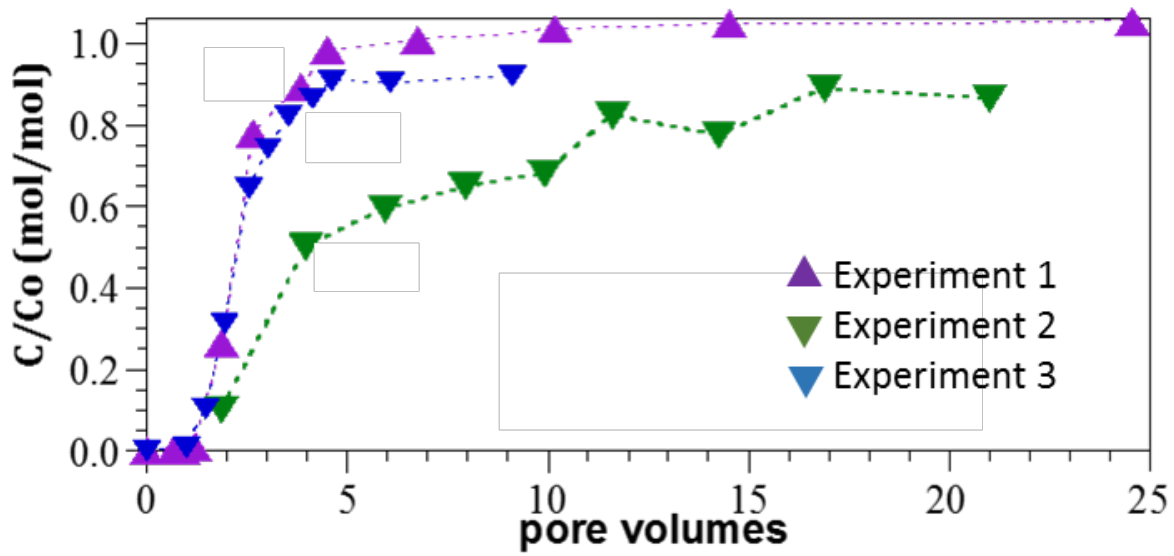

Figure 13. Results of three replicate column sorption experiments with iodate in the column influent.

Previous studies for $\mathrm{I}^{-}$and $\mathrm{IO}_{3}{ }^{-}$have observed a low $\mathrm{K}_{\mathrm{d}}$, in the range of 0 to $5.64 \mathrm{~mL} / \mathrm{g}$ for $\mathrm{I}^{-}$and 0.83 to $7.56 \mathrm{~mL} / \mathrm{g}$ for $\mathrm{IO}_{3}{ }^{-}$for Hanford Site sediments (Xu et al. 2015). In the study by Xu et al., $\mathrm{IO}_{3}{ }^{-} \mathrm{K}_{\mathrm{d}}$ values were always higher than values for $\mathrm{I}^{-}$for the same sediments. Other studies have suggested that partitioning of iodine to Hanford Site sediments may be partially related to sediment organic carbon content (Table 9), even at the very low organic carbon (OC) concentrations in the tested Hanford Site sediments (0.04 to $0.15 \mathrm{wt} \% \mathrm{OC}$ ) (Xu et al. 2015). These studies showed greater sorption in the sediments with higher $\mathrm{OC}$ and greater sorption of $\mathrm{IO}_{3}{ }^{-}$than $\mathrm{I}^{-}$to these sediments. Hanford Site sediments (particularly gravel-dominated sediments) typically have low OC concentrations of less than $0.1 \mathrm{wt} \%$ (Serne et al. 1993), with the observed range being 0.01 to 0.22 wt\% (DOE 1994; MinChem Database [Mackley et al. 2010] - unpublished). Adsorption of Organo-I, I', and $\mathrm{IO}_{3}{ }^{-}$to iron-oxides and phyllosilicate mineral surfaces is expected to differ, with a likely highest-to-lowest ranking of sorption being Organo-I $>\mathrm{IO}_{3}^{-}>\mathrm{I}^{-}$, although experiments are required to test this hypothesis. 
Table 9. Iodide and iodate $K_{d}$ values for composite sediments recovered from 200 West Area borehole cores (Xu et al. 2015).

\begin{tabular}{|c|c|c|c|c|c|c|}
\hline $\begin{array}{l}\text { Composite } \\
\text { Sediment }^{(a)}\end{array}$ & $\begin{array}{c}\text { Organic } \\
\text { Carbon } \\
(\%)\end{array}$ & $\begin{array}{c}\text { Inorganic } \\
\text { Carbon } \\
(\%)\end{array}$ & $\begin{array}{c}\text { Total Sediment } \\
\text { lodine } \\
(\mu \mathrm{g} / \mathrm{g})\end{array}$ & $\begin{array}{c}\text { Total } \\
\text { DOC }^{(b)} \\
(\mu \mathrm{M})\end{array}$ & $\begin{array}{l}\text { lodide- } \\
\text { spiked } \mathrm{K}_{\mathrm{d}}(\mathrm{c}) \\
(\mathrm{mL} / \mathrm{g})\end{array}$ & $\begin{array}{l}\text { lodate- } \\
\text { spiked } \mathrm{K}_{\mathrm{d}} \text { (c) } \\
(\mathrm{mL} / \mathrm{g})\end{array}$ \\
\hline $\mathrm{H} 1$ & 0.12 & 0.92 & 4.79 & $284 \pm 33$ & 0.08 & 1.78 \\
\hline $\mathrm{H} 2$ & 0.04 & 0.01 & 0.68 & 0 & 0.00 & 0.83 \\
\hline H3 & 0.15 & 0.18 & 2.10 & $94 \pm 17$ & 3.38 & 3.94 \\
\hline
\end{tabular}

(a) $\mathrm{H} 1$ - composite of fine-grained sediments, mostly silt, from the vadose zone of borehole cores 299-W11-92 and 299-W15226. Natural calcium carbonate cementation of the sediment was apparent. $\underline{\mathrm{H} 2}$ - composite from different depths within one well (299-W11-92).

$\mathrm{H3}$ - composite of saturated zone sediments of two different wells: 299-W11-92 and 299-W15-226.

(b) Total DOC is the total OC released from the sediment to the aqueous phase $(<0.45 \mu \mathrm{m})$ after 21 days of contact during the sediment/groundwater batch iodine uptake experiment.

(c) Suspensions were spiked with either iodide or iodate (as $\left.{ }^{125} \mathrm{l}\right)$. However, the spiked species transformed to other species during the contact period. Consequently, these are not species-specific $\mathrm{K}_{\mathrm{d}}$ values.

Earlier studies had focused on I- partitioning, with reported $\mathrm{K}_{\mathrm{d}}$ values ranging from 0 to $2 \mathrm{~mL} / \mathrm{g}$, but most frequently between 0 and $0.2 \mathrm{~mL} / \mathrm{g}$ (Cantrell et al. 2003). These earlier studies also assumed a reversible anion exchange sorption mechanism where sorption and desorption occurred at equal rates (Kaplan et al. 2000; Um et al. 2004). More recent studies have shown that there was a strongly bound iodine fraction that did not desorb under chemical conditions conducive to anion exchange. Using subsurface sediments, desorption $\mathrm{K}_{\mathrm{d}}$ values were much higher than the iodine adsorption $\mathrm{K}_{\mathrm{d}}$ values, indicating that sorption was only partially reversible (Xu et al. 2015). In these studies, similar trends were noted for $\mathrm{I}^{-}$and $\mathrm{IO}_{3}{ }^{-}$, but results indicated that $\mathrm{IO}_{3}{ }^{-}$sorption to Hanford Site sediments was greater than $\mathrm{I}^{-}$ sorption.

\subsubsection{Microbial Processes}

Microorganisms and/or their cell exudates can mediate many important processes associated with iodine transformations between species, associations with organic compounds, and adsorption. Results from sediment traps incubated at locations within the Hanford Site 200-ZP-1 OU iodine plume with background, low, and high levels of ${ }^{129}$ I show the presence of microbial families that include Pseudomonads and Actinobacteria (Lee et al. 2015), which are taxa that have shown the ability to both oxidize $\mathrm{I}^{-}$and reduce $\mathrm{IO}_{3}{ }^{-}$. Microbes have been shown to be involved in iodine accumulation (Microbe-I, Figure 9) and formation of Organo-I compounds (Organo-I, Figure 9), including volatile compounds such as methyl iodide $\left(\mathrm{CH}_{3} \mathrm{I}\right)$ (Amachi et al. 2003, 2004; Fuse et al. 2003; Muramatsu et al. 1996), although these processes have not been evaluated for the Hanford Site. Microbial processes can also affect the subsurface geochemistry and may, thereby, affect sediment adsorption and redox capacity relevant to iodine fate and transport. The above microbial processes need to be considered in the context of the biogeochemical system in terms of the microbial ecology and presence of conditions conducive to potential microbial activity within the Hanford Site ${ }^{129}$ I plumes.

Biotransformation of iodine species includes oxidation of iodide to iodine and then spontaneous formation of more oxidized species, and reduction of iodate to iodide (see Figure 9, blue circle). Microbes enriched from sediments obtained from iodine-contaminated portions of the Hanford 200 West Area have demonstrated the potential for both iodide oxidation and iodate reduction. Preliminary data using Hanford isolate Agrobacterium DVZ35 in a sediment-free growth media has shown the ability to 
PNNL-24709, Rev. 2

RPT-DVZ-AFRI-030, Rev. 2

reduce iodate to iodide when nitrate is also present as an electron acceptor (Figure 14) [Lee at al. In review (Journal of Hazardous Materials)]. Iodate was completely reduced to iodide, while nitrate was reduced to products other than nitrite. Most Agrobacterium tumefaciens species have enzymes allowing denitrification through nitric oxide, but do not have nitrous oxide reductase, so the absence of nitrite is not surprising (Kampschreur et al. 2012). These studies also showed that Agrobacterium DVZ35 was able to maintain iodate reduction when, after initial nitrate depletion, additional nitrate was spiked into the medium (data not shown). A small amount of iodate reduction occurred in the control with only growth media present (Figure 14). Iodate reduction (greater than the control) did not occur when nitrate was initially absent from the growth medium.

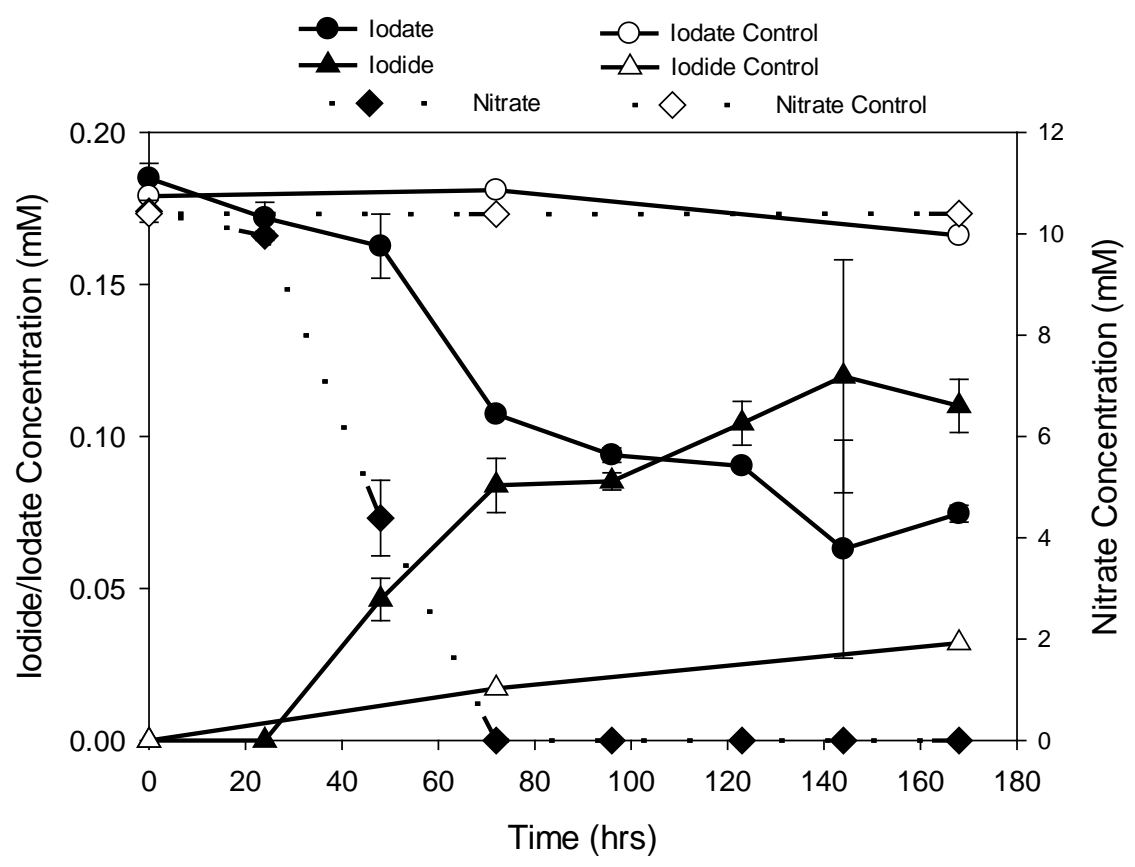

Figure 14. Iodate (with associated increase in iodide concentration) and nitrate reduction by Agrobacterium DVZ35 in a growth media.

In addition, a number of Shewanella species have shown the ability to reduce iodate under anoxic conditions (Mok et al. 2017). Preliminary results from these experiments indicate that iodate reduction is accomplished using proteins implicated in ferric iron reduction by these bacteria. In experiments performed with S. oneidensis MR-1, less than 5\% of the supplied iodate was converted to iodide, indicating other mechanisms for iodate transformation, such as volatilization or accumulation. In contrast to Agrobacterium DVZ35, S. oneidensis was able to reduce iodate in the absence of nitrate.

In a more recent experiment on iodate reduction by MR-1, a significantly higher amount of iodate was able to be reduced in a short period of time ( $<2$ days). In these experiments, iodate was added at $250 \mu \mathrm{M}$, as $\mathrm{NaIO}_{3}$ (anoxic), to anoxic phosphate-buffered M1 medium (Kostka and Nealson 1998), either with or without $S$. oneidensis strain MR-1 (cell density of $\sim 1 \times 10^{+8}$ cells $/ \mathrm{mL}$ ) and with sodium lactate at $20 \mathrm{mM}$ as electron donor and with $\mathrm{IO}_{3}{ }^{-}$as the sole electron acceptor. Samples were contained in 20-mL glass headspace vials crimp-sealed with butyl rubber stoppers (100\% $\mathrm{N}_{2}$ in headspace) and were incubated in a Coy glovebag $\left(98 \% \mathrm{~N}_{2}, 2 \% \mathrm{H}_{2}, \mathrm{O}_{2}<20 \mathrm{ppm}\right)$ on a rocking shaker at room temperature. The vials were subsampled periodically using syringe and needle and were filtered at $0.2 \mu \mathrm{m}$ into $6-\mathrm{mL}$ glass headspace vials, which were then sealed with rubber stoppers. Samples were stored out of the 
glovebag, sealed, in the dark at room temperature until analysis. Samples were analyzed for total iodine $\left({ }^{127} \mathrm{I}\right)$ and iodine speciation via inductively coupled plasma mass spectrometry (ICP-MS). Approximately $80 \%$ of the added iodate was reduced in the biotic treatments, and the reduced iodate was quantitatively recovered as iodide (Figure 15). There was no significant reduction of iodate in the no-cell controls. At the end of the incubation (48 h), total iodine in solution was only slightly less in the MR-1 treatment (235 $\mu \mathrm{M})$ compared to the abiotic control $(248 \mu \mathrm{M})$.

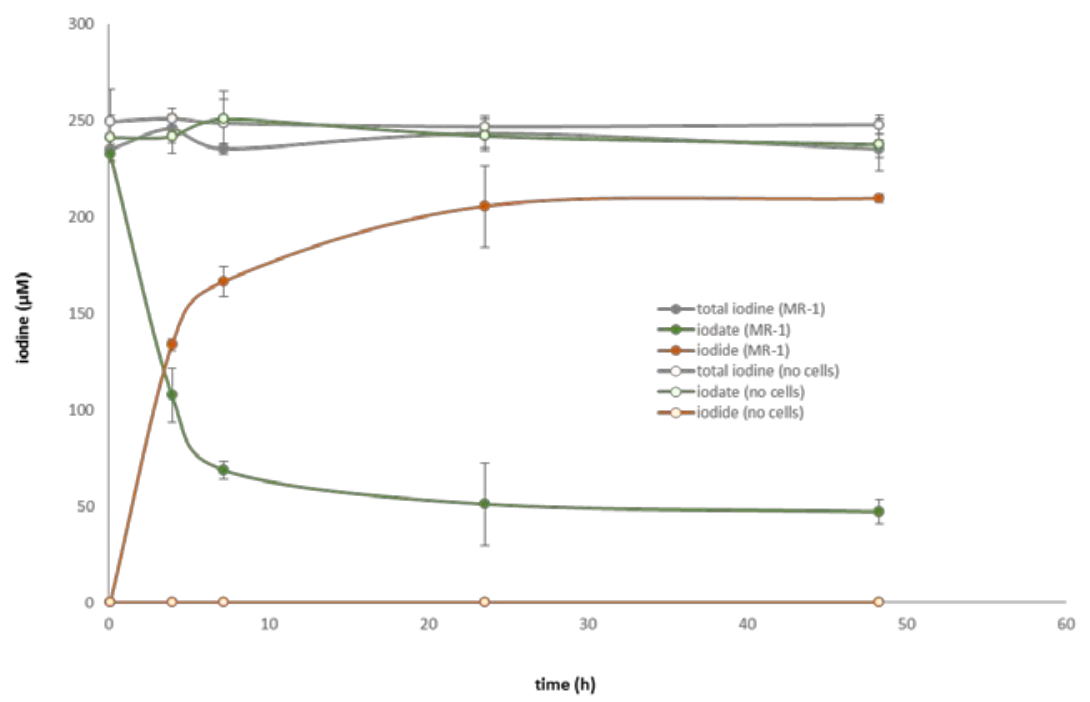

Figure 15. Iodate bioreduction by Shewanella oneidensis strain MR-1 (wild type) vs. no-cell controls, in anoxic M1 medium (phosphate-buffered at pH 7.0), with lactate (20 mM) as electron donor.

Results from the above experiments differ from nearly identical microcosms performed in the DiChristina Environmental Geomicrobiology lab at Georgia Tech in that iodide recovery was only 5\% of the total iodate added to the experiment. Volatilization of methyl iodide was hypothesized as the mechanism for loss of the additional iodine added to the microcosms. The primary difference in the experimental setup was that the headspace of the microcosms performed by DiChristina (in preparation) were continuously flushed with nitrogen to maintain anoxic conditions, while the similar PNNL experiments were performed in sealed serum bottles kept in an anaerobic glove bag. The difference in the experimental setup was to prevent possible volatilization of methyl iodide from the serum vials in experiments using ${ }^{125}$ I. One hypothesis that has been posed is that in the sealed serum vials, the methyl iodide builds up in concentration, causing inhibition of enzymes responsible for methylation of the iodide; therefore, all of the iodide remains as iodide. When methyl iodide is flushed from the headspace, the enzyme is not inhibited and methylation of iodide continues. Iodate reduction experiments were performed using S. putrfaciens MR-4, in which inorganic species were less than total iodine for roughly $20 \mathrm{~h}$ in the middle of the experiment (Farrenkopf et al. 1997). Improved methyl halide production from iodide through intermittent venting of reaction flasks has also been demonstrated by other researchers (Bayer et al. 2009; Cheng et al. 2016).

A number of bacteria isolated from sediments in iodine-contaminated portions of the Hanford 200 West Area were tested for the ability to oxidize iodide (Table 10) (Lee et al. 2017). Nine of the fourteen isolates demonstrate iodide oxidation through the formation of molecular iodine as an oxidation intermediate. Four isolates were selected to examine iodide oxidation, as well as the ability to oxidize 
PNNL-24709, Rev. 2

RPT-DVZ-AFRI-030, Rev. 2

2,2'-azino-bis(3-ethylbenzothiazoline-6-sulphonic acid) (ABTS), a substrate for multi-copper oxidases that have been shown to be involved in iodide oxidation (Kulys et al. 2005; Suzuki et al. 2012; Ihssen et al. 2014). Preliminary results showed that all four isolates were able to oxidize iodide when grown on a variety of sugars and organic acids. Addition of glucose appeared to stimulate the most growth, enzyme production, and iodide oxidation (Figure 16). Because the amount of molecular iodine measured in the experiments is typically less than the amount of iodide added to the experiments, the reaction may continue to more oxidized forms of iodine, such as hypoiodous acid or iodate, or other reactions, such as volatilization or accumulation, may be occurring. Scoping experiments are in progress to help determine which mechanism accounts for the remainder of the iodide added.

Table 10. Hanford isolates tested for iodide oxidation.

\begin{tabular}{ll}
\hline Strain & Affiliation (accession number) \\
\hline DVZ17 & Ralstonia sp. PNP11 (DQ887520.1) \\
DVZ23 & Pseudomonas frederiksbergensis strain DSM 13022 (NR_117177.1) \\
DVZ18 & Pseudomonas sp. PAMC 26822 (KF011696.1) \\
DVZ27 & Pseudomonas mandelii strain NF22-1 (KF151354.1) \\
DVZ60 & Cupriavidus necator strain N-1 (NR_028766.1) \\
DVZ21 & Arthrobacter ilicis strain ICMP 2608 (NR_104950.1) \\
DVZ35 & Agrobacterium tumefaciens strain IAM 12048 (NR_041396.1) \\
DVZ24 & Pseudomonas mosselii strain CFML 90-83 (NR_024924.1) \\
DVZ52 & Lysobacter niastensis strain GH41-7 (NR_043868.1) \\
DVZ47 & Shinella kummerowiae strain CCBAU 25048 (NR_044066.1) \\
DVZ6 & Pseudomonas mosselii strain CFML 90-83 (NR_024924.1) \\
DVZ2 & Bacillus thuringiensis strain IAM 12077 (NR_043403.1) \\
DVZ29 & Enterobacter hormaechei strain 0992-77 (NR_042154.1) \\
DVZ19 & Microbacterium invictum strain DC-200 (NR_042708.1) \\
\hline
\end{tabular}


PNNL-24709, Rev. 2

RPT-DVZ-AFRI-030, Rev. 2
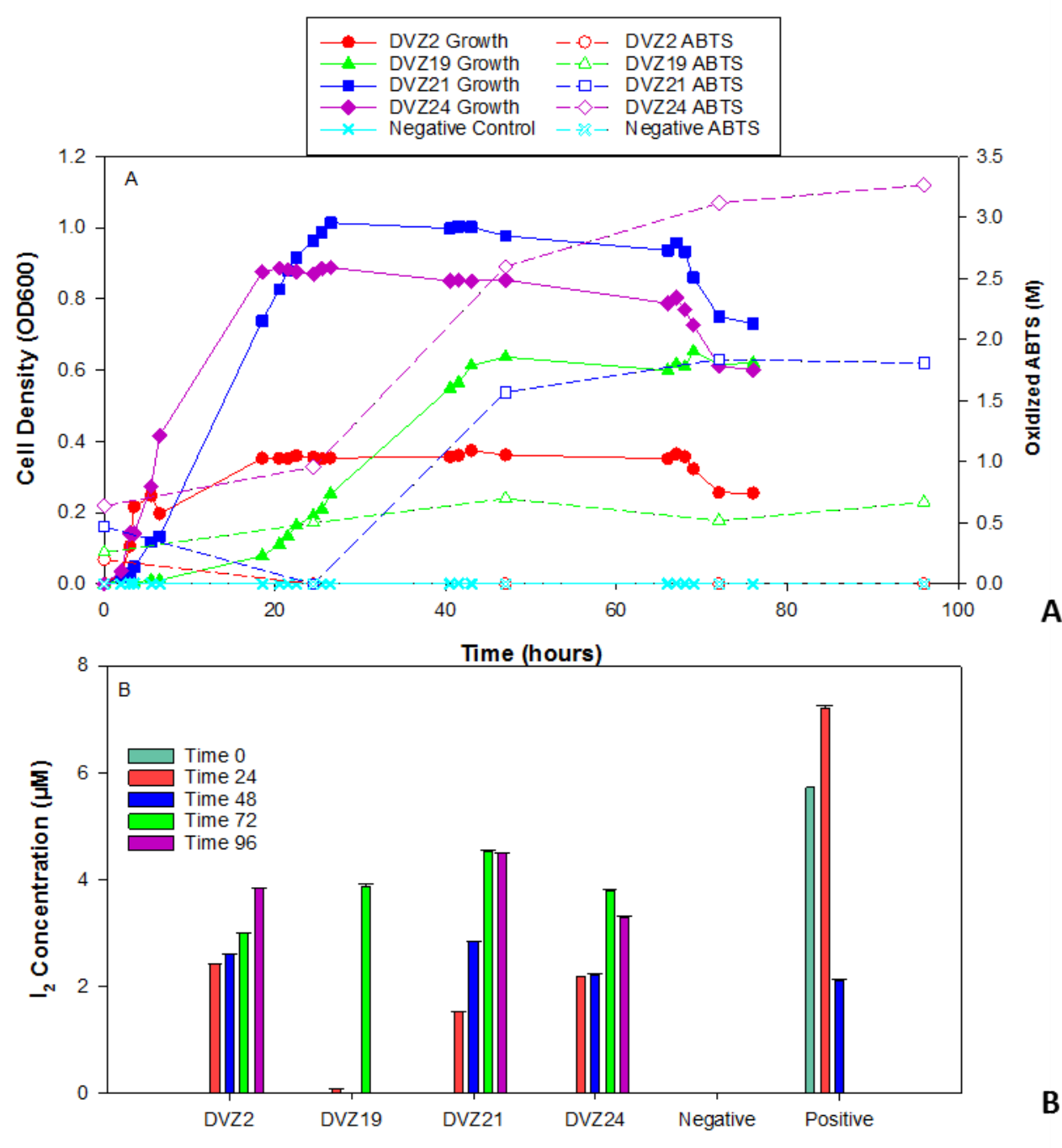

Figure 16. Growth and ABTS oxidation by different Hanford bacterial isolates (A) and molecular iodine concentration over time for four microbial isolates (DVZ2, DVZ19, DVZ21, and DVZ24) as an indicator for iodide oxidation (B). Negative controls contained no bacteria. Positive controls contained an enzyme that oxidizes ABTS and iodide.

Evidence from some results generated to date indicated lower-than-expected recovery of inorganic iodine species in microcosm experiments. These results suggest that there may be volatilization (Figure 9, green balloon), through either the oxidation or the methylation. Experiments are currently in progress to track the formation of volatile iodine species during oxidation of residual and added iodide and iodate in Hanford groundwater. In addition, the lack of mass balance for iodine in current experiments appears to be dependent on cell concentration, so bioaccumulation of iodine species may also be occurring (Figure 9, brown balloon). 
PNNL-24709, Rev. 2

RPT-DVZ-AFRI-030, Rev. 2

\subsubsection{Redox Transformations}

Minerals that participate in redox reactions (e.g., iron and manganese) may mediate iodine transformation processes, either directly or coupled with microbial processes. Reduction of iodate in Hanford Site sediments was observed as part of partitioning experiments (Xu et al. 2015) and could have been driven by sediment-associated ferrous iron or microbial reactions. Data from the 200 Area suggest that Fe(II) concentrations in Ringold Formation sediments could be on the order of 3.4 to 6.9 wt\% (MinChem Database [Mackley et al. 2010] - unpublished). Thus, ferrous iron incorporated in minerals may be a reactive facies (as iron sulfide, if present, or other ferrous minerals) that needs to be considered relative to iodine fate and transport.

A series batch and stop-flow soil-column experiments were conducted to evaluate oxidation-reduction transformations of iodine species using samples of sediments obtained from borehole C9483 (depth interval 387-388 ft bgs) in the 200-UP-1 OU downgradient of the iodine plume at the location of the hydraulic containment wells. Batch experiments were conducted at several soil/water ratios with a contact time of about 48 hours, measuring concentration of iodate and iodide at that time for comparison to the measured added iodate concentration. For the analysis, it was assumed that the iodide $\mathrm{K}_{\mathrm{d}}$ was zero. The batch experiments were conducted using oxic artificial groundwater (including about $27 \mathrm{mg} / \mathrm{L}$ nitrate) spiked with iodate or iodide. Control experiments with no sediment added showed no iodide oxidation and no iodate reduction.

Soil columns were loaded with a constant concentration of the specified iodine species by introducing 20 pore volumes of influent artificial groundwater containing the iodine species. Flow was then stopped and the columns were incubated for different time intervals. At a sampling time, $7 \mathrm{~mL}$ ( $10 \%$ of the PV) was pushed out of the column through the effluent end by adding that amount of clean artificial groundwater at the influent end. The effluent sample was then analyzed for iodine species. In essence, this soil-column technique enables evaluation of different sediment contact times with an apparatus that allows incubation at a variable sediment-to-water ratios ( $\sim .5$ and 4.8$)$ by varying the amount of glass beads included in the column packing with the field sediments. Experimental conditions for the soil column experiments are shown in Table 11. 
PNNL-24709, Rev. 2

RPT-DVZ-AFRI-030, Rev. 2

Table 11. Matrix of soil column experiments and summarized results.

\begin{tabular}{|c|c|c|c|}
\hline Soil/Water Ratio & $\begin{array}{l}\text { Oxic/Anoxic } \\
\text { Groundwater }\end{array}$ & $\begin{array}{l}\text { Sediment } \\
\text { Treatment }\end{array}$ & $\begin{array}{l}\text { Summarized Results for } \\
\text { lodate Reduction Rate }\end{array}$ \\
\hline$\sim 0.5$ & Oxic with nitrate & None & $2.4 \mathrm{nmol} \mathrm{h}^{-1} \mathrm{~g}^{-1}$ \\
\hline$\sim 4.8$ & Oxic with nitrate & None & $0.58 \mathrm{nmol} \mathrm{h}^{-1} \mathrm{~g}^{-1}$ \\
\hline-0.5 & Anoxic with nitrate & None & $2.0 \mathrm{nmol} \mathrm{h}^{-1} \mathrm{~g}^{-1}$ \\
\hline$\sim 4.8$ & $\begin{array}{l}\text { Oxic with no } \\
\text { added nitrate }\end{array}$ & None & $1.4 \mathrm{nmol} \mathrm{h}^{-1} \mathrm{~g}^{-1}$ \\
\hline$\sim 4.8$ & Oxic with nitrate & $\begin{array}{l}2 \% \text { glutaraldehyde } \\
\text { to suppress } \\
\text { microbial activity }\end{array}$ & $0.07 \mathrm{nmol} \mathrm{h}^{-1} \mathrm{~g}^{-1}$ \\
\hline$\sim 0.3$ & Oxic with nitrate & $\begin{array}{l}5 \% \text { peroxide to } \\
\text { oxidize sediments } \\
\text { and suppress } \\
\text { microbial activity }\end{array}$ & $0.02 \mathrm{nmol} \mathrm{h}^{-1} \mathrm{~g}^{-1}$ \\
\hline
\end{tabular}

Iodide oxidation was not observed in any of the tests except where sediments were treated with peroxide, and it is likely that observed oxidation was from residual peroxide in the column. For the batch iodate reduction experiments, the reduction rate normalized for the variable mass of sediment was $0.165 \pm$ $0.058 \mathrm{nmol} \mathrm{h}^{-1} \mathrm{~g}^{-1}$. Absolute iodate reduction was higher in treatments with higher sediment-to-water ratios (e.g., Figure 12). Iodate reduction rates in soil column experiments are summarized in Table 11. A relatively rapid iodate reduction rate was observed in oxic and anaerobic sediment experiments that contained artificial groundwater with and without nitrate. Although experiments by others have concluded that microbial nitrate reduction results in cometabolic reduction of iodate (i.e., the presence of nitrate increases the rate of iodate reduction in no-sediment microbial experiments, Section 2.3.2), in these sediment-groundwater experiments, removal of nitrate from the artificial groundwater resulted in a slight increase in the overall iodate reduction rate. Pretreatment of the sediment with a bactericide ( $2 \%$ gluteraldehyde for 7 days before addition of iodate-containing groundwater) significantly decreased the iodate reduction rate (4.6x slower), suggesting microbial participation in iodate reduction. Peroxide pretreatment of the sediment, which should oxidize most ferrous iron phases and also significantly reduce microbial activity, resulted in a 2-order of magnitude decrease in the iodate reduction rate. Jointly these results suggest that there is also some abiotic control of iodate reduction (e.g., from ferrous iron surface phases). Extrapolation of laboratory rates to the field is uncertain. However, the results suggest that some reduction may occur in the field through a combination of biotic and abiotic mechanisms. Because the iodate reduction appears to be caused by a combination of abiotic phases (e.g., ferrous iron surface phases) and microbial reduction, there may be a maximum functional capacity for these abiotic and biotic processes depending on mass of abiotic phases and available substrate for microbial processes. This abiotic/biotic reduction capacity was not quantified in these experiments. A finite reductive capacity may become overwhelmed such that the continuing current rate of transformation near the source and core of the plume becomes slow and iodate can persist in the groundwater (along with iodide). Transformation to or formation of Organo-I complexes was not evaluated in the above soil column experiments. 
PNNL-24709, Rev. 2

RPT-DVZ-AFRI-030, Rev. 2

\subsubsection{Organic lodine}

\subsubsection{Summary of Work Conducted in FY16}

Organic materials in the subsurface may interact with iodine and affect its fate and transport through (1) formation of immobile sediment-associated Organo-I compounds, (2) formation of mobile soluble Organo-I compounds, (3) formation of volatile Organo-I compounds, (4) providing electron donors for microbially mediated reduction reactions that directly or indirectly affect iodine speciation, and

(5) providing adsorption capacity for iodine species.

As a first step in understanding interaction of iodine species and organic compounds, samples of 200UP-1 OU groundwater (C9412, C9415, and C9416) were analyzed to evaluate the organic compounds present. These analyses were conducted as a scoping study to provide insight into the type of organic compounds present in 200-UP-1 OU groundwater. Groundwater samples were analyzed on a 12 Tesla Bruker SolariX Fourier transform ion cyclotron resonance (FTICR) mass spectrometer (MS) using electrospray ionization. Groundwater samples were diluted with liquid chromatography-MS grade methanol to a ratio of 2:1 (V/V) methanol:groundwater and injected directly into the MS. DataAnalysis software (BrukerDaltonik, Version 4.2) was used to convert raw spectra to a list of identified potentially specific compounds (peaks). Chemical formulas were assigned using in-house built software following the Compound Identification Algorithm, described by Kujawinski and Behn (2006) and modified by Minor et al. (2012), taking into consideration the presence of C, H, O, N, S, and P and excluding other elements. Organic compound composition was further examined by van Krevelen (VK) analysis, which classifies organic molecules into different biochemical classes based on their $\mathrm{H} / \mathrm{C}$ and $\mathrm{O} / \mathrm{C}$ atomic ratios (Kim et al. 2003). Following the classification described by Tfaily et al. (2015), VK diagrams can be classified into regions (Figure 17).

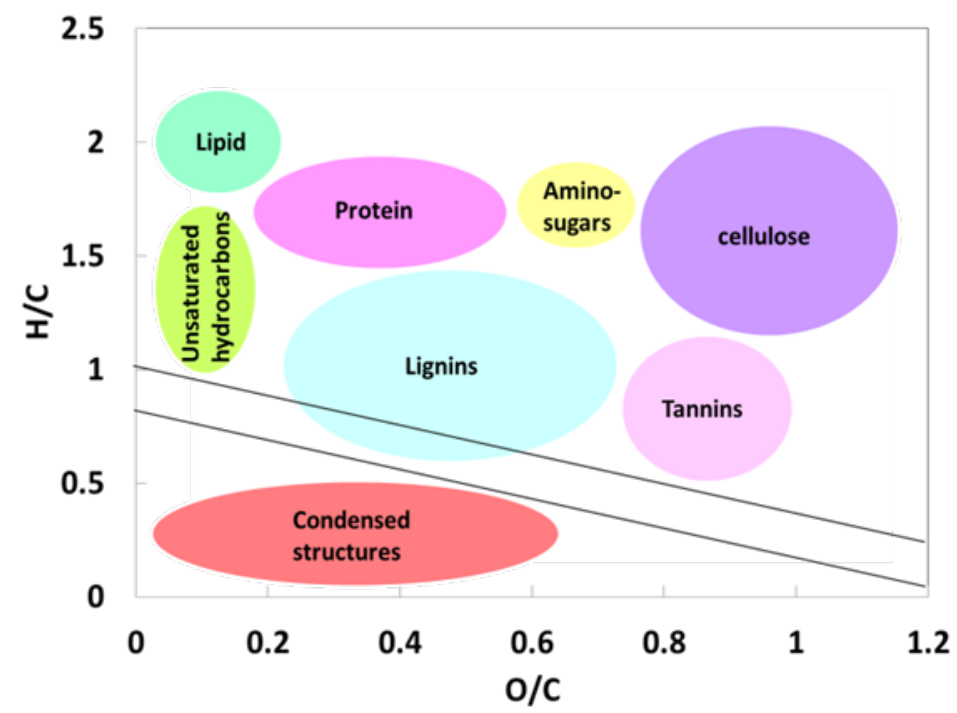

Figure 17. Organic compound classification by van Krevelen analysis based on their H/C and O/C atomic ratios. 
PNNL-24709, Rev. 2

RPT-DVZ-AFRI-030, Rev. 2

FTICR-MS analysis of groundwater collected was not able to determine the composition for a large portion of the identified potentially specific compounds (peaks). However, the multiple peaks from each groundwater sample analysis that could be assigned are depicted on Figure 18. For the well C9416 sample (within the chromium plume), 33\% of the detected peaks were assigned molecular formulas. CHO compounds dominated the formula assignment ( 40\%), followed by CHOS ( 25\%), CHON ( 15\%), and CHNOS ( 10\%), with other series making up minor fractions. Based on H/C and O/C ratios, the majority of the compounds were lipid-like with some condensed structures (aromatic compounds) (Figure 18a). For the well C9415 sample (within the iodine plume), 13\% of the detected peaks were assigned molecular formulas. CHO (25\%) and CHOS (40\%) series dominated the formula assignment, followed by CHON (15\%) and CHONS (20\%). The compound classes were split between lipid-like, unsaturated hydrocarbons, and condensed structures (aromatic compounds) (Figure 18b). For the well C9412 sample (downgradient of the iodine plume at the location of hydraulic containment wells), only $10 \%$ of the detected peaks were assigned molecular formulas. CHOS (45 \%) and CHNOS (32\%) series dominated the formula assignment (Figure 18c). 
PNNL-24709, Rev. 2

RPT-DVZ-AFRI-030, Rev. 2
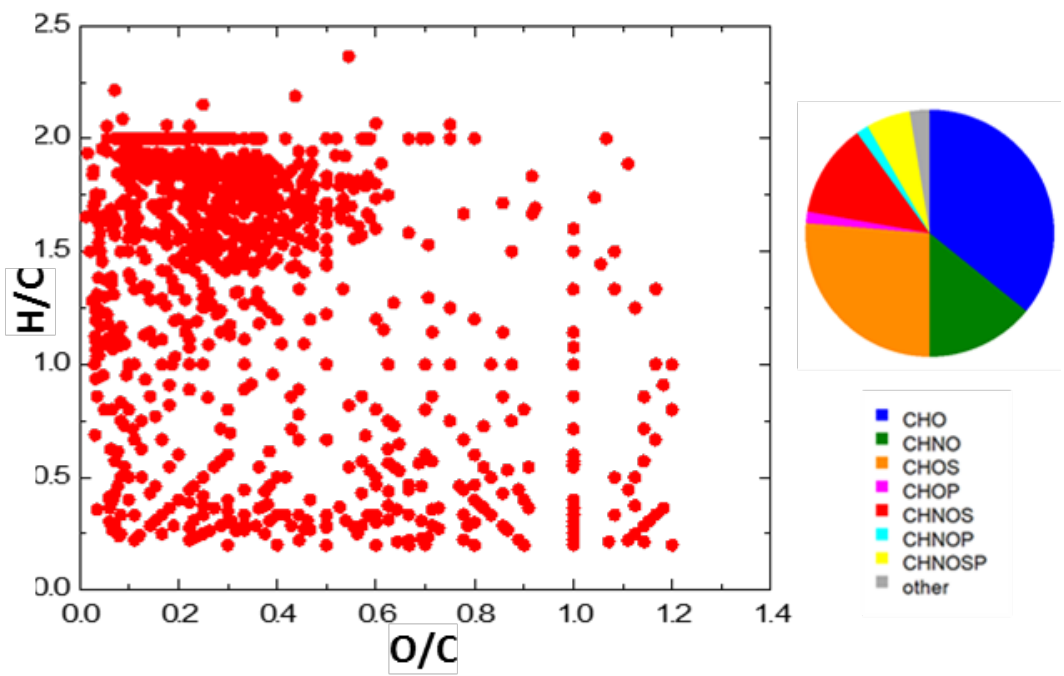

(a)
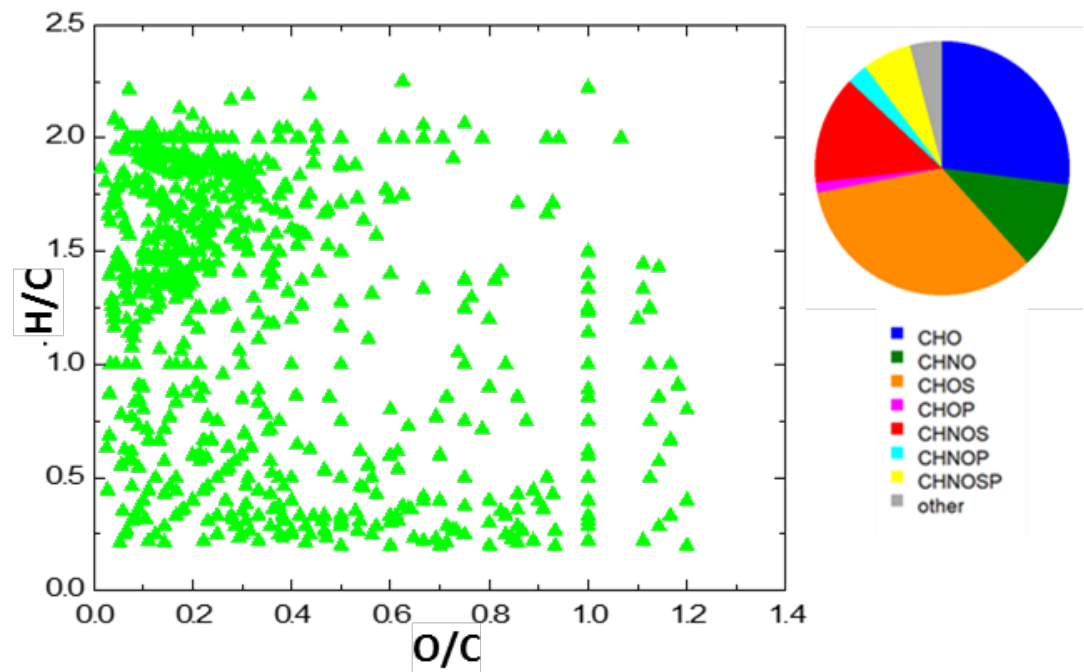

(b)
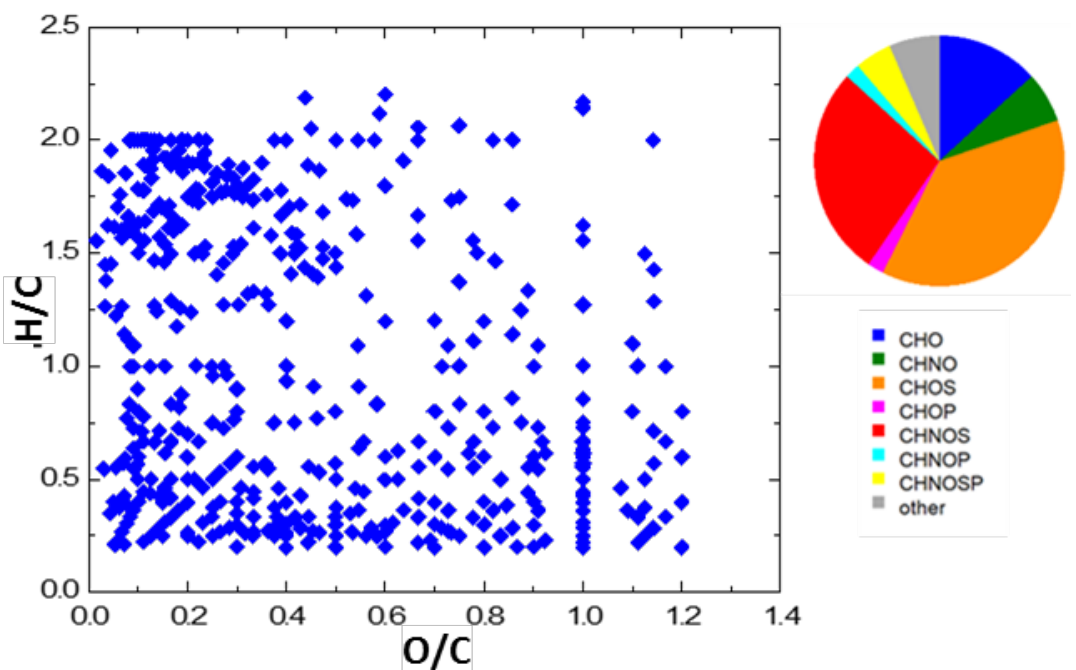

(c)

Figure 18. van Krevelen plot of organic compound data and assigned formula categories for (a) well C9416, (b) C9415, and (c) C9412. 
PNNL-24709, Rev. 2

RPT-DVZ-AFRI-030, Rev. 2

In summary, the analyses showed that a broad range of organic compounds were present in the 200-UP-1 OU aquifer groundwater. The majority of these compounds could not be identified with the initial analysis techniques applied. However, for the compounds that were identified, there are a wide range of organic compound classes present. These classes include lipid-like, aliphatic, olefinic, and aromatic compounds. A preliminary assessment of potential iodine association with these identified organic compounds was conducted, with some positive indications. The assessment evaluated compound mass ratios that might indicate a specific peak being associated with an organic-iodine compound rather that a pure organic compound. These results were also used to determine appropriate experimental approaches for future efforts to (1) verify the identified complexes and (2) understand the extent to which Organo-I complexes exist in the subsurface.

\subsubsection{Summary of the Work Conducted in FY17}

Because Organo-I complexes impact the fate and transport of iodine, the objectives of efforts during FY17 were to (1) determine how analytical standards of Organo-I complexes fragment and which organic compounds react with iodate/iodide in artificial ground water (AGW) [see Truex et al. 2017 for the AGW recipe], and (2) identify Organo-I complexes from field sediments and pore water. This work was completed as scoping work, and as such, should be considered For Information Only (FIO).

To address the first objective, a total of 14 organic compounds (6 Organo-I complexes and 8 iodide/iodate free complexes) were purchased to determine the fragmentation pattern of iodide and iodate bound to known organic standards (Table 12, Figure 19). The 6 Organo-I complexes were dissolved in water to a final concentration of $0.5 \mu \mathrm{g} / \mu \mathrm{l}$ prior to MS analysis. The 8 iodine-free organic standards at $1 \mu \mathrm{g} / \mu \mathrm{l}$ were spiked with $\mathrm{KI}$ and $\mathrm{KIO}_{3}$ dissolved in Hanford AGW to a final concentration of $10^{-4} \mathrm{M}$.

Table 12. Organic standards used in this study, both pre-bound with iodine and iodine free.

\begin{tabular}{|c|c|c|c|}
\hline Standards & $\begin{array}{l}\text { Molecular } \\
\text { Formula }\end{array}$ & $\begin{array}{c}\text { Neutral } \\
\text { mass }\end{array}$ & {$[\mathrm{M}-\mathrm{H}]-$} \\
\hline \multicolumn{4}{|c|}{ Commercial organo-iodine standards } \\
\hline 3,5-Diiodo-4-hydroxyphenylpyruvic acid & $\mathrm{C}_{9} \mathrm{H}_{6} \mathrm{l}_{2} \mathrm{O}_{4}$ & 431.8355 & 430.8277 \\
\hline 4-lodopyrazole & $\mathrm{C}_{3} \mathrm{H}_{3} \mathrm{IN}$ & 193.9341 & 192.9263 \\
\hline 4-lodo-6-phenylpyrimidine & $\mathrm{C}_{10} \mathrm{H}_{7} \mathrm{IN}_{2}$ & 281.9654 & 280.9576 \\
\hline 2-lodo-5-methoxyphenol & $\mathrm{C}_{7} \mathrm{H}_{7} \mathrm{IO}_{2}$ & 249.9491 & 248.9412 \\
\hline 1-Iodo-3-nitrobenzene & $\mathrm{IC}_{6} \mathrm{H}_{4} \mathrm{NO}_{2}$ & 248.9287 & 247.9208 \\
\hline (Diacetoxyiodo)benzene & $\mathrm{C}_{10} \mathrm{H}_{11} \mid \mathrm{O}_{4}$ & 321.9702 & 320.9624 \\
\hline \multicolumn{4}{|c|}{ Organic standards } \\
\hline Glucosamine & $\mathrm{C}_{6} \mathrm{H}_{13} \mathrm{NO}_{5}$ & 179.0794 & 178.0715 \\
\hline $\mathrm{N}$-acetyl-D-glucosamine 6-sulfate & $\mathrm{C}_{8} \mathrm{H}_{14} \mathrm{NO}_{9} \mathrm{~S}$ & 300.0389 & 299.0311 \\
\hline Maltose monohydrate & $\mathrm{C}_{12} \mathrm{H}_{22} \mathrm{O}_{11}$ & 342.1162 & 341.1084 \\
\hline Ellagic acid & $\mathrm{C}_{14} \mathrm{H}_{6} \mathrm{O}_{8}$ & 302.0063 & 300.9984 \\
\hline Tannic acid & $\mathrm{C}_{76} \mathrm{H}_{52} \mathrm{O}_{46}$ & 1700.1730 & 1699.1651 \\
\hline Tyrosine & $\mathrm{C}_{9} \mathrm{H}_{11} \mathrm{NO}_{3}$ & 181.0739 & 180.0625 \\
\hline Syringaldehyde & $\mathrm{C}_{9} \mathrm{H}_{10} \mathrm{O}_{4}$ & 182.0579 & 181.0501 \\
\hline 4-hydroxybenzaldehyde & $\mathrm{C}_{7} \mathrm{H}_{6} \mathrm{O}_{2}$ & 122.0368 & 121.0290 \\
\hline
\end{tabular}


PNNL-24709, Rev. 2

RPT-DVZ-AFRI-030, Rev. 2

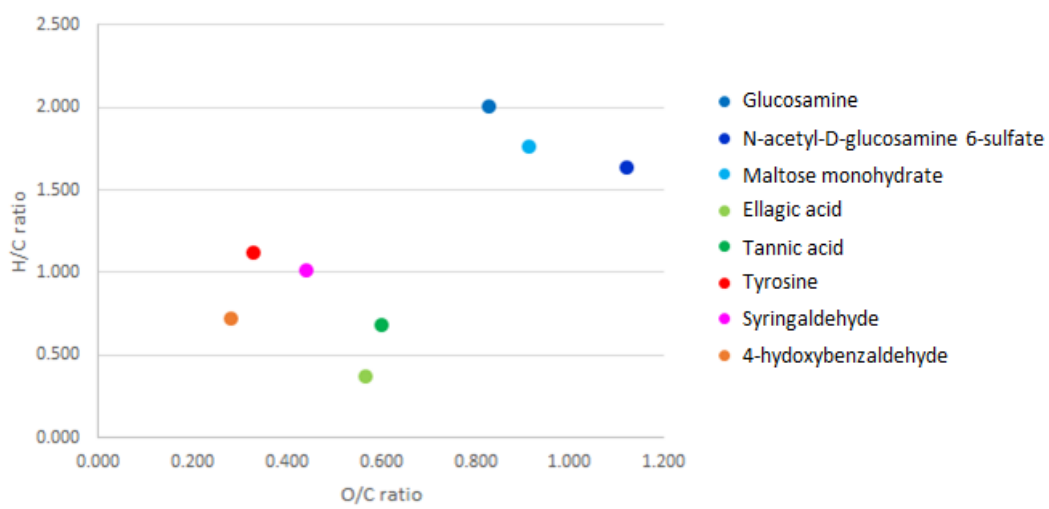

Figure 19. van Krevelen diagram of the 8 standards used for the $\mathrm{KI}$ and $\mathrm{KIO}_{3}$ spiking experiments. The standards fall within the different regions of the diagram highlighting the structural differences.

Analyses were conducted to determine which iodine fragments would be produced using MS. Initial MS1 analyses of organic-free $\mathrm{KI}$ and $\mathrm{KIO}_{3}$ at $10^{-4} \mathrm{M}$ in AGW produced peaks of $\mathrm{m} / \mathrm{z} 126.9048$ and 174.889, the exact masses of iodide and iodate, respectively. Peaks with $\mathrm{m} / \mathrm{z} 126.905$ were also identified in the $\mathrm{KIO}_{3}$, indication that fragmentation was cleaving off the oxygen molecules (Figure 20a and b).
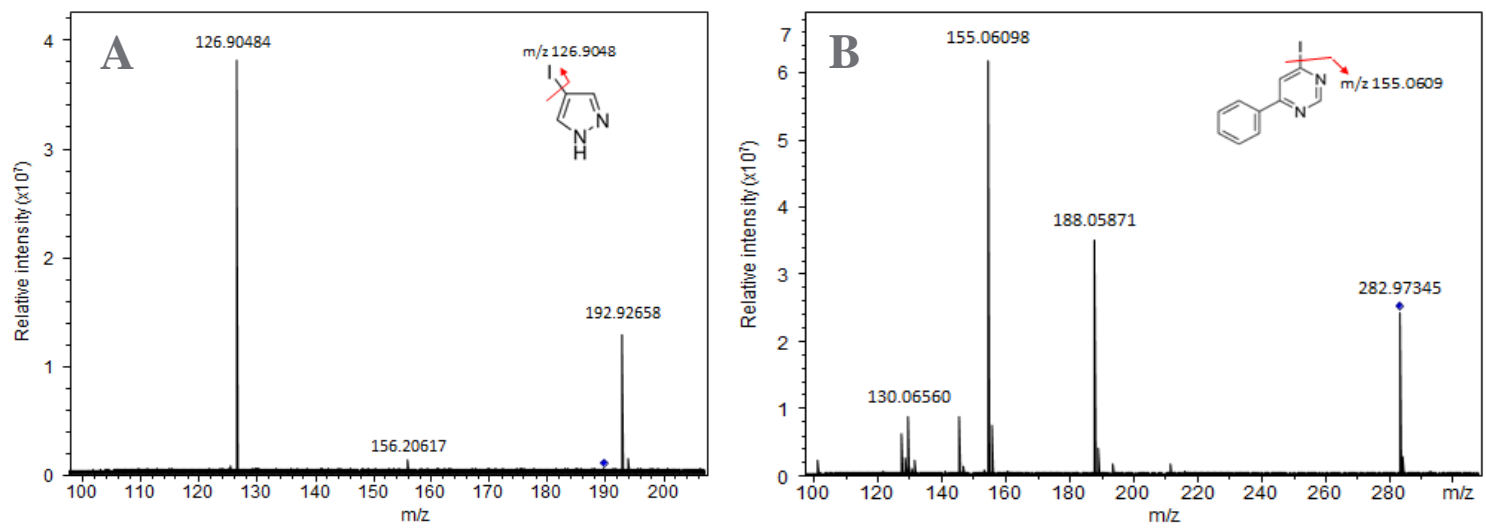

Figure 20. (A) MS/MS of 4-iodopyrazole $\left(\mathrm{C}_{3} \mathrm{H}_{3} \mathrm{~N}_{2} \mathrm{I}\right)$ in negative ionization ([M-H $\left.]^{-}\right)$. Fragmentation of the standard produced an $\mathrm{m} / \mathrm{z}$ 126.9048, the exact mass of iodide. (B) MS/MS of 4-iodo-6phenylpyrimidine $\left(\mathrm{C}_{10} \mathrm{H}_{7} \mathrm{~N}_{2} \mathrm{I}\right)$ in positive ionization $\left([\mathrm{M}+\mathrm{H}]^{+}\right)$. The loss of IH produced the fragment $\mathrm{m} / \mathrm{z}$ 155.0609, the exact mass of the standard without iodine.

After determining the fragment $\mathrm{m} / \mathrm{z}$ for both iodide and iodate, $8 \mathrm{KI}$ and $\mathrm{KIO}_{3}$ spiked organic standards were analyzed by MS and MS/MS both 3 and 10 days post spiking. The organic standards reacted differently to iodine speciation, and the number of Organo-I complexes changed with time (Table 13). For the individual standards spiked with iodide, 6 of the 8 standards initially formed Organo-I complexes; however, with time all standards bound iodide. Additionally, with time the complexes changed, with new complexes forming (value in parentheses in Table 13) and existing ones either decreasing in abundance, and therefore below limits of detection, or lost the iodide complexation completely. 
PNNL-24709, Rev. 2

RPT-DVZ-AFRI-030, Rev. 2

Table 13. Results from $\mathrm{KI}$ and $\mathrm{KIO}_{3}$ spiked organic standards experiment. Values in the table indicate the number of MS peaks identified to contain iodide (m/z 126.905) and iodate (m/z 174.889) 3 or 10 days after spiking. Values in parentheses identify the number of new Organo-I peaks identified after 10 days of spiking. Values in brackets in the iodate 10 day standards indicate the number of peaks identified to contain $\mathrm{m} / \mathrm{z} 126.905$, equal to that of iodide.

\begin{tabular}{lcccc}
\hline & \multicolumn{2}{c}{$\begin{array}{c}\text { Number of Peaks } \\
\text { Following lodide } \\
\text { Spike }\end{array}$} & $\begin{array}{c}\text { Number of Peaks } \\
\text { Following lodate } \\
\text { Spike }\end{array}$ \\
\cline { 2 - 5 } & $\mathbf{3}$ day & 10 day & 3 day & 10 day \\
\hline Glucosamine & 2 & $3(2)$ & 6 & $4(16)[2]$ \\
N-acetyl-D-glucosamine 6-sulfate & 0 & $1(1)$ & 18 & $16(12)[4]$ \\
Maltose monohydrate & 1 & $1(0)$ & $7[2]$ & $5[1]$ \\
Ellagic Acid & 0 & $4(4)$ & NA & NA \\
Tannic Acid & 2 & $2(0)$ & $0[4]$ & $0[7]$ \\
Tyrosine & 2 & $2(4)$ & $7[1]$ & $7(2)$ \\
Syringaldehyde & 1 & $1(0)$ & 12 & $7(10)[15]$ \\
4-hydroxybenzaldehyde & 4 & $4(1)$ & $8[3]$ & $5(11)[3]$ \\
Mix of all standards & $4(1)$ & $3(9)$ & $0[5]$ & {$[11]$} \\
\hline NA = not analyzed & \multicolumn{5}{c}{} \\
\hline
\end{tabular}

In summary, mass spectrometry analysis of the Organo-I standards confirmed that this is a viable technique to identify iodide and iodate organic complexes. The presence of iodate is more difficult to confirm given that the fragmentation of the organo-iodate complexes can produce fragments corresponding not only to iodate (m/z 174.889) but also iodide ( $\mathrm{m} / \mathrm{z}$ of 126.905). In addition, this use of standards highlighted that (1) iodine speciation and the organic matter structures influences complexation, (2) iodate binds more readily than iodide, (3) cations present in Hanford AGW play a role in Organo-I binding, and (4) the residence time influences binding kinetics.

To address the second objective (i.e., identify Organo-I complexes from field sediments and pore water), subsurface pore water and sediment samples were collected from within the iodine plume and from a non-iodine-contaminated zone of the Hanford Site. A total of 19 samples [10 from the iodine plume (7 water and 3 sediment) and 9 (8 water and 1 sediment) from the non-contaminated site (from herein referred to as background)] were collected from $271.70 \mathrm{ft}$ to $452.60 \mathrm{ft}$ below ground (Table 14). A subsample of each water sample was analyzed using ICP-MS to determine the I concentration. For the sediment samples, organic matter was extracted and a subset was analyzed for total ${ }^{127} \mathrm{I}$. 
PNNL-24709, Rev. 2

RPT-DVZ-AFRI-030, Rev. 2

Table 14. Pore water and sediment sample locations from the Hanford Site (data presented here is FIO).

\begin{tabular}{llllcc}
\hline Sample & Matrix & $\begin{array}{c}\text { Well } \\
\text { Location }\end{array}$ & $\begin{array}{c}\text { Sample } \\
\text { No. }\end{array}$ & $\begin{array}{c}\text { Sample } \\
\text { Depth } \\
(\mathbf{f t})\end{array}$ & $\begin{array}{c}\text { lodine-127 } \\
(\boldsymbol{\mu g} / \mathbf{L})\end{array}$ \\
\hline Background & Water & C9412 & B348C8 & 296.98 & 11.00 \\
Background & Water & C9412 & B348D4 & 327.20 & 11.00 \\
Background & Water & C9412 & B348F0 & 357.80 & 10.70 \\
Background & Water & C9412 & B348F6 & 386.70 & 11.50 \\
Background & Water & C9412 & B348H2 & 406.90 & 11.20 \\
Background & Water & C9412 & B348H8 & 436.50 & 12.10 \\
Background & Water & C9412 & B34HR0 & 452.60 & 12.50 \\
Background & Water & C9482 & B31F63 & 371.30 & below detection (detection limit = 1.26) \\
\hline lodine plume & Water & C9415 & B349L2 & 271.70 & 10.30 \\
lodine plume & Water & C9415 & B349L8 & 315.79 & 12.30 \\
lodine plume & Water & C9415 & B349M4 & 336.48 & 13.10 \\
lodine plume & Water & C9415 & B349N0 & 366.80 & 14.60 \\
lodine plume & Water & C9415 & B349N6 & 395.60 & 15.90 \\
lodine plume & Water & C9415 & B349P2 & 415.90 & 57.57 \\
lodine plume & Water & C9415 & B349P8 & 316.65 & 0.84 \\
Background & Sediment & C9482 & B31F57 & 374.50 & 0.10 \\
lodine plume & Sediment & C9415 & B349R1 & 276.50 & 0.22 \\
lodine plume & Sediment & C9415 & B349R5 & 316.79 & 0.98 \\
lodine plume & Sediment & C9415 & B349R9 & 337.98 & \\
\hline
\end{tabular}

Organic matter was extracted from the sediments using a sequential extraction method (Tfaily et al. 2017) of water and organic solvents. A process blank was also prepared simultaneously with the sediments. Water, methanol, and MTBE extracts from the sediment samples were analyzed using ICP analysis. The water extracts were the only samples with detectable iodine (see Table 14). This indicates that iodine species preferentially bind to polar compounds and are less likely to bind to nonpolar compounds. The results of the mass spectrometry analyses suggested that OM composition is different between the sediment and pore water.

To compare OM composition between the sediments and pore water from the contaminated sites and pore water from uncontaminated sites (i.e., background), multivariate analysis was performed (Figure 21). For the sediment samples, $15-25 \%$ of the detected peaks were assigned a molecular formula, compared to $9-16 \%$ for the pore water samples. The high percentage of unassigned peaks in the pore water samples might be an indication that organic matter in these samples contains elements other than the default elements that were used in formula assignment (i.e., C, H, O, S, and P). In both the sediment and pore water samples, CHOS was the dominant formula assignment, with CHON and CHONP series also dominating in the sediment ( $>23 \%$ ) and CHONS and CHONSP ( $>15 \%)$ in the pore water (Table 15). The H/C and O/C ratios of the organic compounds also classified the majority of the compounds observed in the sediment samples as lipid-like compounds (Table 15). Conversely, pore water samples were dominated by aromatic compounds. In summary, the differences in organic matter composition between sediment and pore water samples suggest that pore water OM would be a better candidate for iodine/iodate binding compared to sediment samples due to the higher abundance of lignin-like and aromatic-like compounds. 
PNNL-24709, Rev. 2

RPT-DVZ-AFRI-030, Rev. 2

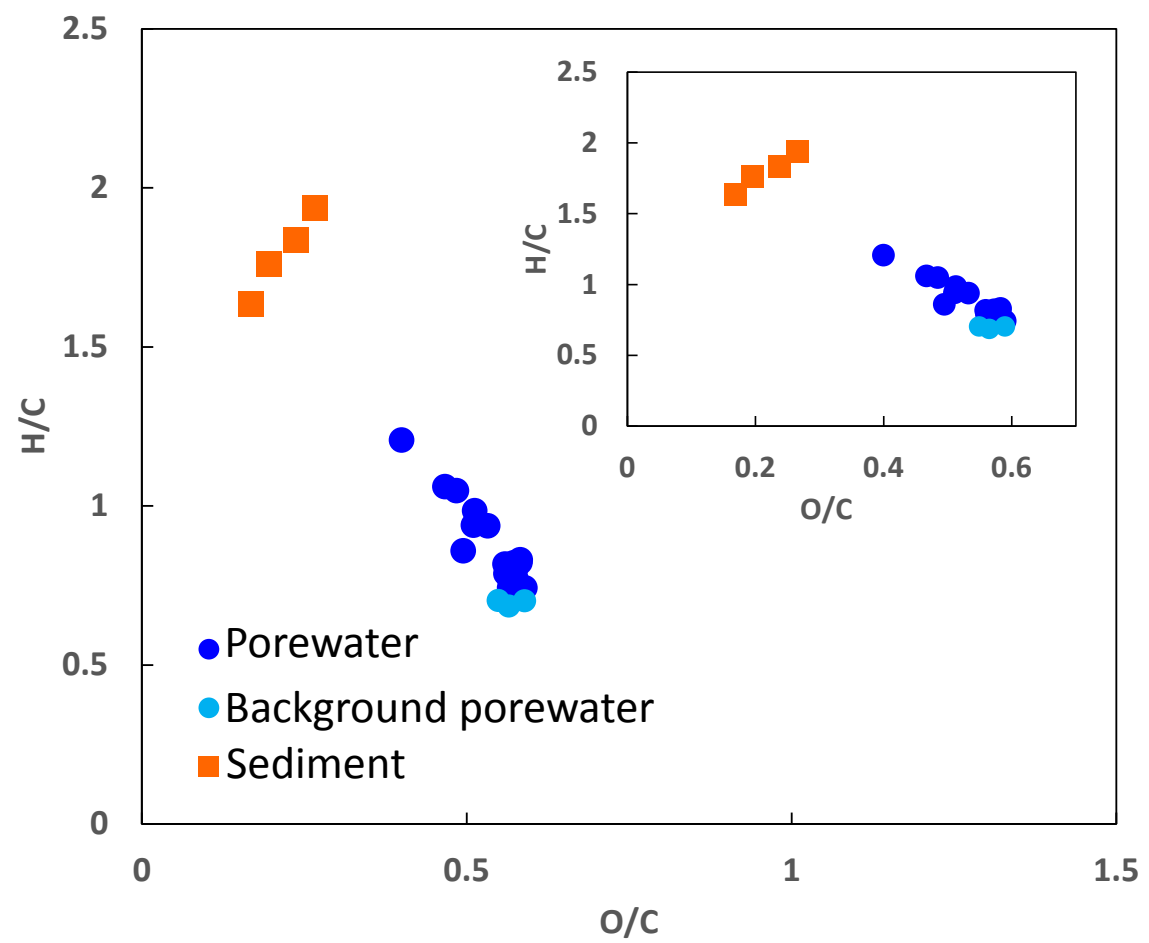

Figure 21. van Krevelen diagram of sediment and pore water OM. The van Krevelen diagram is a two dimensional (2D) scatter plot that has axes on the basis of the ratio of the number of major elements (e.g., H/C, O/C) in molecules.

Table 15. FTICR-MS classification of compounds with assigned molecular formulas in the sediment and pore water. The numbers in the table represent \% relative abundances of FT-ICR MS class composition and compound classes, and the bottom row represents the total number of peaks observed in each sample.

\begin{tabular}{|c|c|c|c|c|c|c|c|c|c|c|c|c|}
\hline Sample & B349N0 & B349N6 & B349P8 & B349P2 & B349L2 & B349L8 & B349M4 & B31F63 & B349R9 & B349R5 & B349R1 & B31F57 \\
\hline $\mathrm{CHO}$ & 4.1 & 3.9 & 5.3 & 3.6 & 5.3 & 7.1 & 5.2 & 1.6 & 9.8 & 8.7 & 9.9 & 4.9 \\
\hline $\mathrm{CHON}$ & 1.8 & 2.3 & 2.5 & 2.3 & 4.1 & 6.9 & 2.9 & 1.8 & 22.8 & 9.8 & 17.9 & 17.6 \\
\hline $\mathrm{CHOS}$ & 21.9 & 25.4 & 25.6 & 25.2 & 23.2 & 23.5 & 23.0 & 23.3 & 24.4 & 30.2 & 22.2 & 24.5 \\
\hline $\mathrm{CHOP}$ & 1.6 & 1.5 & 1.2 & 1.3 & 2.3 & 2.8 & 1.3 & 3.4 & 1.6 & 3.3 & 4.8 & 7.8 \\
\hline CHONS & 38.7 & 36.9 & 36.5 & 37.5 & 33.8 & 31.9 & 36.5 & 37.9 & 6.7 & 12.0 & 4.5 & 10.8 \\
\hline CHONP & 4.2 & 3.0 & 4.2 & 3.8 & 4.6 & 5.2 & 3.3 & 11.6 & 28.5 & 21.7 & 33.8 & 27.0 \\
\hline CHOSP & 12.8 & 13.6 & 11.6 & 11.1 & 14.2 & 11.4 & 12.9 & 6.0 & 1.6 & 8.2 & 1.1 & 3.4 \\
\hline CHONSP & 14.9 & 13.2 & 13.0 & 15.0 & 12.5 & 11.3 & 14.8 & 14.5 & 4.7 & 6.3 & 5.7 & 3.9 \\
\hline Lipids & 5.1 & 5.4 & 9.3 & 5.8 & 8.9 & 9.0 & 6.3 & 6.2 & 68.1 & 54.3 & 64.2 & 54.0 \\
\hline UnSaturated_HCS & 2.9 & 2.9 & 1.4 & 2.7 & 3.0 & 7.7 & 2.3 & 3.3 & 9.0 & 4.7 & 7.6 & 9.5 \\
\hline Condensed_HCS & 64.4 & 63.1 & 62.4 & 62.8 & 59.1 & 55.5 & 63.1 & 68.4 & 2.1 & 18.4 & 1.2 & 14.5 \\
\hline Proteins & 1.7 & 2.4 & 2.4 & 2.1 & 3.0 & 2.7 & 2.7 & 1.6 & 11.7 & 5.3 & 19.5 & 10.0 \\
\hline Amino_Sugars & 0.2 & 0.7 & 0.7 & 0.2 & 0.6 & 0.6 & 0.4 & 0.2 & 3.2 & 1.9 & 2.6 & 2.5 \\
\hline Carbohydrates & 3.9 & 3.4 & 2.3 & 3.7 & 3.9 & 3.5 & 3.1 & 2.4 & 3.2 & 2.5 & 2.6 & 1.0 \\
\hline Lignin & 13.9 & 14.2 & 13.8 & 14.9 & 14.6 & 14.7 & 14.6 & 12.1 & 2.7 & 10.6 & 2.3 & 8.0 \\
\hline Tannins & 7.9 & 7.8 & 7.6 & 7.8 & 6.8 & 6.4 & 7.5 & 5.9 & 0.0 & 2.2 & 0.0 & 0.5 \\
\hline $\begin{array}{l}\text { Total Number of } \\
\text { Peaks }\end{array}$ & 1185 & 1165 & 1139 & 1166 & 1246 & 1141 & 1188 & 1433 & 1091 & 1447 & 1501 & 1061 \\
\hline
\end{tabular}


PNNL-24709, Rev. 2

RPT-DVZ-AFRI-030, Rev. 2

The results of the MS1 and tandem mass spectrometry (MS/MS) potentially suggest an absence of Organo-I/iodate complexation in the sediments, consistent with the low iodine/iodate concentrations observed by ICP analysis. On the contrary, 3 out of 8 pore water samples indicated the presence of iodate and iodide after fragmentation, suggesting a presence of organic-I complexes in these samples, especially in the region between $\mathrm{m} / \mathrm{z} 450$ and 550 (Figure 22, Figure 23).

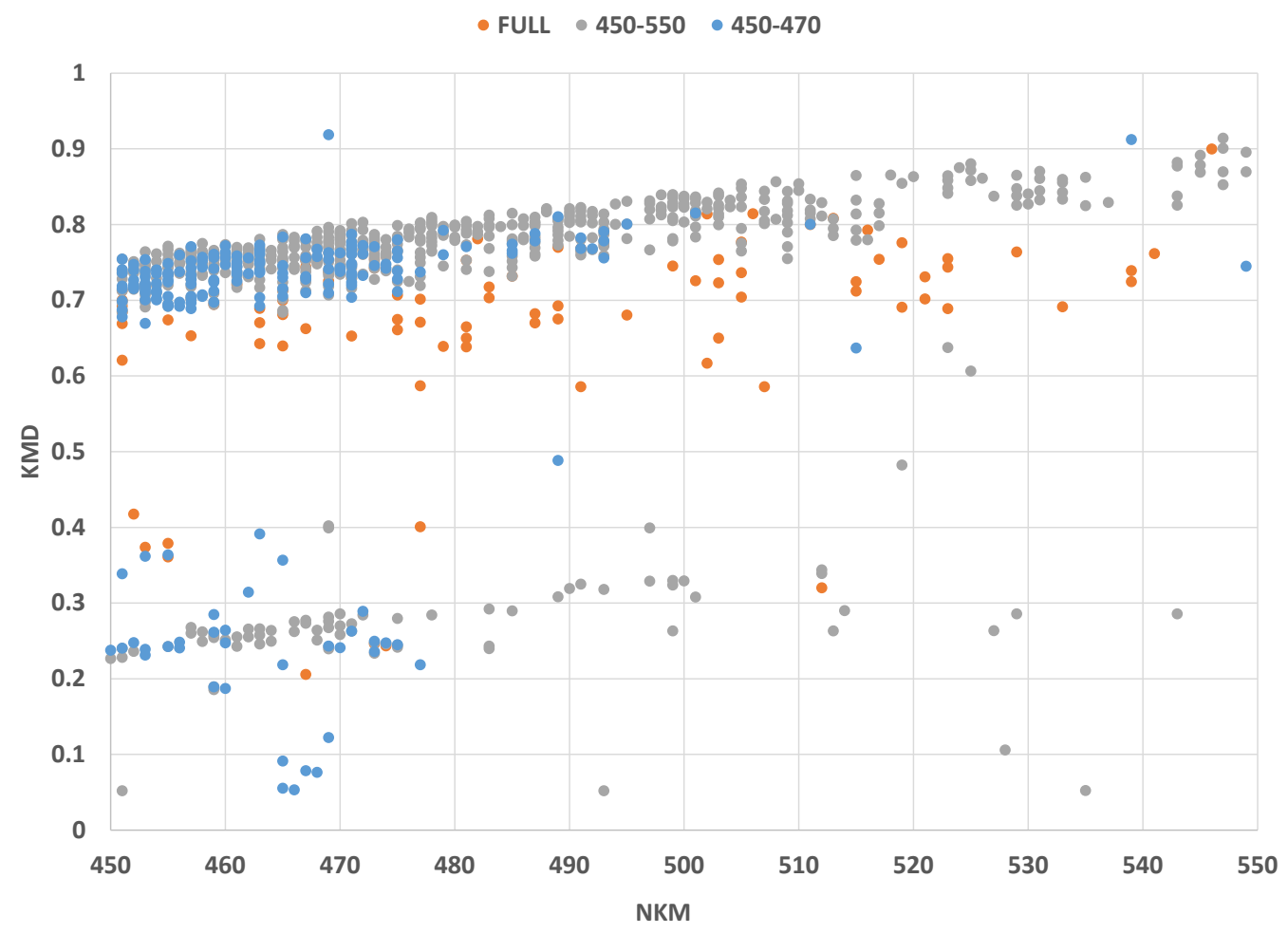

Figure 22. Kendrick plot of all peaks observed in the $\mathrm{m} / \mathrm{z} 450-550$ region before (full-orange) and after fragmentation (grey and blue).

This process narrowed the target list into 23 compounds that potentially contain iodate. Out of the 23 compounds, 11 were assigned formulas containing $\mathrm{C}, \mathrm{H}, \mathrm{O}, \mathrm{N}, \mathrm{S}$, or $\mathrm{P}$, but not iodate, and thus were eliminated from the target list. Of the remaining 12 peaks, the compounds $\mathrm{m} / \mathrm{z}$ were as follows: 450.7905, 450.8110, 450.8342, 456.8570, 460.7938, 462.8276, 462.8465, 464.8380, 464.8795, 466.7773, 466.8589, and 468.7981. The potential formulas of these compounds were identified (VK diagram of assigned formulas can be found in Figure 24) using a formula calculator developed by National High Magnetic Field laboratory, suggesting the target contains iodate, and in addition, Ca. These results were consistent with the results obtained from the standards with iodine/iodate. In both the water and standards, unique peaks with negative mass defect were observed. This is a characteristic of a compound that contains elements other than $\mathrm{C}, \mathrm{H}, \mathrm{O}, \mathrm{N}, \mathrm{S}$, and $\mathrm{O}$. 
PNNL-24709, Rev. 2

RPT-DVZ-AFRI-030, Rev. 2
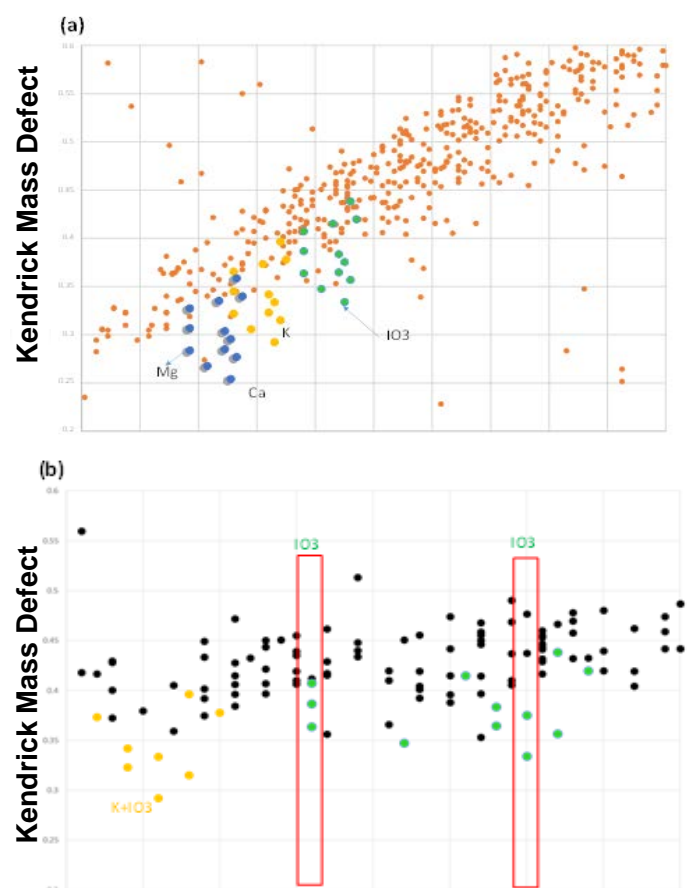

(c)

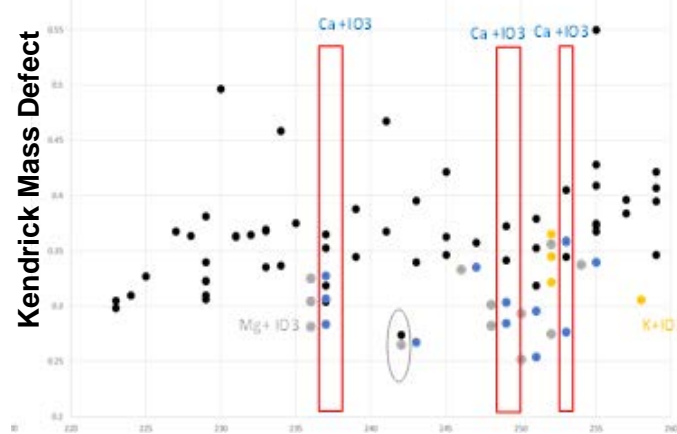

Nominal Kendrick Mass

Figure 23. Kendrick plot of (a) all peaks observed in the m/z 450-550 region before fragmentation, (b), and (c) zoom-in at specific regions of the Kendrick plot. 
PNNL-24709, Rev. 2

RPT-DVZ-AFRI-030, Rev. 2

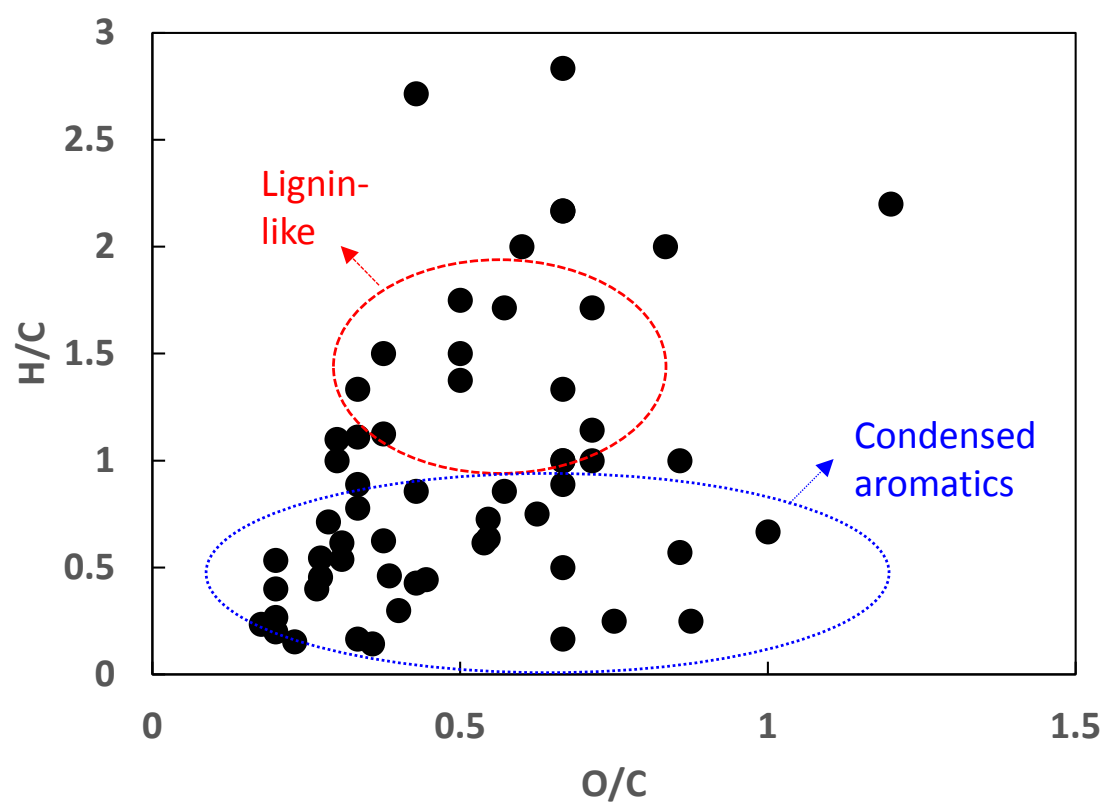

Figure 24. van Krevelen diagram of the assigned formulas of our potential iodate-containing organic compounds.

In summary, while the Organo-I complexation structures in the 200-UP-1 site at Hanford could not be confidently identified, the results suggested that these compounds exist at Hanford. The differences in organic matter composition based on VK plots and as revealed by mass spectrometry suggested that pore water samples have a higher abundance of aromatic compounds that are a better target for iodine complexation, consistent with the experiments using reference compounds. The standards and spiking experiments further revealed preferential binding of iodide/iodate to organic matter.

\subsection{5 lodate-Carbonate Precipitation}

There has been recent evidence of $\mathrm{IO}_{3}{ }^{-}$co-precipitation with calcium carbonate (Zhang et al. 2013; Podder et al. 2017). This finding may have important implications related to iodine partitioning near the source terms, where extreme chemical conditions may promote calcite dissolution and re-precipitation that can facilitate co-precipitation of $\mathrm{IO}_{3}{ }^{-}$and incorporation into the newly formed calcium carbonate. Co-precipitation of $\mathrm{IO}_{3}{ }^{-}$with calcium carbonate may also have important implications related to the longterm fate of iodine in the far field, where natural calcium carbonate dissolution and precipitation cycling may occur.

$\mathrm{IO}_{3}{ }^{-}$incorporation during calcium carbonate precipitation was studied using a series of macroscopic, bench-scale batch experiments. In summary, experiments were conducted by mixing stock solutions $(0.1 \mathrm{M}$ or $1 \mathrm{M})$ of $\mathrm{CaCl}_{2}$ and $\left(\mathrm{NH}_{4}\right)_{2} \mathrm{CO}_{3}$ in equal amounts to form calcite (1) in the presence of $\mathrm{IO}_{3}{ }^{-}$at varying initial spike concentrations up to $500 \mu \mathrm{g} / \mathrm{L}$ and (2) for selected treatments in the presence of $\mathrm{IO}_{3}{ }^{-}$ and chromate (up to $500 \mu \mathrm{g} / \mathrm{L}$ ). In some experiments (referred to as "late-spike"), $\mathrm{IO}_{3}{ }^{-}$was added about a day after the calcite-forming solutions were mixed, after the precipitation of calcite appeared to be complete. These experiments were conducted to determine the extent of $\mathrm{IO}_{3}{ }^{-}$adsorption to freshly precipitated calcium carbonate. The aqueous-phase concentration of $\mathrm{IO}_{3}{ }^{-}$was measured periodically over a period of 28 days. For some experiments, after 28 days, additional solution was added to determine if 
PNNL-24709, Rev. 2

RPT-DVZ-AFRI-030, Rev. 2

the iodine concentration would re-stabilize at the same iodine concentration, or if the iodine concentration would decrease correspondingly to the dilution caused by solution addition (referred to as "extended tests”). After the experiments, the ICP-MS data (total iodine, in $\mu \mathrm{g} / \mathrm{L}$ ) was converted to $\mu \mathrm{g}$ of iodine per gram of produced calcite $(\mu \mathrm{g} / \mathrm{g})$; a summary of the data including the relevant variables is provided in Table 16.

Results show a decrease of $\mathrm{IO}_{3}{ }^{-}$concentration correlated with the starting $\mathrm{IO}_{3}{ }^{-}$concentration and the molarity of the starting solutions (Figure 25). Removal of $\mathrm{IO}_{3}{ }^{-}$from solution appears to occur by both adsorption and precipitation. Late-spike experiments showed less $\mathrm{IO}_{3}{ }^{-}$removal from solution than when $\mathrm{IO}_{3}{ }^{-}$was added at same time as the calcite-forming solutions were initially mixed (Figure 26). These results suggest that $\mathrm{IO}_{3}$ incorporation in precipitates occurred during the calcite precipitation process and late-spike removal of $\mathrm{IO}_{3}{ }^{-}$was by adsorption. In the extended tests, the aqueous iodine concentration decreased after adding additional solution (minimal change occurred in the solid phase iodine concentration in Table 16), suggesting that the aqueous iodine concentration was controlled by adsorption rather dissolution of the iodine-bearing phase (i.e., calcite). In preliminary experiments where both $\mathrm{IO}_{3}{ }^{-}$ and chromate were included, $\mathrm{IO}_{3}{ }^{-}$removal increased with increasing chromate concentration. These experiments suggest chromate and $\mathrm{IO}_{3}{ }^{-}$do not compete for co-precipitation during calcite precipitation. Potentially, chromate may be affecting the calcite structure, enabling increased $\mathrm{IO}_{3}{ }^{-}$incorporation into calcium carbonate (e.g., by initially promoting more vaterite formation; vaterite has been shown to more easily accommodate oxyanions such as chromate), or chromate-iodate precipitates may be forming (Burns and Hawthorne 1993). However, the first potential mechanism is less likely because the XRD results suggest that vaterite formation was not promoted when iodate was present in the calcite-forming solution (Figure 29). The results of these recent experiments demonstrate that $\mathrm{IO}_{3}{ }^{-}$precipitation more easily occurs concurrently with calcite precipitation and that the water chemistry affects this process. Thus, the results extend the observations of iodate-calcite interactions reported by others (e.g., Zhang et al. 2013). 
PNNL-24709, Rev. 2

RPT-DVZ-AFRI-030, Rev. 2

Table 16. Final concentrations of iodine in $\mu \mathrm{g} \mathrm{I} / \mathrm{g}$ calcite for calcite tests described in Section 2.3.5. "Starting solution molarity" refers to the molarity of the calcium chloride and ammonium carbonate used to produce calcite, and additional variables are included in "other additions or info" column. Tests were conducted in duplicate; the average of two tests is included here with the standard deviation on the mean.

\begin{tabular}{|c|c|c|c|c|}
\hline \multirow{2}{*}{$\begin{array}{l}\text { Starting } \\
\text { Solution } \\
\text { Molarity }\end{array}$} & \multirow{2}{*}{$\begin{array}{l}\text { Starting lodine } \\
\text { Concentration } \\
\text { in Solution } \\
(\mu \mathrm{g} / \mathrm{L})\end{array}$} & \multirow{2}{*}{$\begin{array}{l}\text { Other } \\
\text { Additions } \\
\text { or Info }\end{array}$} & \multicolumn{2}{|c|}{$\begin{array}{l}\text { lodine Associated with the Solic } \\
\text { at the End of the Experiment } \\
(\mu \mathrm{g} / \mathrm{g})\end{array}$} \\
\hline & & & $\begin{array}{c}\text { Average } \\
\text { (from } 2 \\
\text { replicates) } \\
\end{array}$ & $\begin{array}{l}\text { Standard } \\
\text { deviation }\end{array}$ \\
\hline \multirow{14}{*}{$0.1 \mathrm{M}$} & 0 & - & - & - \\
\hline & 1 & - & 0.04 & 0.01 \\
\hline & 2.5 & - & 0.21 & 0.01 \\
\hline & 10 & - & 0.96 & 0.01 \\
\hline & 20 & - & 1.88 & 0.04 \\
\hline & 50 & - & 5.73 & 2.06 \\
\hline & 50 & Late spike & 1.11 & 0.18 \\
\hline & 50 & $100 \mathrm{ppb} \mathrm{Na}$ & 6.83 & 0.68 \\
\hline & 50 & $50 \mathrm{ppb} \mathrm{Cr}$ & 6.76 & 0.21 \\
\hline & 100 & - & 13.5 & 0.07 \\
\hline & $100(80)$ & Extended test & 12.9 & 1.23 \\
\hline & 100 & 100 ppb Na & 13.6 & 2.52 \\
\hline & 250 & - & 34.2 & 0.92 \\
\hline & 250 & $100 \mathrm{ppb} \mathrm{Na}$ & 45.8 & 7.18 \\
\hline \multirow{13}{*}{$1 \mathrm{M}$} & 50 & - & 1.04 & 0.01 \\
\hline & 50 & $100 \mathrm{ppb} \mathrm{Na}$ & 1.06 & 0.02 \\
\hline & 50 & Late spike & 0.71 & 0.05 \\
\hline & 50 & $50 \mathrm{ppb} \mathrm{Cr}$ & 1.08 & 0.08 \\
\hline & 250 & - & 5.34 & 0.10 \\
\hline & 250 & Late spike & 1.86 & 0.08 \\
\hline & 250 & $100 \mathrm{ppb} \mathrm{Na}$ & 5.27 & 0.16 \\
\hline & 300 & - & 6.45 & 0.11 \\
\hline & $300(240)$ & Extended test & 6.11 & 0.11 \\
\hline & 300 & 100 ppb Na & 7.43 & 0.96 \\
\hline & 500 & - & 10.7 & 0.01 \\
\hline & $500(400)$ & Extended test & 10.2 & 0.02 \\
\hline & 500 & 100 ppb Na & 10.6 & 0.00 \\
\hline
\end{tabular}

In the majority of these experiments, $\mathrm{NaIO}_{3}$ was used to produce an $\mathrm{IO}_{3}$ spike. (All tests included in Table 16 were spiked with $\mathrm{NaIO}_{3}$.) The $\mathrm{Na}$ in the spike may have been contributing to the $\mathrm{IO}_{3}$ incorporation process, because Na may be charge balancing the substitution (Podder et al. 2017; see also Section 2.3.6). To determine if $\mathrm{Na}$ was aiding in the substitution process, batch experiments were conducted using $\mathrm{KIO}_{3}$ or $\mathrm{NaIO}_{3}$. When using $0.1 \mathrm{M}$ starting solutions $\left(\mathrm{CaCl}_{2}\right.$ and $\left.\left(\mathrm{NH}_{4}\right)_{2} \mathrm{CO}_{3}\right)$ and spiking with $\mathrm{KIO}_{3}$, the removal of iodate followed similar removal rates as seen in the $\mathrm{NaIO}_{3}$ experiments. The $\mathrm{KIO}_{3}$ tests were conducted as scoping tests, while the project operated under a fully implemented NQA-12000 QA program (see Section 5.0), the scoping tests were not for technical accuracy per the QA program, and the results of these tests are therefore considered FIO. Compared to the previously 
PNNL-24709, Rev. 2

RPT-DVZ-AFRI-030, Rev. 2

described experiments using $\mathrm{NaIO}_{3}$, as well as an additional $500 \mathrm{ppb} \mathrm{NaIO}_{3}$ scoping test, the use of $\mathrm{KIO}_{3}$ did not noticeably change the amount of iodine removed from solution. (At 4 hours, approximately $50 \%$ of the iodine in solution was removed from both the $\mathrm{KIO}_{3}$ tests and corresponding $\mathrm{NaIO}_{3}$ tests; results not shown.)

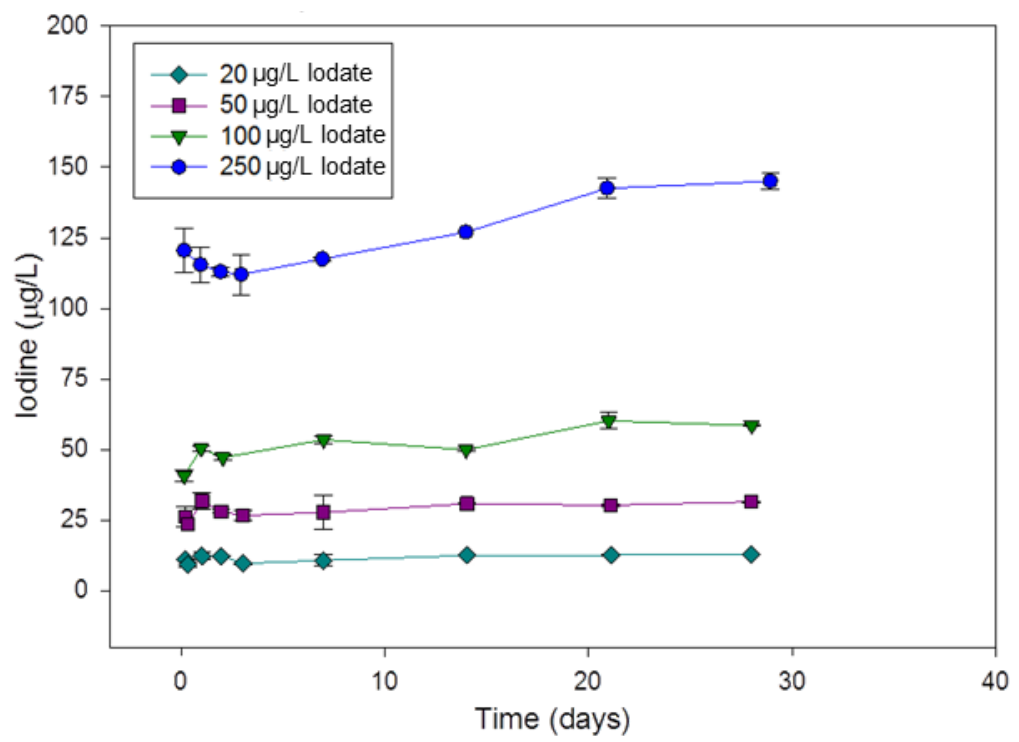

(a)

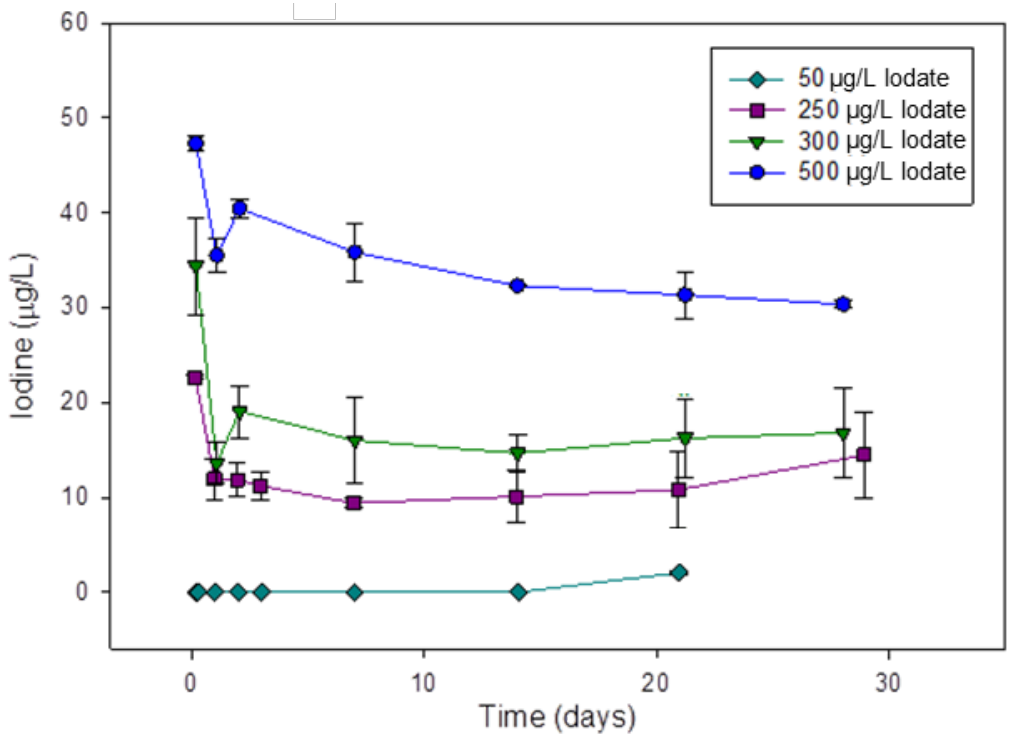

(b)

Figure 25. Iodate concentrations (measured as total iodine) over time for experiments when iodate was added in one of the calcite-forming solutions prior to their mixing. The calcite-forming solutions had concentrations of (a) $0.1 \mathrm{M}$ or (b) $1 \mathrm{M}$. Initial iodate concentrations are shown in the legend. The first iodate measurement (time zero) was taken $4 \mathrm{~h}$ after mixing of the calcite-forming solutions (i.e., after precipitation of calcite occurred). Error bars reflect standard deviations from the mean (two replicates). 
PNNL-24709, Rev. 2

RPT-DVZ-AFRI-030, Rev. 2

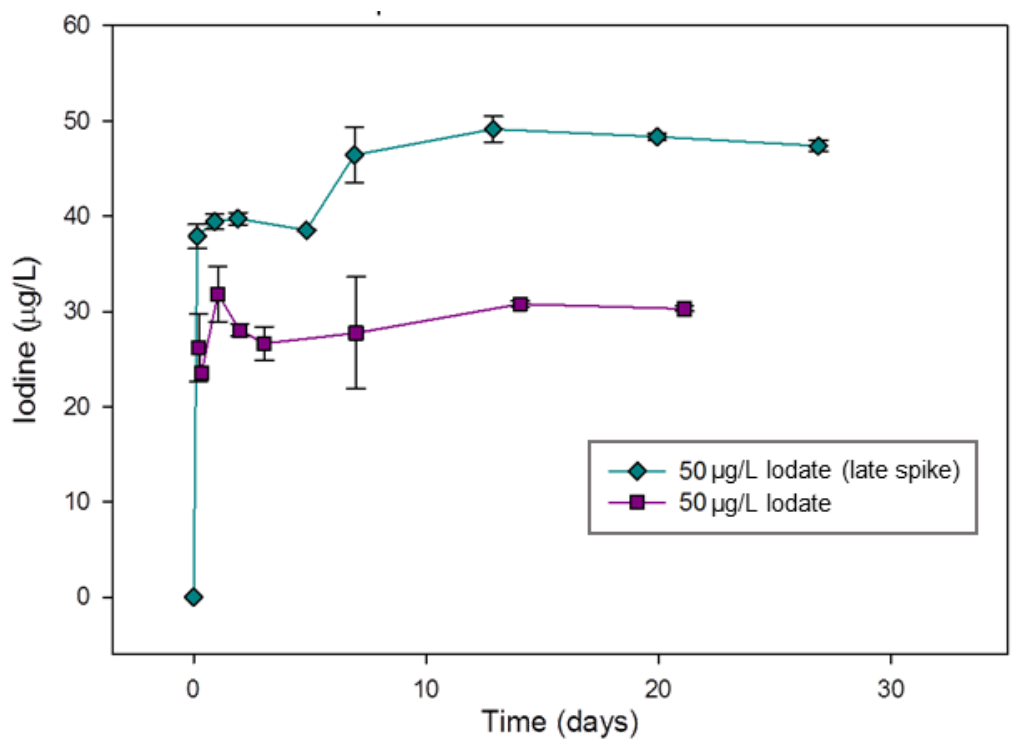

Figure 26. Iodate concentrations (measured as total iodine) over time for experiments when iodate was added in one of the calcite-forming solutions prior to their mixing (purple square) compared to the experiment when iodate was added $24 \mathrm{~h}$ after mixing of the calcite-forming solutions (turquoise diamond, late spike). The first iodate measurement (time zero) was taken $4 \mathrm{~h}$ after mixing of the calcite-forming solutions (i.e., after precipitation of calcite occurred) for the immediate-spike test (purple square). The time zero sample of the late-spike experiment was taken prior to the addition of the iodate and the subsequent sample was taken $4 \mathrm{~h}$ later. The $0.1 \mathrm{M}$ calcite-forming solutions were used in both experiments. Added iodate concentrations are shown in the legend. Error bars reflect standard deviations from the mean (two replicates).

\subsubsection{Calcite Stability Experiments}

Because the incorporation of iodate into calcite is a potential remedial option, the stability of the coprecipitated calcite was investigated. To this end, aa series of batch experiments were conducted to precipitate calcium carbonate minerals in the presence of iodate and follow iodine uptake as a function of time. The solubility of the calcite solid produced in the experiments was then tested to determine if inclusion of $\mathrm{IO}_{3}$ in the calcite structure changed the solubility of the mineral. The calcium carbonate samples chosen for stability testing were precipitated in the absence (i.e., pure $\mathrm{CaCO}_{3}$ ) or presence of iodate and/or chromate (i.e., iodate and/or chromate doped calcium carbonate).

Stability testing was conducted by adding an excess amount of calcium carbonate to solutions at differing $\mathrm{pH}$ values ( $\mathrm{pH} 7.4$ to 12.6). The $\mathrm{pH}$ of the solution was controlled by addition of $\mathrm{NaHCO}_{3}$, $\mathrm{Na}_{2} \mathrm{CO}_{3}$, and $\mathrm{HCl}$. An excess amount of calcium carbonate solid was added to a 50-mL

polytetrafluoroethylene (PTFE) bottle, followed by calculated amounts of $\mathrm{NaHCO}_{3}$ or $\mathrm{Na}_{2} \mathrm{CO}_{3}$ needed to reach target $\mathrm{pH}$ values, and then double deionized (DDI) water was added to a final initial volume of $30 \mathrm{~mL}$. For the lower end of the target $\mathrm{pH}$ values, $\mathrm{HCl}$ was added to obtain the desired $\mathrm{pH}$. The poly bottles were fitted with an inlet and outlet tube to allow air to flow into the solution without pressurization (see Figure 27). The suspensions were then bubbled with humidified air for several days. Prior to entering the PTFE bottles, the air was passed through a gas washing bottle filled with DDI water to increase the humidity of the air. The $\mathrm{pH}$ was measured frequently (every 1-3 days) using a pH electrode 
PNNL-24709, Rev. 2

RPT-DVZ-AFRI-030, Rev. 2

until the measured $\mathrm{pH}$ values were comparable to the target $\mathrm{pH}$ levels. If necessary, $1 \mathrm{M}$ or $2.5 \mathrm{M} \mathrm{NaOH}$ was used to adjust the $\mathrm{pH}$. Once the desired $\mathrm{pH}$ values were reached, and remained stable for two consecutive $\mathrm{pH}$ measurements (defined as the time 0 ), the PTFE bottles were removed from the gas and capped, and then suspensions were agitated on a shaker at 30 rpm continuously for the duration of the experiment. Samples were taken several times at weekly or biweekly intervals until the equilibrium conditions were reached. The determination of equilibrium was based on evaluation of two consecutive data points from ICP-OES analysis that showed nearly identical solution concentration of $\mathrm{Ca}( \pm 10 \%)$ and $\mathrm{pH}$. The presence of a solid phase was monitored throughout the experiment as an indicator that the calcium carbonate was still in excess.

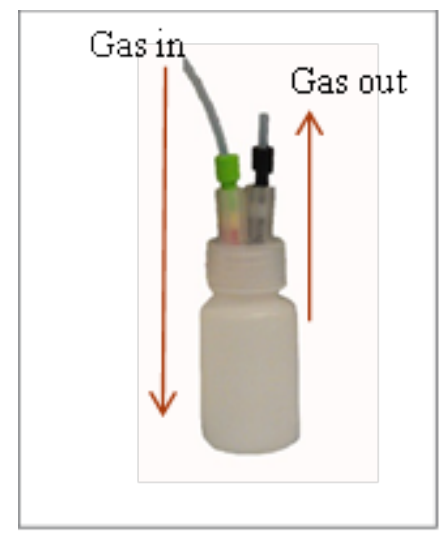

Figure 27. Vented poly bottle

These experiments are still ongoing, and therefore the preliminary data presented here is considered FIO. Tests were conducted on calcite produced without any additional spikes, as well as calcite containing $4.75 \mu \mathrm{g} / \mathrm{g}$ and $9.15 \mu \mathrm{g} / \mathrm{g}$ iodine, as determined by alkaline fusion (referred to as 7C and 9C respectively, see Section 2.3.5.2). An additional calcite solid containing chromium and iodine is currently still undergoing $\mathrm{pH}$ adjustment for solubility testing (sample 13F). Figure 28 shows the preliminary data from the pure $\mathrm{CaCO}_{3}$ and the two experiments with iodine (named 7C and 9C, respectively), compared to published calculated solubility data. This initial set of data shows that there is no difference in the solubility of calcite with and without iodate. 
PNNL-24709, Rev. 2

RPT-DVZ-AFRI-030, Rev. 2

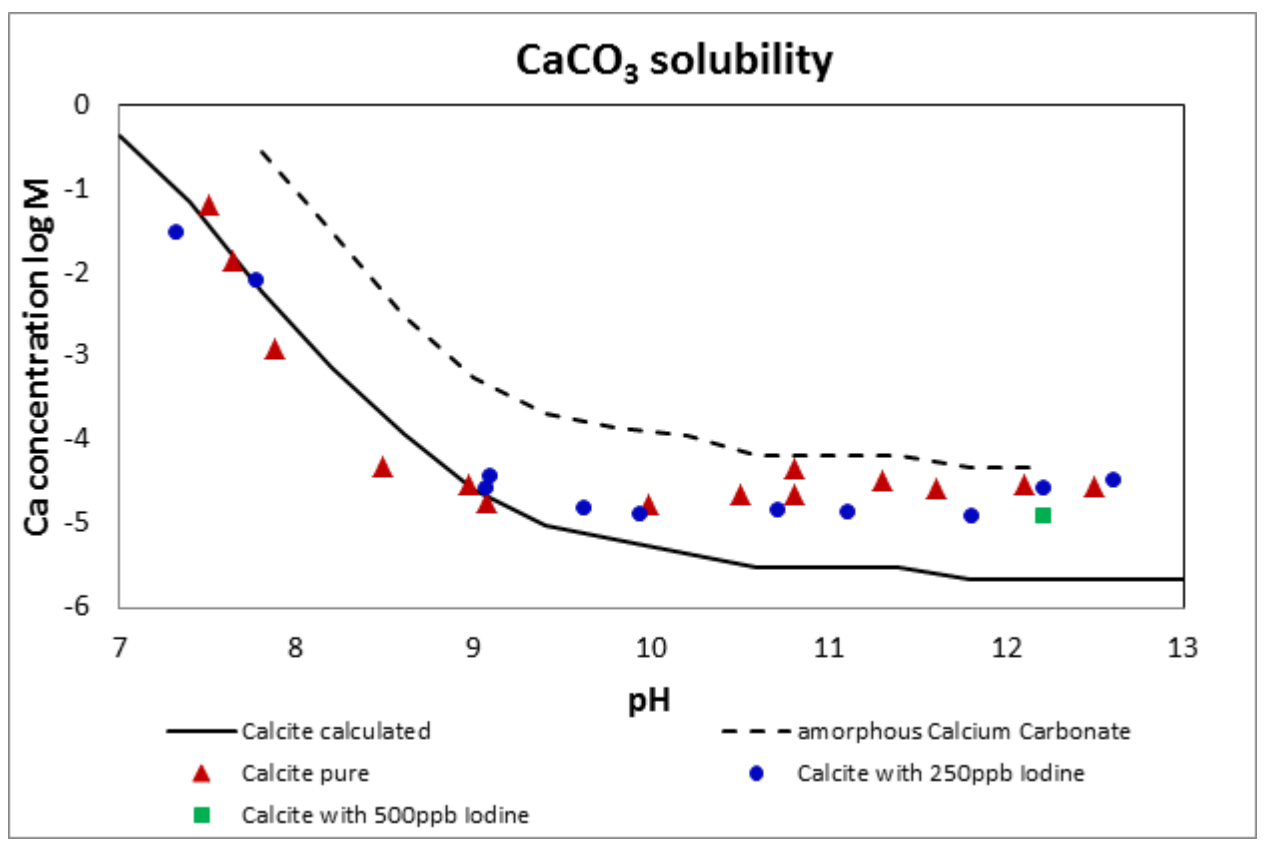

Figure 28. Calcite solubility as a function of $\mathrm{pH}$ for calcite produced without iodine spikes $(1 \mathrm{M})$ and with $250 \mu \mathrm{g} / \mathrm{L}$ (7C) or $500 \mu \mathrm{g} / \mathrm{L}$ (9C) starting iodine concentrations (FIO).

\subsubsection{Solid Phase Characterization}

A variety of solid phase characterization techniques, such as alkaline fusion, X-ray diffraction (XRD), Scanning Electron Microscopy / Energy Dispersive X-Ray Spectroscopy (SEM/EDS), Scanning Electron Microscopy/Focused Ion Beam (SEM/FIB), Transmission Electron Microscope/Selected Area Diffraction (TEM/SAED) and Nanoscale Secondary Ion Mass Spectrometry (NanoSIMS), were used to gain insights on the identity of calcium carbonate minerals or other minerals formed during the calcite precipitation experiments. These techniques were also used to study the morphological features of the precipitated phases and mechanisms of iodine interaction with them, and to determine the location of iodate within calcite structure. These data are included here as FIO.

The alkaline fusion followed PNNL Technical Procedure PNNL-ESL-Fusion, Rev. 2 (Geiszler, 2016). Two of the calcite solids produced in FY16 (Section 2.3.5) underwent alkaline fusion, after the triple rinse described in Section 2.3.5. The two calcite samples were produced with $1 \mathrm{M}$ starting solutions. One test had a 250-ppb I spike. The other had an initial 500-ppb I spike, but was extended after an addition of I-free solution, resulting in a 375-ppb I spike concentration. Alkaline fusion results indicated that the calcite samples contained 4.75 and $9.15 \mu \mathrm{g} / \mathrm{g}$ I, respectively. These values are within $15 \%$ of the calculated values of these tests; the difference is partially because the I rinsed off prior to the alkaline fusion was not included in the calculated values. However, the relatively small difference (the calculated iodine concentrations in $\mu \mathrm{g} / \mathrm{g}$ were 10.2-12.4\% higher than the alkaline fusion results) between the calculated and fusion $\mu \mathrm{g} / \mathrm{g}$ values show that the calculated values in Table 16 are relatively accurate (within 15\%).

The results of the XRD analyses suggest that calcite was the only calcium carbonate mineral detected with this technique, in five samples coming out of experiments conducted with different $\mathrm{Cr}$ and I spike concentrations (Figure 29). Unlike the presence of aqueous $\mathrm{Cr}$ in the calcite-forming solution, which 
PNNL-24709, Rev. 2

RPT-DVZ-AFRI-030, Rev. 2

forced the system towards vaterite formation instead of calcite. The iodine presence in the calcite-forming solution apparently did not affect the formation of calcite.

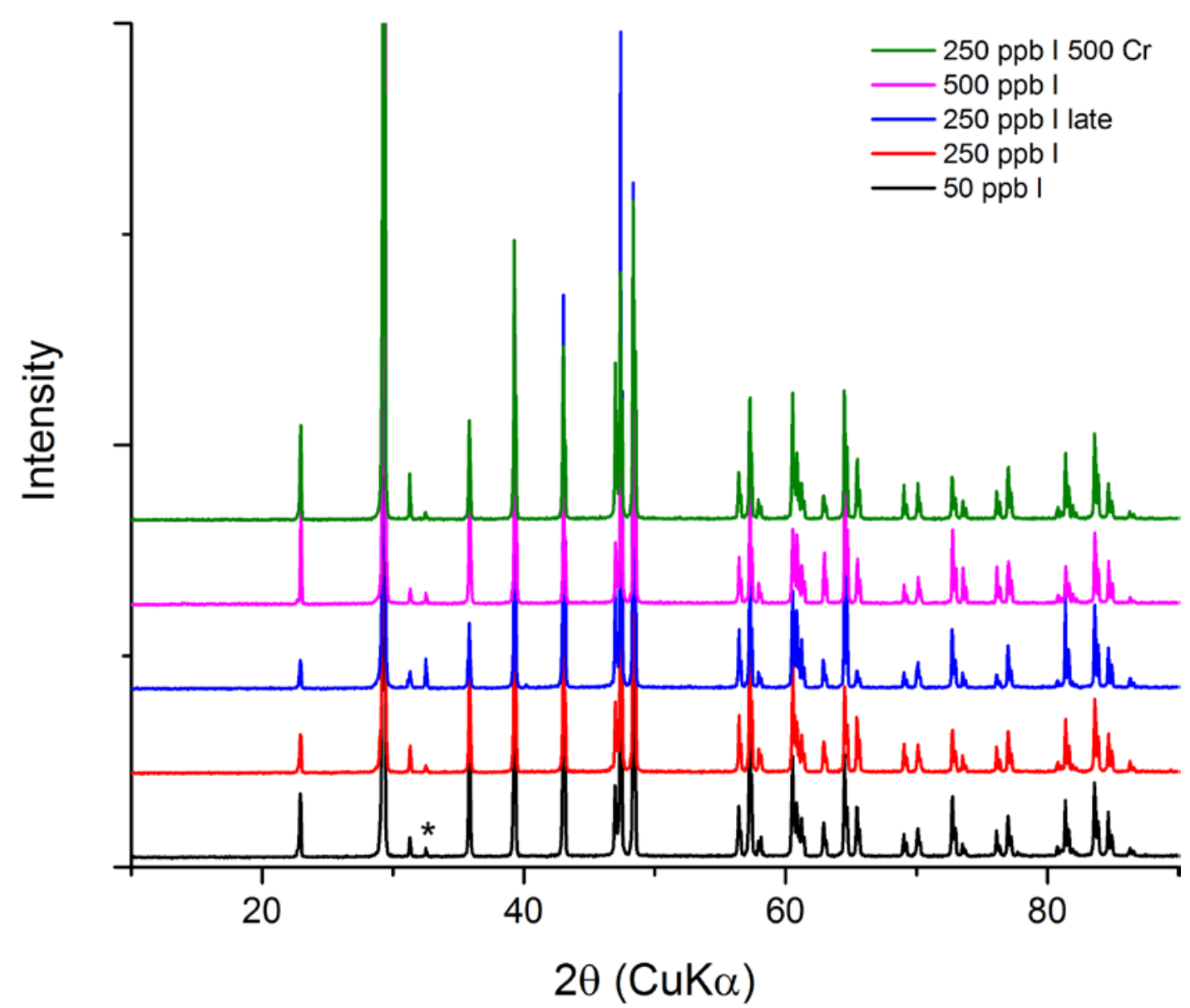

Figure 29. XRD results for calcite samples produced with variable iodine and/or chromium spike concentrations (FIO).

SEM inspections revealed the morphology of the freshly formed calcite showing typical calcium carbonate morphological cubical features (Figure 30), while the micrographs of calcite precipitated in the presence of chromate showed a slight deviation from the typical structure (Figure 30, bottom row). TEM images and inspections, EDS measurements and nanoSIMS interrogations revealed that most likely (although not confirmed yet) iodate was present in regions of calcite close to the surface (Figure 31 and Figure 32). The TEM images (Figure 31) showed that the calcite crystal structure was perturbed in locations close to the surface, indicating the inclusion of other ions into the calcite structure (besides Ca, $\mathrm{C}$, and $\mathrm{O}$ ). In addition, NanoSIMS interrogations (Figure 32) demonstrated good correlation between $\mathrm{O}$ and I in regions close to the surface of calcite particles, again reinforcing the idea that iodate is accumulated inside calcite crystals but close to the surface. 

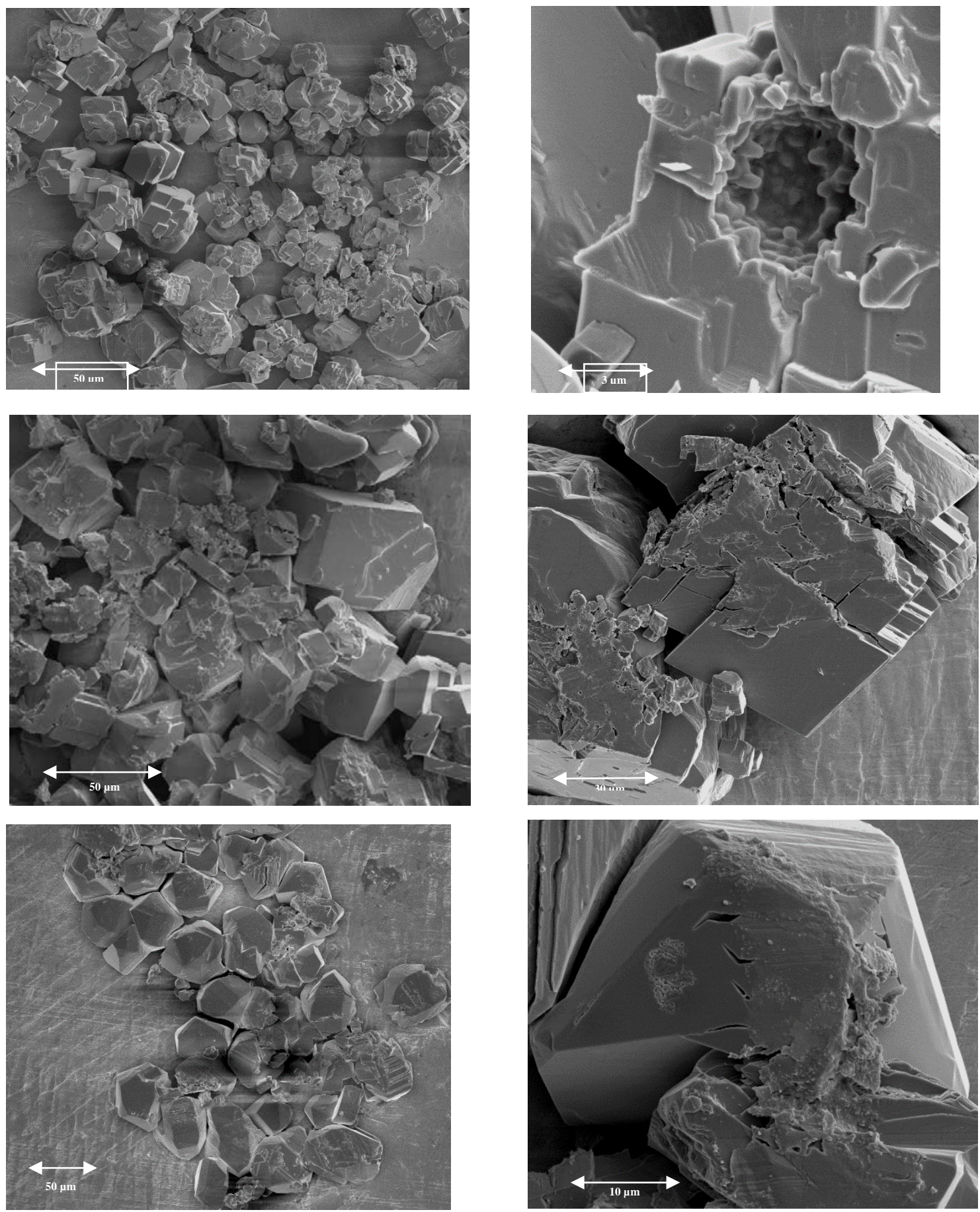

Figure 30. "FIO” SEM images from calcite precipitated from $1 \mathrm{M} \mathrm{CaCl}_{2}$ and $\left.\left(\mathrm{NH}_{4}\right)_{2} \mathrm{CO}_{3}\right\urcorner$ with variable iodine and/or chromate spike concentrations. Top row: $50 \mu \mathrm{g} / \mathrm{L}$ iodate spike; middle row: $250 \mu \mathrm{g} / \mathrm{L}$ iodate spike added after precipitation ("late spike”); bottom row: $250 \mu \mathrm{g} / \mathrm{L}$ i iodate spike and an additional 500 $\mu \mathrm{g} / \mathrm{L}$ chromate spike. Note that the scale of the SEM micrographs is approximate. 

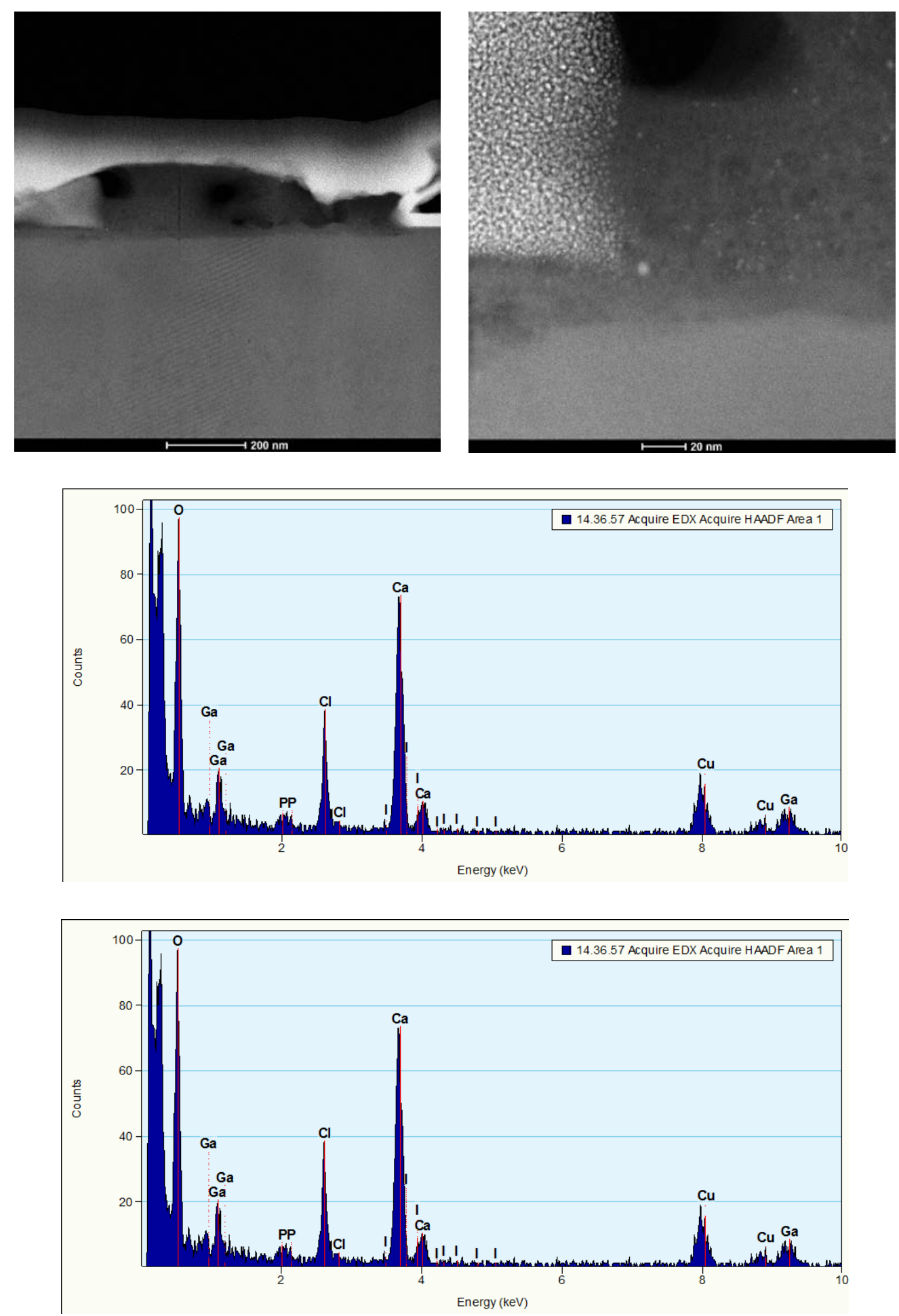

Figure 31. "FIO” TEM images and EDS spectra of a FIB-ed calcite sample that contained iodate showing that most likely iodate was present in locations close to the surface of calcite particles (Courtesy of Libor Kovarik, Environmental Molecular Sciences Laboratory (EMSL). 


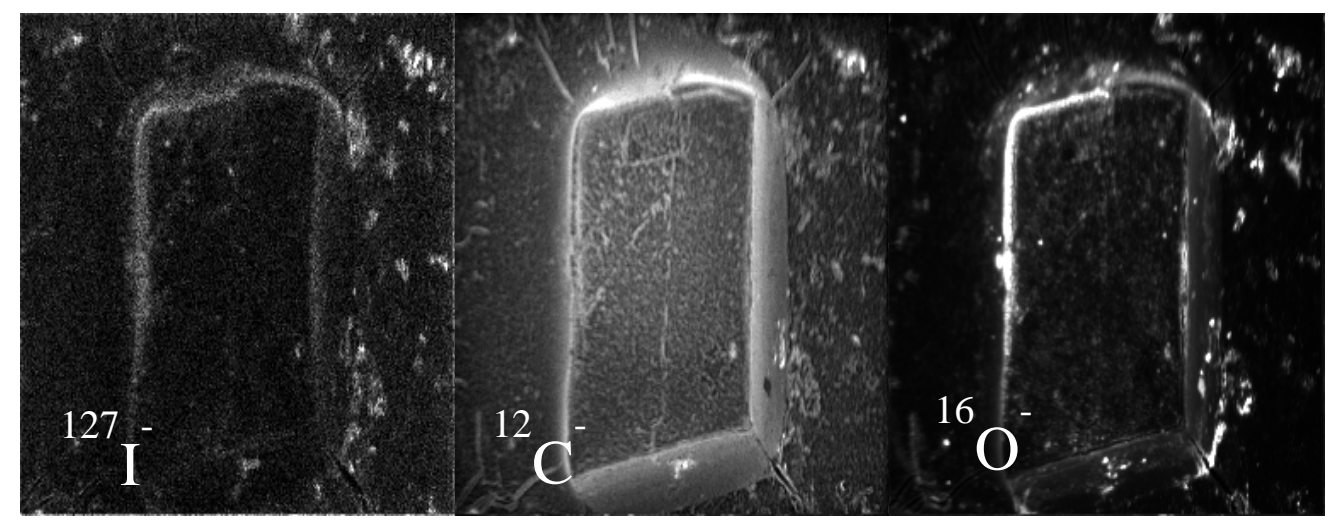

Figure 32. The preliminary, "FIO" nanoSIMS observations indicate that I was accumulated along crystal boundaries and was part of the crystal structure and not simply due to surface contamination (Courtesy of John Cliff, EMSL).

\subsubsection{Additional Scoping Work: lodine Removal via Calcite Precipitation in the Presence of Efficient Reductants}

Some areas of the Hanford Site have multiple contaminants, and geochemical interactions are largely unknown. Remedial strategies need to consider potential impacts on all contaminants within a given location. For example, the Tc and I plumes overlap at the 200-UP-1 OU in the 200 West Area within the Central Plateau. Attenuation mechanisms that inhibit I mobility can increase the mobility of Tc. Pertechnetate ( $\left.\mathrm{Tc}(\mathrm{VII}) \mathrm{O}_{4}^{-}\right)$is the predominant form of Tc, and is less mobile in its reduced forms (Tc(IV)O $\mathrm{O}_{2}$ and/or $\mathrm{Tc}(\mathrm{IV})_{\mathrm{X}} \mathrm{S}_{\mathrm{x}}$ ), whereas iodine is less mobile in its oxidized form as iodate.

To assess time-dependent aqueous iodate removal in the presence of strong and efficient reductants, a series of scoping batch experiments were conducted. Two reductants were used, zero-valent iron (ZVI) and sulfur-modified iron (SMI). The scoping studies are presented here as FIO.

Results from these experiments demonstrated that a significant amount of iodate in solution was reduced to iodide within the first $4 \mathrm{~h}$, and substantially less of the iodate was able to be removed during calcite precipitation, compared to controls that contained no ZVI or SMI (23.5\% removed in the presence of ZVI vs. 69.6\% removed without ZVI present, Figure 33). These experiments demonstrate the potential unintended consequences associated with remediating multiple contaminant plumes. 
PNNL-24709, Rev. 2

RPT-DVZ-AFRI-030, Rev. 2
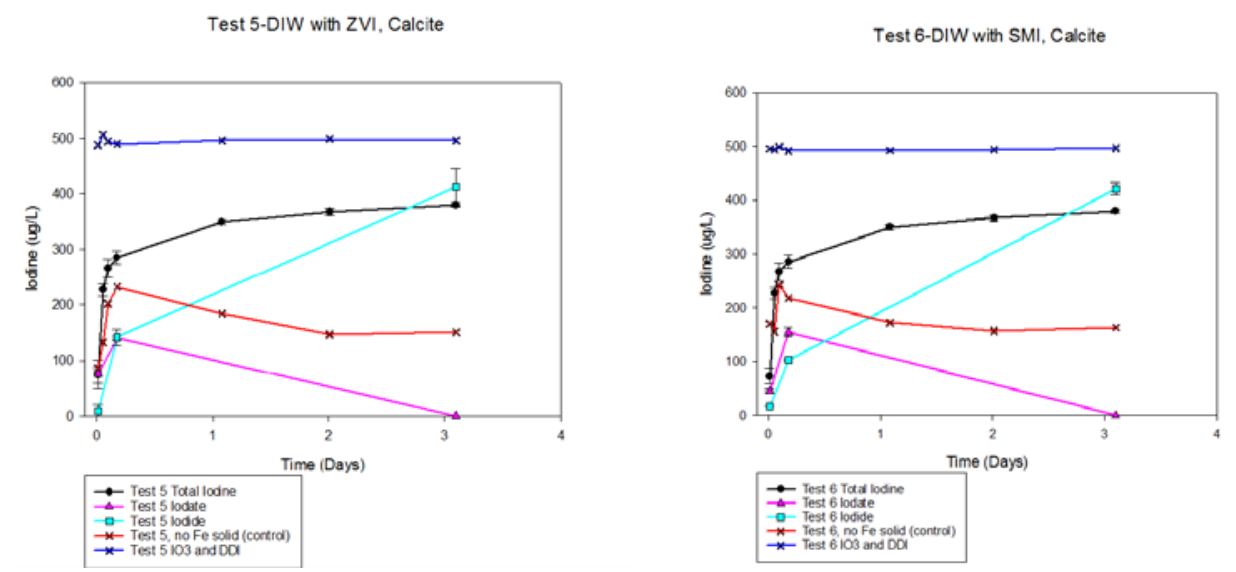

Figure 33. Results of the scoping experiments showing that in the presence of a reducing agent used to immobilize co-contaminants such as Tc, calcite precipitation is not able to remove iodate from solution as efficiently as without the reducing agent present due to the reduction of iodate to iodide.

\subsubsection{Ab Initio Molecular Dynamics Simulation of lodate incorporation into Calcite}

The specific objective of molecular dynamics simulation is to determine the local environment for iodine incorporation as iodate, the most likely charge compensation scheme(s) (CCS), and any tendency to segregate at the surface. These elements are needed for determining long-term calcite stability and solubility to help evaluate calcite and iodine co-precipitation as a remedy alternative. The approach employed to achieve this objective consists of a systematic evaluation of iodine incorporation schemes in bulk calcite and surface environments to determine the most energetically favorable CCS, as well as bulk versus surface preference of the substituents. The methods used in this effort were based on information included in the following references: Kerisit et al. 2005; Kresse and Furthmuller 1996a, b; Kresse and Hafner 1993; Rehr and Albers 2000; Podder et al. 2017; Rehr et al. 2009, 2010; Shuller-Nickles et al. 2014; Lu et al. 2010; Xu et al. 2015. This work was conducted as scoping studies, and data are FIO.

\subsubsection{Standard Compounds}

Simulations of three standard iodate compounds were performed, at various temperatures, to evaluate the ability of the simulation approach to reproduce experimental data, develop an understanding of the effect of temperature on the extended X-ray absorption fine structure (EXAFS) spectra, and determine how the local environment around the iodate ion might influence the shape of EXAFS spectra. The EXAFS spectra calculated from the largest $\mathrm{NaIO}_{3}(3 \times 3 \times 3)$ and $\mathrm{Ca}\left(\mathrm{IO}_{3}\right)_{2} \cdot \mathrm{H}_{2} \mathrm{O}(2 \times 2 \times 2)$ supercells showed good overall agreement with the experimental data of Laurencin et al. (2014) obtained at $77 \mathrm{~K}$ (Figure 34). 
PNNL-24709, Rev. 2

RPT-DVZ-AFRI-030, Rev. 2
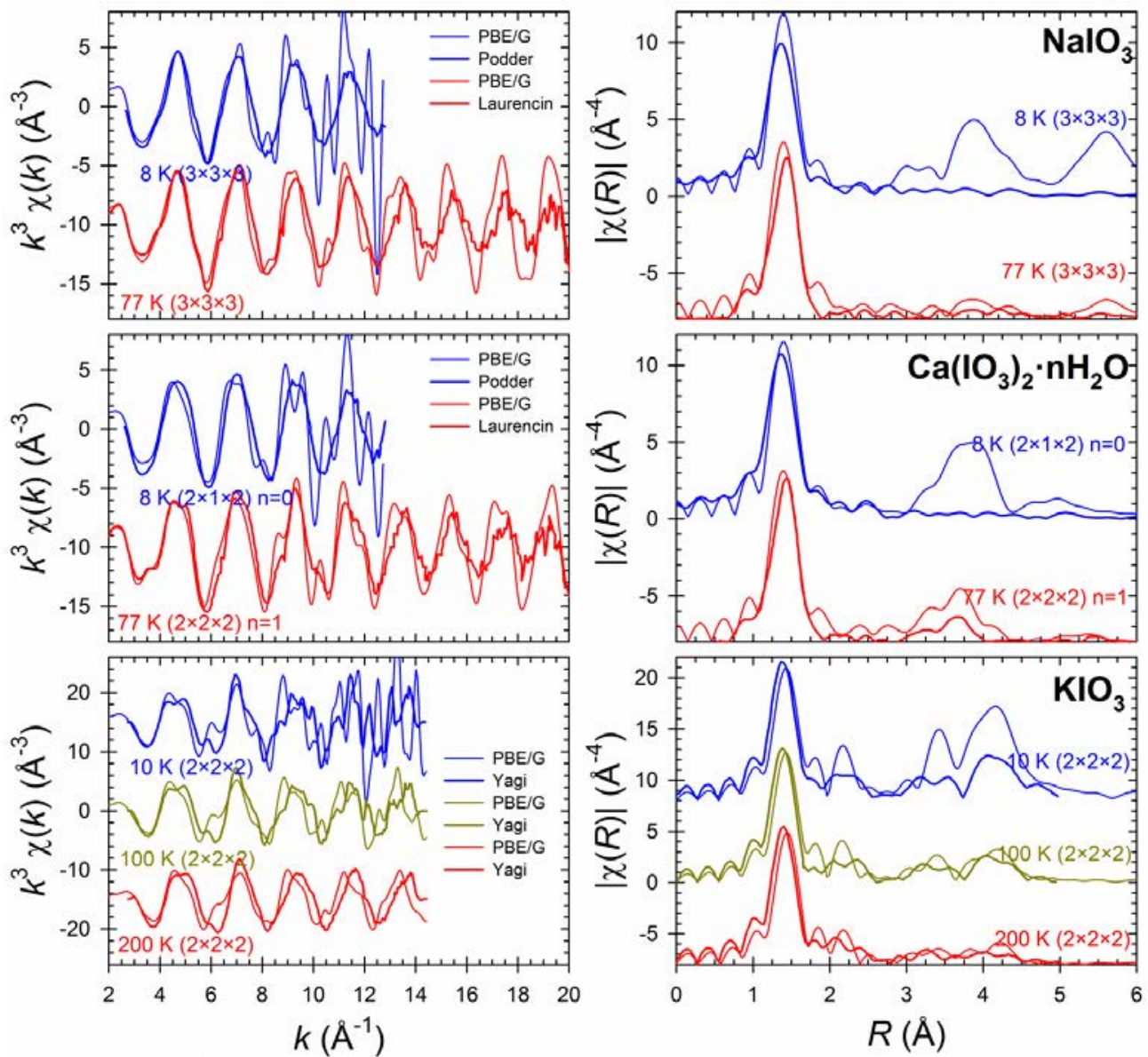

Figure 34. Experimental and calculated I K-edge EXAFS spectra (left) and corresponding Fourier transform magnitudes (right) for I in $\mathrm{NaIO}_{3}$ (top), $\mathrm{Ca}\left(\mathrm{IO}_{3}\right)_{2} \cdot \mathrm{nH}_{2} \mathrm{O}$ (middle), and $\mathrm{KIO}_{3}$ (bottom) for temperatures ranging from 8 to $200 \mathrm{~K}$. The experimental data are from Podder et al. (2017), Laurencin et al. (2014), and Yagi et al. (2001). The simulated supercell sizes are also shown in each case. All of the experimental and calculated data in this figure are FIO.

Table 17. Comparison of calculated $\mathrm{I}-\mathrm{O}$ bond lengths $(\AA)$ in $\mathrm{NaIO}_{3}$ and $\mathrm{Ca}\left(\mathrm{IO}_{3}\right)_{2}$ with $\mathrm{XRD}$ data. These data are from published sources (indicated by superscripts) or are FIO.

\begin{tabular}{|c|c|c|c|c|c|c|c|c|}
\hline Comp. & \multicolumn{2}{|c|}{$\mathrm{NaIO}_{3}$} & \multicolumn{6}{|c|}{$\mathrm{Ca}\left(\mathrm{IO}_{3}\right)_{2}$} \\
\hline Pair & $\mathrm{I}-\mathrm{O}(1)$ & $\mathrm{I}-\mathrm{O}(2)$ & $\mathrm{I}(1)-\mathrm{O}(1)$ & $\mathrm{I}(1)-\mathrm{O}(2)$ & $I(1)-O(3)$ & $\mathrm{I}(2)-\mathrm{O}(1)$ & $\mathrm{I}(2)-O(2)$ & $\mathrm{I}(2)-O(3)$ \\
\hline XRD & $1.802^{(a)}$ & $1.811^{\text {(a) }}$ & $1.825^{(\mathrm{b})}$ & $1.796^{(\mathrm{b})}$ & $1.801^{(\mathrm{b})}$ & $1.814^{(\mathrm{b})}$ & $1.795^{(\mathrm{b})}$ & $1.804^{(\mathrm{b})}$ \\
\hline DFT & 1.827 & 1.838 & 1.856 & 1.829 & 1.832 & 1.840 & 1.823 & 1.828 \\
\hline$\Delta(\%)$ & 1.4 & 1.5 & 1.7 & 1.8 & 1.7 & 1.4 & 1.6 & 1.3 \\
\hline $\begin{array}{ll}\text { (a) Sven } \\
\text { (b) Ghos }\end{array}$ & $\begin{array}{l}\mathrm{n} \text { and Ståhl } \\
\mathrm{t} \text { al. } 1978\end{array}$ & & & & & & & \\
\hline
\end{tabular}


PNNL-24709, Rev. 2

RPT-DVZ-AFRI-030, Rev. 2

\subsubsection{2 lodate Incorporation in Calcite: Effect of Charge Compensation Scheme $\left(\mathrm{Na}^{+} / \mathrm{IO}_{3}{ }^{-}\right)$}

In the pure calcite structure (\#0 in Figure 35), each carbonate oxygen is coordinated to two calcium ions. Because of the planar configuration of the carbonate ion, these two nearest-neighbor calcium positions are symmetrically equivalent. When a carbonate ion is substituted by iodate, however, the local symmetry is broken and the two positions are no longer equivalent. As a result, calcium substitution by sodium (Figure 35), as in the first charge compensation scheme considered in this work, can occur at the first nearest-neighbor position (\#1), with a long I-Na distance of $\sim 3.7 \AA$, or at the second nearestneighbor position (\#2), with a short I-Na distance of $~ 3.3 \AA$. When the sodium ion is in a distant position, calcium ions occupy the two nearest-neighbor positions (\#3 in Figure 35). Our calculations show that configuration \#2 is more stable than configuration \#1 by approximately $40 \mathrm{~kJ} / \mathrm{mol}$.
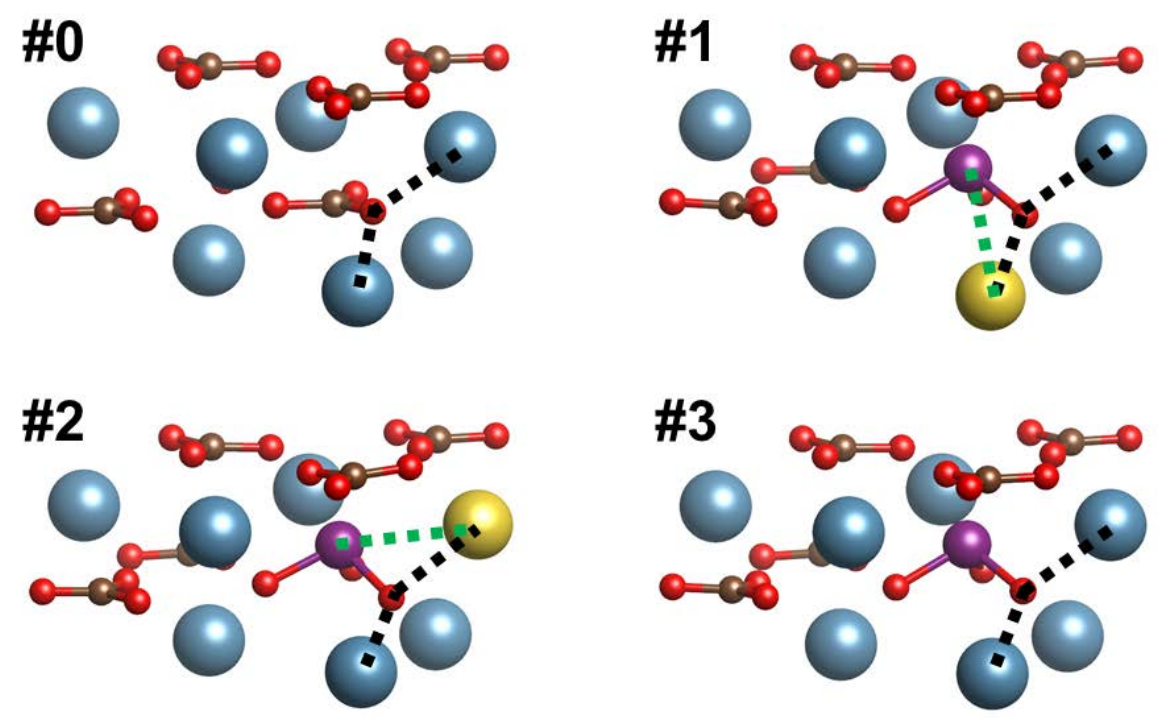

Figure 35. Atomistic models illustrating the incorporation of iodate at the carbonate position in calcite and charge compensation by sodium in the two nearest-neighbor positions (\#1 and \#2) and in a distant position (\#3). The corresponding atomic positions in pure calcite are also shown $(\# 0)$. Calcium atoms are shown in blue, oxygen in red, carbon in brown, iodine in purple, and sodium in yellow.

\subsubsection{2.3.6.3 lodate incorporation in calcite: Effect of charge compensation scheme $\left(\mathrm{H}^{+} / \mathrm{OO}_{3}{ }^{-}\right)$}

As with the first substitution scheme, a series of calculations was performed to evaluate the effect of proton placement for $\mathrm{H}^{+} / \mathrm{IO}_{3}{ }^{-}$co-substitution in calcite, i.e., the $\mathrm{pH}$ effect. Here, an $\mathrm{IO}_{3}{ }^{-}$group replaced one carbonate group in a $2 \times 2 \times 1$ calcite supercell. Then, two distinct cases were tested: $(1) \mathrm{H}^{+}$associated with oxygen atoms of nearest-neighbor carbonate groups - either in the same plane as the $\mathrm{IO}_{3}{ }^{-}$or in a nearest neighbor carbonate plane; and (2) $\mathrm{H}^{+}$associated with each of the oxygen atoms of the $\mathrm{IO}_{3}{ }^{-}$(Figure 36). There is a preference for $\mathrm{H}^{+}$to associate with oxygen atoms in nearest-neighbor carbonate groups over oxygen atoms in the iodate group. The simulations demonstrate that both surface area and $\mathrm{pH}$ influence the extent to which iodate is incorporated into calcite and that $\mathrm{pH}$ can be manipulated to enhance iodine and calcite precipitation. 
PNNL-24709, Rev. 2

RPT-DVZ-AFRI-030, Rev. 2
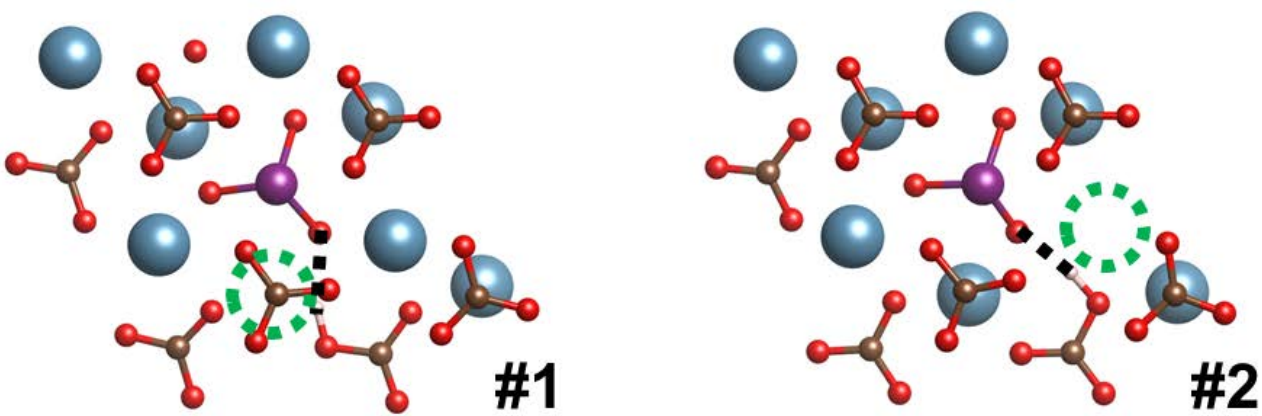

Figure 36. Atomistic models illustrating the incorporation of iodate at the carbonate position in calcite and charge compensation by hydrogen in the two nearest-neighbor positions (\#1 and \#2). Calcium atoms are shown in blue, oxygen in red, carbon in brown, iodine in purple, and hydrogen in white. The positions of the calcium vacancy are shown by green dotted circles. 


\subsection{Description and Interpretation of Major ${ }^{129} \mathrm{I}$ Plumes}

\subsection{West Area}

\subsection{1 lodine Plume Information}

In the 200 West Area, ${ }^{129}$ I plumes are present in the 200-UP-1 and 200-ZP-1 OUs (Figure 37). An updated map of the ${ }^{129}$ I plume map is shown in Figure 38. For the 200-UP-1 OU, ${ }^{129}$ I plumes in southern 200 West Area originated from U-Plant and REDOX Plant waste sites, with the latter being the primary sources (DOE 2014). These plumes, one from the 216-U-1 and 216-U-2 cribs near U-Plant and a second from the REDOX Plant waste sites (e.g., 216-S-1\&2, 216-S-7, and 216-S-9) in the southern portion of the 200 West Area, merge downgradient, becoming one indistinguishable groundwater contaminant plume. For the 200-ZP-1 OU (DOE 2014), sources of ${ }^{129}$ I include past leaks from single-shell tanks and liquid waste from chemical processing at T-Plant. ${ }^{129}$ I contamination is present near the 241-T, -TX, and -TY Tank farms (Waste Management Areas [WMA] T and TX-TY).

Plume maps over a 20-year period beginning in 1993 (Figure 39) show that the 200-UP-1 plume (the primary plume in the 200 West Area) has oscillated, but declined, in areal extent, although the plume core area above $10 \mathrm{pCi} / \mathrm{L}$ has not declined. The overall plume extent (as defined by the $1 \mathrm{pCi} / \mathrm{L}$ contour) is large and the plume thickness is up to tens of meters, although there is uncertainty in this estimate. The recent ${ }^{129} \mathrm{I}$ concentration results range from $1 \mathrm{pCi} / \mathrm{L}$ (maximum contaminant level) to $10+\mathrm{pCi} / \mathrm{L}$ within the $200-\mathrm{UP}-1$ plume. The $90^{\text {th }}$ percentile ${ }^{129}$ I concentration is $3.5 \mathrm{pCi} / \mathrm{L}$, meaning that $90 \%$ of the data for ${ }^{129} \mathrm{I}$ in the plume falls below this value (DOE 2012b). However, there are a few recently recorded groundwater concentrations that exceed $10 \mathrm{pCi} / \mathrm{L}$. The temporal concentration profiles for seven wells within the central portion of the plume (Figure 40) are shown in Figure 41. These data indicate stable to declining trends in most portions of the plume and some increases in a downgradient portion of the plume where concentrations are above $10 \mathrm{pCi} / \mathrm{L}$. These data, in conjunction with the plume maps (Figure 39), are consistent with influences from (1) historical pulses of iodine into the groundwater that have now diminished in magnitude and (2) declining hydraulic gradients from dissipation of the historical 200 West Area groundwater mound that existed during processing operations. Thus, the current plume was generated from a historical source that has diminished, and a discrete plume is now migrating in the aquifer. The overall declines in plume area (Figure 39) and concentration are consistent with natural attenuation processes affecting the plume. Increases in concentrations for discrete locations in the central portion of the plume are consistent with movement of a higher concentration core along a flow path. A higher concentration core may still be attenuating, but temporal data at individual wells may be showing the progression of a plume core past the location of the well. In addition, ${ }^{129}$ I currently in the vadose zone may still be a future source for groundwater contamination, even though the existing plume appears to be in a stable to declining condition.

Several co-contaminants are present within the ${ }^{129}$ I plumes, including chromium, nitrate, ${ }^{99} \mathrm{Tc}$, uranium, and tritium. Chromium, nitrate, uranium, and technetium may be present in forms that could interact with the same reactive facies as ${ }^{129} \mathrm{I}$. These co-contaminants will be addressed by a pump-andtreat remediation approach for the 200-ZP-1 and 200-UP-1 OUs. The pumping operations will also affect the ${ }^{129}$ I plumes because of the altered hydraulic gradients and by displacement of ${ }^{129} \mathrm{I}$ that is extracted and re-injected. 
PNNL-24709, Rev. 2

RPT-DVZ-AFRI-030, Rev. 2

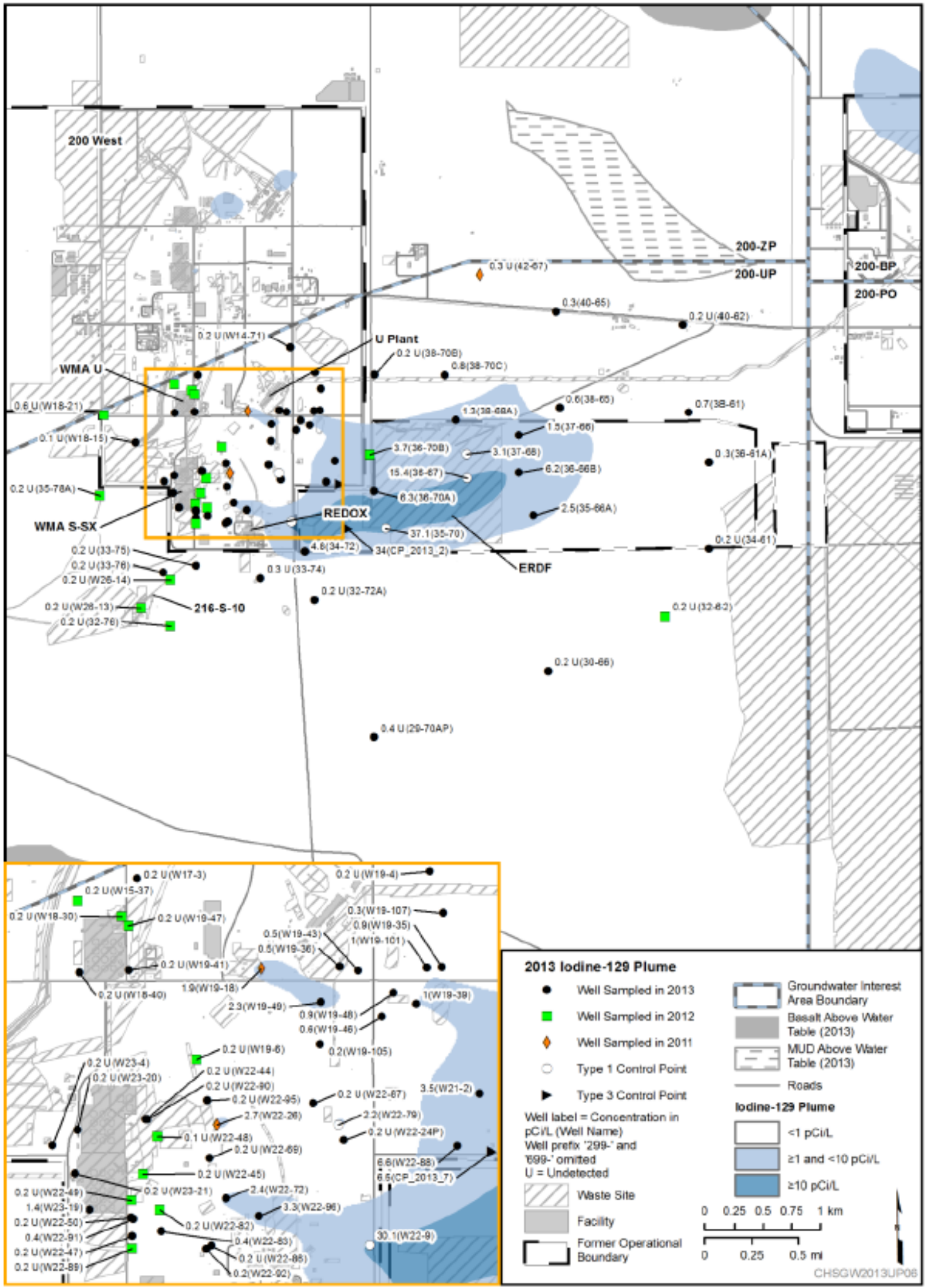

Figure 37. ${ }^{129}$ I groundwater plumes emanating from the 200 West Area (adapted from DOE 2014). 
PNNL-24709, Rev. 2

RPT-DVZ-AFRI-030, Rev. 2

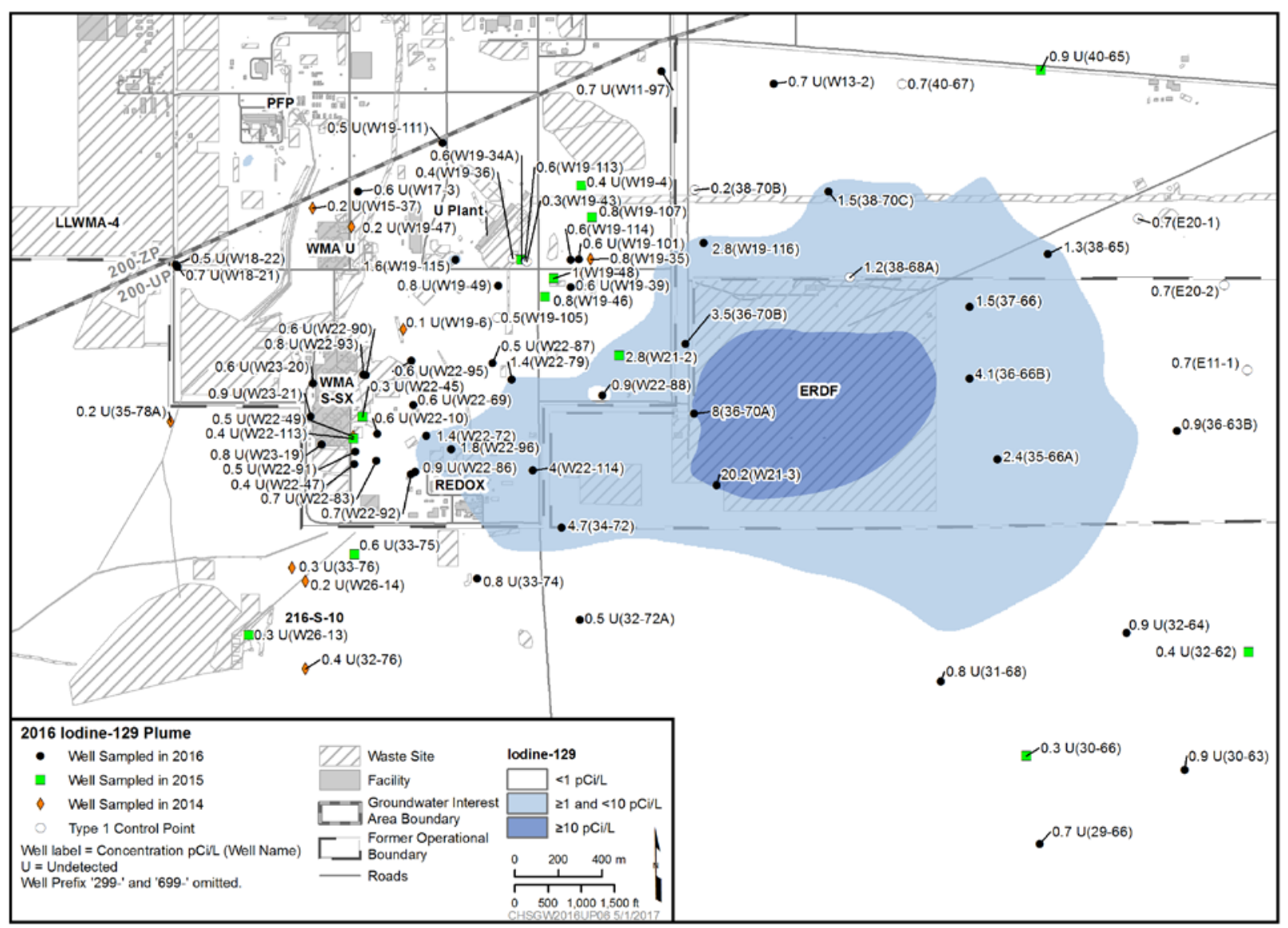

Figure 38. Map of the iodine plume as of 5/1/2017. The open circles (Type 1 Control Point) to the east of the distal end of the plume are the hydraulic containment wells. The wells were completed in 2015, and have been in operation since at least the beginning of 2016. 
PNNL-24709, Rev. 2

RPT-DVZ-AFRI-030, Rev. 2

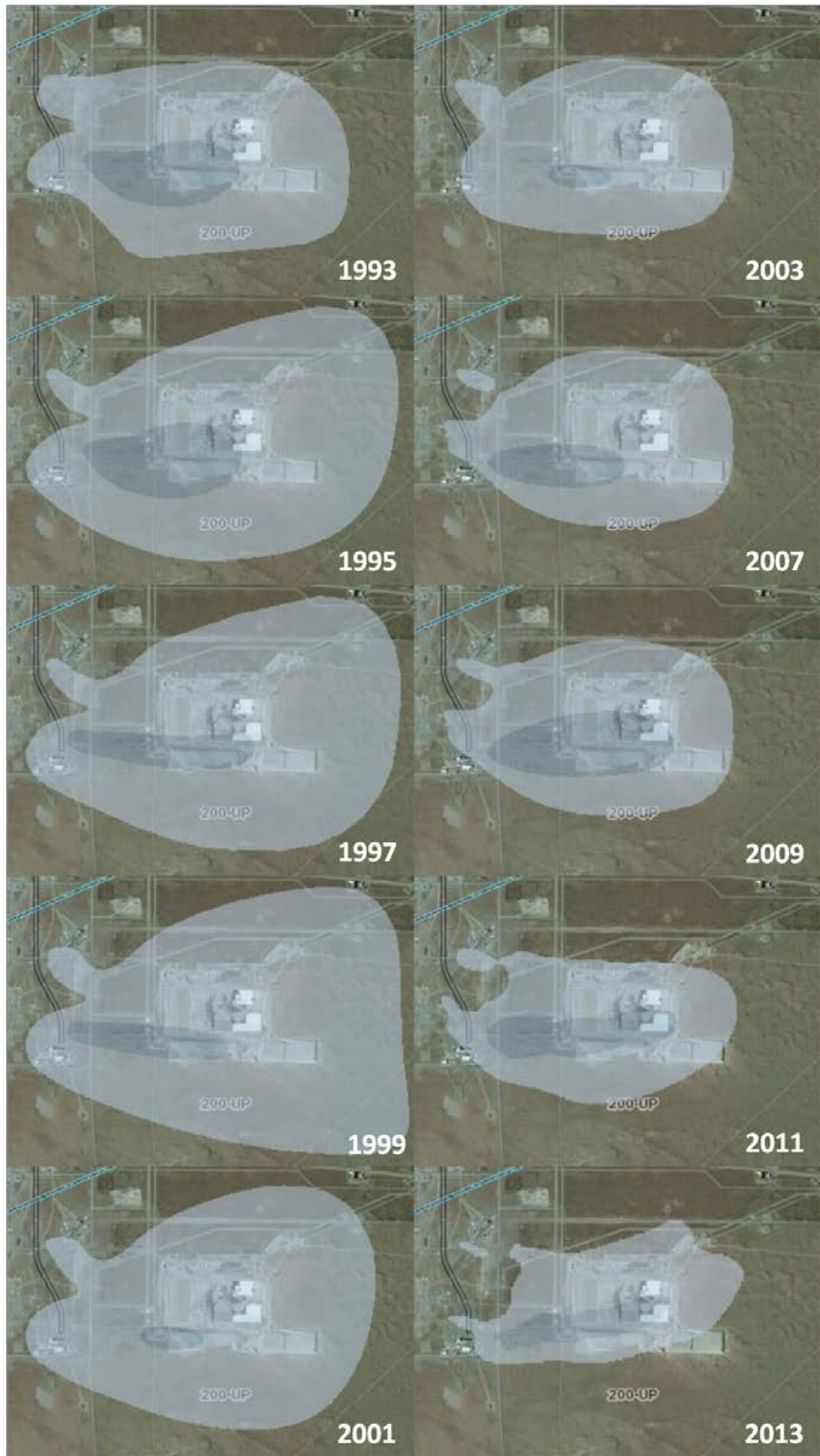

Figure 39. ${ }^{129}$ I plume depictions over a 20-year period for the 200-UP-1 OU. Plume images were obtained using the Plume Status feature of the PHOENIX web-based data tool for the Hanford Site (http://phoenix.pnnl.gov/apps/plumes/index.html, accessed on 8/18/2015). Note that the set of wells used for plume contouring has varied over time. 
PNNL-24709, Rev. 2

RPT-DVZ-AFRI-030, Rev. 2

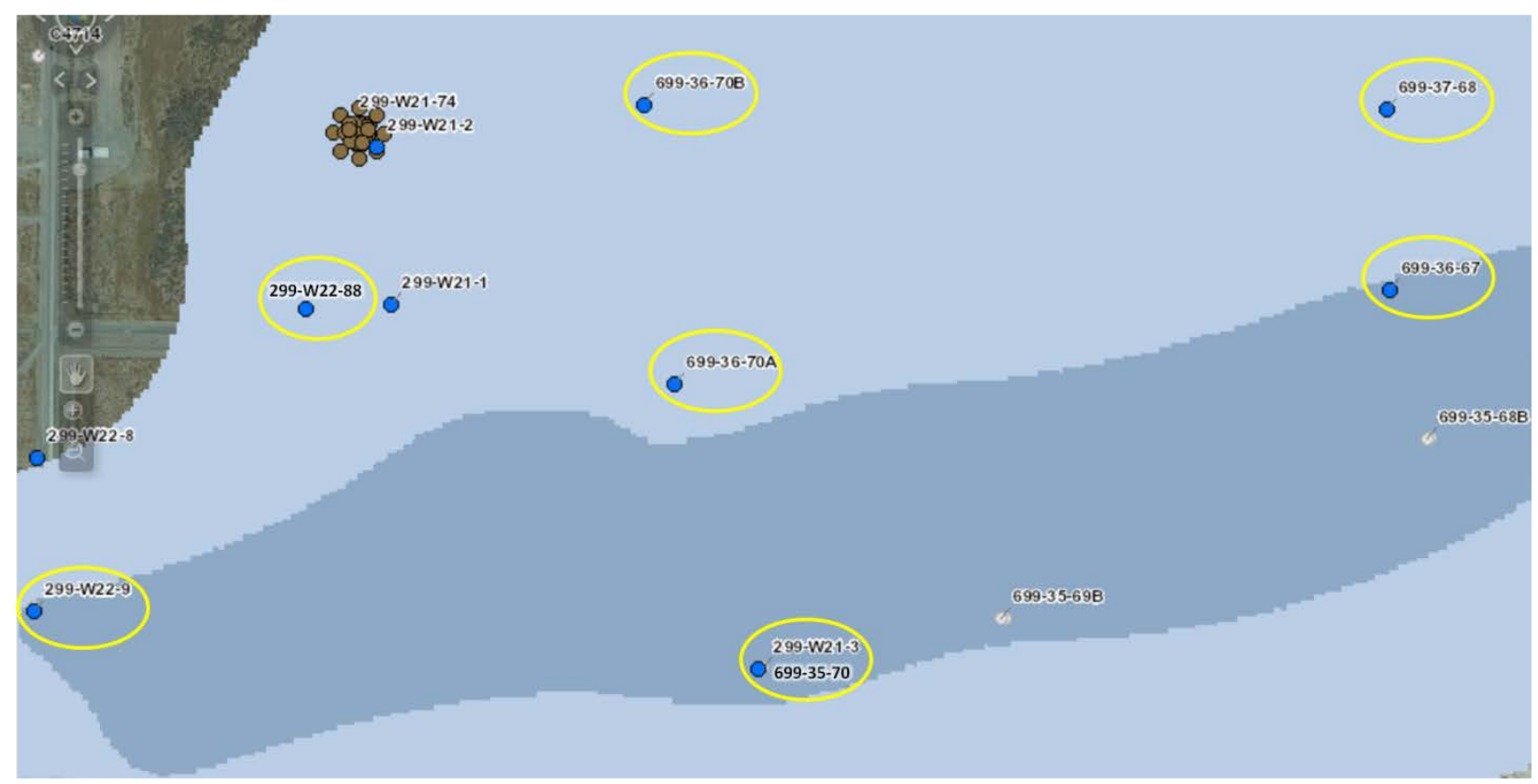

Figure 40. Wells selected for plotting temporal data (yellow circles). Well locations are shown with a background of the $2013^{129}$ I plume contours, where light blue is 1 to $10 \mathrm{pCi} / \mathrm{L}$ and darker blue is greater than $10 \mathrm{pCi} / \mathrm{L}$. Image was obtained using the PHOENIX web-based data tool for the Hanford Site (http://phoenix.pnnl.gov/, accessed on 8/18/2015). 
PNNL-24709, Rev. 2

RPT-DVZ-AFRI-030, Rev. 2

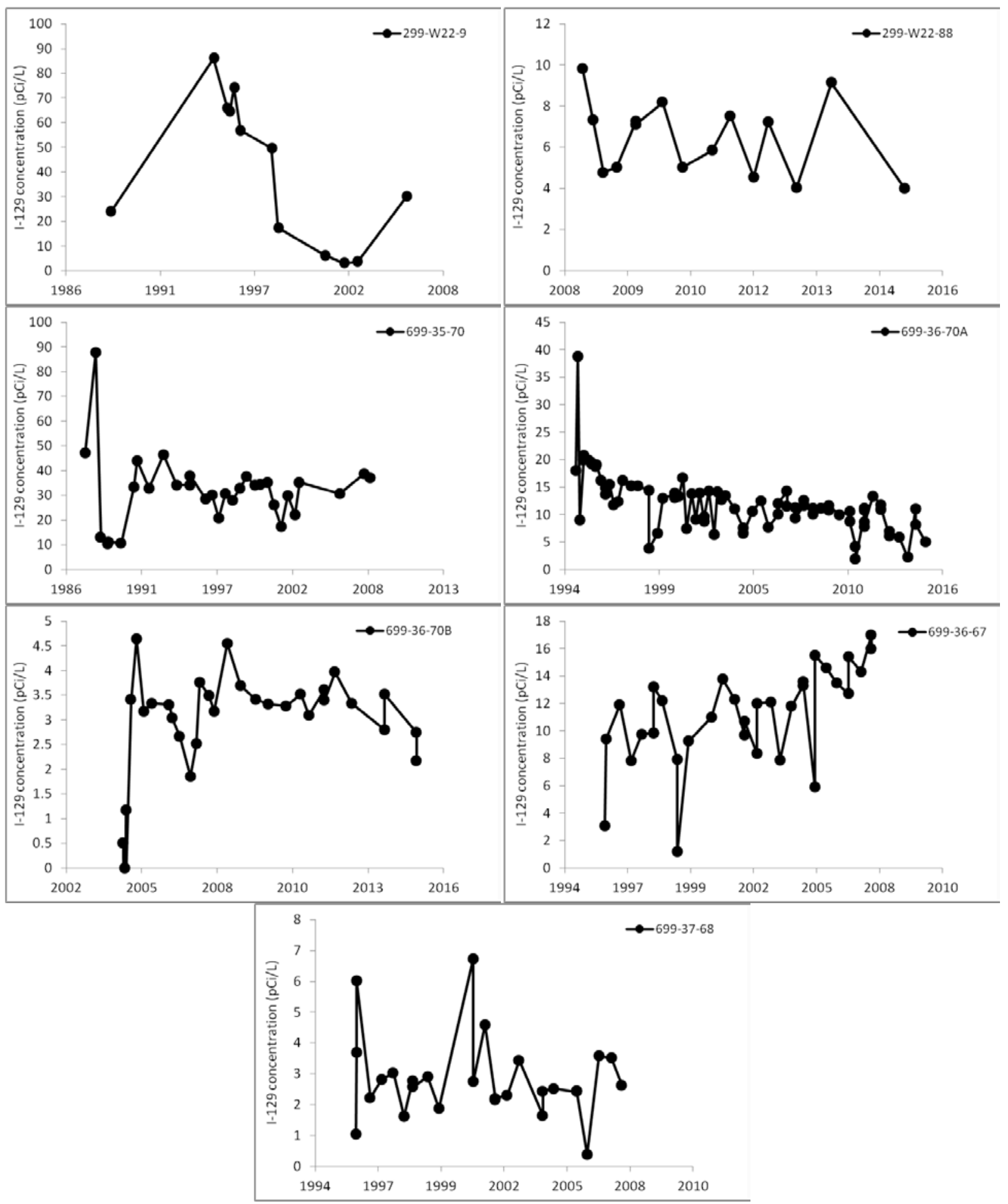

Figure 41. Temporal ${ }^{129}$ I concentration profiles in seven wells within the central portion of the 200-UP-1 OU. Data were obtained using the PHOENIX web-based data tool for the Hanford Site (http://phoenix.pnnl.gov/, accessed on 8/18/2015). 
PNNL-24709, Rev. 2

RPT-DVZ-AFRI-030, Rev. 2

Future plume behavior depends on fate and transport factors, including natural attenuation, and the nature of the continuing iodine contamination flux from the vadose zone. There are several potential alternative conceptual models for future plume behavior. Section 4.0 describes these alternative conceptual models and the type of data that can be used to select the one will best describe future plume behavior in support of remedy decisions.

\subsubsection{0-UP-1 Operable Unit Plume Vadose Zone Source Evaluation}

As discussed in Section 2.0, iodine-contaminated solutions were disposed to the U1/U2 cribs, S-1/2 crib, and the S-7 crib as the identified sources for the ${ }^{129}$ I plume in the 200-UP-1 OU. To support evaluation of plume behavior, the characteristics of the discharge of ${ }^{129}$ I from these source areas into the groundwater needs to be quantified. In particular, predictions of the contaminant discharge to the groundwater in the future are needed as part of evaluating remediation approaches and the potential need for contaminant source mitigation. An evaluation of these source areas was conducted using the approach described by Truex et al. (2015) to provide insight into the expected profile of contaminant discharge into groundwater over time. This assessment uses numerical modeling as a means to estimate contaminant flux to the groundwater for the available ${ }^{129} \mathrm{I}$ and aqueous waste disposal inventories, recharge conditions, and subsurface hydrogeologic properties (Appendix B). The discharge characteristics of the U1/U2, S1/2, and S-7 cribs are summarized in Table 18.

Table 18. Disposal characteristics of U1/U2, S-1/2, and S7 cribs.

\begin{tabular}{ccccc}
\hline Crib & $\begin{array}{c}\text { Volume } \\
\text { (L) }\end{array}$ & $\begin{array}{c}\text { I-129 } \\
\text { (Ci) }\end{array}$ & $\begin{array}{c}\text { Average I-129 } \\
\text { Concentration } \\
\text { (pCi/L) }\end{array}$ & $\begin{array}{c}\text { Discharge } \\
\text { Period }\end{array}$ \\
\hline U1/U2 & $1.59 \mathrm{e} 7$ & $2.27 \mathrm{e}-6$ & 0.143 & $1951-1960$ \\
& & & & $1966-1967$ \\
$\mathrm{~S}-1 / 2$ & $1.60 \mathrm{e} 8$ & $1.36 \mathrm{e}-1$ & 850 & $1952-1956$ \\
$\mathrm{~S}-7$ & $3.90 \mathrm{e} 8$ & $3.51 \mathrm{e}-1$ & 900 & $1956-1965$ \\
\hline
\end{tabular}

The first element of the analysis estimated transport of a non-sorbing, non-reactive solute to examine how hydraulic conditions and the available ${ }^{129} \mathrm{I}$ and aqueous disposal inventories affect the temporal profile of solute (contaminant) discharge to groundwater from these sites. From this analysis, it was determined that insufficient ${ }^{129} \mathrm{I}$ and aqueous waste inventory was disposed at the U1/U2 cribs for these cribs to be a significant source to the groundwater plume. Contributions to the ${ }^{129}$ I plume from the U1/U2 plumes can only be explained if more concentrated waste than the average value listed in Table 18 was disposed at short-circuit conditions (e.g., transport down unsealed well casings) or with additional aqueous driving forces from discharges at nearby waste sites (Appendix B). Because of these results and the small ${ }^{129}$ I inventory at the U1/U2 cribs, future ${ }^{129}$ I discharge from the vadose zone to the groundwater at these cribs is expected to be very low and, consistent with current groundwater plume observations, at ${ }^{129}$ I concentrations less than $1 \mathrm{pCi} / \mathrm{L}$.

A series of simulations was conducted with the STOMP simulator (White and Oostrom 2006) for the S-1/2 and S-7 cribs, which received considerable waste volumes at average concentration of 850 and $900 \mathrm{pCi} / \mathrm{L}$, respectively (Table 18). The applicable governing equations for the simulator are the component mass-conservation equation for water and the solute transport equation, which is solved using 
a total-variation diminishing scheme. The numerical models were configured with the geologic sediment layers, average thicknesses, and hydraulic properties according to Appendix B. The water retention values for the van Genuchten (1980) saturation-water pressure constitutive model are obtained from a Hanford Site subsurface data package (Last et al. 2006a) and the water relative permeability is computed using the Mualem (1976) relation. For all layers, similar longitudinal and transverse dispersivity values ( 0.3 and $0.03 \mathrm{~m}$, respectively) were used as in the Hanford Site numerical assessment simulations using the STOMP simulator, as discussed by Zhang et al. (2005). Both the S-7 and S-1/2 models comprise a domain of $1600 \mathrm{~m}$ in the $x$ direction (west to east), $500 \mathrm{~m}$ in the $y$ direction (south to north), and $104 \mathrm{~m}$ in the $z$ direction (bottom to top). The domain was discretized into $130 \times 65 \times 95$ grid cells for a total of 802,750 nodes. Standard refinement procedures were used to obtain the final discretized domains yielding converged mass fluxes across the water table. A plane of symmetry is assumed to be located at $y$ $=500 \mathrm{~m}$, dissecting the cribs in half. The crib centers are located at $\mathrm{x}=500 \mathrm{~m}$ and $\mathrm{y}=500 \mathrm{~m}$ of each model, with the water table $67 \mathrm{~m}$ below the top. Groundwater was assumed to flow from west to east with a Darcy velocity of $6.12 \mathrm{~m} /$ year (36 m/year linear velocity). The pre-operations recharge was assumed to be $4.0 \mathrm{~mm} /$ year, increasing to $44 \mathrm{~mm} /$ year during and after operations.

For each of the two cribs, a total of 11 simulations were conducted (Table 19), varying the partitioning coefficient $\left(\mathrm{K}_{\mathrm{d}} ; \mathrm{L} / \mathrm{M}\right)$, and a first-order reaction rate $(k ; 1 / \mathrm{T})$. Although the nature and rate of ${ }^{129}$ I transformation reactions still need to be experimentally determined, the assumed values listed in Table 19 provide an initial analysis what might happen to the disposed contaminant if it were subject to biogeochemical reactions that transform iodine species and lead to compounds or conditions that sequester iodine (e.g., form low-solubility precipitates) or remove iodine (e.g., volatilize it).

Table 19. Partition coefficient $\left(K_{d}\right)$ and first-order reaction rate constant $(k)$ for the $S-1 / 2$ and $S-7$ simulations.

\begin{tabular}{ccc}
\hline Simulation & $\begin{array}{c}\text { Partition } \\
\text { Coefficient } \\
\text { (mL/g) }\end{array}$ & $\begin{array}{c}\text { First-order } \\
\text { Reaction } \\
\text { Rate } \\
\text { (1/day) }\end{array}$ \\
\hline Base Case & 0 & 0 \\
1 & 0.1 & 0 \\
2 & 0.2 & 0 \\
3 & 0.5 & 0 \\
4 & 1.0 & 0 \\
5 & 0 & 0.01 \\
6 & 0 & 0.1 \\
7 & 0.1 & 0.01 \\
8 & 0.1 & 0.1 \\
9 & 0.2 & 0.01 \\
10 & 0.2 & 0.1 \\
\hline
\end{tabular}

Predicted discharge of ${ }^{129}$ I from the S-7 waste site across the water table into groundwater (Figure 42 ), as a function of $K_{d}$, indicate large initial fluxes for the cases with a relatively low $K_{d}$ and a considerable delayed arrival for the case where it is equal to $1.0 \mathrm{~mL} / \mathrm{g}$. The late arrival of ${ }^{129} \mathrm{I}$ for this $\mathrm{K}_{\mathrm{d}}$ value is not consistent with field observations, showing considerable groundwater concentrations at 
several locations, starting in the mid-1980s (Figure 41). For the simulations with the lower $\mathrm{K}_{\mathrm{d}}$ values, the initial discharge peak quickly declines to a much lower discharge level, slowly declining (tailing) over a long period of time, lasting hundreds of years. The short-term discharge behavior, up to year 2100 , is shown in Figure 43, showing the large initial peaks for the low $\mathrm{K}_{\mathrm{d}}$ cases and the subsequent near-term discharge decline in more detail. The large initial peak of ${ }^{129}$ I discharge to groundwater, up to $~ 1.0 \mathrm{e} 8$ $\mathrm{pCi} /$ day, is due to the large rate and total volume of the waste disposal, which is more than a factor 10 greater than the pore volume in the vadose zone beneath the S-7 footprint. For the low $\mathrm{K}_{\mathrm{d}}$ cases, the discharges then decline rapidly over a period of about 30 years to $\sim 2.0 \mathrm{e} 6 \mathrm{pCi} /$ day. A slight increase is observed around 2010, when the recharge front of $44 \mathrm{~mm} /$ year has reached the water table. As illustrated in Figure 44a, most of the vadose zone ${ }^{129}$ I plume during disposal has concentrations close to the disposed waste water of $900 \mathrm{pCi} / \mathrm{L}$. During this phase, the aqueous saturations are high in the contaminated zone (Figure 45a) due to the high infiltration rate and disposed large volumes. As a result of the high flow rates and concentrations, the discharge during and right after disposal reaches the initial peaks indicated in Figure 42 and Figure 43. After disposal, concentrations remain high in the vadose zone plume (Figure 44b and Figure 44c), while the saturations decrease considerably due to the draining unsaturated zone and the adjustment to the new recharge rate. As a result, the ${ }^{129} \mathrm{I}$ discharge reduces to the level of about $2.0 \mathrm{e} 6 \mathrm{pCi} /$ day, as indicated in Figure 42. The decrease in contaminant discharge by about a factor 50 for the low $\mathrm{K}_{\mathrm{d}}$ cases does not mean that the predicted groundwater concentrations will see a similar decline. During and directly after the disposal, the aqueous fluxes are large compared to the groundwater flow rate and limited mixing occurs directly below the vadose zone plume. When, later on, recharge dominates contaminant transport across the water table, the aqueous fluxes are relatively small compared to the groundwater flow rate, leading to increased mixing and dilution below the vadose zone plume.

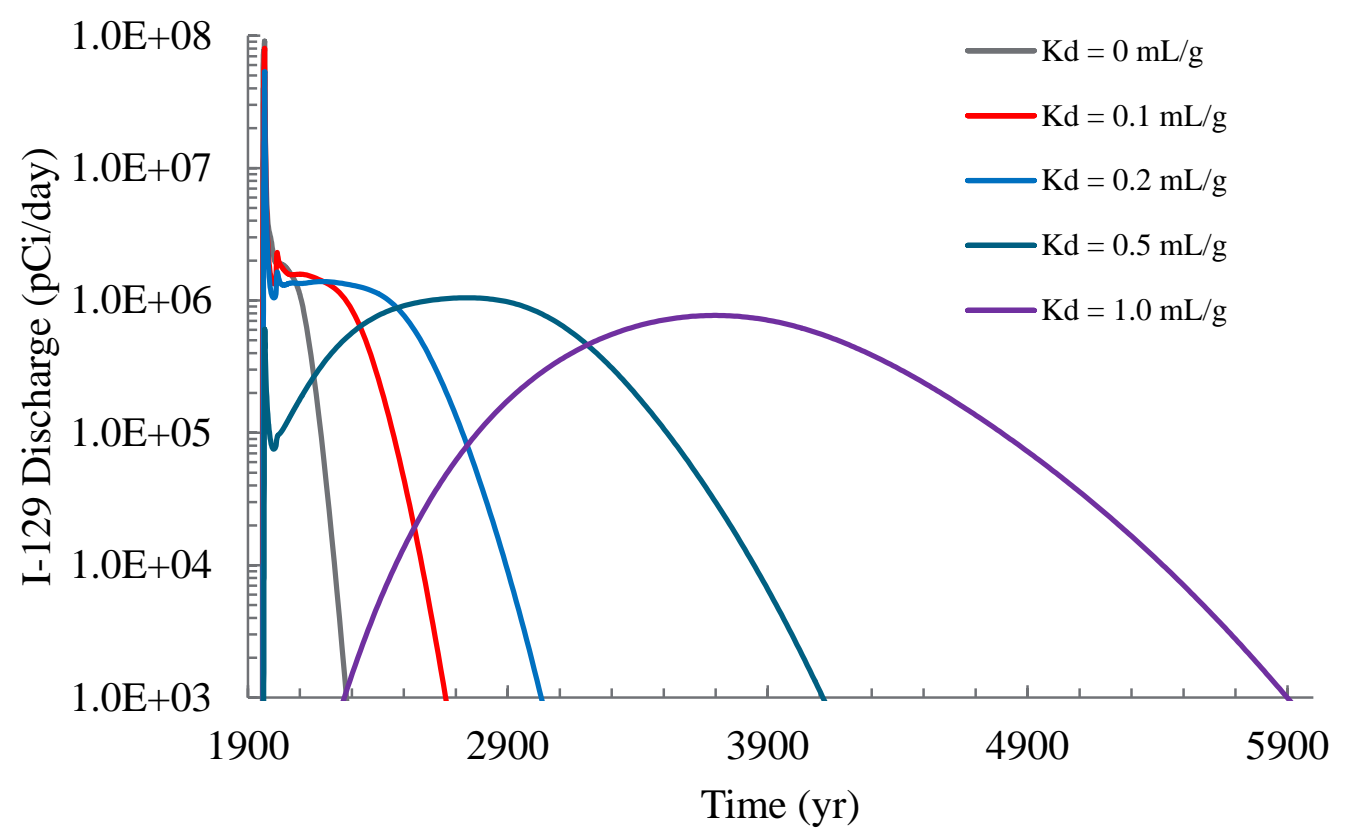

Figure 42. Predicted long-term ${ }^{129}$ I discharge across the water table emanating from the S-7 crib for various partition coefficient $\left(\mathrm{K}_{\mathrm{d}}\right)$ values. 
PNNL-24709, Rev. 2

RPT-DVZ-AFRI-030, Rev. 2

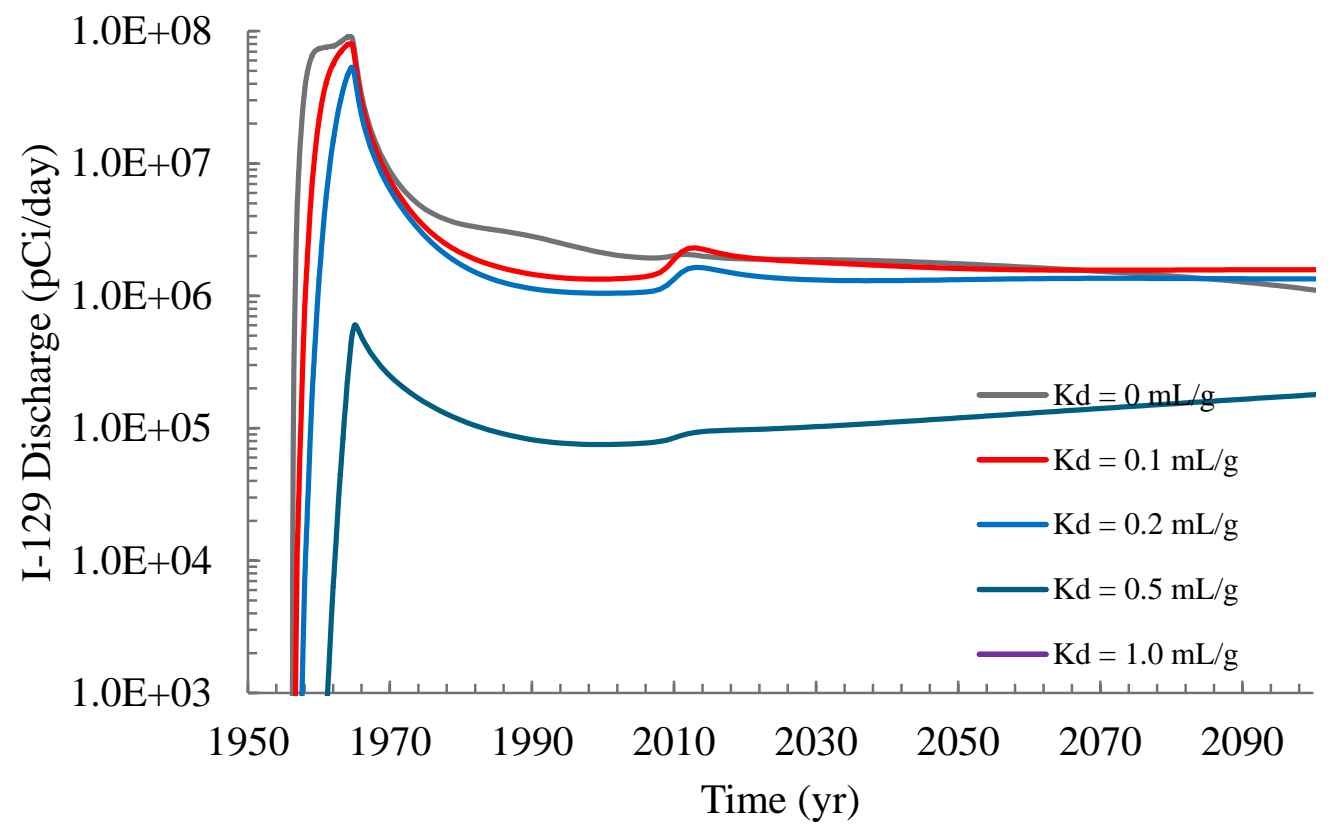

Figure 43. Near-term predicted ${ }^{129}$ I discharge across the water table emanating from the S-7 crib for various partition coefficient $\left(\mathrm{K}_{\mathrm{d}}\right)$ values. 
PNNL-24709, Rev. 2

RPT-DVZ-AFRI-030, Rev. 2

\section{Concentration (pCi/L)}
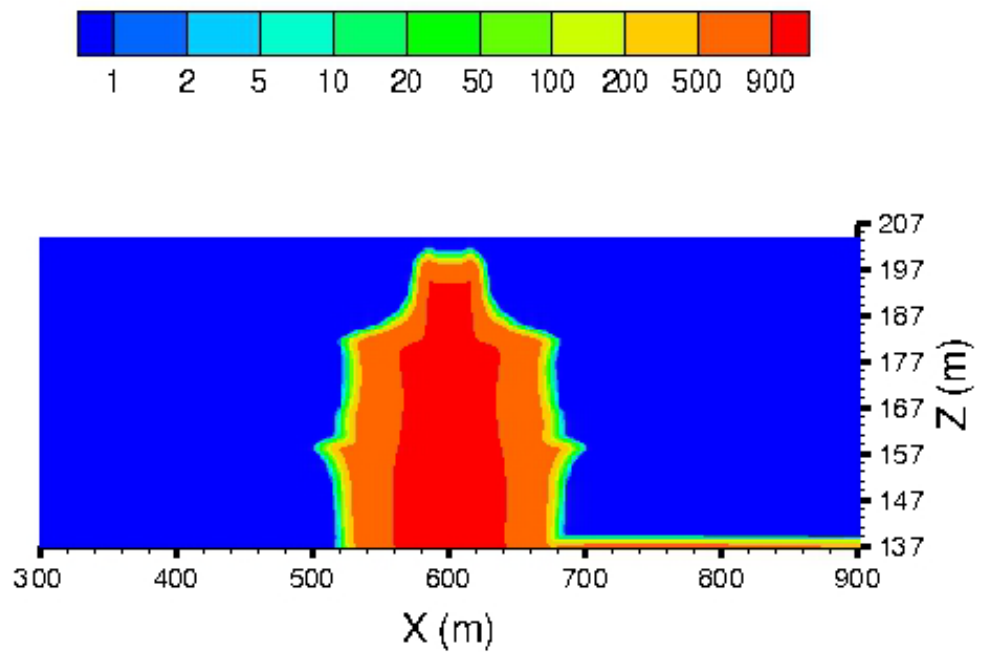

(a)

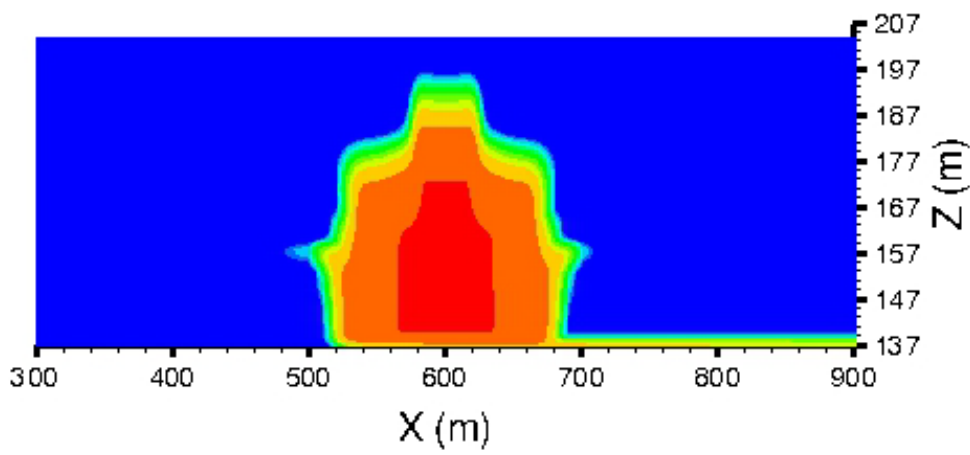

(b)

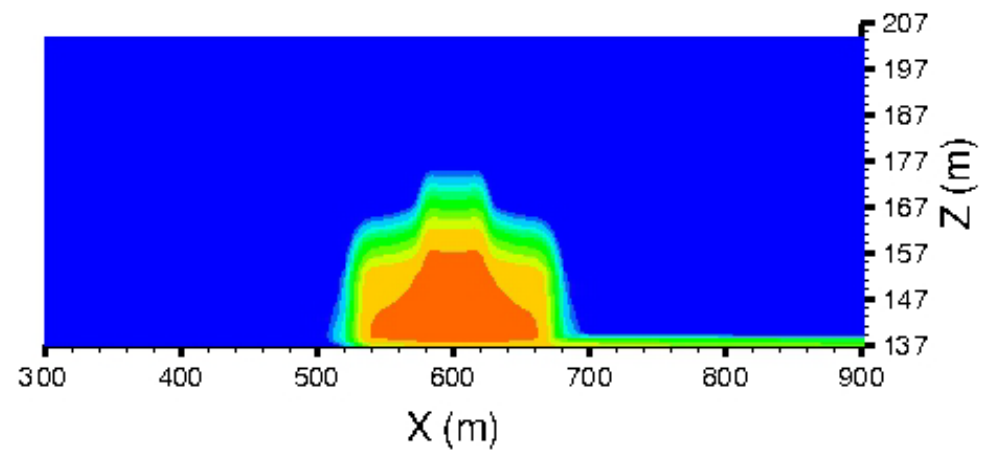

(c)

Figure 44. ${ }^{129}$ I concentrations (pCi/L) for the Base Case at (a) 1965, (b) 2000, and (c) 2100. 
PNNL-24709, Rev. 2

RPT-DVZ-AFRI-030, Rev. 2

\section{Aqueous Saturation}
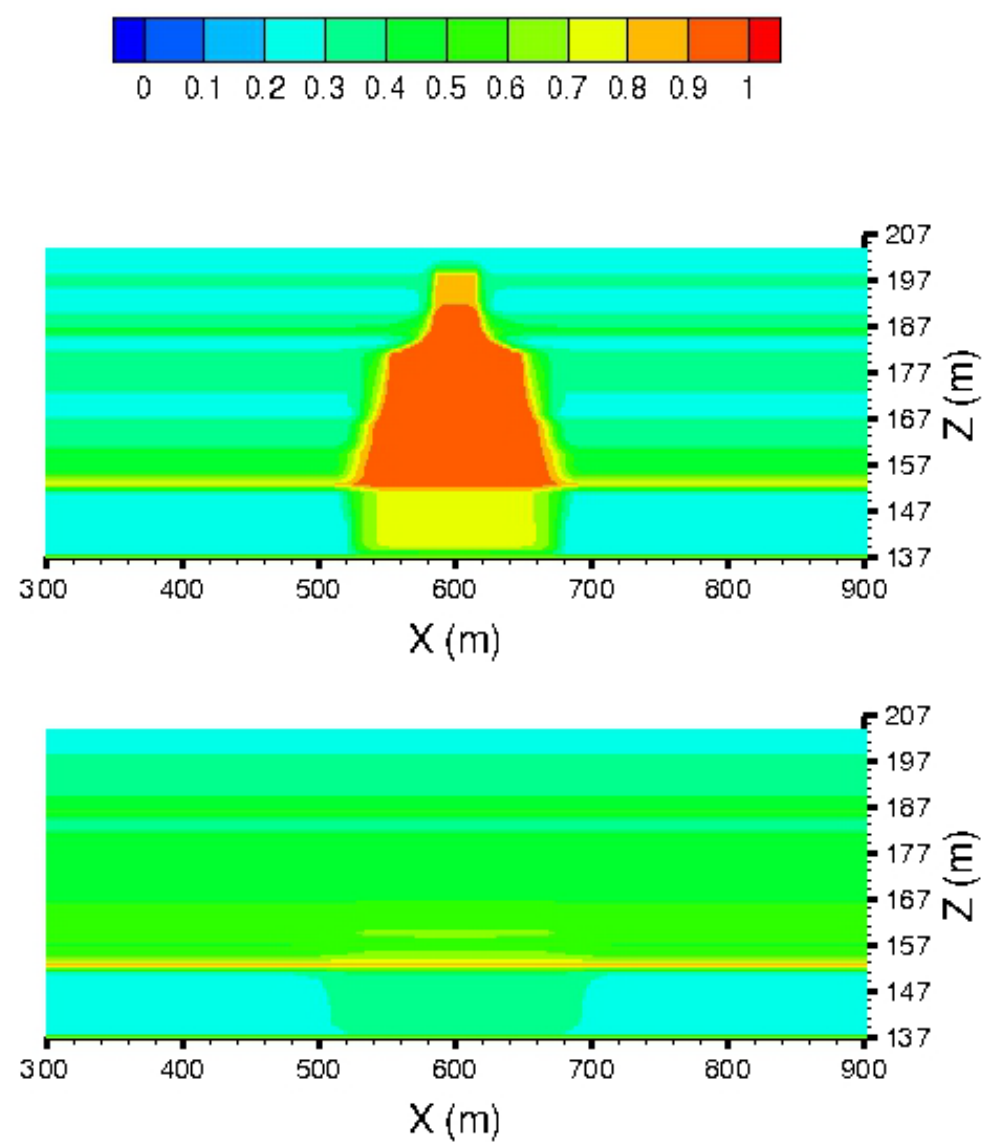

(a)

(b)

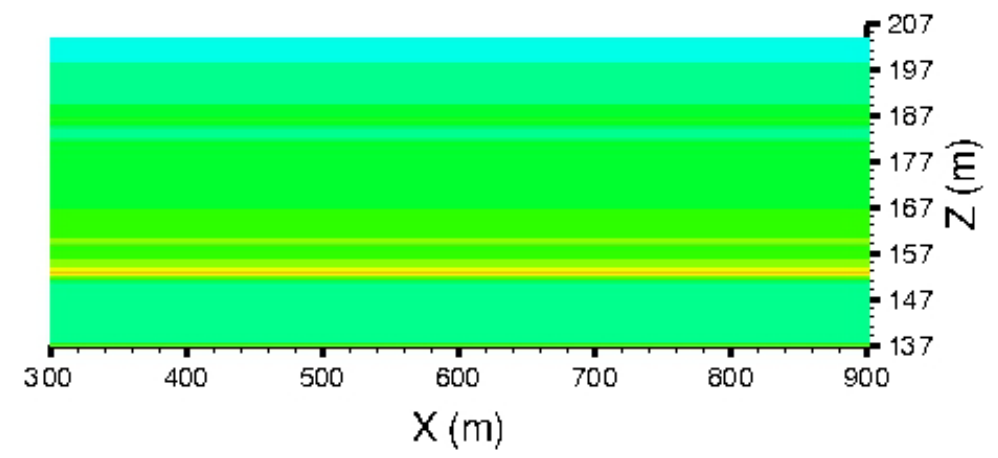

(c)

Figure 45. Aqueous saturations for the Base Case at (a) 1965, (b) 2000, and (c) 2100.

The predicted normalized cumulative ${ }^{129}$ I discharge, for $K_{d}$ values ranging from 0 to $1 \mathrm{~mL} / \mathrm{g}$, are shown in Figure 46 and Figure 47, showing long-term and near-term behavior, respectively. For all simulations, $100 \%$ of the disposed ${ }^{129}$ I will eventually be transported through the vadose zone into the groundwater due to recharge. The results show that for the larger two values, the contaminant arrival is not consistent with the relatively large plumes that have been present for more than 20 years, as shown in Figure 39. For the lower $K_{d}$ values, the mass fraction that is initially transported across the water table with the large volume of disposed waste water ranges from 0.25 to 0.7 , with the largest value for the nonsorbing case. 
PNNL-24709, Rev. 2

RPT-DVZ-AFRI-030, Rev. 2

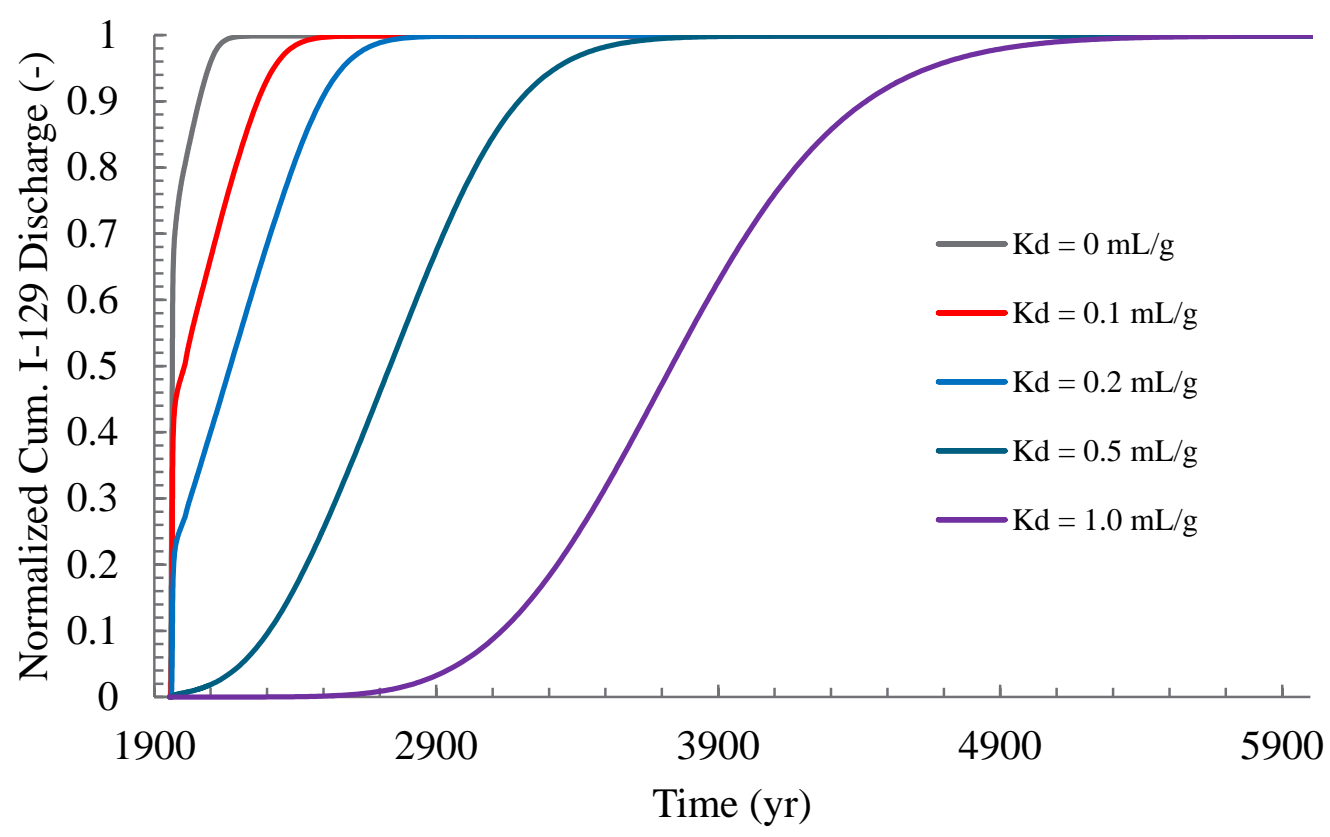

Figure 46. Predicted normalized cumulative ${ }^{129}$ I discharge across the water table emanating from the S-7 crib for various partition coefficient $\left(\mathrm{K}_{\mathrm{d}}\right)$ values.

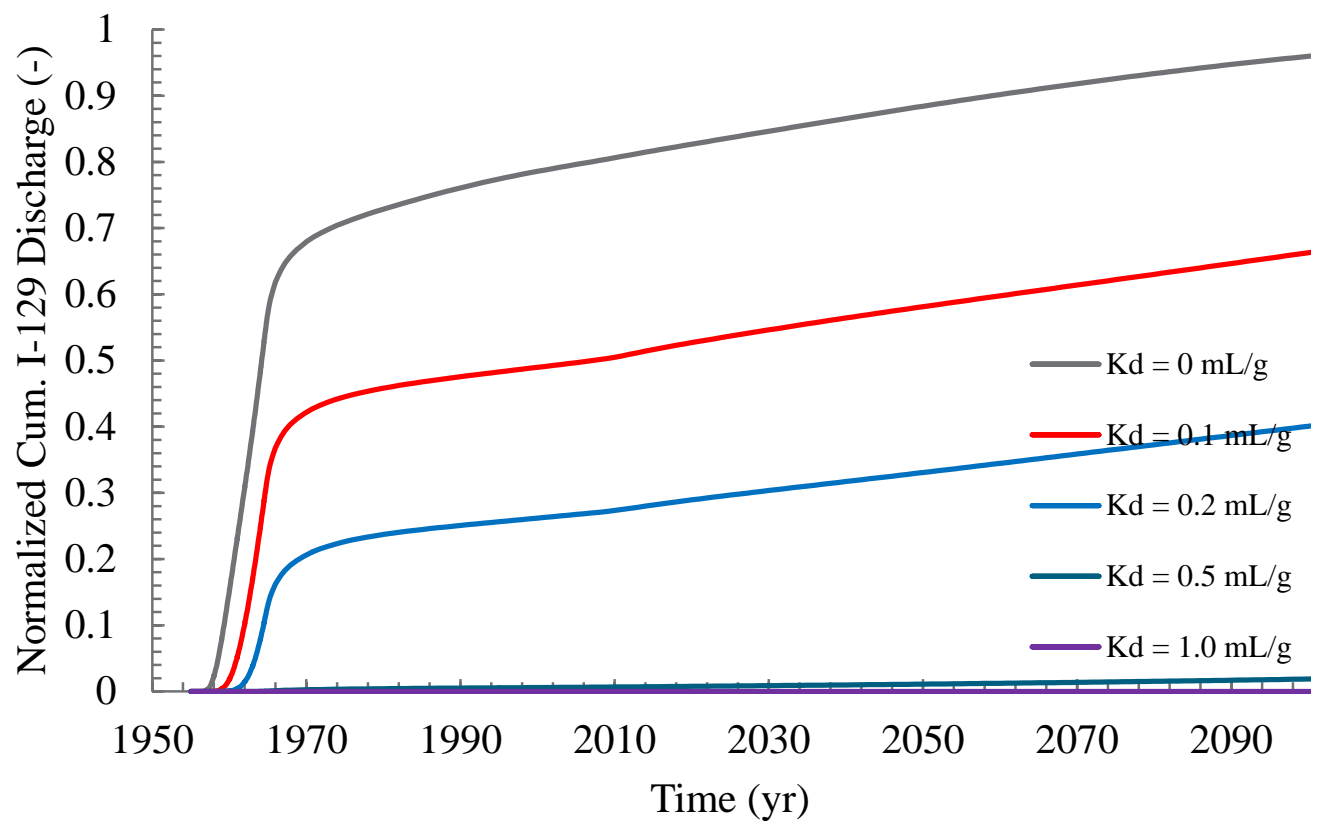

Figure 47. Near-term predicted normalized cumulative ${ }^{129}$ I discharge across the water table emanating from the S-7 crib for various partition coefficient $\left(\mathrm{K}_{\mathrm{d}}\right)$ values.

The results shown in Figure 42, Figure 43, Figure 46, and Figure 47 suggest that the assumption of a uniform $\mathrm{K}_{\mathrm{d}}$ of $0.5 \mathrm{~mL} / \mathrm{g}$ or larger leads to a contaminant discharge behavior that is not consistent with field observations. The addition of a reaction leading to removal of ${ }^{129} \mathrm{I}$ will further reduce the discharge rate for these cases without enhancing the arrival times. For that reason, simulations combining the larger 
PNNL-24709, Rev. 2

RPT-DVZ-AFRI-030, Rev. 2

$K_{d}$ values with a reaction rate were not considered. For the cases with the lower $K_{d}$ values, the temporal discharge behavior shown in these figures is consistent with the field observations (Figure 39 and Figure 41). To further investigate these sorption conditions, simulations were conducted where $K_{d}$ values of 0 , 0.1 , and $0.2 \mathrm{~mL} / \mathrm{g}$ were combined with a first-order reaction rate of 0.01 /year and 0.1 /year (Table 19). The predicted ${ }^{129}$ I discharge for these simulations indicates that superimposing a reaction leads to a decrease in discharge because of a reduction in the ${ }^{129}$ I vadose zone inventory compared to the nonreactive cases (Figure 48). All the cases with a $k=0.1$ year lead to a rapidly declining recharge, with most of the ${ }^{129}$ I removed from the vadose zone by 2030, independent of the $K_{d}$. For the intermediate reaction rate of 0.01 /year, ${ }^{129} \mathrm{I}$ discharge is mostly affected when sorbing is considered after the initial peak has occurred.

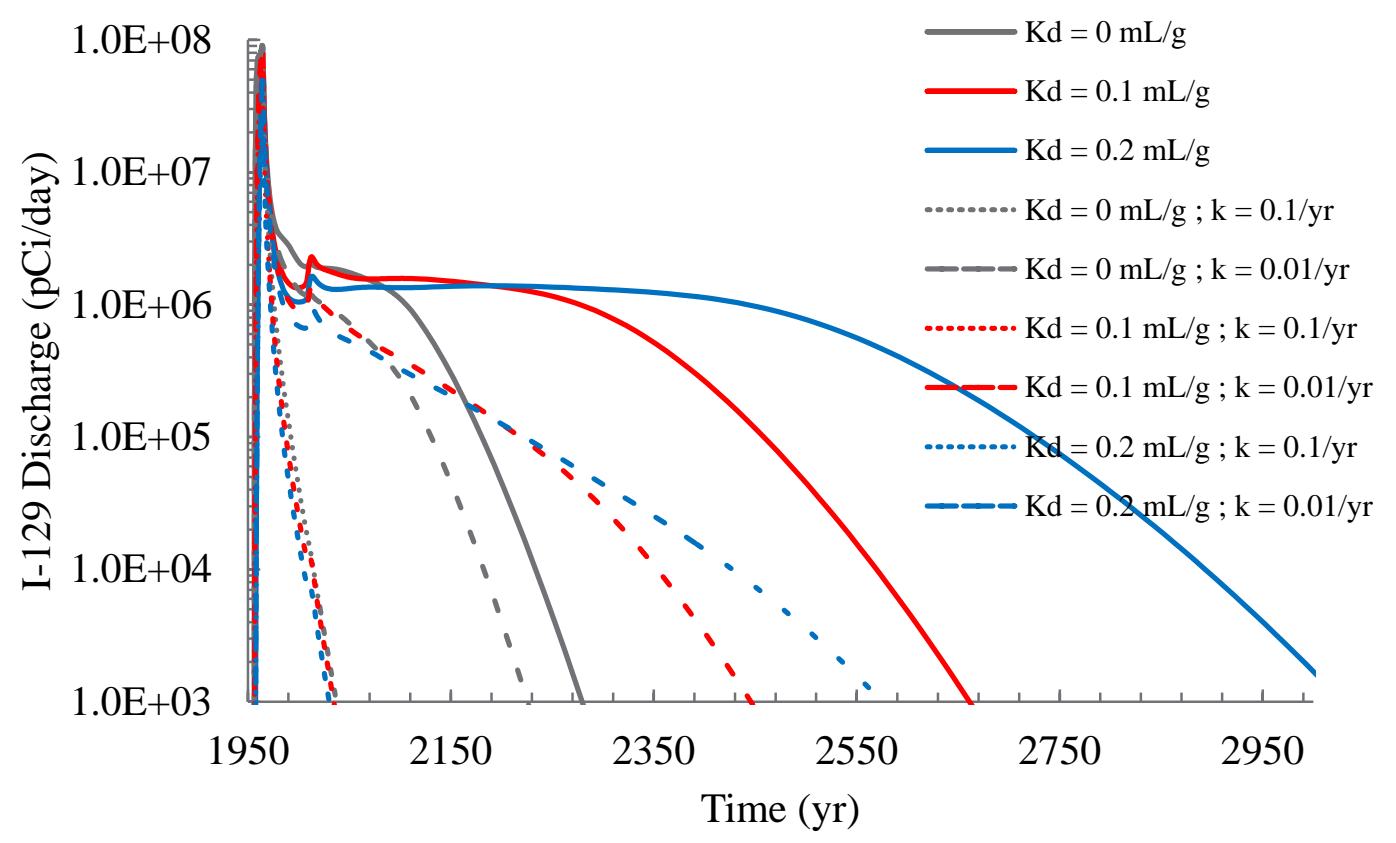

Figure 48. Predicted ${ }^{129}$ I discharge across the water table emanating from the S-7 crib for various $\mathrm{K}_{\mathrm{d}}$ values for various combinations partition coefficient $\left(\mathrm{K}_{\mathrm{d}}\right)$ and reaction rates $(k)$ values.

In Figure 49 through Figure 55, vertical transects of simulated groundwater concentration are presented at 2000, 2016, and 2100 for various combinations of partition coefficients and reaction rates listed in Table 19. The vertical transects are located directly below the center of the crib's footprint and at 100, 500, and $1000 \mathrm{~m}$ directly downstream from the center of the crib. The transects in Figure 49a, representing non-sorbing and nonreactive ${ }^{129} \mathrm{I}$ (Base Case), show concentrations near $300 \mathrm{pCi} / \mathrm{L}$ at the center and somewhat lower concentration downstream through $x=500 \mathrm{~m}$. These values are smaller than in the lower part of the vadose zone (see Figure 44b) due to dilution by the migrating groundwater. At the transect $1000 \mathrm{~m}$ from the crib center, the larger concentrations are associated with the initial waste water discharge into the groundwater during and right after the disposal phase (Figure 42 and Figure 43). Over time, the downstream concentrations decrease (Figure 49a and Figure 49b), although the concentrations directly below the footprint of the crib remain large. The persistence of these large concentrations would lead to stable plume downstream of the S-7 crib, and this is not consistent with field observation of a declining plume (Figure 39). 
PNNL-24709, Rev. 2

RPT-DVZ-AFRI-030, Rev. 2

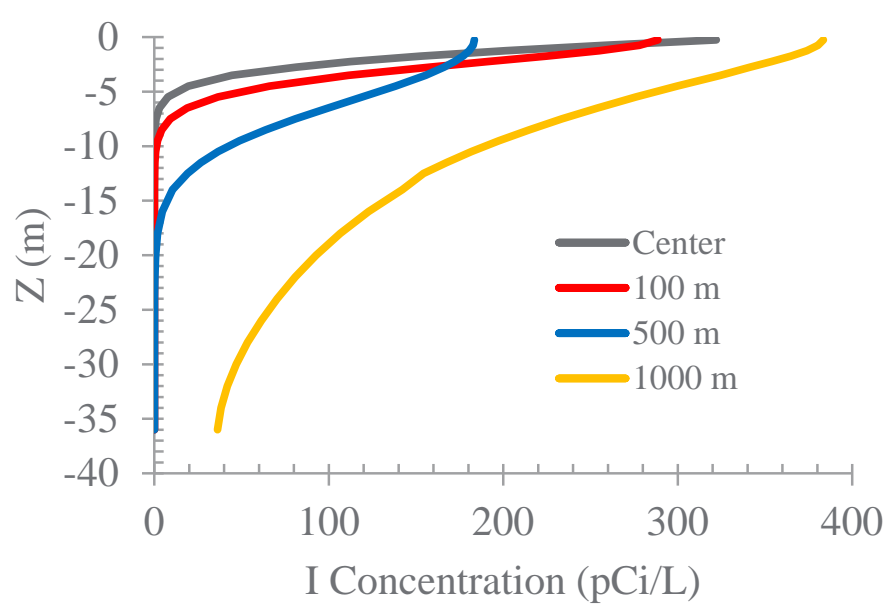

(a)

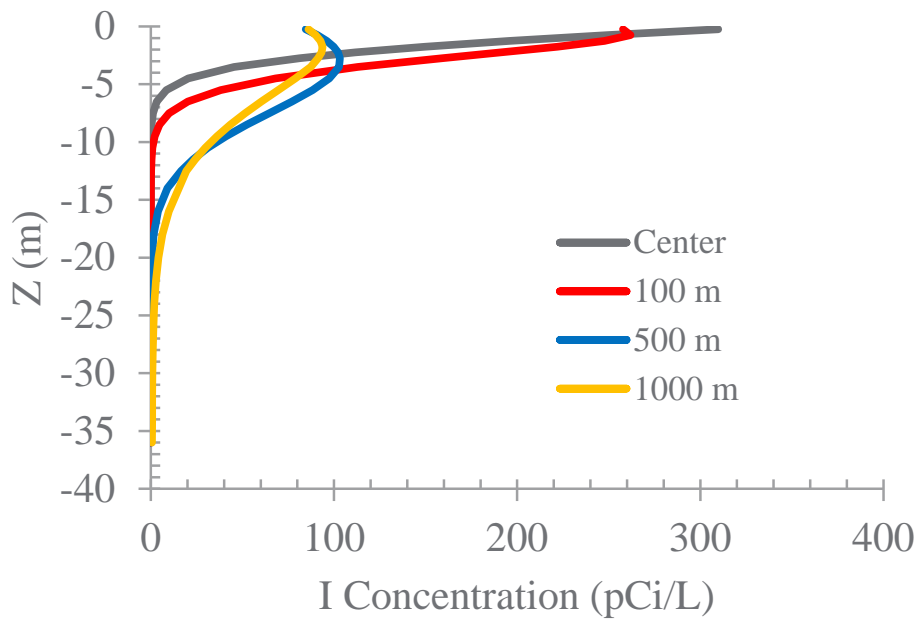

(b)

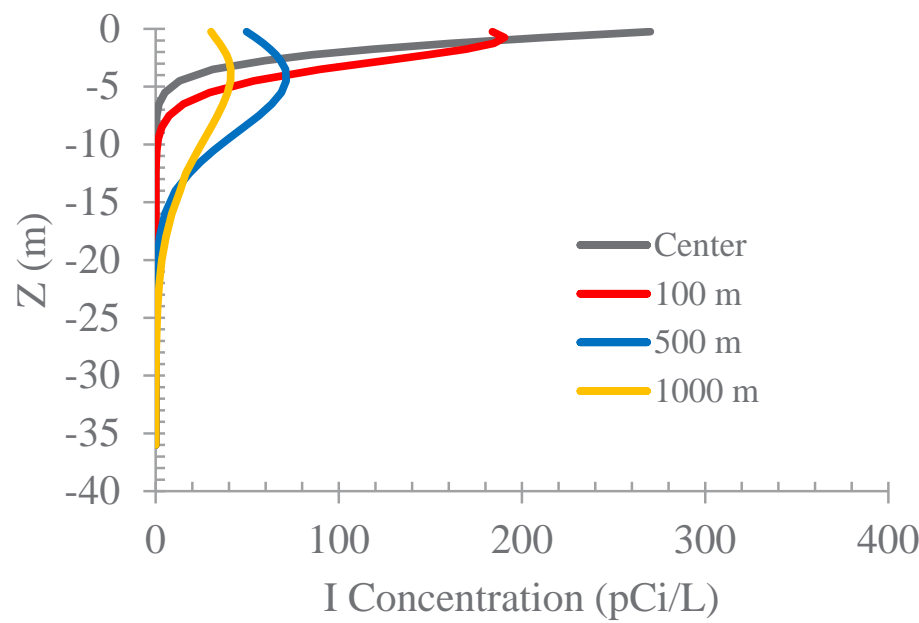

(c)

Figure 49. Predicted ${ }^{129}$ I groundwater concentrations at (a) 2000, (b) 2016, and (c) 2100 at various distances downstream of the footprint center of the S-7 crib for a $K_{d}=0 \mathrm{~mL} / \mathrm{g}$ (water table is at $z=0 \mathrm{~m})$. 
PNNL-24709, Rev. 2

RPT-DVZ-AFRI-030, Rev. 2

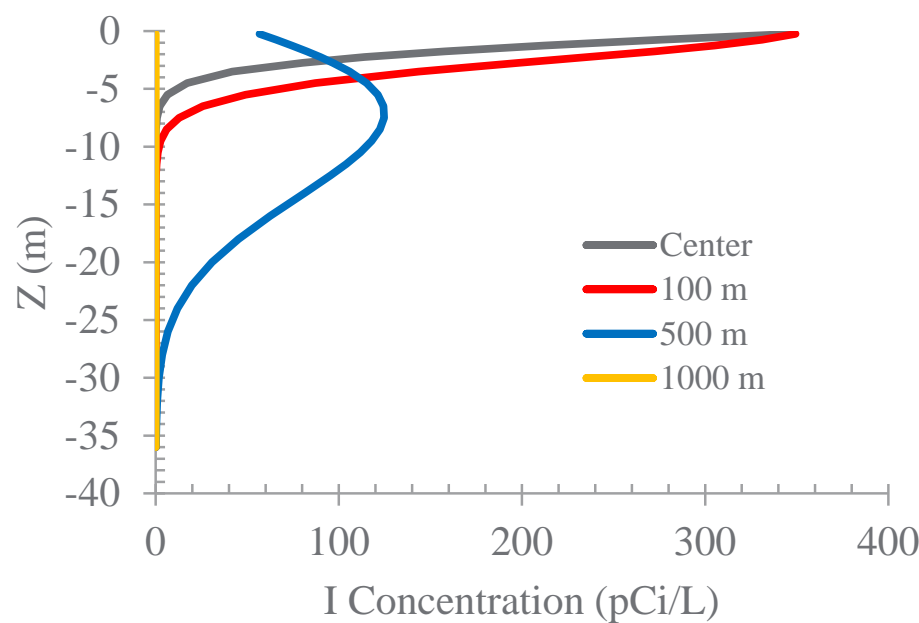

(a)

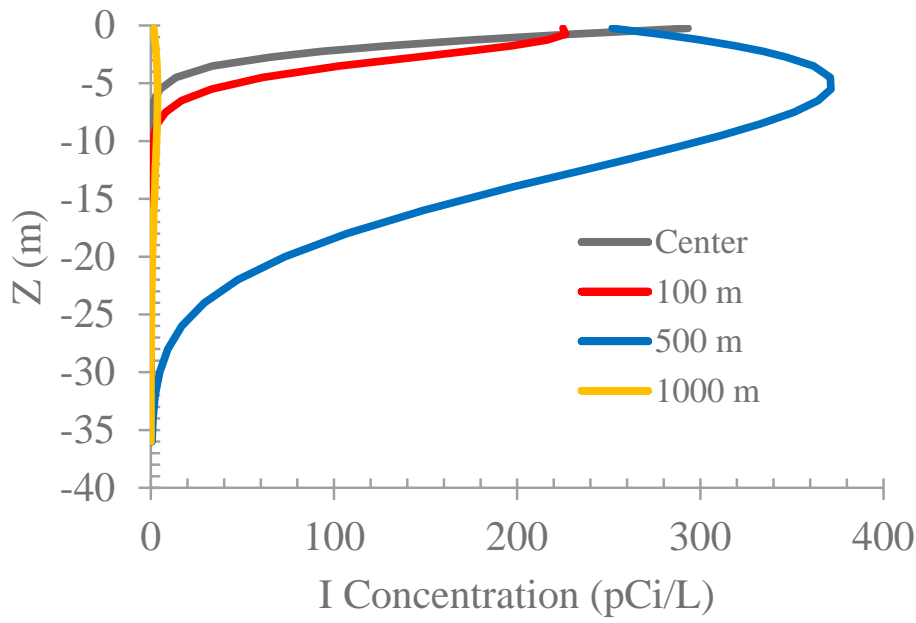

(b)

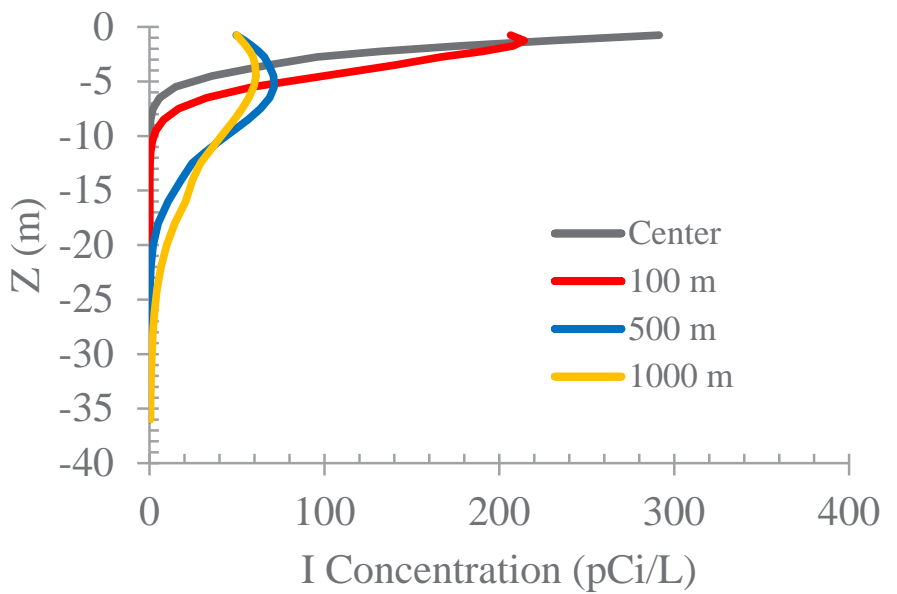

(c)

Figure 50. Predicted ${ }^{129}$ I groundwater concentrations at (a) 2000, (b) 2016, and (c) 2100 at various distances downstream of the footprint center of the S-7 crib for a $\mathrm{K}_{\mathrm{d}}=0.2 \mathrm{~mL} / \mathrm{g}$ (water table is at $z=0 \mathrm{~m}$ ). 
PNNL-24709, Rev. 2

RPT-DVZ-AFRI-030, Rev. 2

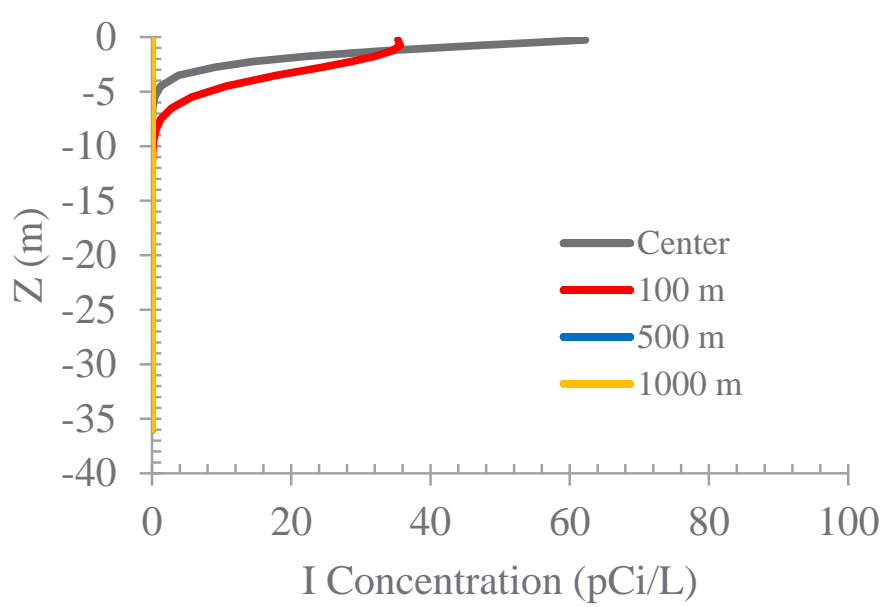

(a)

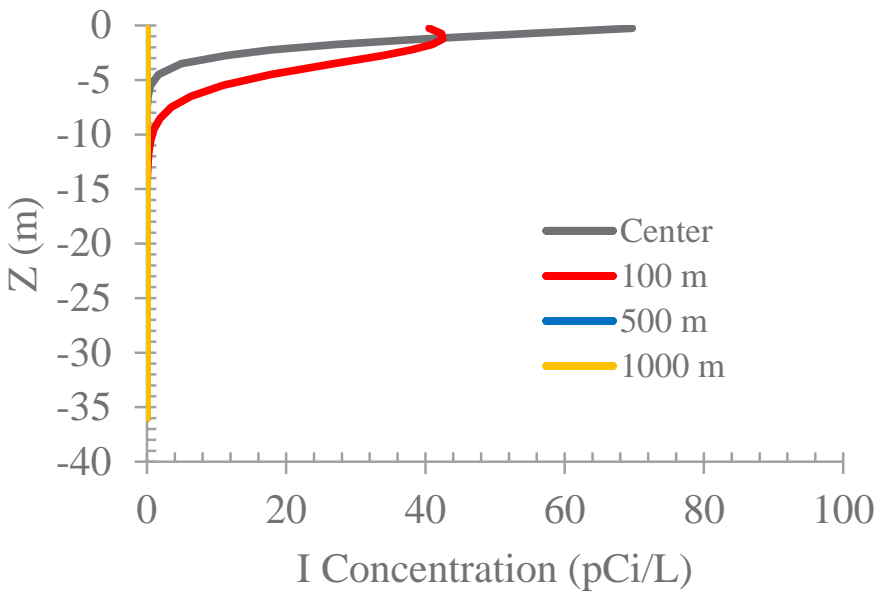

(b)

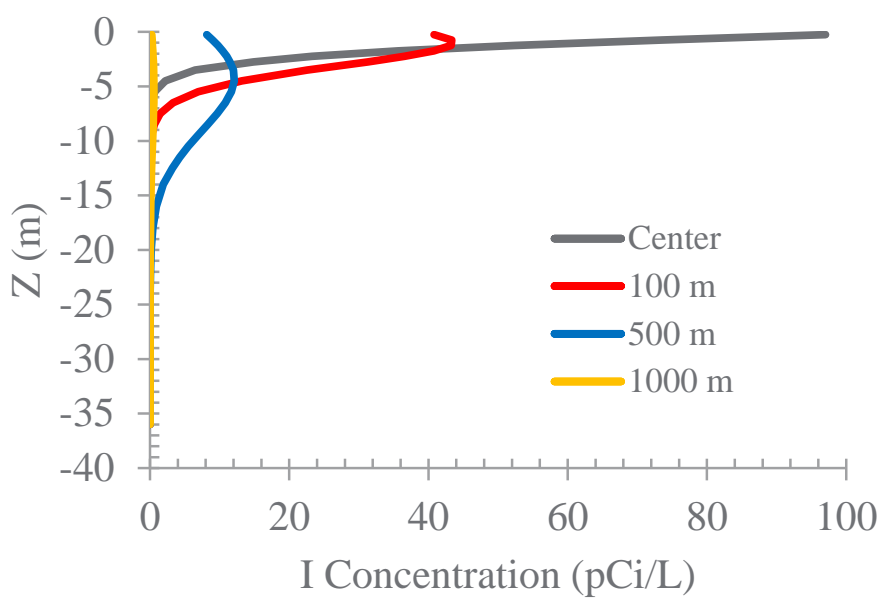

(c)

Figure 51. Predicted ${ }^{129}$ I groundwater concentrations at (a) 2000, (b) 2016, and (c) 2100 at various distances downstream of the footprint center of the S-7 crib for a $\mathrm{K}_{\mathrm{d}}=0.5 \mathrm{~mL} / \mathrm{g}$ (water table is at $z=0 \mathrm{~m}$ ). 
PNNL-24709, Rev. 2

RPT-DVZ-AFRI-030, Rev. 2

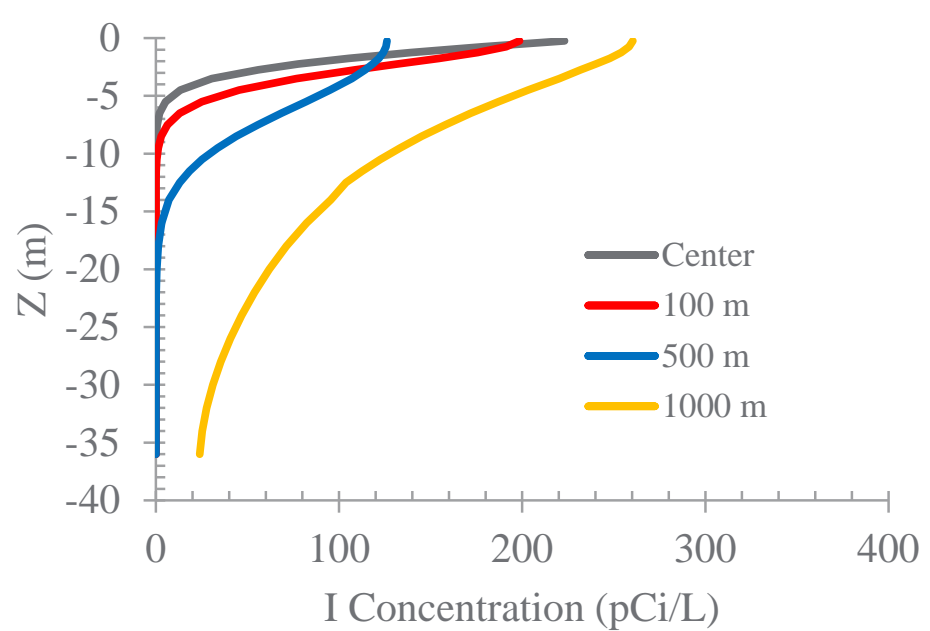

(a)

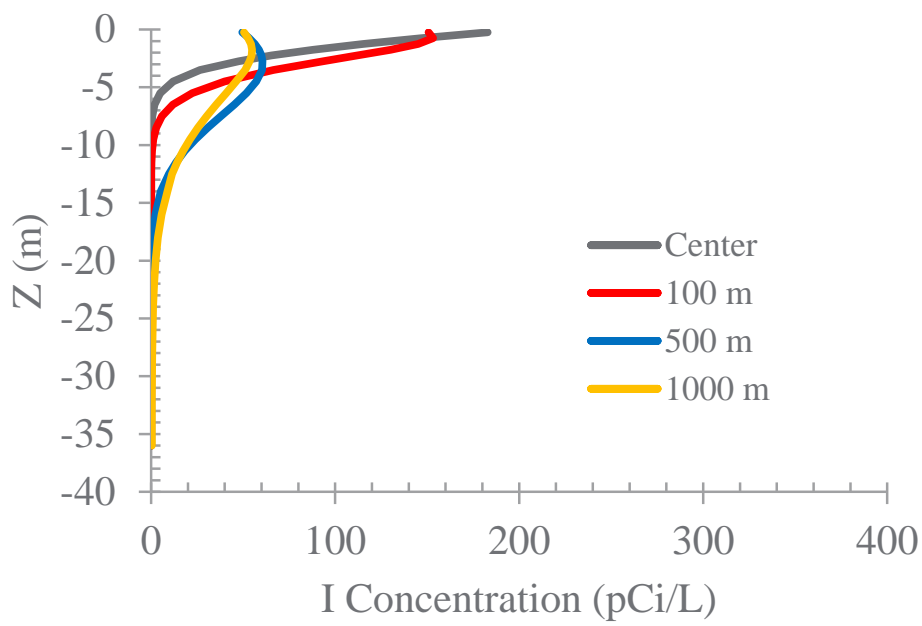

(b)

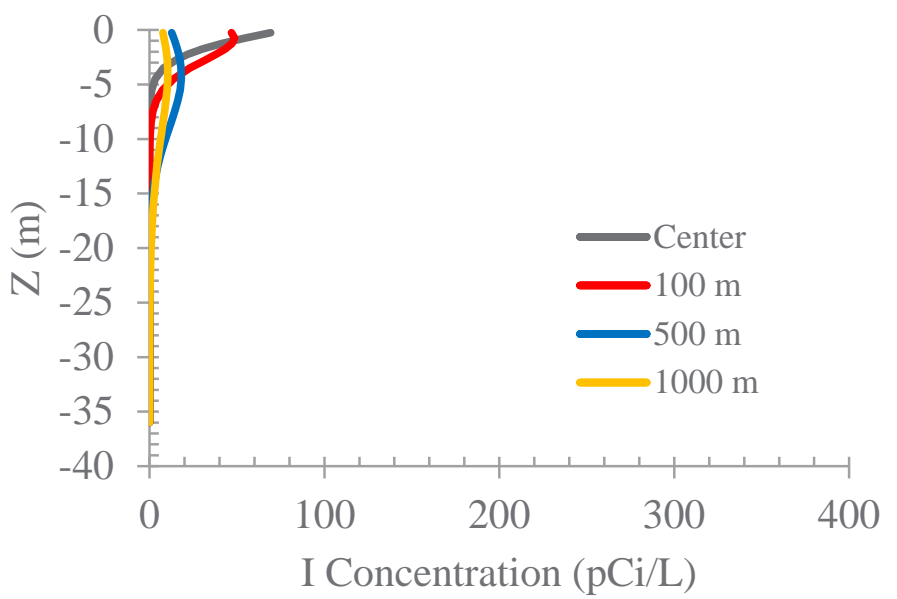

(c)

Figure 52. Predicted ${ }^{129}$ I groundwater concentrations at (a) 2000, (b) 2016, and (c) 2100 at various distances downstream of the footprint center of the S-7 crib for a $\mathrm{K}_{\mathrm{d}}=0 \mathrm{~mL} / \mathrm{g}$ and $k=0.01 / \mathrm{yr}$ (water table is at $z=0 \mathrm{~m}$ ). 
PNNL-24709, Rev. 2

RPT-DVZ-AFRI-030, Rev. 2

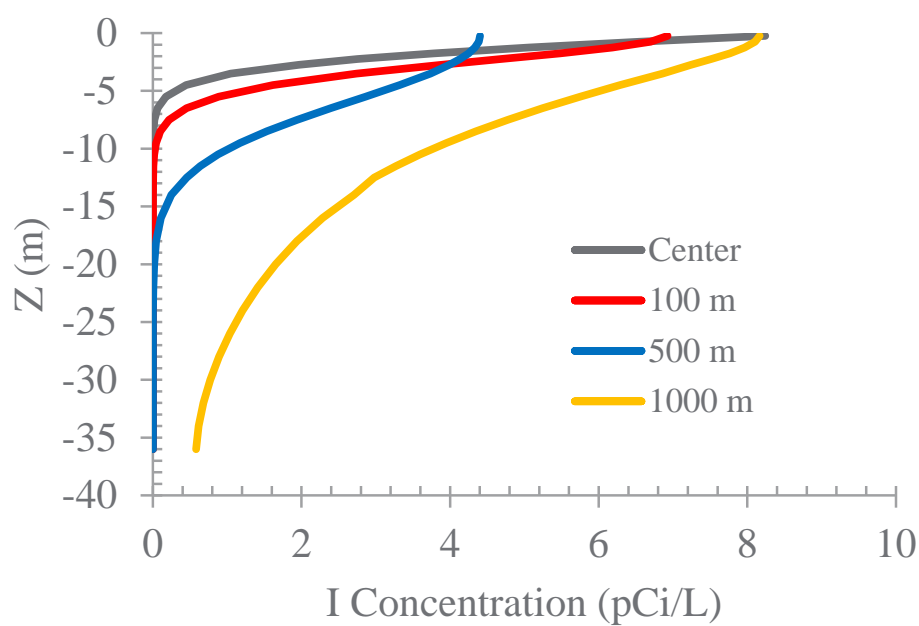

(a)

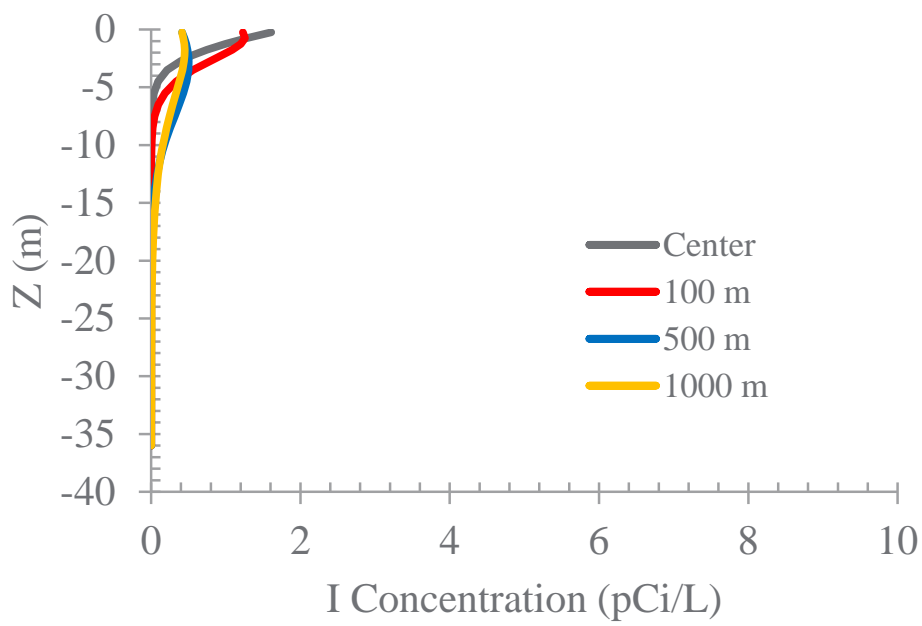

(b)

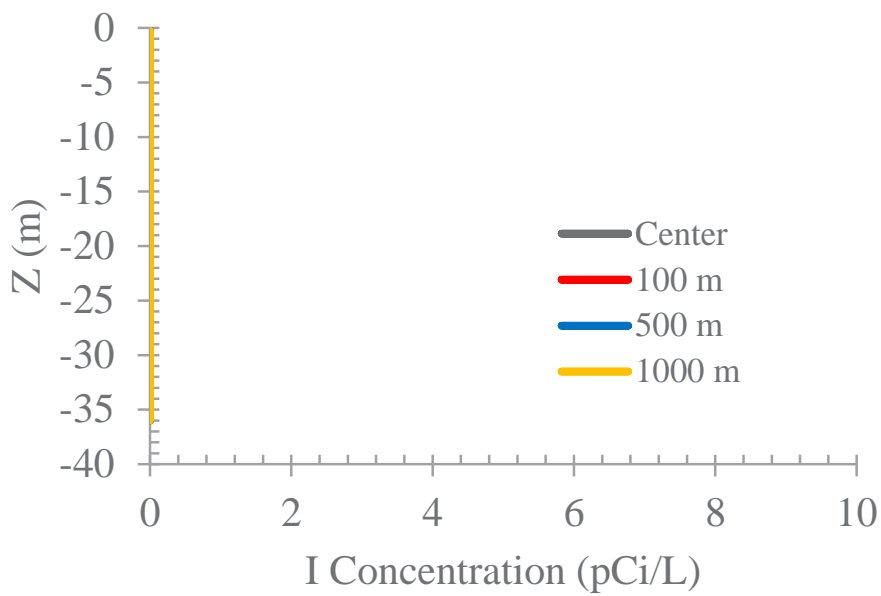

(c)

Figure 53. Predicted ${ }^{129}$ I groundwater concentrations at (a) 2000, (b) 2016, and (c) 2100 at various distances downstream of the footprint center of the S-7 crib for a $\mathrm{K}_{\mathrm{d}}=0 \mathrm{~mL} / \mathrm{g}$ and $k=0.1 / \mathrm{yr}$ (water table is at $z=0 \mathrm{~m}$ ). 
PNNL-24709, Rev. 2

RPT-DVZ-AFRI-030, Rev. 2

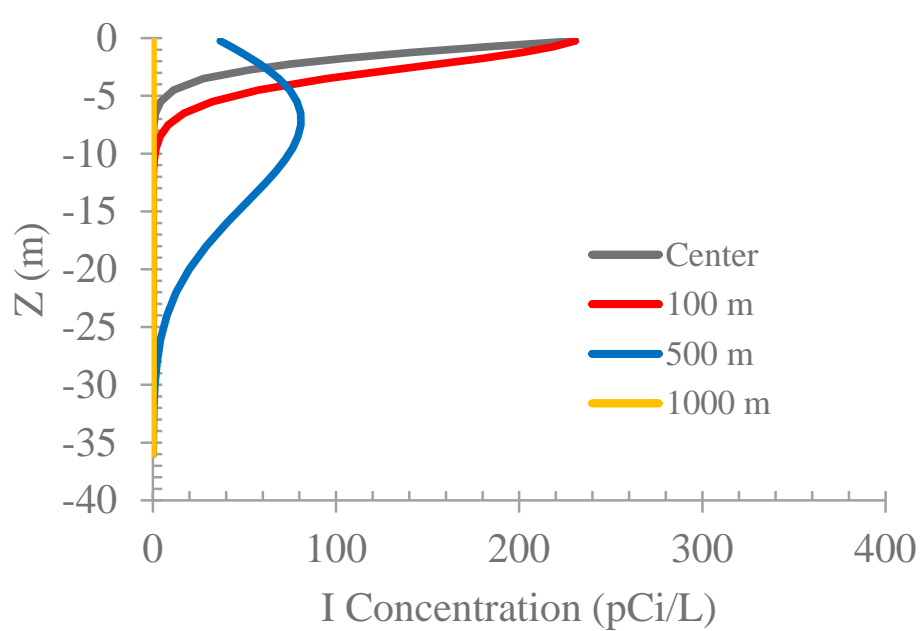

(a)

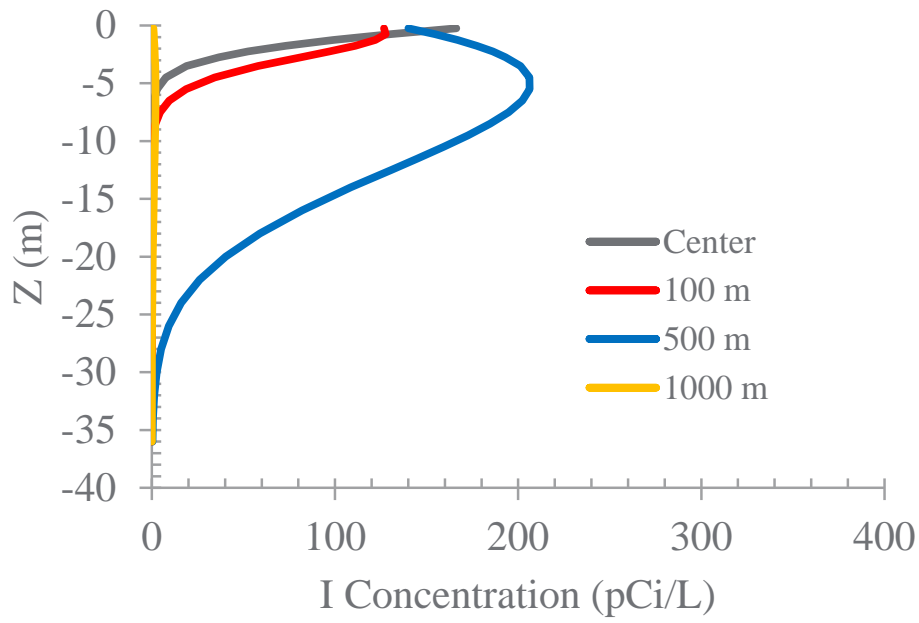

(b)

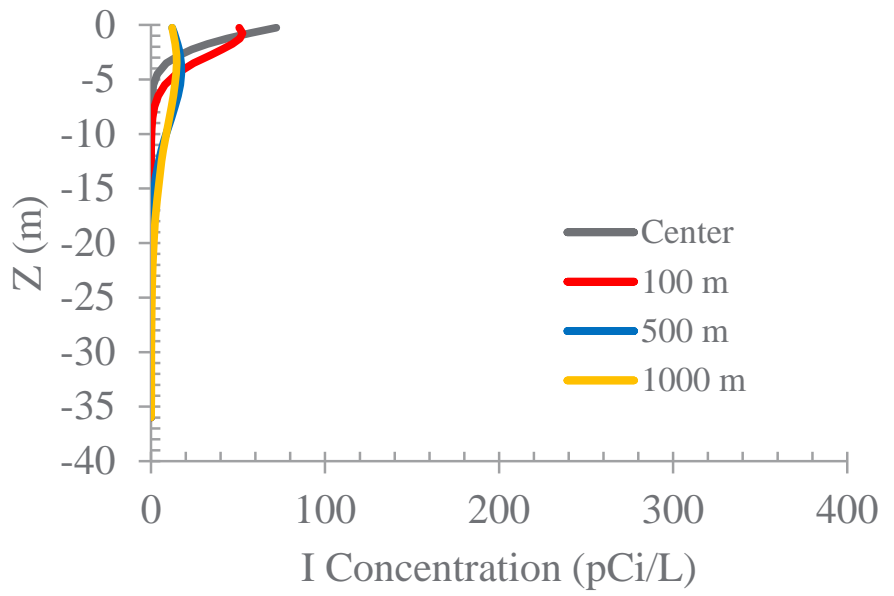

(c)

Figure 54. Predicted ${ }^{129}$ I groundwater concentrations at (a) 2000, (b) 2016, and (c) 2100 at various distances downstream of the footprint center of the S-7 crib for a $\mathrm{K}_{\mathrm{d}}=0.2 \mathrm{~mL} / \mathrm{g}$ and $k=$ $0.01 / \mathrm{yr}$ (water table is at $z=0 \mathrm{~m}$ ). 
PNNL-24709, Rev. 2

RPT-DVZ-AFRI-030, Rev. 2

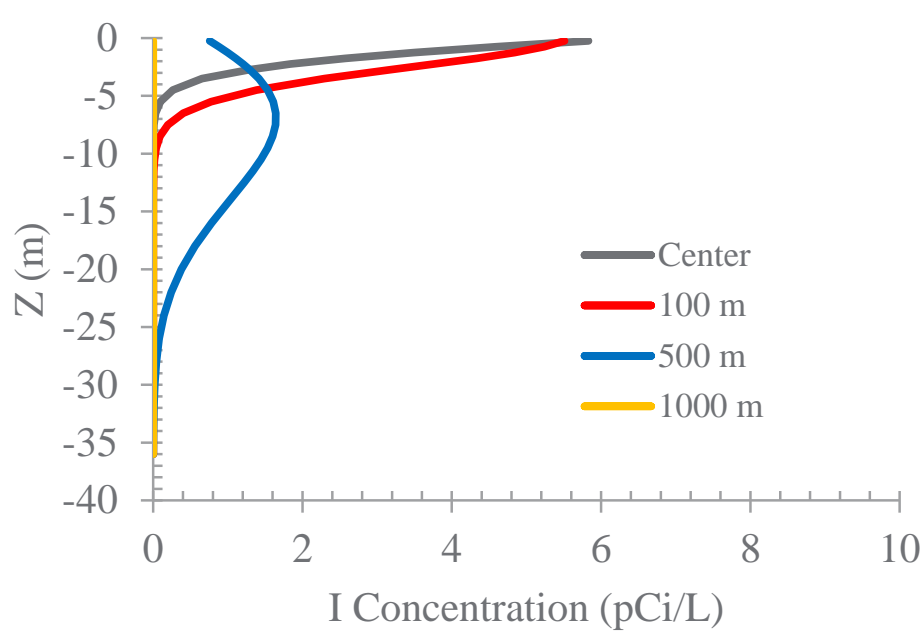

(a)

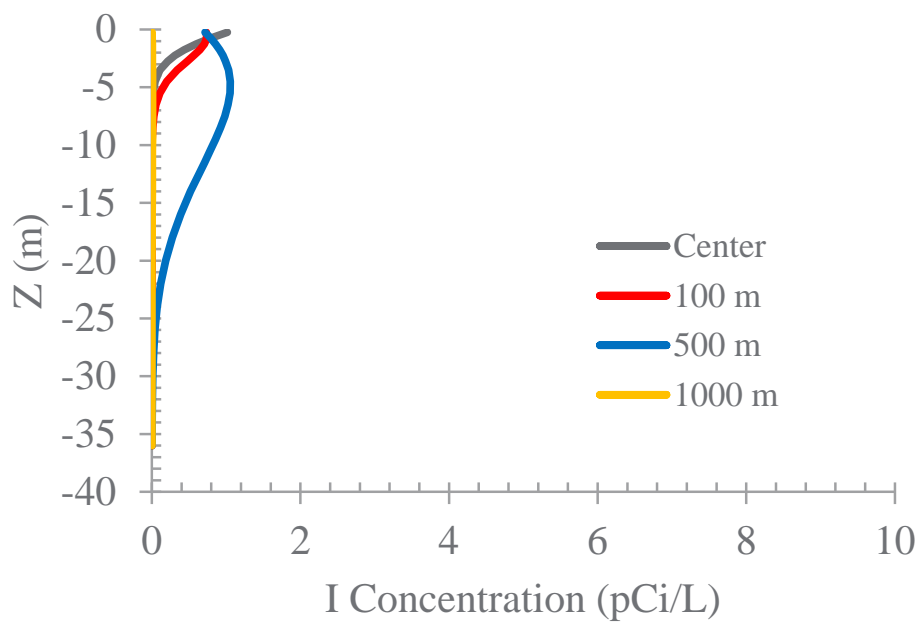

(b)

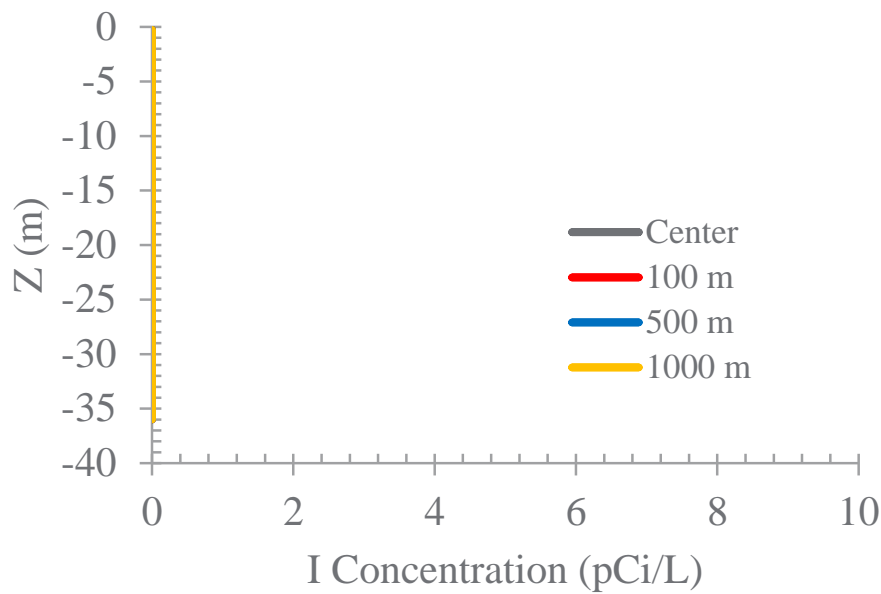

(c)

Figure 55. Predicted ${ }^{129}$ I groundwater concentrations at (a) 2000, (b) 2016, and (c) 2100 at various distances downstream of the footprint center of the S-7 crib for a $\mathrm{K}_{\mathrm{d}}=0.2 \mathrm{~mL} / \mathrm{g}$ and $k=$ $0.1 / \mathrm{yr}$ (water table is at $z=0 \mathrm{~m}$ ). 
The transects in Figure 50, representing Case 2 (Table 19) with a moderate $K_{d}=0.2 \mathrm{~mL} / \mathrm{g}$, also show a persistent source but also a rather late arrival of ${ }^{129} \mathrm{I}$ downstream. Figure 50b shows large concentrations at $500 \mathrm{~m}$ downstream of the crib at 2016, associated with the initial discharge. The contaminant arrival at $1000 \mathrm{~m}$ away from the crib only started to occur at 2100 . The late arrival patterns shown in Figure 50 are not corresponding with the large ${ }^{129}$ I plume that was already present at 1993 (Figure 39), suggesting that even a moderate $K_{d}$ value cannot explain the field observations. The effect of increasing $K_{d}$ value is further illustrated in Figure 51 . For a value of just $0.5 \mathrm{~mL} / \mathrm{g}$, downstream arrival is considerably delayed while the concentrations below the crib footprint increase with time.

The effects of the removal of non-sorbing ${ }^{129}$ I due to reaction with $k=0.01$ /year is shown in Figure 52. The reaction considerably decreases the predicted concentrations over time, compared to the nonreactive case results shown in Figure 49. The concentration predictions for this case are consistent with the field observations (Figure 41) and the declining contaminant plume shown in Figure 39. When increasing the reaction rate to 0.1/year, concentrations decrease rapidly (Figure 53), consistent with the discharge reduction for this case shown in Figure 48. The predictions for this high rate show that currently (Figure 53b) the predicted concentrations are mostly in the $1 \mathrm{pCi} / \mathrm{L}$ range, which is considerably lower than the field observations in Figure 41. Combining a moderate reaction rate of $k=0.01$ year with a $\mathrm{K}_{\mathrm{d}}=0.2 \mathrm{~mL} / \mathrm{g}$ yields a groundwater contaminant plume with increasing concentration at a kilometer downstream from the crib center (Figure 54b), which is also not consistent with field observations. Applying a higher reaction rate of 0.1 /year for the same $\mathrm{K}_{\mathrm{d}}$ results in rapidly declining concentrations (Figure 37), similar to what was predicted for the non-sorbing contaminant (Figure 53). Figure 53 and Figure 55 indicate that when rates of this magnitude are used for these simulations, reaction dominates the discharge behavior, resulting in rapid removal of the contaminants from the vadose zone.

${ }^{129}$ I disposal at the S-1/2 crib occurred with similar rates but over a shorter amount of time compared to the S-7 site (Table 19). The waste concentrations were similar. The shorter duration of the disposal results in initial peak discharge values that are smaller than for the S-7 site (Figure 56). For the same reason, the effects of sorption on discharge become evident at smaller values. For this site, only the simulation with a $\mathrm{K}_{\mathrm{d}}$ of 0 and $0.1 \mathrm{~mL} / \mathrm{g}$ lead to considerable initial peaks. For larger values, retardation results in a delayed arrival inconsistent with field observations. Interestingly, the cumulative arrival behavior for the $\mathrm{K}_{\mathrm{d}}=0.2 \mathrm{~mL} / \mathrm{g}$ simulation (Figure 57) is similar to the $\mathrm{K}_{\mathrm{d}}=0.5 \mathrm{~mL} / \mathrm{g}$ results shown in Figure 46. Superimposing reaction on non-sorbing and sorbing also results in similar trends (Figure 58) as for the S-7 crib (Figure 48). The main difference between the two cribs is that due to the smaller disposed volume of the S-1/2 crib, the range of $\mathrm{K}_{\mathrm{d}}$ and $k$ values resulting in predicted behavior consistent with field observation is slightly smaller than for the S-7 crib. 
PNNL-24709, Rev. 2 RPT-DVZ-AFRI-030, Rev. 2

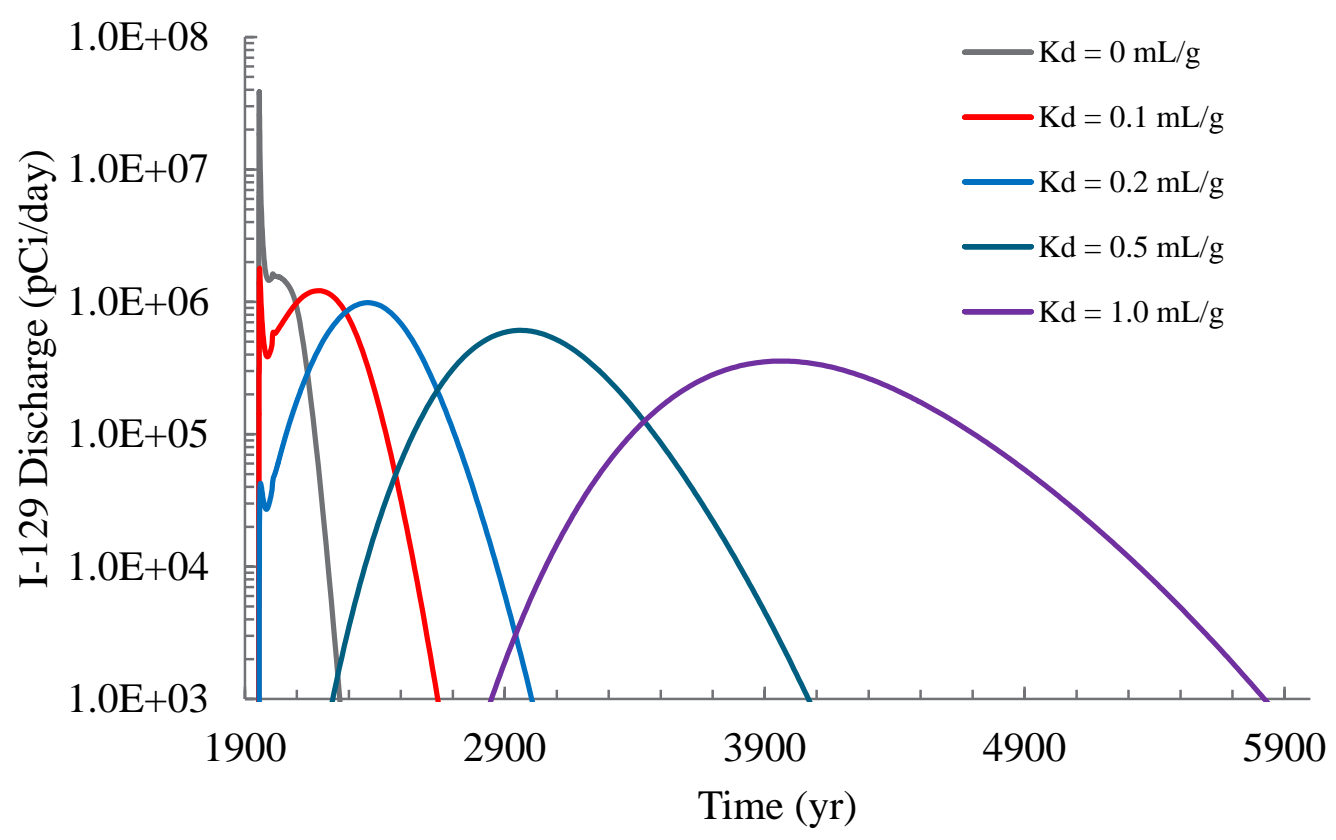

Figure 56. Predicted long-term ${ }^{129}$ I discharge across the water table emanating from the S-1/2 crib for various partition coefficient $\left(\mathrm{K}_{\mathrm{d}}\right)$ values.

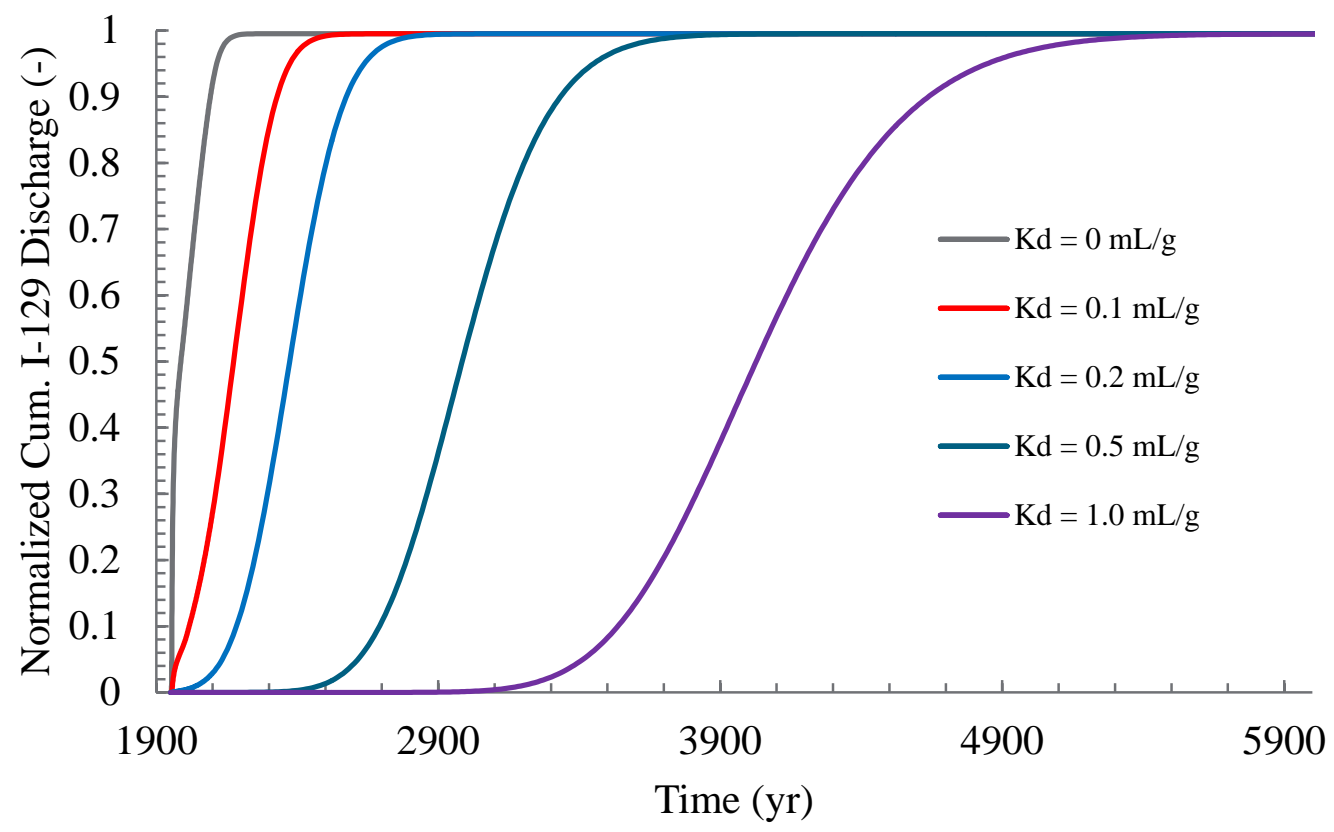

Figure 57. Predicted normalized cumulative ${ }^{129}$ I discharge across the water table emanating from the S- $1 / 2$ crib for various partition coefficient $\left(K_{d}\right)$ values. 
PNNL-24709, Rev. 2

RPT-DVZ-AFRI-030, Rev. 2

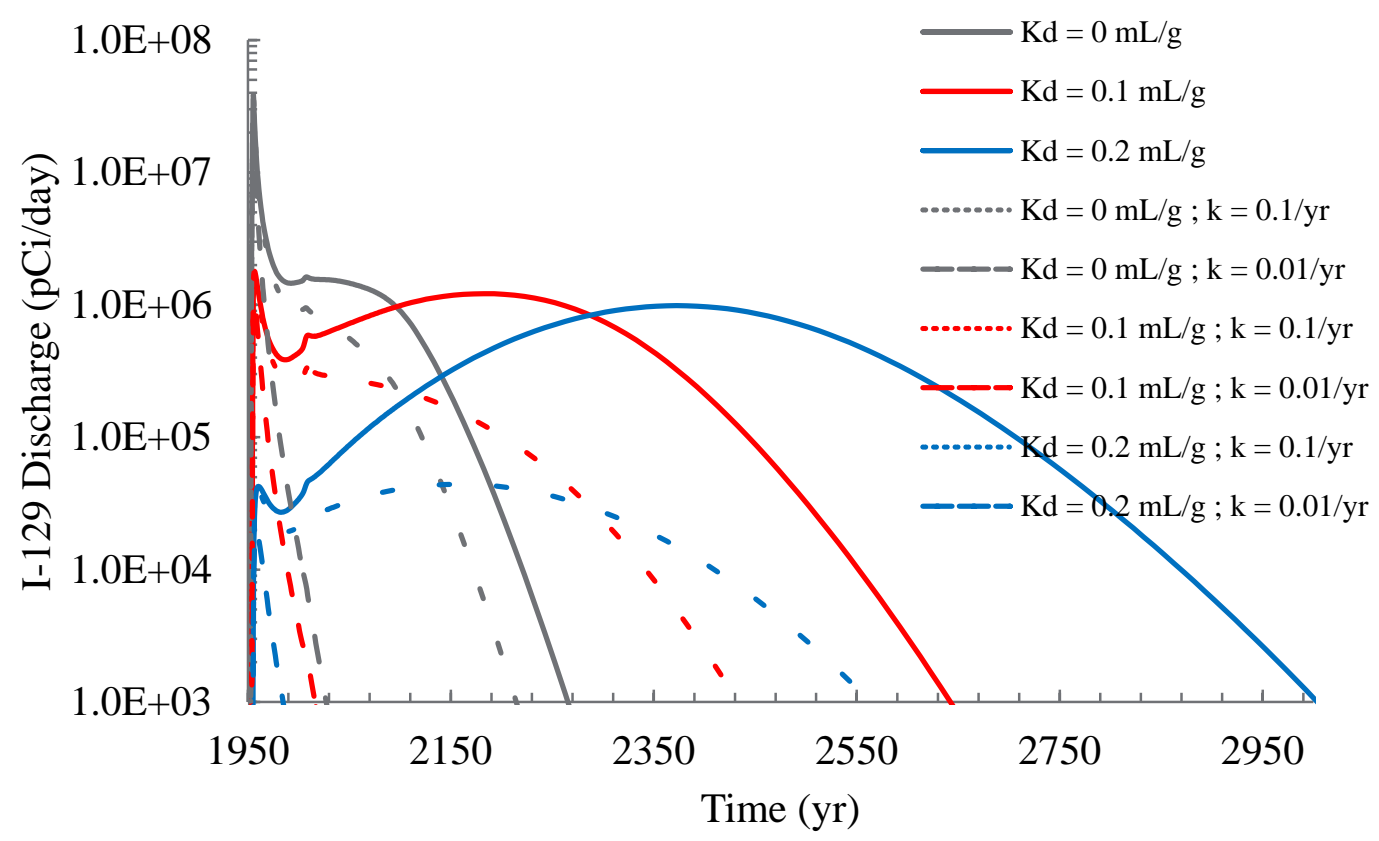

Figure 58. Predicted ${ }^{129}$ I discharge across the water table emanating from the $S-1 / 2$ crib for various $K_{d}$ values for various combinations partition coefficient $\left(K_{d}\right)$ and reaction rates $(k)$ values.

While current field data show ${ }^{129}$ I concentrations to be below $1 \mathrm{pCi} / \mathrm{L}$ near the S-1/2 and S-7 disposal sites, the ${ }^{129}$ I contaminant analysis estimates that current concentrations would be higher (though with a continually declining profile) for most considered combinations of $\mathrm{K}_{\mathrm{d}}$ values and reaction rate constants. For $\mathrm{K}_{\mathrm{d}}>0.2-0.5 \mathrm{~mL} / \mathrm{g}$, transport through the vadose zone is too retarded to explain previous and current concentrations. For lower values, sorption alone could only account for a portion of the concentration decrease needed to account for the observed difference between the observed and predicted ${ }^{129}$ I groundwater concentrations below the waste disposal sites. Reaction processes that transform iodine species and lead to compounds or conditions that sequester or remove iodine may also contribute to decreasing the groundwater concentration. Potential processes include iodate-calcite precipitation (Section 2.3.5), formation of Organo-I compounds that accumulate in sediment (Section 2.3.4), formation of volatile iodine compounds (e.g., methyl iodide, Section 2.3), and/or sediment dissolution/precipitation reactions that can lead to sequestration of contaminants (e.g., Truex et al. 2014). Adding a reaction that produces ${ }^{129}$ I in a form that is removed from transport (e.g., made functionally immobile or volatile) can lower predicted groundwater concentrations. As higher rates of this type of reaction are added, the contaminant discharge tail becomes more sharply declining. A combination of reaction and sorption is likely most appropriate and, if needed, information on reaction and sorption could be incorporated into a numerical model to best match the observed ${ }^{129}$ I plume data. However, under all cases, the contaminant flux to the groundwater at S-1/2 or S-7 cribs is not expected to increase in the future, and the site is currently in a declining tail portion of the contaminant discharge profile. Thus, if current concentrations are less than $1 \mathrm{pCi} / \mathrm{L}$ beneath these sites, the vadose zone source would not need to be remediated and the 200-UP-1 OU ${ }^{129}$ I plume can be addressed as a detached plume. 
PNNL-24709, Rev. 2

RPT-DVZ-AFRI-030, Rev. 2

\subsection{East Area}

In the 200 East Area, ${ }^{129}$ I plumes are present in the 200-PO-1 and 200-BP-5 OUs (Figure 59). In the 200-PO-1 OU (DOE 2014), high current and historical concentrations of iodine in the groundwater detected near the PUREX cribs and trenches (e.g., 216-A-10, 216-A-5, 216-A-6, and 216-A-45) and near the 216-A-29 ditch, 216-B-3 pond, and the 241-A and AX Tank Farms (WMA A-AX) point to this area as a primary source of the ${ }^{129} \mathrm{I}$ plume. ${ }^{129} \mathrm{I}$ in the northern portion of 200 East Area primarily migrated into the 200-BP-5 OU from the 200-PO-1 OU in the late 1980s and early 1990s (DOE 2014). Other potential sources of ${ }^{129}$ I are the BY cribs, an unplanned release at 241-BX-102, and the 216-B-8 crib.

Plume maps over a 20-year period beginning in 1993 show that the 200-PO-1 plume (primary plume in the 200 East Area) has oscillated in areal extent, but has remained of similar size (Figure 60). The overall plume extent (as defined by the $1 \mathrm{pCi} / \mathrm{L}$ contour) is very large and the plume thickness is up to tens of meters, although there is uncertainty in this estimate. The recent ${ }^{129}$ I concentrations are all below $10 \mathrm{pCi} / \mathrm{L}$. The temporal concentration profiles for the nine wells with historical ${ }^{129}$ I concentrations above $15 \mathrm{pCi} / \mathrm{L}$ are shown in Figure 61. These data show generally declining trends (though some show an initial increase followed by a decline), indicating a diminishing source. These data, in conjunction with the plume maps (Figure 60), are consistent with influences from historical pulses of iodine into the groundwater that have now diminished in magnitude. Because of the variations in groundwater flow direction, and a potential continuation of some contaminant flux from these source areas, the plume is still present beneath the former source areas. The recent plume map trends and declining plume concentrations are consistent with natural attenuation processes affecting the plume. However, ${ }^{129} \mathrm{I}$ currently in the vadose zone may still be a future source for groundwater contamination, even though the existing plume appears to be in a stable to declining condition.

Several co-contaminants are present within the 200 East Area ${ }^{129} \mathrm{I}$ plumes, including nitrate, ${ }^{99} \mathrm{Tc}$, uranium, and tritium. Nitrate, uranium, and technetium may be present in forms that could interact with the same reactive facies as ${ }^{129} \mathrm{I}$. 
PNNL-24709, Rev. 2

RPT-DVZ-AFRI-030, Rev. 2

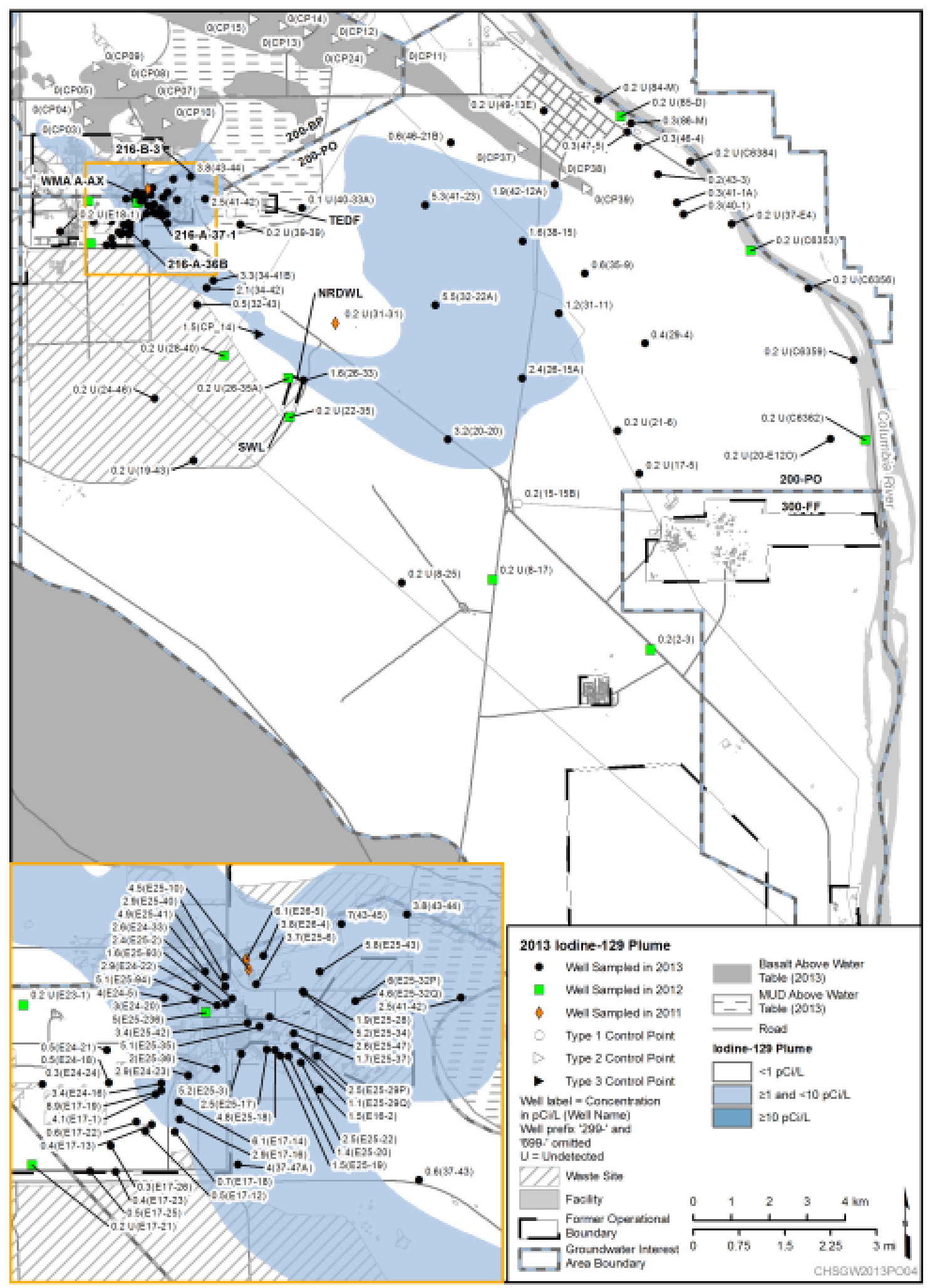

Figure 59. ${ }^{129}$ I groundwater contamination emanating from the 200 East Area (adapted from DOE 2014). 
PNNL-24709, Rev. 2

RPT-DVZ-AFRI-030, Rev. 2

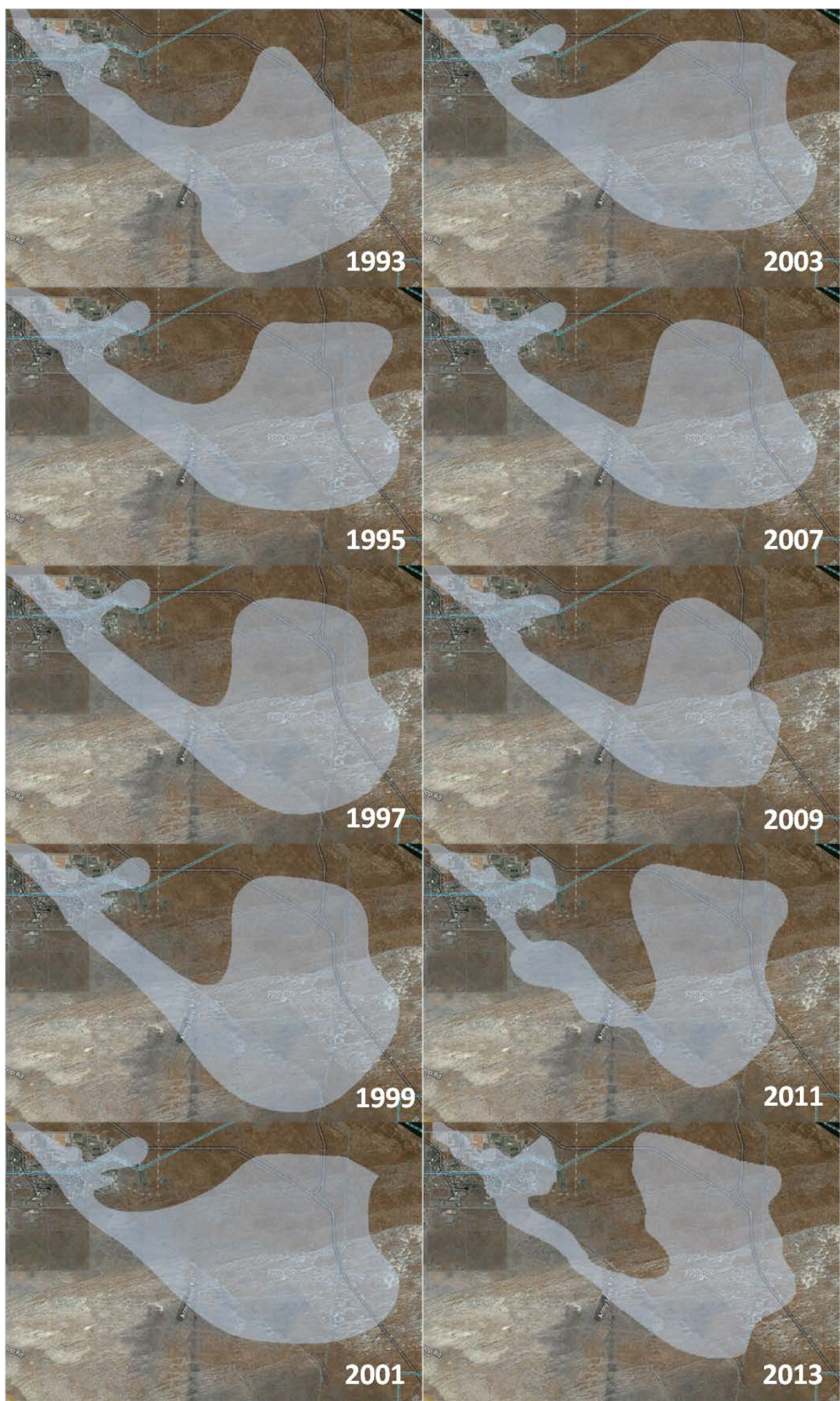

Figure 60. ${ }^{129}$ I plume depictions over a 20-year period for the 200-UP-1 OU. Plume images were obtained using the Plume Status feature of the PHOENIX web-based data tool for the Hanford Site (http://phoenix.pnnl.gov/apps/plumes/index.html, accessed on 8/18/2015). Note that the wells used for plume contouring has varied over time. 
PNNL-24709, Rev. 2

RPT-DVZ-AFRI-030, Rev. 2

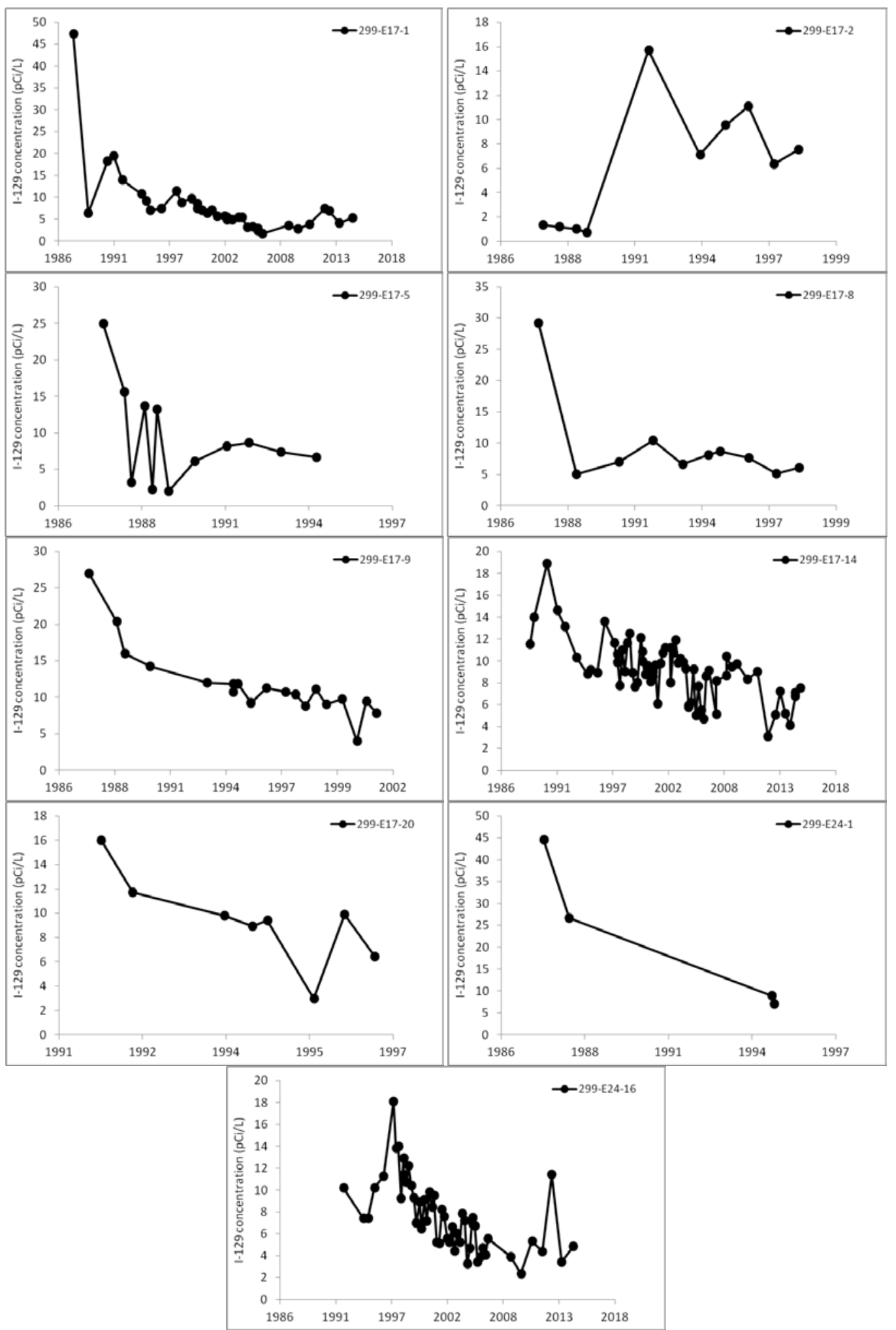

Figure 61. Temporal ${ }^{129}$ I concentration profiles in nine 200-PO-1 OU wells for which concentrations were historically greater than $15 \mathrm{pCi} / \mathrm{L}$. Data were obtained using the PHOENIX web-based data tool for the Hanford Site (http://phoenix.pnnl.gov/, accessed on 8/18/2015). 
PNNL-24709, Rev. 2

RPT-DVZ-AFRI-030, Rev. 2

Future plume behavior depends on fate and transport factors, including natural attenuation, and the nature of the continuing iodine contamination flux from the vadose zone. There are several potential alternative conceptual models for future plume behavior. Section 4.0 describes these alternative conceptual models and the type of data that can be used to select the one will best describe future plume behavior in support of remedy decisions. 
PNNL-24709, Rev. 2

RPT-DVZ-AFRI-030, Rev. 2

\subsection{Alternative Conceptual Models for Future Plume Behavior}

Several alternative conceptual models were developed to represent variations in the controlling factors for future iodine plume behavior. These alternatives are related to the types of groundwater iodine species present, whether or not specific transformation reactions are significant within the aquifer, and whether or not a significant flux of contaminants from the vadose zone will occur. Section 4.1 describes the alternative conceptual models. Sections 4.2 and 4.3 describe supporting data/research needs and recommendations for continued monitoring and characterization activities to help select the most valid conceptual model in support of future remedy decisions.

\subsection{Alternative Conceptual Models}

Four alternative conceptual models are described below. Current data are not sufficient to identify the most valid conceptual model, but strongly suggest that Alternative 2 is more valid than Alternative 1 and that Alternatives 3 and 4 are potential refinements to Alternative 2 that will have some additional effect on future plume behavior, especially in relation to the ability of natural attenuation to meet remediation objectives. Updated experimental results included in Revision 1 and Revision 2 of this document show that all of the attenuation mechanisms described in Alternative 4 are potentially viable. Resolving the importance of these mechanisms in the field is a primary target for the data gaps presented in Section 4.2.

- Alternative Conceptual Model 1. This conceptual model was used in the 200-UP-1 feasibility study for evaluating potential ${ }^{129}$ I remedies and led to the 200-UP-1 Record of Decision stating that additional evaluation of ${ }^{129}$ I remediation was required to support a final decision for ${ }^{129}$ I remediation. In this conceptual model, iodine was considered to be present only as iodide, with no transformation of iodide occurring over time. Thus, iodine transport was based on a $\mathrm{K}_{\mathrm{d}}$ value of $0.1 \mathrm{~mL} / \mathrm{g}$ and numerical model simulations showed the plume continuing to migrate as a detached plume over long distances and for a long timeframe prior to dissipating. Post-feasibility-study information from samples of 200 West Area groundwater (including samples within the 200-UP-1 OU) showed that iodine is present as a mix of iodide, iodate, and Organo-I species, with the iodate species being predominant. Thus, this alternative conceptual model is inconsistent with the existing iodine speciation data. Relative to the 200-UP-1 OU, this conceptual model also assumed that there is no future flux of ${ }^{129}$ I from the vadose zone that would cause a continuing source of contamination above cleanup levels. This aspect of Alternative Conceptual Model 1 is consistent with current observations of the 200-UP-1 groundwater plume, which is essentially detached from the disposal sites, and with the 200-UP-1 vadose zone evaluation in Section 3.1.2. However, the significance of continued vadose zone contaminant sources still needs to be verified for other ${ }^{129}$ I disposal sites in the Hanford Central Plateau.

- Alternative Conceptual Model 2. This conceptual model is based on the current information from samples of 200 West Area groundwater (including samples within the 200-UP-1 OU) that show iodine is present as a mix of iodide, iodate, and Organo-I species, with iodate being the predominant species. For this alternative, plume behavior would be impacted by differential transport of iodine species due to their different sorption characteristics (Section 2.3). These sorption characteristics would result in greater plume attenuation than with Alternative 1. (The iodate sorption extent is larger 
than iodide and iodate has the ability to be incorporated into calcite.) This alternative is for conditions where the transformation between iodine species over time is found to be insignificant. It will be important to evaluate the iodine species distribution throughout the plume and to assess transformation rates as part of evaluating the validity of this alternative. Current laboratory tests (Section 2.3) and results included in Revision 2 of this report show that transformations can occur in the Hanford 200-UP-1 OU or other aquifer sediments. As with Alternative 1, this conceptual model would be based on a condition with no future flux of ${ }^{129}$ I from the vadose zone that would cause a continuing source of contamination above cleanup levels. This aspect of the alternative is consistent with current observations of the 200-UP-1 groundwater plume, which is essentially detached from the disposal sites, and with the 200-UP-1 vadose zone evaluation in Section 3.1.2. However, the significance of continued vadose zone contaminant sources still needs to be verified for other ${ }^{129} \mathrm{I}$ disposal sites in the Hanford Central Plateau.

- Alternative Conceptual Model 3. This conceptual model is the same as Alternative 2 (based on data that show iodine is present as a mix of iodide, iodate, and Organo-I species), but considers the case where transformations occur over time and result primarily in shifting the relative percentages of iodide and iodate species in the subsurface. These transformations would then affect the plume behavior because of differential transport and sorption properties of iodine species and the potential for some mechanisms removing iodine from transport, such as adsorption and co-precipitation (Section 2.3). These conceptual model elements would result in greater plume attenuation than with Alternatives 1 and 2. It will be important to evaluate the iodine species distribution throughout the plume and to assess transformation rates as part of evaluating the validity of this alternative. Current laboratory tests (Section 2.3) show that transformations can occur in 200-UP-1 OU aquifer sediments. As with Alternative 1, this conceptual model would be based on a condition with no future flux of ${ }^{129} \mathrm{I}$ from the vadose zone that would cause a continuing source of contamination above cleanup levels. This aspect of the alternative is consistent with current observations of the 200-UP-1 groundwater plume, which is essentially detached from the disposal sites, and with the 200-UP-1 vadose zone evaluation in Section 3.1.2. However, the significance of continued vadose zone contaminant sources still needs to be verified for other ${ }^{129}$ I disposal sites in the Hanford Central Plateau.

- Alternative Conceptual Model 4. This conceptual model is the same as Alternative 3 (based on data that show iodine is present as a mix of iodide, iodate, and Organo-I species and that transformation can occur over time), but considers the case where transformations include significant formation of Organo-I species (based also on data generated during FY17 and included in this revision of the report in Section 2.3.4.1). These transformations would then affect the plume behavior because of differential transport of iodine species and the potential for some mechanisms removing iodine from transport (Section 2.3). However, in addition to the attenuation processes in Alternative 3, significant transformation to Organo-I species also creates additional loss mechanisms through accumulation as immobile organic deposits or through production of volatile Organo-I (e.g., methyl-iodide) species (Figure 9), in addition to losses from co-precipitation with calcium carbonate. These conceptual model characteristics would result in greater plume attenuation than with Alternatives 1,2 , or 3 . It will be important to evaluate the iodine species distribution throughout the plume and to assess transformation rates as part of evaluating the validity of this alternative. Current laboratory tests (Section 2.3 and results included in Revision 2 of this report show that transformations can occur in 200-UP-1 OU aquifer sediments). As with Alternative 1, this conceptual model would be based on a condition with no future flux of ${ }^{129}$ I from the vadose zone that would cause a continuing source of contamination above cleanup levels. This aspect of the alternative is consistent with current 
PNNL-24709, Rev. 2

RPT-DVZ-AFRI-030, Rev. 2

observations of the 200-UP-1 groundwater plume, which is essentially detached from the disposal sites, and with the 200-UP-1 vadose zone evaluation in Section 3.1.2. However, the significance of continued vadose zone contaminant sources still needs to be verified for other ${ }^{129}$ I disposal sites in the Hanford Central Plateau.

\subsection{Supporting Data and Research Needs}

The supporting data and research needs to help select the most valid conceptual model in support of future remedy decisions are described below in four categories. Resolving the importance of identified attenuation mechanisms in the field is a primary target for the data gaps

\section{- Environmental Data}

- Groundwater samples need to be analyzed to quantify the iodine species distribution throughout plumes (i.e., with distance from sources) using ${ }^{127} \mathrm{I}$ and ${ }^{129} \mathrm{I}$ data, as appropriate.

- Organo-iodine compounds should be identified in different areas of the Hanford subsurface. This information should build from the information describing the organic compounds present in Hanford groundwater and sediments (Sections 2.3.4.1 and 2.3.4.2).

- Information should be collected about the aqueous and sorbed iodine speciation at different Hanford subsurface locations. Arguments and data included in Revision 2 of this report, supported by previously literature, strongly suggest that iodate is the predominant species in the Hanford subsurface.

\section{- Evaluation of Transformation Reactions}

- The reaction rates of transformation identified as relevant for fate and transport should be quantified. This task will refine kinetic parameter estimates needed for fate and transport modeling based on the results of FY16 and FY17 studies.

- Redox reactions associated with iodide and iodate were investigated, showing iodate reduction in Hanford sediments have been observed (Section 2.3.3). Additional information about pathways and mechanisms of this transformation will assist in interpreting potential attenuation of the ${ }^{129} \mathrm{I}$ plume.

- Transformations to Organo-I species and their stability with respect to transformation back to iodide or iodate needs to be evaluated.

- The fate of transformation products (e.g., Organo-I accumulation, solubility, volatility) needs to be determined for key species that are expected end products of reactions.

- The effect of co-contaminants on the above transformation reactions needs to be evaluated.

\section{- Fate and Transport Parameters}

- Transport studies should be conducted to demonstrate important mechanisms identified in FY16 and FY17 that are suitable for use in numerical model validation. This task will provide data directly useful to refining the numerical transport models needed to evaluate iodine plume behavior. Improved sorption parameters for relevant iodine species and Hanford Site sediments and/or specific minerals are needed to support selection of appropriate parameter values for numerical models. 
PNNL-24709, Rev. 2

RPT-DVZ-AFRI-030, Rev. 2

- Stability of precipitated iodine materials with respect to dissolution should be further studied to define how to model the interaction with aqueous iodine species.

- The effect of co-contaminants on sorption and dissolution processes needs to be evaluated.

- Interpretation of transformation data as fate and transport parameters for application at the field scale is needed to support numerical model configuration.

\section{- Vadose Zone Evaluation}

- Evaluation of each iodine disposal site using the approach outlined by Truex and Carroll (2013) and Truex et al. (2015) was conducted for 200-UP-1 to evaluate the potential for continuing or future sources to groundwater. The evaluation suggests that the source areas for 200-UP-1 will not have significant additional ${ }^{129}$ I discharges to groundwater in the future. The study also suggested that sequestration mechanisms for iodine may have occurred in the vadose zone. Thus, future evaluation of these sequestration processes and study of other ${ }^{129}$ I discharge sites would be of value for interpreting the potential for continuing ${ }^{129}$ I sources to groundwater.

\subsection{Monitoring and Characterization Implications}

${ }^{129}$ I plume behavior in the 200 West Area will be influenced by current and planned pump-and-treat operations for up to 25 to 40 years. Thus, monitoring of plume concentration trends to assess fate and transport will be difficult. However, sampling to include "snapshots" of iodine speciation across the plume over time at a consistent set of monitoring wells would support (1) conceptual model evaluation and refinement in conjunction with laboratory testing of transformation and (2) development of better defined fate and transport parameters. In addition to iodine speciation, indicators of transformation that should be monitored include groundwater geochemistry, microbial indicators identified from ongoing research, ${ }^{127}$ I speciation, and co-contaminant concentrations.

${ }^{129}$ I plume behavior in the 200 East Area may be partially influenced by potential pump-and-treat operations in the 200-BP-5 OU. However, a large portion of the plume will remain unaffected by the pump-and-treat operations, and monitoring of plume concentration trends to assess fate and transport will be useful. As for the 200 West Area, 200 East Area sampling should include "snapshots" of plume concentrations over time at a consistent set of monitoring wells within the plume as a means to assess plume trends. In addition, this snapshot sampling should include evaluation of iodine speciation to support conceptual model evaluation and refinement in conjunction with laboratory testing of transformation and to better define fate and transport parameters. In addition to iodine speciation, indicators of transformation should be monitored, as described above for the 200 West Area.

Collection and analysis of characterization data to support estimating the future flux of ${ }^{129}$ I from the vadose zone, as described by Truex and Carroll (2013) and Truex et al. (2015), are also needed to as input for refining the conceptual model with respect to future plume behavior. 
PNNL-24709, Rev. 2

RPT-DVZ-AFRI-030, Rev. 2

\subsection{Quality Assurance}

The Pacific Northwest National Laboratory (PNNL) Quality Assurance (QA) Program is based upon the requirements as defined in DOE Order 414.1D, Quality Assurance, and 10 CFR 830, Energy/Nuclear Safety Management, Subpart A, Quality Assurance Requirements. PNNL has chosen to implement the following consensus standards in a graded approach:

- ASME NQA-1-2000, Quality Assurance Requirements for Nuclear Facility Applications, Part 1, Requirements for Quality Assurance Programs for Nuclear Facilities.

- ASME NQA-1-2000, Part II, Subpart 2.7, Quality Assurance Requirements for Computer Software for Nuclear Facility Applications, including problem reporting and corrective action.

- ASME NQA-1-2000, Part IV, Subpart 4.2, Guidance on Graded Application of Quality Assurance (QA) for Nuclear-Related Research and Development.

The procedures necessary to implement the requirements are documented through PNNL's "How Do I...? (HDI), a system for managing the delivery of laboratory-level policies, requirements, and procedures.

The DVZ-AFRI Quality Assurance Plan (QA-DVZ-AFRI-001) is the minimum applicable QA document for DVZ-AFRI projects under the NQA-1 QA program. This QA Plan also conforms to the QA requirements of DOE Order 414.1D, Quality Assurance, and 10 CFR830, Subpart A, Quality Assurance Requirements. The DVZ-AFRI is subject to the Price Anderson Amendments Act.

The implementation of the DVZ-AFRI QA program is graded in accordance with NQA-1-2000, Part IV, Subpart 4.2, Guidance on Graded Application of Quality Assurance (QA) for Nuclear-Related Research and Development. The two technology levels defined for this DVZ-AFRI QA Program that are applicable to this report are:

- Basic Research consists of research tasks that are conducted to acquire and disseminate new scientific knowledge.

- Applied Research consists of research tasks that acquire data and documentation necessary to assure satisfactory reproducibility of results.

The work for Revision 0 of this document was performed under the Basic Research level. For Revision 0, the effort was focused on compiling and synthesizing existing scientific and technical information into a conceptual model description. The work for Revision 1 and Revision 2 of this document included reporting the results of experimental efforts that were applied to address some of the data gaps identified in Revision 0. Therefore, the Revision 1 and Revision 2 work was conducted under the Applied Research level to ensure the reproducibility and defensibility of these experimental results. As such, reviewed calculation packages are available upon request for Revision 1 and Revision 2 experimental work except where experimental information is denoted as a scoping or preliminary study. In Revision 2, the organo-iodide work in Section 2.3.4.2, the KIO3-calcite experiments in Section 2.3.5, the solid phase characterization of calcite samples in Section 2.3.5.2, the scoping experiments in Section 2.3.5.3, and the modeling work (Section 2.3.6) was conducted as scoping work, and all results in these sections are considered FIO. The data in Section 2.3.5.1 is preliminary data, and as such should also be 
PNNL-24709, Rev. 2

RPT-DVZ-AFRI-030, Rev. 2

considered FIO. FIO data includes Figure 17 through Figure 24, Figure 27 through Figure 36, and Table 12 through Table 15.

The Applied Research portion of this work used PNNL's Environmental Sciences Laboratory (ESL) for chemical analyses required as part of laboratory and field experiments and testing. The ESL operates under a dedicated QA plan that complies with the Hanford Analytical Services Quality Assurance Requirements Document (HASQARD; DOE/RL-96-68), Rev. 3. ESL implements HASQARD through Conducting Analytical Work in Support of Regulatory Programs (CAWSRP). Data Quality Objectives established in CAWSRP were generated in accordance with HASQARD requirements. Chemical analyses of testing samples and materials were conducted under the ESL QA Plan. 


\subsection{Brief Summary of Recent Findings, Recommendations and Conclusions}

The research conducted in FY17 and included in Revision 2 of this report showed that:

- The solubility of the iodate-bearing calcite was not different from the solubility of pure calcite; therefore, the incorporation of the iodate in calcite may be considered as a potential remediation strategy for removal of aqueous iodate from contaminated sites at Hanford.

- Both co-precipitation and adsorption of iodate contributed to aqueous phase iodate attenuation. This does have implications on the natural attenuation pathway because calcite is a common mineral at the Hanford subsurface and may serve as a sorbent for iodate.

- Crystalline calcite formed in the precipitation experiments. Iodate appeared to be accumulated on regions close to the surface and crystal boundaries rather than in the bulk calcite structure. Additional transport experiments should determine the fraction of the solid-phase (i.e., calcite) associated iodate that may be released back into solution under Hanford subsurface relevant conditions.

- Among different factors considered in this effort, surface area and $\mathrm{pH}$ can significantly influence the extent of iodate incorporation into calcite. The charge compensation scheme involving $\mathrm{H}^{+}$appears to be a viable mechanism of iodate incorporation into calcite.

- For Organo-I complexes, (i) iodine speciation and the organic matter structures influence complexation, (ii) iodate binds more readily than iodide, (iii) cations present in Hanford AGW play a role in Organo-I binding, and (iv) the residence time influences binding kinetics. Based on these results, transport experiments should be designed and conducted to determine the mobility of the Organo-I species under Hanford relevant conditions and generate parameters for modeling.

- While the Organo-I complexation structures in the 200-UP-1 site at Hanford could not be confidently identified, the results suggested that these compounds exist at Hanford. The differences in organic matter composition indicated that pore water samples have a higher abundance of aromatic compounds that are a better target for iodine complexation. The standards and spiking experiments further revealed preferential binding of iodide/iodate to organic matter. Based on these results, transport experiments should be designed and conducted to determine the mobility of the Organo-I species under Hanford relevant conditions and generate parameters for modeling.

- Iodate was the predominant aqueous chemical species of iodine in groundwater samples at 200-UP-1. Additional arguments and thermodynamic considerations presented in this report support this important finding. Because the sorption and transport behavior of iodide and iodate are different, the remedial actions should focus more on the removal of aqueous iodate in the contaminated subsurface at Hanford.

- Microbiologically-mediated transformation of iodine species (i.e., iodate reduction to iodide) can occur fast ( $80 \%$ transformation in $<2$ days). The potential for species transformation should be considered when designing remedial strategies at Hanford.

- Iodate reduction to iodide was fast in the presence of strong reductants (such as ZVI and SMI) which can be used to remove redox sensitive contaminants such as Tc from the aqueous phase. Most of the aqueous iodate was rapidly transformed to iodide and, therefore, was not incorporated into calcite but, instead, remained in the aqueous phase. The iodate reduction to iodide was much faster than iodate 
incorporation into calcite, suggesting that this remedial pathway is not efficient in removing aqueous iodate when strong reductants are present. The remediation efforts should not only consider multiple interactions among contaminants, but also the coupled effects of natural attenuation pathways and those resulting from applying remediation technologies simultaneously targeting individual contaminants.

There are three basic components of the conceptual model: Inputs, Source Flux to Groundwater, and Plume Behavior. Inputs include information about ${ }^{129}$ I discharges to the subsurface and other boundary conditions (e.g., recharge from precipitation) that influence ${ }^{129}$ I fate and transport. Information is available from several sources to define the important input parameters. The source flux to groundwater component identifies factors important to consider in defining the nature of sources to historical, current, and future groundwater plumes. This information is needed to provide a context for examining fate and transport and remediation of groundwater plumes, which are the risk driver for remediation activities. Analyses completed to date to quantify potential future ${ }^{129}$ I flux to the groundwater suggest that for the 200-UP-1 OU, this flux will not add to the current plume. However, similar evaluations for other source areas are still needed. Prediction of plume behavior associated with ${ }^{129}$ I fate and transport is needed for risk assessment and to support remedy decisions and remedy design and implementation. Recent information describing the relative quantity of three primary iodine chemical species present in the groundwater (iodide, iodate, and organic-iodine complexes, with iodate being predominant) is pertinent to predicting plume behavior because each chemical species has different transport characteristics and may be subject to transformation reactions. The transformation reactions can change the relative quantity of chemical species, result in accumulation as a solid phase, or promote volatilization of iodine. The study of the transformation reactions would also provide information about the importance of the iodine species at the Hanford subsurface. Thus, transformation reactions are relevant to plume attenuation and for application of remediation technologies. Existing data describing iodine species transport properties and transformation reactions have been compiled. In addition, technical gaps were identified associated with the need to refine this information in support of future remedy decisions.

Because there are uncertainties in the iodine species transport parameters and transformation reactions with respect to plume behavior at the Hanford Site, alternative conceptual models were developed based on potential outcomes of ongoing research. The first two alternatives describe scenarios with different iodine chemical species controlling the overall transport behavior of ${ }^{129}$ I for a condition where no significant species transformation reactions are occurring. The other two alternatives describe scenarios where different types of transformation reactions are important. These alternative conceptual models provide a structure to guide development of studies that will help distinguish the alternative that best describes plume behavior as part of refining the iodine conceptual model for the Hanford Site and providing an appropriate technical basis for fate and transport analyses and remediation decisions.

Recommended additional efforts include (1) collecting appropriate environmental data, especially in relation to iodine chemical speciation; (2) refining information about observed sorption and transformation reactions and quantifying these reactions and processes for use in future remediationrelated analyses; (3) refining the values of iodine transport properties, especially considering the iodine chemical speciation and Hanford Site sediment characteristics; and (4) evaluating the potential for continuing or future sources to groundwater from vadose zone sources other than at the 200-UP-1 OU. In conjunction with these efforts, monitoring and characterization efforts in ${ }^{129}$ I-contaminated zones should 
PNNL-24709, Rev. 2

RPT-DVZ-AFRI-030, Rev. 2

be designed to support the above studies and to provide enhanced information about plume behavior through collection of plume trend information.

Because there are identified data gaps and several potential alternative conceptual models for ${ }^{129} \mathrm{I}$ behavior at the Hanford Site, it is recommended that a periodic update to the conceptual model be published as the conceptual model is refined. 
PNNL-24709, Rev. 2

RPT-DVZ-AFRI-030, Rev. 2

\subsection{References}

10 CFR 830. 2011. “Nuclear Safety Management.” Code of Federal Regulations, U.S. Department of Energy, Washington, D.C.

Amachi, S., Kasahara, M., Hanada, S., Kamagata, Y., Shinoyama, H., Fujii, T., and Muramatsu, Y. 2003. "Microbial Participation in Iodine Volatilization from Soils.” Environ. Sci. Tech., 37(17):3885-3890.

Amachi, S., Kasahara, M., Fujii, T., Shinoyama, H., Hanada, S., Kamagata, Y., Ban-Nai, T., and Muramatsu, Y. 2004. "Radiotracer Experiments on Biological Volatilization of Organic Iodine from Coastal Seawaters.” Geomicrobiology J., 21(7):481-488.

ASME NQA-1-2000, Quality Assurance Requirements for Nuclear Facility Applications. American Society of Mechanical Engineers, New York.

Bayer, T.S., Widmaier, D.M., Temme, K., Mirsky, E.A., Santi, D.V., and Voigt, C.A. 2009. "Synthesis of Methyl Halides from Biomass Using Engineered Microbes." Journal of the American Chemical Society 131(18):6508-6515.

Burns, P.C., and Hawthorne, F.C. 1993. "The Crystal Structure of Dietzeite, Ca2H2O(IO3)2(CrO4), a Heteropolyhedral Framework Mineral.” Canadian Mineralogist, 31:313-319.

Bustad, L.K., Book, S.A., Garner, R.J., Soldat, J.K., Brauer, F.P., and Burger, L.L. 1983. Iodine-129: Evaluation of Releases from Nuclear Power Generation. Report No. 075, National Council on Radiation Protection and Measurements, Bethesda, Maryland.

Cantrell, K.J., Serne, R.J., and Last, G.V. 2003. Hanford Contaminant Distribution Coefficient Database and Users Guide. PNNL-13895, Rev. 1, Pacific Northwest National Laboratory, Richland, Washington.

Cheng, H.-Y., Masiello, C.A., Bennett, G.N., and Silberg, J.J. 2016. “Volatile Gas Production by Methyl Halide Transferase: An In Situ Reporter of Microbial Gene Expression in Soil.” Environmental Science \& Technology, 50(16):8750-8759.

Corbin, R.A., Simpson, B.C., Anderson, M.J., Danielson, W.F., Field, J.G., Jones, T.E., and Kincaid, C.T. 2005. Hanford Soil Inventory Model, Revision 1. RPP-26744, Rev. 0, CH2M Hill Hanford Group, Inc., Richland, Washington.

DOE. 1994. 100 Area Soil Washing Bench Scale Tests. DOE/RL-93-107, Draft A, U.S. Department of Energy, Richland Operations Office, Richland, Washington. Available at: http://www5.hanford.gov/arpir/?content=findpage\&AKey=D196101077.

DOE. 2005. Technical Guidance Document for Tank Closure Environmental Impact Statement Vadose Zone and Groundwater Revised Analyses, Final Rev. 0. U.S. Department of Energy, Richland, Washington. Available at: http://www.hanford.gov/files.cfm/TCEISVadose.pdf.

DOE. 2007. Hanford Analytical Services Quality Assurance Requirements Document, Volumes 1 and 4. DOE/RL-96-68, U.S. Department of Energy, Richland, Washington. 
PNNL-24709, Rev. 2

RPT-DVZ-AFRI-030, Rev. 2

DOE. 2012a. Final Tank Closure and Waste Management Environmental Impact Statement for the Hanford Site, Richland, Washington. DOE/EIS-0391, U.S. Department of Energy, Richland, Washington.

DOE. 2012b. Remedial Investigation/Feasibility Study for the 200-UP-1 Groundwater Operable Unit. DOE/RL-2009-122, U.S. Department of Energy, Richland Operations Office, Richland, Washington.

DOE. 2014. Hanford Site Groundwater Monitoring Report for 2013. DOE-RL-2014-32, Rev. 0, U.S. Department of Energy, Richland Operations Office, Richland, Washington.

DOE Order 414.1D, Quality Assurance. U.S. Department of Energy, Washington, D.C. Approved $4 / 25 / 2011$.

Eslinger, P.W., Kincaid, C.T., Nichols, W.E., and Wurstner, S.K. 2006. A Demonstration of the System Assessment Capability (SAC) Rev. 1 Software for the Hanford Remediation Assessment Project. PNNL-16209, Pacific Northwest National Laboratory, Richland, Washington.

Farrenkopf, A.M., Dollhopf, M.E., Chadhain, S.N., Luther, G.W., III, and Nealson, K.H. 1997. "Reduction of iodate in seawater during Arabian Sea shipboard incubations and in laboratory cultures of the marine bacterium Shewanella putrefaciens strain MR-4.” Marine Chemistry, 57(3-4):347-354.

Fayer, M.J., and Keller, J.M. 2007. Recharge Data Package for Hanford Single-Shell Tank Waste Management Areas. PNNL-16688, Pacific Northwest National Laboratory, Richland, Washington.

Fehn, U. 2012. “Tracing Crustal Fluids: Applications of Natural ${ }^{129} \mathrm{I}$ and ${ }^{36} \mathrm{Cl} . ”$ Annual Rev. Earth Planetary Sci., 40(1):45-67.

Freshley, M.D., and Graham, M.J. 1988. Estimation of Ground-Water Travel Time at the Hanford Site: Description, Past Work, and Future Needs. PNL-6328, Pacific Northwest Laboratory, Richland, Washington.

Fuse, H., Inoue, H., Murakami, K., Takimura, O., and Yamaoka, Y. 2003. "Production of Free and Organic Iodine by Roseovarius spp.” FEMS Microbiology Letters, 229(2):189-194.

Geiszler, KN. 2016. Solubilization of Metals from Solids Using a KOH-KNO3 Fusion. PNNL-ESLFusion Rev. 2, PNNL, Richland, WA.

Gephart, R.E. 2003. Hanford: A Conversation About Nuclear Waste and Cleanup. Battelle Press, Columbus, Ohio.

Ghose, S., Wan, C., and Wittke, O. 1978. “The crystal structure of synthetic lautarite, $\mathrm{Ca}\left(\mathrm{IO}_{3}\right)_{2}$." Acta Crystallographica B, 34:84-88.

Harkness, J.S., Dwyer, G.S., Warner, N.R., Parker, K.M., Mitch, W.A., and Vengosh, A. 2015. “Iodide, Bromide, and Ammonium in Hydraulic Fracturing and Oil and Gas Wastewaters: Environmental Implications.” Environ. Sci. Tech., 49(3):1955-1963. 
PNNL-24709, Rev. 2

RPT-DVZ-AFRI-030, Rev. 2

Higley, B.A., Place, D.E., Corbin, R.A., and Simpson, B.C. 2004. Hanford Defined Waste ModelRevision 5.0. RPP-19822, Rev. 0, CH2M Hill Hanford Group, Inc., Richland, Washington.

Hou, X., Hansen, V., Aldahan, A., Possnert, G., Lind, O.C., and Lujaniene, G. 2009. “A Review on Speciation of Iodine-129 in the Environmental and Biological Samples.” Analytica Chimica Acta, 632(2):181-196.

Hou, X., Povinec, P.P., Zhang, L., Shi, K., Biddulph, D., Chang, C.-C., Fan, Y., Golser, R., Hou, Y., Ješkovský, M., Jull, A.J.T., Liu, Q., Luo, M., Steier, P., and Zhou, W. 2013. “Iodine-129 in Seawater Offshore Fukushima: Distribution, Inorganic Speciation, Sources, and Budget.” Environ. Sci. Tech., 47(7):3091-3098.

Ihssen, J., Schubert, M., Thöny-Meyer, L., and Richter, M. 2014. "Laccase Catalyzed Synthesis of Iodinated Phenolic Compounds with Antifungal Activity.” PloS One 9(3): e89924; http://dx.doi.org/10.1371/journal.pone.0089924.

Kampschreur, M. J., Kleerebezem, R., Picioreanu, C., Bakken, L.R., Bergaust, L., de Vries, S., Jetten, M.S.M., and Van Loosdrecht, M.C.M. 2012. "Metabolic modelling of denitrification in Agrobacterium tumefaciens: a tool to study inhibiting and activating compounds for the denitrification pathway.” Frontiers in Microbiology 3. doi:10.3389/fmicb.2012.00370.

Kantelo, M.V., Bauer, L.R., Marter, W.L., Murphy Jr., C.E., and Zeigler, C.C. 1990. Radioiodine in the Savannah River Site Environment. Westinghouse Savannah River Company, Aiken, South Carolina.

KAPL. 2010. Nuclides and Isotopes: Chart of the Nuclides, 17th Edition. Knolls Atomic Power Laboratory, Niskayuna, New York.

Kaplan, D.I., Mattigod, S.V., Parker, K., and Iversen, G. 2000. I-129 Test and Research to Support Disposal Decisions. WSRC-TR-2000-00283, Rev. 0, Savannah River National Laboratory, Aiken, South Carolina.

Kaplan, D.I., Yeager, C., Denham, M.E., Zhang, S., Xu, C., Schwehr, K.A., and Santschi, P.H. 2012. Biogeochemical Considerations Related to the Remediation of I-129 Plumes. SRNL-STI-2012-00425, Savannah River Site, Aiken, South Carolina.

Kaplan, D.I., Denham, M.E., Zhang, S., Yeager, C., Xu, C., Schwehr, K.A., Li, H.P., Ho, Y.F., Wellman, D., and Santschi, P.H. 2014. "Radioiodine biogeochemistry and prevalence in groundwater.” Critical Reviews in Environmental Science and Technology, 44:22872335.

Kerisit, S., Marmier, A., and Parker, S.C. 2005. “Ab initio surface phase diagram of the $\{10-14\}$ calcite surface.” The Journal of Physical Chemistry B Letters, 109:18211-18213.

Kim, S., Kramer, R.W., and Hatcher, P.G. 2003. “Graphical Method for Analysis of UltrahighResolution Broadband Mass Spectra of Natural Organic Matter, the Van Krevelen Diagram.” J. Am. Chem. Soc., 75:5336-5344. 
PNNL-24709, Rev. 2

RPT-DVZ-AFRI-030, Rev. 2

Kostka, J., and Nealson, KH. 1998. "Isolation, Cultivation, and Characterization of Iron- and ManganeseReducing Bacteria.” In Techniques in Microbial Ecology, Eds. R.S. Burlage, R. Atlas, D. Stahl, G. Geesey, and G. Sayler. Oxford University Press, New York.

Kresse, G., and Hafner, J. 1993. “Ab initio molecular dynamics for liquid metals.” Physical Review B, 47:558-561.

Kresse, G., and Furthmuller, J. 1996a. "Efficient iterative schemes for ab initio total-energy calculations using a plane-wave basis set.” Physical Review B, 54:11169-11186.

Kresse, G., and Furthmuller, J. 1996b. "Efficiency of ab-initio total energy calculations for metals and semiconductors using a plane-wave basis set.” Computational Materials Science, 6:1550 .

Kulys, J., Bratkovskaja, I., and Vidziunaite, R. 2005. "Laccase-catalysed iodide oxidation in presence of methyl syringate.” Biotechnology and Bioengineering, 92(1):124-128.

Kujawinski, E.B., and Behn, M.D. 2006. “Automated analysis of electrospray ionization Fourier transform ion cyclotron resonance mass spectra of natural organic matter.” Anal. Chem., 78:4363-4373.

Last, G.V., Freeman, E.J., Cantrell, K.J., Fayer, M.J., Gee, G.W., Nichols, W.E., Bjornstad, B.N., and Horton, D.G. 2006a. Vadose Zone Hydrogeology Data Package for Hanford Assessments. PNNL-14702, Rev. 1, Pacific Northwest National Laboratory, Richland, Washington.

Last, G.V., Nichols, W.E., and Kincaid, C.T. 2006b. Geographic and Operational Site Parameters List (GOSPL) for Hanford Assessments. PNNL-14725, Rev. 1, Pacific Northwest National Laboratory, Richland, Washington.

Last, G.V., Rockhold, M.L., Murray, C.J., and Cantrell, K.J. 2009. Selection and Traceability of Parameters to Support Hanford-Specific RESRAD Analyses, Fiscal Year 2008 Status Report. PNNL-18564, Pacific Northwest National Laboratory, Richland, Washington.

Laurencin, D., Vantelon, D., Briois, V., Gervais, C., Coulon, A., Grandjean, A., and Campayo, L. 2014. "Investigation of the local environment of iodate in hydroxyapatite by combination of X-ray absorption spectroscopy and DFT modeling.” RSC Advances, 4:14700-14707.

Lindberg, R.D., and Runnells, D.D. 1984. “Ground Water Redox Reactions: An Analysis of Equilibrium State Applied to $\mathrm{E}_{\mathrm{h}}$ Measurements and Geochemical Modeling.” Science, 225:925-927.

Lee, B.D., Ellis, J.T., Eisenhauer, E.E.R., Saurey, S.D., and Lee, M.H. 2015. “Microbial Diversity of Bacterial Communities Indigenous to 129I-Contaminated Groundwater Plumes at the Hanford Site, Washington.” Submitted to Microbial Ecology.

Lee, B.D., Lee, M.H., McDonald, J., Brooks, S., Truex, M., Qafoku, N., and Szecsody, J. 2017. "Changes in Iodine Speciation Across the Length of the Hanford 200-UP-1 Operable Unit Radioiodine Plume and Possible Biogeochemical Drivers of Speciation.” Proceedings WM2017, Phoenix, Arizona. March 2017. 
Lu, Z., Jenkyns, H.C., and Rickaby, R.E.M. 2010. "Iodine to calcium ratios in marine carbonate as a paleo-redox proxy during oceanic anoxic events.” Geology, 38:1107-1110.

Luther, G.W., III. 2011. “Thermodynamic Redox Calculation for One and Two Electron Transfer Steps: Implications for Halide Oxidation and Halogen Environmental Cycling.” In Aquatic Redox Chemistry, Tratnyek, P., Grundl, T.J., Haderlein, S.B., Eds. American Chemical Society, Washington, DC. Chapter 2, pp 15-35.

Mackley, R.D., Last, G.V., Serkowski, J.A., Middleton, L.A., and Cantrell, K.J. 2010. MinChem: A Prototype Petrologic Database for Hanford Site Sediments. PNNL-19803, Pacific Northwest National Laboratory, Richland, Washington.

Minor, E.C., Steinbring, C.J., Longnecker, K., and E.B. Kujawinski. 2012. “Characterization of dissolved organic matter in Lake Superior and its watershed using ultrahigh resolution mass spectrometry.” Org. Geochem., 43:1-11.

Mok, J.-K., Toporek, Y.K., Shin, H.-D., Lee, B.D., Lee, M.H., and DiChristina, T.J. (In Review). “Iodate Reduction by Shewanella oneidensis Does Not Involve Nitrate Reductase.”

Geomicrobiol. J.

Mualem Y. 1976. “A new model predicting the hydraulic conductivity.” Geoderma, 65:81-92.

Muramatsu, Y., and Wedepohl, K.H. 1998. "The Distribution of Iodine in the Earth’s Crust.” Chemical Geology, 147(3):201-216.

Muramatsu, Y., Yoshida, S., Uchida, S., and Hasebe, A. 1996. "Iodine Desorption from Rice Paddy Soil.” Water, Air, and Soil Pollution, 86(1-4):359-371.

Muramatsu, Y., Yoshida, S., Fehn, U., Amachi, S., and Ohmomo, Y. 2004. "Studies with Natural and Anthropogenic Iodine Isotopes: Iodine Distribution and Cycling in the Global Environment.” J. Environ. Radioactivity, 74(1-3):221-232.

NNDC. 2015. “Decay Radiation Search, NuDat 2 Database, version 2.6” (web page). National Nuclear Data Center, Brookhaven National Laboratory, Upton, New York. Available at: http://www.nndc.bnl.gov/nudat2/indx_dec.jsp. Accessed Sep. 10, 2015.

Podder, J., Lin, J., Sun, W., Botis, S.M., Tse, J., Chen, N., Hu, Y., Li, D., Seaman, J., and Pan, Y. 2017. "Iodate in calcite and vaterite: Insights from synchrotron X-ray absorption spectroscopy and first-principles calculations.” Geochimica et Cosmochimica Acta, 198:218-228.

Raisbeck, G.M., and Yiou, F. 1999. “ “ ${ }^{129}$ I in the Oceans: Origins and Applications.” Sci. Total Environ., 237/238:31-41.

Rehr, J.J., and Albers, R.C. 2000. “Theoretical approaches to x-ray absorption fine structure.” Review of Modern Physics, 72:621-654.

Rehr, J.J., Kas, J.J., Prange, M.P., Sorini, A.P., Takimoto, Y., and Vila, F.D. 2009. "Ab initio theory and calculations of X-ray spectra.” Comptes Rendus de Physique, 10:548-559.

Rehr, J.J., Kas, J.J., Vila, F.D., Prange, M.P., and Jorissen, K. 2010. "Parameter-free calculations of xray spectra with FEFF9.” Physical Chemistry Chemical Physical, 12:5503-5513. 
PNNL-24709, Rev. 2

RPT-DVZ-AFRI-030, Rev. 2

Sakurai, T., Takahashi, A., Ishikawa, N., and Komaki, Y. 1989. "The Behavior of Iodine in a Simulated Spent-Fuel Solution.” Nuclear Technology, 85:206-212.

Serne, R.J., Conca, J.L., LeGore, V.L., Cantrell, K.J., Lindenmeier, C.W., Campbell, J.A., Amonette, J.E., and Wood, M.I. 1993. Solid-Waste Leach Characteristics and Contaminant-Sediment Interactions. Volume 1: Batch Leach and Adsorption Tests and Sediment Characterization. PNL-8889, Vol. 1, Pacific Northwest Laboratory, Richland, Washington.

Shuller-Nickles, L.C., Bender, W., Walkder, S., and Becker, U. 2014. "Quantum-mechanical methods for quantifying incorporation of contaminants in proximal minerals.” Minerals, 4:690715.

Stumm, W., and Morgan, J.J. 1996. Aquatic Chemistry, 3rd Edition. John Wiley \& Sons, New York.

Suzuki, M., Eda, Y., Ohsawa, S., Kanesaki, Y., Yoshikawa, H., Tanaka, K., Muramatsu, Y., Yoshikawa, J., Sato, I., Fujii, T., and Amachi, S. 2012. "Iodide Oxidation by a Novel Multicopper Oxidase from the Alphaproteobacterium Strain Q-1.” Applied and Environmental Microbiology, 78(11):3941-3949.

Svensson, C., and Ståhl, K. 1988. “The crystal structure of $\mathrm{NaIO}_{3}$ at 293 K.” Journal of Solid State Chemistry, 77:112-116.

Tfaily, M.M., Chu, R.K., Tolić, N., Roscioli, K.M., Anderton, C.R., Paša-Tolić, L., Robinson, E.W., and Hess, N.J. 2015. "Advanced solvent based methods for molecular characterization of soil organic matter by high-resolution mass spectrometry.” Ana. Chem., 87:5206-5215.

Tfaily, M.M., Chu, R.K., Toyoda, J., Tolić, N., Robinson, E.W., Paša-Tolić, L., and Hess, N.J. 2017. "Sequential extraction protocol for organic matter from soils and sediments using high resolution mass spectrometry.” Analytica Chimica Acta 972:54-61.

Truex M.J., Szecsody, J.E., Qafoku, N., Strickland, C.E., Moran, J.J., Lee, B.D., Snyder, M.M.V., Lawter, A.R., Resch, C.T., Gartman, B.N., Zhong, L., Nims, M.K., Saunders, D.L., Williams, B.D., Horner, J.A., Leavy, I.I., Baum, S.R., Christiansen, B.B., Clayton, R.E., McElroy, E.M,. Appriou, D., Tyrrell, K.J., and Striluk, M.L. 2017. Contaminant Attenuation and Transport Characterization of 200-DV-1 Operable Unit Sediment Samples. PNNL-26208; RPT-DVZ-AFRI-037, Pacific Northwest National Laboratory, Richland, Washington.

Truex, M.J., Oostrom, M., and Tartakovsky, G.D. 2015. Evaluating Transport and Attenuation of Inorganic Contaminants in the Vadose Zone for Aqueous Waste Disposal Sites. PNNL24731, Pacific Northwest National Laboratory, Richland, Washington.

Truex, M.J., and Carroll, K.C. 2013. Remedy Evaluation Framework for Inorganic, Non-Volatile Contaminants in the Vadose Zone. PNNL-21815, Pacific Northwest National Laboratory, Richland, Washington.

Truex, M.J., Szecsody, J.E., Qafoku, N., and Serne, R.J. 2014. Conceptual Model of Uranium in the Vadose Zone for Acidic and Alkaline Wastes Discharged at the Hanford Site Central Plateau. PNNL-23666, Pacific Northwest National Laboratory, Richland, Washington. 
PNNL-24709, Rev. 2

RPT-DVZ-AFRI-030, Rev. 2

Um, W., Serne, R.J., and Krupka, K.M. 2004. "Linearity and Reversibility of Iodide Adsorption on Sediments from Hanford, Washington under Water Saturated Conditions.” Water Research, 38(8):2009-2016.

van Genuchten, M.T. 1980. "A Closed Form Equation for Predicting the Hydraulic Conductivity of Unsaturated Soils.” Soil Science Society of America Journal, 44(5):892-898.

Watrous, R.A., Wootan, D.W., and Finfrock, S.F. 2002. Activity of Fuel Batches Processed Through Hanford Separations Plants 1944 Through 1989. RPP-13489, Rev. 0, CH2M Hill Hanford Group, Inc., Richland, Washington.

White, M.D., and Oostrom, M. 2006. STOMP: Subsurface Transport Over Multiple Phases, Version 4.0, User's Guide. PNNL-15782, Pacific Northwest National Laboratory, Richland, Washington.

Whitehead, D. 1984. “The Distribution and Transformations of Iodine in the Environment.” Environ. International., 10(4):321-339.

Xu, C., Kaplan, D.I., Zhang, S., Athon, M., Ho, Y.-F., Li, H.-P., Yeager, C.M., Schwehr, K.A., Grandbois, R., Wellman, D., and Santschi, P.H. 2015. "Radioiodine Sorption/Desorption and Speciation Transformation by Subsurface Sediments from the Hanford Site.” J. Environ. Radioact., 139:43-55.

Yagi, K., Umezawa, S., Terauchi, H., and Kasatani, H. 2001. "EXAFS study of phase transitions in $\mathrm{KIO}_{3}$.” Journal of Synchrotron Radiation, 8:803-805.

Zhang, Z.F., Freedman, V.L., Waichler, S.R., and Wurstner, S.K. 2005. 2005 Closure Assessments for SSX Tank Farms: Numerical Simulations. PNNL-15399, Pacific Northwest National Laboratory, Richland, Washington.

Zhang, S., Xu, C., Creeley, D., Ho, Y.-F., Li, H.-P., Grandbois, R., Schwehr, K.A., Kaplan, D.I., Yeager, C.M., Wellman, D., and Santschi, P.H. 2013. "Iodine-129 and Iodine-127 Speciation in Groundwater at the Hanford Site, U.S.: Iodate Incorporation into Calcite.” Environ. Sci. Tech., 47(17):9635-9642. 
PNNL-24709, Rev. 2

RPT-DVZ-AFRI-030, Rev. 2

\section{Appendix A}

\section{Summary of Current Biogeochemical Process Information}




\section{Appendix A}

\section{Summary of Current Biogeochemical Process Information}

\section{A.1 Aqueous lodine Conversion}

\section{A.1.1 General Aqueous lodine Chemistry}

Iodine is a complicated element because under environmentally relevant conditions it can exist in multiple physical (solid, liquid, or gas) and oxidation states $(-1,0,+1,+5$, and +7$)$. It readily reacts with organic compounds, further complicating its chemistry in most natural environments. The solubility of elemental iodine in water at $25^{\circ} \mathrm{C}$ is $340 \mathrm{mg} / \mathrm{L}$ with a vapor pressure of $4.1 \times 10^{-4}$ atm (Lauterbach and Ober 1996). Henry's Law constant at $25^{\circ} \mathrm{C}$ for $\mathrm{I}_{2}$ is estimated to be $381 \mathrm{~g} / \mathrm{L} \cdot$ atm (Parsly 1970). Thermodynamic data from HSC Chemistry ${ }^{\circledR}$ (Outotec, Espoo, Finland) indicates a value of $483 \mathrm{~g} / \mathrm{L} \cdot \mathrm{atm}$, assuming ideal behavior for both the vapor and solution. Iodine hydrolyzes in water by four main reactions (Parsly 1970):

$\mathrm{I}_{2(\mathrm{~g})}=\mathrm{I}_{2(\mathrm{aq})}$

$\log \mathrm{K}_{20^{\circ} \mathrm{C}}=0.65$

$\mathrm{I}_{2(\mathrm{aq})}+\mathrm{I}^{-}=\mathrm{I}_{3}^{-}$

$\log \mathrm{K}_{20^{\circ} \mathrm{C}}=2.89$

$\mathrm{I}_{2(\mathrm{aq})}+\mathrm{H}_{2} \mathrm{O}=\mathrm{H}^{+}+\mathrm{I}^{-}+\mathrm{HIO}$

$\log \mathrm{K}_{20^{\circ} \mathrm{C}}=-12.49$

$\mathrm{I}_{2(\mathrm{aq})}+\mathrm{H}_{2} \mathrm{O}=\mathrm{H}_{2} \mathrm{OI}^{+}$

$\log \mathrm{K}_{20^{\circ} \mathrm{C}}=-10.80$

The reactions for several species are shown in Table A.1, with iodide ( $\left.\mathrm{I}^{-}\right)$as the reactant species. Under conditions prevalent in groundwater and surface water, only the $-1,0$, and +5 valence states are common. Additional species may occur in natural waters because iodide forms aqueous complexes with various soft metals, but requires high iodide concentrations to account for a significant fraction of the metal species.

Table A.1. Reactions of log K association constants of selected aqueous iodine species (Kaplan et al. 2014).

\begin{tabular}{lc}
\hline Reaction & log $\mathrm{K}_{\mathbf{2 0}}{ }^{\circ} \mathbf{C}$ \\
\hline $\mathrm{I}^{-}+\mathrm{H}^{+}=\mathrm{HI}$ & 0 \\
$2 \mathrm{I}^{-}=\mathrm{I}_{2(\mathrm{aq})}+2 \mathrm{e}^{-}$ & -21.33 \\
$3 \mathrm{I}^{-}=\mathrm{I}_{3}^{-}+2 \mathrm{e}^{-}$ & -18.44 \\
$\mathrm{I}^{-}+\mathrm{H}_{2} \mathrm{O}=\mathrm{HIO}_{(\mathrm{aq})}+\mathrm{H}^{+}+2 \mathrm{e}^{-}$ & -33.81 \\
$\mathrm{I}^{-}+\mathrm{H}_{2} \mathrm{O}=1 \mathrm{IO}^{-}+2 \mathrm{H}^{+}+2 \mathrm{e}^{-}$ & -44.53 \\
$\mathrm{I}^{-}+2 \mathrm{e}^{-}=\mathrm{I}^{-3}$ & -0.90 \\
$\mathrm{I}^{-}+3 \mathrm{H}_{2} \mathrm{O}=\mathrm{HIO}_{3(\mathrm{aq})}+5 \mathrm{H}^{+}+6 \mathrm{e}^{-}$ & -112.56 \\
$\mathrm{I}^{-}+3 \mathrm{H}_{2} \mathrm{O}=1 \mathrm{IO}_{3}^{-}+6 \mathrm{H}^{+}+6 \mathrm{e}^{-}$ & -113.31 \\
$\mathrm{I}^{-}+4 \mathrm{H}_{2} \mathrm{O}=1 \mathrm{IO}_{4}^{-}+8 \mathrm{H}^{+}+8 \mathrm{e}^{-}$ & -168.10 \\
\hline
\end{tabular}

Various forms of iodine react with organic molecules. Elemental iodine reacts in much the same way as chlorine and bromine, to form organo-iodine (Organo-I) compounds. The syntheses of polyvalent Organo-I compounds has been reviewed (Stang 2003; Zhdankin and Stang 2002). Skulski (2000) reviewed aromatic Organo-I compounds. Another area of research into organic iodine reactions has been the reactions that might occur with organic substances in nuclear reactors during an accident (e.g., 
PNNL-24709, Rev. 2

RPT-DVZ-AFRI-030, Rev. 2

Malinauskas and Bell 1987; Paquette et al. 1986; Skulski 2000; Taghipour and Evans 2002; Wren and Ball 2001).

Inorganic iodine chemistry under conditions associated with most ${ }^{129}$ I environmental plumes is somewhat simplified because the only stable aqueous species that are common are $\mathrm{I}^{-}, \mathrm{I}_{2}{ }^{\circ}$, and $\mathrm{IO}_{3}{ }^{-}$. Figure A. 1 shows the relation of these species to $\mathrm{pH}$ and $\mathrm{E}_{\mathrm{h}}$ and was calculated using the background ${ }^{127} \mathrm{I}$ concentrations measured at the site; $8 \mu \mathrm{g} / \mathrm{L}^{127} \mathrm{I}$ (Zhang et al. 2013). Also included in the figure is the range of common $\mathrm{pH} / \mathrm{Eh}$ conditions found in unimpacted natural systems, as estimated by $6200 \mathrm{pH} / \mathrm{Eh}$ paired measurements (Baas-Becking et al. 1960). These calculations predict that iodide should be the dominant species under the groundwater conditions at the 200 West Area. However, because the lines in the $\mathrm{pH} /$ Eh plots identify the conditions where two species exist at $50 \%$, it is also expected that there would be a small fraction of $\mathrm{IO}_{3}{ }^{-}$and an inconsequential amount of $\mathrm{I}_{2} . \mathrm{I}_{2}$ is the only species expected to change appreciably with total iodine concentration; it was also modeled at the highest stable ${ }^{127} \mathrm{I}$ concentrations measured by Zhang et al. (2013), $75 \mu \mathrm{g} / \mathrm{L}$. As expected, the $\mathrm{I}_{2}$ region increased, but still indicates that $\mathrm{I}_{2}$ will not be a significant species in this system. See Section 1.2 for a more detail explanation of why using $E_{h}$ to predict iodine speciation in groundwater is problematic.

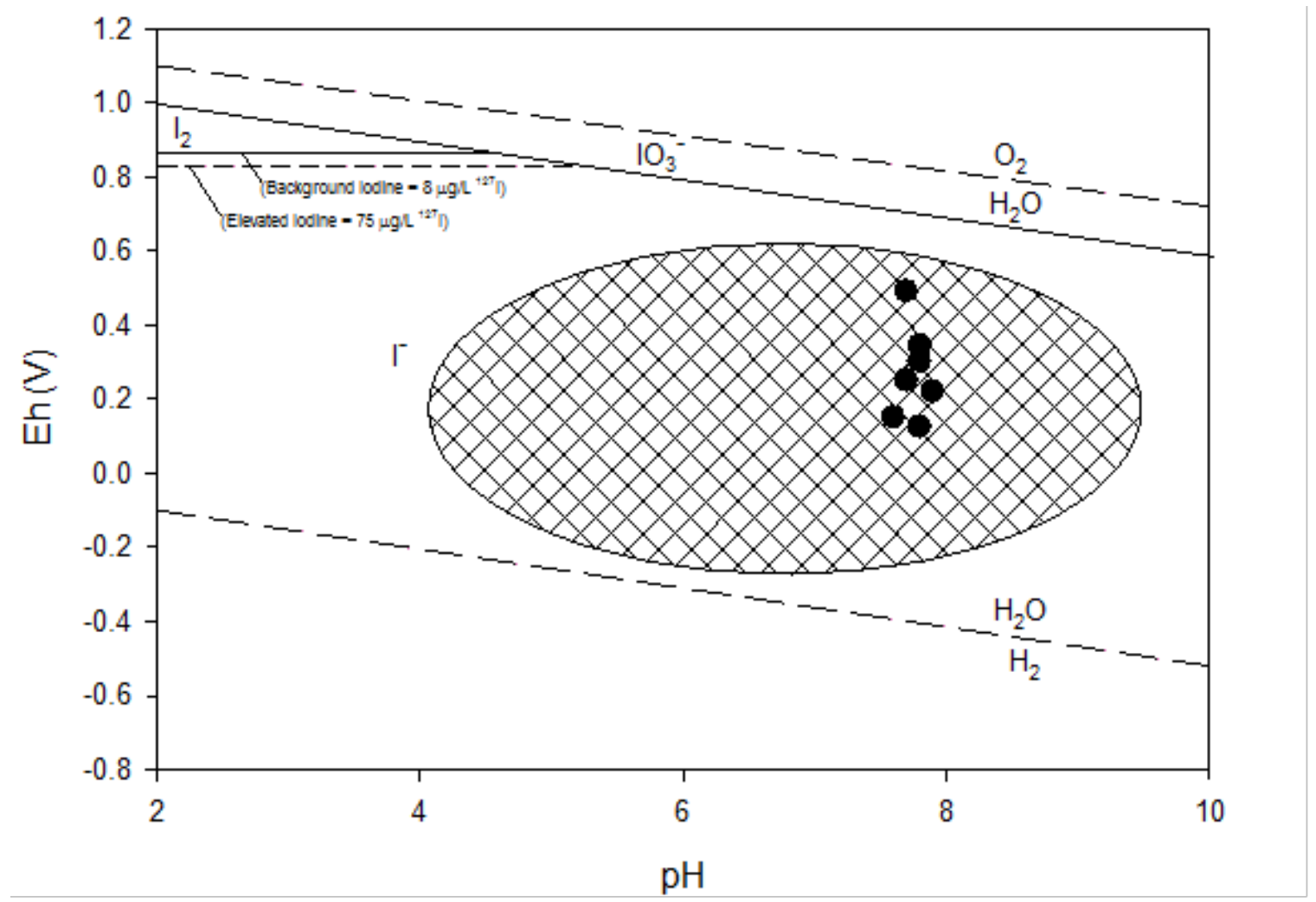

Figure A.1. pH-Eh diagram of aqueous iodine speciation in the 200-UP-1 OU; total iodine concentration $=8 \mu \mathrm{g} / \mathrm{L}$ (background) and $75 \mu \mathrm{g} / \mathrm{L}$ (plume impacted) (Geochemist’s Workbench ${ }^{\circledR}$ [Aqueous Solutions LLC, Champaign, Illinois]; Bethke and Yeakel 2013). Points identify pH-Eh conditions measured in groundwater in the 200-UP-1 OU (Zhang et al. 2013). The hatched zone shows the general pH-Eh limits common in the environment (based on 6200 paired measurements (Baas-Becking et al. 1960). Organo-I species were not considered in these calculations. 
An important omission in these calculations is the consideration of any Organo-I species; these species are omitted because association constants are not available. Because iodine and organic carbon (OC) form extremely strong bonds, covalent bonds, the presence of small concentrations of dissolved OC can have significant effects on iodine speciation. Such Organo-I species have been shown to account for as much as $40 \%$ of the iodine species in estuaries, rivers, and rain (Santschi and Schwehr 2004), or as much as $80 \%$ in subsurface aquifer environments (Kaplan et al. 2011; Otosaka et al. 2011). Low concentrations of Organo-I (and iodate) have also been detected recently in 200 West Area groundwater (Zhang et al. 2013). Other potential contributing reasons for why thermodynamic speciation calculations do not predict actual ${ }^{129}$ I speciation distributions are (1) contaminant plumes may not be in steady state, and (2) thermodynamic models do not consider processes involving microbes, well known to accumulate and alter iodine speciation.

\section{A.1.2 Aqueous lodine - Dissolved Natural Organic Matter Interactions}

The coexistence of inorganic and organic iodine species has been reported in various environments (Arah and Kirk 2000; Baker et al. 2001; Couture and Seitz 1983; Muramatsu et al. 1989; Santschi and Schwehr 2004; Xu et al. 2011a, b; Xu et al. 2012; Yuita 1992; Yuita and Kihou 2005). For example, methyl iodide is an important gaseous form of iodine in the marine atmosphere and in releases from nuclear fuel reprocessing facilities, while dissolved Organo-I compounds comprise up to $40 \%$ of total iodine in aqueous samples from estuaries, rivers, and rain (Santschi et al. 2012). Organic carbon interactions with ${ }^{129} \mathrm{I}$ are discussed in more detail below.

\section{A.1.3 Aqueous lodine Speciation at the Hanford Site}

One reason why little is known about ${ }^{129}$ I at U.S. Department of Energy (DOE) sites is because the analytical chemistry techniques to assay the extremely low ambient ${ }^{129} \mathrm{I}$ concentrations $\left(10^{-7}\right.$ to $\left.10^{-11} \mathrm{M}\right)$ have either not been readily available or the procedures are arduous (Kaplan et al. 2014). By combining recently developed analytical techniques (Schwehr et al. 2005; Zhang et al. 2010) applicable to iodine (both ${ }^{127} \mathrm{I}$ and ${ }^{129} \mathrm{I}$ ) with existing spectroscopic techniques for natural organic matter (NOM), it has become possible to address applied and basic geochemistry problems.

The only characterization of groundwater iodine speciation at the Hanford Site was by presented by Zhang et al. (2013). They measured both stable ${ }^{127}$ I and radioactive ${ }^{129} \mathrm{I}$, but only ${ }^{127} \mathrm{I}$ had sufficient concentrations to permit full speciation measurements. The results from seven samples (two from the 200-UP-1 OU and five from the 200-ZP-1 OU) that were characterized in the work by Zhang et al. are presented in Table A.2. 
PNNL-24709, Rev. 2

RPT-DVZ-AFRI-030, Rev. 2

Table A.2. Chemistry and ${ }^{127}$ I speciation of filtered Hanford Site groundwater (Zhang et al. 2013).

\begin{tabular}{|c|c|c|c|c|c|c|c|c|c|c|c|c|}
\hline Well & $\mathrm{pH}$ & $\begin{array}{l}\text { Eh } \\
(\mathrm{mV})\end{array}$ & $\begin{array}{l}\text { DOC } \\
(\mu \mathrm{M})\end{array}$ & $\begin{array}{c}\mathrm{Ca} \\
(\mathrm{mg} / \mathrm{L})\end{array}$ & $\begin{array}{c}\mathrm{Si} \\
(\mathrm{mg} / \mathrm{L})\end{array}$ & $\begin{array}{c}\text { lodide } \\
\text { ( } \mu \mathrm{g} / \mathrm{L})\end{array}$ & $\begin{array}{l}\text { lodate } \\
(\mu \mathrm{g} / \mathrm{L})\end{array}$ & $\begin{array}{c}\text { Organo-I } \\
(\mu \mathrm{g} / \mathrm{L})\end{array}$ & $\begin{array}{l}\text { Total I } \\
(\mu \mathrm{g} / \mathrm{L})\end{array}$ & $\begin{array}{c}\text { Iodide } \\
(\%)\end{array}$ & $\begin{array}{c}\text { lodate } \\
\text { (\%) }\end{array}$ & $\begin{array}{c}\text { Organo- } \\
(\%)\end{array}$ \\
\hline 299-W14-11 & 7.7 & 250 & 50.2 & 59.4 & 7.5 & 0.35 & 59.50 & 15.18 & 75.03 & 0.5 & 79.3 & 20.2 \\
\hline 299-W14-13 & 7.7 & 249 & 63.0 & 81.9 & 7.4 & 0.33 & 42.72 & 17.01 & 60.05 & 0.6 & 71.1 & 28.3 \\
\hline 299-W14-15 & 7.9 & 220 & 25.5 & 35.4 & 5.6 & 0.43 & 32.63 & 5.66 & 38.72 & 1.1 & 84.3 & 14.6 \\
\hline 299-W11-43 & 7.6 & 150 & 37.2 & 78.8 & 7.0 & 0.36 & 6.66 & 2.76 & 9.78 & 3.7 & 68.1 & 28.3 \\
\hline 299-W11-88 & 7.8 & 321 & 15.6 & 22.1 & 15.0 & 0.17 & 7.08 & 2.08 & 9.33 & 1.8 & 75.9 & 22.3 \\
\hline 699-36-70B & 7.8 & 334 & 35.3 & 19.4 & 10.7 & 0.23 & 5.87 & 2.28 & 8.38 & 2.8 & 70.0 & 27.2 \\
\hline 699-38-70B & 7.8 & 125 & 21.5 & 29.7 & 8.9 & 1.38 & 4.18 & 3.68 & 9.24 & 15.0 & 45.2 & 39.8 \\
\hline Average & 7.8 & 236 & 35.5 & 49.5 & 8.9 & 0.46 & 22.66 & 6.95 & 30.08 & 3.6 & 70.6 & 25.8 \\
\hline
\end{tabular}

The groundwater samples studied by Zhang et al. (2013) had an extremely narrow range of alkaline $\mathrm{pH}$ values, from $\mathrm{pH} 7.6$ to 7.9, which is consistent with the fact that the system is highly buffered to $\mathrm{CaCO}_{3}$ phases. The iodine plumes clearly have elevated levels of total OC and stable ${ }^{127} \mathrm{I}$. Dissolved organic carbon (DOC) in the groundwater ranged from 20 to $63 \mu \mathrm{M}$ with an average of $35 \mu \mathrm{M}$. These DOC concentrations are similar to those recently reported in the humid region of the Savannah River Site (SRS) in Aiken, South Carolina: 10 to $60 \mu \mathrm{M}$ (Otosaka et al. 2011). The two wells closest to the disposal source, 299-W14-11 and 299-W14-13, had the greatest DOC concentrations and a relatively high calcium concentration. $\mathrm{Si}$, as one of the most abundant trace elements in groundwater, had a concentration range between 6 and $15 \mathrm{mg} / \mathrm{L}$.

Iodate was the dominant species for ${ }^{127} \mathrm{I}$ in all the groundwater samples analyzed by Zhang et al. (2013), accounting for $45 \%$ to $84 \%$ of total iodine (Table A.2). Organo-I ranked second in abundance, comprising $15 \%$ to $40 \%$ of the total iodine. Iodide was generally the least abundant in the groundwater, accounting for $<4 \%$ of the total iodine, except for well $699-38-70 \mathrm{~B}$, where iodide accounted for $15 \%$. On average, iodate accounted for $70.6 \%$, Organo-I accounted for $25.8 \%$, and iodide accounted for $3.6 \%$ of the total aqueous iodine (Table A.2). For comparison, the average ${ }^{129}$ I speciation distribution at the $\mathrm{F}$ Area plume at the SRS was 31\% iodide, 34\% iodate, and 35\% Organo-I (Otosaka et al. 2011). The two wells in the 200 West Area enriched in DOC, 299-W14-11 and 299-W14-13, did not have unusually high Organo-I levels. In fact, the percentage of Organo-I remained relatively stable regardless of the variation in DOC concentration. ${ }^{127}$ I concentrations were much greater near source terms (e.g., wells 299-W14-11, -13 , and -15) than farther from the source terms. The source of the stable iodine is not known, but iodine commonly exists as a trace constituent of nitric acid. Therefore, the enormous volumes of nitric acid disposed during site operations are a likely contributing source for the groundwater iodine. There did not appear to be trends in the observed speciation with respect to either distance from the sources or whether the groundwater sample was collected from the high- or low-concentration portions of the plume, although only a limited number of samples were collected.

For radioactive ${ }^{129}$ I, Zhang et al. (2013) only detected iodate (Table A.3). If Organo-I or iodide were present, they were below the analytical detection limit of $0.2 \mathrm{nM}{ }^{129} \mathrm{I} .{ }^{129}$ I concentrations decreased with distance from the source. Based on thermodynamic consideration, iodide was expected to be the dominant species in this system. However, it is possible that iodide and iodate, as opposed to only iodide, may have been the dominant species introduced into the cribs. One of the dominant operations that took place at T-Plant and B-Plant involved the use of hot, strong acids to remove cladding from spent fuels. To provide some insight into these conditions, Zhang et al. (2013) prepared $10 \mathrm{mg} / \mathrm{L}$ iodide in $1 \mathrm{M} \mathrm{HNO}_{3}$, heated the solution at $80^{\circ} \mathrm{C}$ for 2 hours, then measured the speciation as: $4.5 \mathrm{mg} / \mathrm{L}$ iodide, $2.2 \mathrm{mg} / \mathrm{L}$ 
iodate, and below detection limit concentrations of $\mathrm{I}_{2}$. These results showed a $55 \%$ decrease in iodide concentrations and 22\% increase in iodate concentrations. Zhang et al. (2013) acknowledged that the lack of $\mathrm{I}_{2}$ detection may have been the result of gaseous $\mathrm{I}_{2}$ escaping the test vials. This test indicates that the existence of iodate in the system, as opposed to iodide, may, in part, be due to the nature of the process operations that generated the disposed liquids.

Table A.3. ${ }^{129}$ I speciation in filtered groundwater from the 200 West Area (Zhang et al. 2013).

\begin{tabular}{|c|c|c|c|c|c|}
\hline Well & $\begin{array}{l}\text { lodide } \\
\text { ( } \mu \mathrm{g} / \mathrm{L})\end{array}$ & $\begin{array}{l}\text { lodate } \\
\text { ( } \mu \mathrm{g} / \mathrm{L})\end{array}$ & $\begin{array}{l}\text { lodate } \\
\text { (pCi/L) }\end{array}$ & $\begin{array}{c}\text { Organo-I } \\
\mu \mathrm{g} / \mathrm{L}\end{array}$ & $\left.{ }^{129} \mathrm{IO}_{3}\right|^{127} \mathrm{IO}_{3}$ Ratio \\
\hline 299-W14-11 & $<\mathrm{DL}^{(\mathrm{a})}$ & 0.22 & 42.5 & $<\mathrm{DL}$ & 0.004 \\
\hline 299-W14-13 & $<\mathrm{DL}$ & 0.21 & 40.6 & $<\mathrm{DL}$ & 0.005 \\
\hline 299-W14-15 & $<\mathrm{DL}$ & 0.13 & 25.9 & $<\mathrm{DL}$ & 0.004 \\
\hline 299-W11-43 & $<\mathrm{DL}$ & 0.02 & 3.6 & $<\mathrm{DL}$ & 0.003 \\
\hline 299-W11-88 & $<\mathrm{DL}$ & 0.02 & 4.1 & $<\mathrm{DL}$ & 0.003 \\
\hline 699-36-70B & $<\mathrm{DL}$ & 0.05 & 9.3 & $<\mathrm{DL}$ & 0.008 \\
\hline 699-38-70B & $<\mathrm{DL}$ & 0.02 & 3.0 & $<\mathrm{DL}$ & 0.004 \\
\hline
\end{tabular}

(a) $\mathrm{DL}=$ detection limit; the detection limit for ${ }^{129} \mathrm{I}^{-}$and ${ }^{129} \mathrm{IO}_{3}{ }^{-}$is $0.08 \mathrm{nM}(2 \mathrm{pCi} / \mathrm{L})$ and for organo${ }^{129} \mathrm{I}$ is $0.2 \mathrm{nM}(5 \mathrm{pCi} / \mathrm{L})$

However, the introduction of ${ }^{129} \mathrm{I}$ primarily as iodate into the subsurface environment would only partially explain the observed groundwater speciation (Table A.3) because stable iodine $\left({ }^{127} \mathrm{I}\right)$ also exists predominantly as iodate. This fact suggests that there are natural biogeochemical drivers promoting the existence of iodine in the oxidized iodate state. The presence of iodine in multiple oxidation states and species within a given aqueous sample is consistent with previous reports of radioiodine and stable iodine speciation measurements at other DOE sites (Kaplan et al. 2014; Otosaka et al. 2011), an oligotrophic lake (Gilfedder et al. 2008, 2009), and in marine systems (see references in Schwehr et al. 2005). There are no iodine speciation studies reported for arid region groundwater similar to that at the Hanford Site. The ${ }^{129}$ I plume at the SRS is appreciably more acidic ( $\mathrm{pH} 3.1$ to 6.0) and more oxidized (as estimated by Eh) than the Hanford Site. All of the SRS groundwater samples had varying percentages of iodide, iodate, and Organo-I that changed as a function of the plume's $\mathrm{pH}$, Eh, and DOC conditions. Schwehr et al. (2005) reported that marine samples (which tend to have a $\mathrm{pH}$ of $\sim 8$, which is closer to the $\mathrm{pH} 7$ to 8.5 of Hanford groundwater, but with relatively higher DOC concentrations) also tended to have even distributions of iodide, iodate, and Organo-I. Gilfedder et al. (2009) reported monthly iodine speciation in an oligotrophic freshwater lake in the Alps. The lake had a pH between 8.0 and 8.5 and the DOC concentrations were very low $(<2 \mathrm{mg} / \mathrm{L})$. Organo-I, iodide, and iodate concentrations varied greatly during the year, but Organo-I was clearly the dominant species, generally accounting for $>80 \%$ of the iodine pool.

\section{A.2 lodine Sorption to Sediments}

Sorption information in this section considers the potential effect of iodine speciation on sorption. Previous Hanford sorption studies have been conducted exclusively with introduced iodide (Gee and Campbell 1980; Kaplan et al. 1996, 1998; Serne et al. 1993; Um et al. 2004). 
PNNL-24709, Rev. 2

RPT-DVZ-AFRI-030, Rev. 2

\section{A.2.1 lodine Speciation on the Solid Phase}

In this appendix, the term "sorption" is used to describe iodine partitioning from the aqueous phase to a solid phase. It is meant to include adsorption, absorption, complexation, precipitation, co-precipitation, and covalent bonding between iodine and OC (especially aromatic moieties). When specific sorption processes are identified by one of the terms above, more specific mechanisms are implied.

There have been two different approaches to identifying iodine species associated with soils and sediments: direct spectroscopic methods and indirect extraction methods. Direct spectroscopic methods include the use of X-ray absorption near-edge structure (XANES) and extended X-ray absorption fine structure spectra (EXAFS) (Fuhrmann et al. 1998; Kodama et al. 2006; Schlegel et al. 2006; Shimamoto and Takahashi 2008). These direct X-ray absorption spectroscopy techniques are limited to analyzing geological samples with elevated iodine concentrations added to the samples. This is because environmental samples tend to have iodine concentrations that are appreciably lower than the detection limits of this method. The detection limit of XANES is on the order of $>10 \mu \mathrm{g}{ }^{129} \mathrm{I} / \mathrm{g}$ soil (Hou et al. 2009). Shimamoto and Takahashi (2008) conducted XANES studies on soils amended with $55 \mu \mathrm{g} \mathrm{I/g}$ soil. They reported that most of the iodine in the soil was in an organic form. XANES studies with a pyrite mineral isolate showed the reduction of $\mathrm{IO}_{3}{ }^{-}$to $\mathrm{I}_{2}$ (Fuhrmann et al. 1998). This finding is very likely a result of using very high iodine concentrations and likely not a common process occurring in natural terrestrial environments. Fuhrmann et al. (1998) also observed that magnetite sorbed iodide but not iodate from solution (this is contrary to popular understanding that iodate sorbs more strongly than iodide to mineral surfaces due to iodate's strong Lewis base characteristic) and that biotite sorbed iodate but not iodide from solution. XANES was also used to independently determine $\mathrm{K}_{\mathrm{d}}$ values of iodate and iodide uptake by a soil (Kodama et al. 2006).

The second method of assessing the speciation of iodine on the solid phase is via sequential extraction or selective extraction. This technique involves adding extractants designed to remove iodine associated with a given phase (e.g., water soluble, carbonate, Fe-[oxy]hydroxide, organic matter [OM], and residual) or sorbed by a specific process (e.g., ion exchangeable). Sequential extractions have been carried out to investigate iodine speciation in sediments (Hou et al. 2003; Schmitz and Aumann 1995; Stutz et al. 1999; Yuita 1992). These extraction designations are operationally defined parameters and, as such, do not carry mechanistic interpretations. In practice, interpretation of sequential extractions suffer a number of pitfalls that are especially important with contaminants that are more prone to complex change oxidation, or precipitate, such as phosphate or plutonium (Nirel and Morel 1990; Scheckel et al. 2003; Tessier and Campbell 1988). However, the sequential extraction method continues to be used, and in the absence of more sophisticated analytical tools, may provide useful insight into how strongly iodine sorbs to the solid phase.

Hou et al. (2003) used a water-soluble $\mathrm{NH}_{4} \mathrm{OAC}$ exchange, carbonate $\left(\mathrm{NH}_{4} \mathrm{OAC}\right.$ [pH 5]), Fe-oxide $\left(\mathrm{NH}_{2} \mathrm{OH}, \mathrm{HCl}, \mathrm{pH} 2,80^{\circ} \mathrm{C}\right.$ to $\left.100^{\circ} \mathrm{C}\right)$, organic $\left(\mathrm{NaOH} 80^{\circ} \mathrm{C}\right.$ to $\left.100^{\circ} \mathrm{C}\right)$, and residue (remaining) fractionation scheme. Schmitz and Aumann (1995) analyzed soils collected from a reprocessing plant in Germany and reported that $39 \%$ to $49 \%$ of the ${ }^{129}$ I was associated with the water soluble fraction, whereas only $4 \%$ to $15 \%$ was associated with the organic fraction and $7 \%$ to $13 \%$ was associated with the residual fraction. However, a different distribution of stable iodine, ${ }^{127} \mathrm{I}$, was observed where only $<4 \%$ occurred in the water-soluble fraction. This difference between the two isotopes may be attributed to the different sources of the two isotopes and underscores an important point- that the fate of iodine in the environment is controlled by biological as well as geochemical factors. In the coastal and estuarine area of Sellafield, 
most of the ${ }^{129} \mathrm{I}$ was associated with the oxides (53\% to 66\%) and organic (23\% to $43 \%$ ) fractions, whereas $<7.5 \%$ was found in the other fractions. A similar result was also obtained from soil samples collected from near the Chernobyl accident: $30 \%$ to $40 \%$ of the ${ }^{129}$ I was associated with the oxides, $40 \%$ to $48 \%$ with the organics, and only $6 \%$ to $13 \%$ with the water-soluble fraction (Hou et al. 2003).

\section{A.2.2 Influence of Sediment Organic Matter on lodine Sorption}

Several studies of sorption in shallow soils indicate that the OM is a primary control on iodine sorption (Assemi and Erten 1994; Bird and Schwartz 1997; Emerson et al. 2014; Fukui et al. 1996; Kaplan 2003; Neal and Truesdale 1976; Sheppard and Thibault 1991; Whitehead 1974; Yoshida et al. 1992; Yu et al. 1996). In a survey of 26 soils and sediments samples from across the United States, with NOM concentrations ranging from 0.046 to $0.5 \mathrm{wt} \%$ (except for one peat sample that was $28.1 \mathrm{wt} \%$ ), Hu et al. (2009) reported that $\sim 90 \%$ of the total iodine in soils was present as organic iodine, while inorganic iodine species became important only in sediments with low OM contents. Similarly, Whitehead (1973) demonstrated that iodine sorption in untreated soils was greater than in soils that were treated to destroy the OM. There was some sorption of iodine in the treated soils, primarily by iron and aluminum oxides (Whitehead 1973). In a single soil profile studied by Bors et al. (1988), sorption of iodide correlated with OC content of samples that ranged from 6.2 to $0.06 \mathrm{wt} \%$ OC. Similar results were reported in studies involving different heating regimes (Muramatsu et al. 1990a, b). When all OM was removed by oxidation at $500^{\circ} \mathrm{C}$, sorption of iodine was reduced substantially, but the decrease in sorption was much less when carbon remained as charcoal after heating to $500^{\circ} \mathrm{C}$ under a nitrogen atmosphere (Muramatsu et al.1990a).

Another approach to demonstrating the importance of OM to iodine sorption by soils is to compare sorption onto individual components that comprise the soil. Whitehead (1974) took this approach and found that organic compost sorbed iodine more strongly than the mineral components of a soil. He also noted that drying the compost prior to the experiments greatly reduced iodine sorption. Neal and Truesdale (1976) measured sorption of iodide and iodate in riverine sediments and concluded that stronger sorption of these species occurred in peaty sediments than in freshly prepared ferric hydroxide. Assemi and Erten (1994) compared sorption of iodine on a soil that was 70\% OC to sorption onto various minerals and found that sorption was much stronger to the soil. They also found that iodine soil sorption decreased substantially when it was heated to $180^{\circ} \mathrm{C}$ or irradiated. Yu et al. (1996) demonstrated the importance of $\mathrm{OM}$ to iodide sorption by showing that the individual high surface area inorganic phases that make up most of a volcanic soil poorly sorb iodide relative to the bulk soil. A different approach was taken by Fukui et al. (1996), who compared iodine sorption onto a soil to sorption onto pure humic material. $\mathrm{K}_{\mathrm{d}}$ values on the humic material were 10 times higher than on the soil.

Sorption of iodine in oxic organic-rich sediments is greater than in anoxic organic-rich sediments (Ashworth and Shaw 2006; Ashworth et al. 2003; Maillant et al. 2007; Sheppard and Hawkins 1995; Whitehead 1974). This was hinted at by Whitehead (1974), who found that drying organic-rich soils before measuring iodine $K_{d}$ values substantially reduced the sorption. (Unfortunately, the implications of these results on experimental protocol have been overlooked by several subsequent related studies.) Sheppard and Hawkins (1995) explicitly noted this difference in iodine sorption between oxic and anoxic organic-rich sediments with experiments on bog soils. Changes in the redox state of an organic-rich soil from oxic to anoxic can also release iodide that was sorbed in the oxic state (Bird and Schwartz 1997). The same relation was observed by Ashworth et al. (2003) and Ashworth and Shaw (2006) in column studies where they noted much lower sorption in saturated anoxic portions of their columns than in 
unsaturated oxic portions. Likewise, the same observation has been made in the field by Maillant et al. (2007), who returned, after 15 years, to the site of an iodide injection into bog soils documented by Sheppard et al. (1989). Iodine $K_{d}$ values were approximately seven times greater in the surface bog soils than in the deeper anoxic bog soils. Release of soil-bound iodine has also been observed in two forest soils (9- to 56-fold increase) under flooded, anaerobic conditions (Yuita 1992). Iodate was the dominant (86\% of water soluble I) form under non-flooded, oxidizing conditions, whereas iodide was the dominant (87\% of water soluble I) form under flooded conditions. In one soil type, the soil solution concentration of Organo-I increased 2.5 fold under flooded conditions. A very extensive sampling of iodine soil water from a forest, upland field, and rice paddy field in Japan revealed a strong negative relationship between soil $\mathrm{E}_{\mathrm{h}}$ and soil water iodine concentrations (Yuita and Kihou 2005). In particular, soil-water iodine concentrations increase with decreasing $E_{h}$ values below $200 \mathrm{mV}$. In summary, it appears that iodine uptake by sediments is largely controlled by OM concentrations and that iodine binds to surface soils under oxic conditions and is released under strongly reducing conditions. It is not clear from these studies whether the changes in redox alter the iodine speciation or the OM speciation, or both. Emerson et al. (2014) conducted identical sorption experiments under oxidizing (lab bench) and reducing (inside an inert atmosphere glovebox) environments using SRS sediments. They measured significantly lower $\mathrm{K}_{\mathrm{d}}$ values when either iodide or iodate was added to the soil suspension under reducing conditions. They attributed this trend to the greater percentage of aqueous iodide under the reducing conditions. They also observed that, especially under oxidizing conditions, steady state was not obtained until after 8 weeks.

Although the above studies demonstrate the importance of OM controlling iodine sorption in sediments, there still remains considerable uncertainty regarding (1) the nature of the Organo-I bonding mechanism; (2) whether the Organo-I bond occurs only through abiotic, biotic, or both types of processes; (3) why iodine sorption to OM occasionally appears to enhance or have no effect on transport; (4) the potential for abiotic iodide oxidation; and (5) the role of naturally occurring sediment microbes in accumulating iodine and promoting iodide oxidation. Much of this uncertainty arises from the fact that humic substances are inherently heterogeneous and complicated. NOM has been described as supramolecular associations of self-assembling heterogeneous and relatively small molecules derived from the decomposition of dead plant and animal residues. These small molecules are held together by weak forces, such as hydrogen bonding, hydrophobic interactions, and electrostatic interactions.

Iodine bonding with soil organic matter (SOM) is greatly influenced by not only the functionality of the SOM, but also the hydrophilic/hydrophobic forces in the SOM (Xu et al. 2011a, b). Studies conducted using SRS sediments indicated that the coincident variations in chemical composition, aromaticity, functional groups (e.g., aliphatic), hydrophobicity, and molecular weight indicated that (1) iodine in different humic acids was bound to a small-size aromatic subunit ( 10 kDa); (2) the largesize subunit ( $\sim 90 \mathrm{kDa}$ ) determined the relative mobility of iodine bound to SOM; and (3) iodine incorporation into the SOM (or iodination) is via covalent aromatic carbon-iodine bonding. The nature of the iodine bond to $\mathrm{OM}$ was further evaluated using various proton and ${ }^{13} \mathrm{C}$ nuclear magnetic resonance (NMR) techniques (Xu et al. 2012). Quantitative structure analyses by ${ }^{13} \mathrm{C}$ direct-polarization magicangle spinning (DPMAS) NMR and solution state ${ }^{1} \mathrm{H}$ NMR of these humic substances indicated that iodine was closely related to the aromatic regions containing esterified products of phenolic and formic acids or other aliphatic carboxylic acids, amide functionalities, quinone-like structures activated by electron-donating groups (e.g., $\mathrm{NH}_{2}$ ), or hemicellulose-lignin-like complex with phenyl-glycosidic linkages. 
The concentration of stable iodine bound to the fulvic acid fraction (519 $\mu \mathrm{g}{ }^{127} \mathrm{I} / \mathrm{g}$-carbon) was approximately an order of magnitude greater than the concentration of stable iodine bound to humic acid fractions (62 $\mu \mathrm{g}{ }^{127} \mathrm{I} / \mathrm{g}$-carbon) (Xu et al. 2011a, b). However, the contrasting radioiodine contents among the two fractions of SOM (humic acids and fulvic acids) could not be solely explained by the difference in the number of reactive binding sites. This difference may be the result of differences in the micromolecular environment of the SOM that play additional key roles in the interactions between iodine and OC. These micro-environments can influence the hydrophobic aliphatic periphery hindering the active aromatic cores and the hydrophilic polysaccharides favoring iodine accessibility toward hydrophilic iodine species.

It is indeed very important to study iodine speciation under ambient conditions (Schwehr et al. 2009; Zhang et al. 2011). Using an SRS subsurface wetland sediment and ambient iodine $\left(10^{-8} \mathrm{M}\right)$ consisting of 29\% iodide, 4\% iodate, and 67\% Organo-I, Schwehr et al. (2009) showed that by incrementally adding more total iodide, incrementally less Organo-I and more iodide was detected in the aqueous phase of sediment suspensions at steady state. At $1000 \mu \mathrm{M}$, only 3\% of the iodine existed as Organo-I. They attributed this change in iodine speciation to the added iodine swamping out the existing SOM binding sites in the soil. Similarly, Zhang et al. (2011) investigated the sorption, transport, and interconversion of iodine species by comparing their mobility in groundwater at ambient iodine concentrations $\left(10^{-8}\right.$ and $10^{-7}$ $\mathrm{M})$ to those at artificially elevated concentrations $\left(10^{-5} \mathrm{M}\right)$. Iodine mobility greatly depended on iodine concentration, in addition to the type of species. At ambient concentrations, $\mathrm{K}_{\mathrm{d}}$ values as high as $49 \mathrm{~mL} / \mathrm{g}$ were measured, whereas at $10^{-5} \mathrm{M}$ iodide, the solute traveled along with the water without retardation. Consequently, it is not possible to assess accurately natural iodine speciation using elevated spike loadings (to ease analytical detection).

The SRS F Area plume flows $0.7 \mathrm{~km}$ before it is intercepted by a riparian zone. As part of the SRS groundwater monitoring program, it has been documented that ${ }^{129} \mathrm{I}$ concentrates in the riparian zone rose to extraordinarily high levels, > $1000 \mathrm{pCi} / \mathrm{L}$ (unfiltered samples) (Kaplan et al. 2013). Studies were undertaken to identify the process/mechanism responsible for the ${ }^{129}$ I concentration, and in particular to quantify and understand the role of OM and microbes (Xu et al. 2011a, b; Xu et al. 2012). Laboratory studies using SRS solid and groundwater materials showed that between $72 \%$ and $77 \%$ of the newly introduced iodide or iodate could not be readily exchanged from the organic-rich riparian sediment, while the rest was transformed by the sediment into colloidal and truly dissolved Organo-I (Xu et al. 2011a). Laboratory iodination experiments indicated that iodine was likely covalently bound to aromatic structures within the SOM. Under very acidic conditions, abiotic iodination of SOM was predominant, whereas under less acidic conditions ( $\mathrm{pH}>5$ ), microbial enzymatically assisted iodination of SOM was predominant. It was concluded that although trace amounts of SOM-bound ${ }^{129}$ I could enhance transport, in general the SOM in the riparian zone immobilized the ${ }^{129} \mathrm{I}$.

Iodide added to a subsurface sandy sediment with very low OM concentrations ( $0.01 \mathrm{wt} \%$ OC) did not convert to iodate, but trace levels were converted to Organo-I (Xu et al. 2011a). When iodate was added to the same sediment, a portion immediately transformed to about 18\% iodide and 3\% Organo-I. The iodide (ad)sorption $K_{d}$ value in the organic-poor sediment was $0.71 \mathrm{~mL} / \mathrm{g}$ and was $23.89 \mathrm{~mL} / \mathrm{g}$ for a desorption test. Similarly for iodate, the (ad)sorption $\mathrm{K}_{\mathrm{d}}$ value was $5.16 \mathrm{~mL} / \mathrm{g}$, and for a desorption test, the $K_{d}$ value was $9.75 \mathrm{~mL} / \mathrm{g}$. By the end of these $K_{d}$ measurements, portions of the iodide or iodate spikes had transformed to other species; hence, these test do not represent "species-specific" $K_{d}$ values, but were mixed-species $\mathrm{K}_{\mathrm{d}}$ values. 
In column studies, Zhang et al. (2011) investigated the sorption, transport, and interconversion of iodine species in an SRS groundwater and subsurface sediment with high OM concentrations, $10.8 \mathrm{mg} / \mathrm{kg}$. At ambient concentrations $\left(10^{-8}\right.$ to $\left.10^{-7} \mathrm{M}\right)$, iodide and iodate were significantly retarded $\left(\mathrm{K}_{\mathrm{d}}\right.$ values as high as $49 \mathrm{~mL} / \mathrm{g}$ ), whereas at concentrations three orders of magnitude greater, iodide traveled predominantly at the same rate as water without retardation. Appreciable amounts of iodide were retained in soils during transport due to iodination of OC. When iodate was introduced in SRS subsurface sediment columns, it quickly reduced to iodide and proceeded to migrate through the sediment in a similar manner as the iodide spike system.

\section{A.2.2.1 Influence of Inorganic Sediment Properties on lodine Sorption}

Sorption of iodine on organic-poor soils is influenced primarily by mineralogy and $\mathrm{pH}$, but complicated by aqueous iodine speciation (Dai et al. 2004, 2009; Kaplan et al. 2000; Mishra and Srinivasu 1992; Neal and Truesdale 1976; Sazarashi et al. 1994; Whitehead 1973, 1974; Yoshida et al. 1992). Whitehead (1973) showed that when OM was removed from a soil, some iodine still sorbed to the mineral fraction-primarily to iron and aluminum oxides. The magnitude of the sorption was inversely related to $\mathrm{pH}$. In several studies, sorption of iodate to the mineral fraction of soils has been greater than sorption of iodide. Neal and Truesdale (1976) observed that there was little sorption of iodide by ferric hydroxide or kaolinite, whereas iodate sorbed strongly to ferric hydroxide. Yoshida et al. (1992) concluded that the difference was that iodide sorption was likely purely electrostatic attraction, while iodate was chemically adsorbed or exchanged by the mineral allophane or sesquioxides. Nishimaki et al. (1994) observed the same behavior of iodide versus iodate sorption, with the iodate sorption showing a two-step mechanism: an initial rapid equilibrium sorption, followed by slow non-equilibrium sorption. The conclusions of Fukui et al. (1996) were consistent with Yoshida et al. (1992), except they reported that iodide sorption seemed to be more complicated than pure electrostatic attraction. For 20 different Chinese soils, Dai et al. (2004) observed that the only strong correlation between soil properties and iodate sorption was the content of free iron and aluminum oxides.

Monomineralic studies of iodine sorption show similar results as those using bulk soils, but provide an additional level of uniformity, permitting greater interpretation of the data. In general, iodate sorbs more strongly to individual minerals than iodide and the common soil minerals that most strongly bind iodate are ferric oxides and hydroxides (Couture and Seitz 1983; Neal and Truesdale 1976; Ticknor and Cho 1990). Fuhrmann et al. (1998) observed an exception to the general iodide-iodate sorption relationship, whereby magnetite sorbed iodide more strongly than iodate. They also looked at redox changes in the sorbed iodate using XANES spectra. They observed that no reduction of iodate occurred when sorbed to the ferrous iron containing minerals biotite and magnetite, but reduction to elemental iodine did occur when iodate was sorbed to pyrite. Further reduction of the elemental iodine to iodide was not observed. Ticknor and Cho (1990) reported that iodate sorption to hematite increased with increased total dissolved solids. Their experiments were done in a synthetic groundwater with high concentrations of $\mathrm{Na}^{+}, \mathrm{Ca}^{+2}, \mathrm{Cl}^{-}$, and $\mathrm{SO}_{4}^{-2}$ (2000, 2170, 6176, and $985 \mathrm{mg} / \mathrm{L}$, respectively), indicating that the presence of one or more of these ions changed the surface chemistry of the hematite to favor iodate sorption. Relatively strong sorption of iodate to freshly precipitated aluminum hydroxide has been measured, but sorption decreased as the aluminum hydroxide aged (Musić et al. 1979).

Iodide also sorbs to common soil minerals. Musić et al. (1979) observed weak sorption of iodide to aluminum hydroxide. Sazarashi et al. (1994) measured $\mathrm{K}_{\mathrm{d}}$ values of 2 to $3 \mathrm{~mL} / \mathrm{g}$ for sorption of iodide 
onto allophane, but observed no sorption to montmorillonite. Weak sorption of iodide to imogolite and ferrihydrite was observed by Yu et al. (1996), with sorption to ferrihydrite inversely related to $\mathrm{pH}$. However, sorption onto these minerals was much less than onto a bulk soil containing these minerals and OM. Substantial sorption of iodide to common minerals has been observed by some investigators. Kaplan et al. (2000) observed strong sorption of iodide to illite, which was inversely related to $\mathrm{pH}$. Titanium oxides are a common minor component of soils, and Mishra and Srinivasu (1992) found that $73 \%$ of iodide at a concentration of $10^{-7} \mathrm{M}$ sorbed to $\mathrm{TiO}_{2}$ powder. Yet organo-clays show even stronger sorption of iodide (Bors et al. 1994).

\section{A.3 lodine Geochemistry at the Hanford Site}

A review of stable and radioiodine geochemistry at the Hanford Site was recently completed by Kaplan et al. (2012). Since then, the first two studies dealing with radioiodine speciation as it relates to the Hanford Site, specifically the 200 West Area, were published: Xu et al. (2015) and Zhang et al. (2013). This section summarizes this previous review and incorporates the findings from these latest studies.

In a compilation of iodine sorption studies using Hanford sediments, Cantrell et al. (2003) concluded that the likely range of iodine $\mathrm{K}_{\mathrm{d}}$ values was 0 to $2 \mathrm{~mL} / \mathrm{g}$ and that the most common range of values was between 0 and $0.2 \mathrm{~mL} / \mathrm{g}$. The tests they reported were almost exclusively designed to measure the extent to which radioiodine sorbed under Hanford subsurface conditions, i.e., $\mathrm{K}_{\mathrm{d}}$ value measurements, and were not designed to understand iodine speciation or sorption mechanisms (Gee and Campbell 1980; Kaplan et al. 1996, 1998; Serne et al. 1993; Um et al. 2004). Among the underlying assumptions in each of these laboratory $\mathrm{K}_{\mathrm{d}}$ measurements was that iodide was the primary species in Hanford groundwater (an assumption motivated by Figure A.1) and that it sorbed to sediments through the reversible anion exchange process (meaning iodine adsorbs and desorbs at equal rates). The recent results shown in Table A. 2 and Table A.3 contradict the assumption that only iodide exists in the Hanford subsurface environment.

The reversibility of iodine sorption to Hanford sediments has also been questioned. Researchers have reported that a large fraction of radioiodine sorbed onto Hanford sediment readily desorbs, consistent with the reversible anion exchange mechanism (or $\mathrm{K}_{\mathrm{d}}$ model) (Kaplan et al. 2000; Um et al. 2004). Yet, there was a more-strongly binding radioiodine fraction that did not desorb under chemical conditions conducive to anion exchange. Using a subsurface sediment, (ad)sorption iodide $\mathrm{K}_{\mathrm{d}}$ values were $<0.3 \mathrm{~mL} / \mathrm{g}$ (depending on iodide spike concentrations), whereas desorption $\mathrm{K}_{\mathrm{d}}$ values using the same sediments were 1.41 to $4.15 \mathrm{~mL} / \mathrm{g}$. Um et al. (2004) noted that, although sorption of iodide was very low on Hanford sediments, the iodide was only partially reversible. The sorption $\mathrm{K}_{\mathrm{d}}$ was $0.2 \mathrm{~mL} / \mathrm{g}$, but the desorption $\mathrm{K}_{\mathrm{d}}$ was $1.4 \mathrm{~mL} / \mathrm{g}$. Hu et al. (2005) made similar observations in studies of iodine sorption to Hanford sediments. Xu et al. (2015) also reported significantly greater desorption $\mathrm{K}_{\mathrm{d}}$ values than sorption $\mathrm{K}_{\mathrm{d}}$ values in three 200 West Area sediments. When iodide was added, the sorption $\mathrm{K}_{\mathrm{d}}$ values ranged from $<0.05$ to $5.64 \mathrm{~mL} / \mathrm{g}$ and the desorption $\mathrm{K}_{\mathrm{d}}$ values ranged from 11.9 to $>30 \mathrm{~mL} / \mathrm{g}$. When iodate was added, the sorption $K_{d}$ values ranged from 0.83 to $7.56 \mathrm{~mL} / \mathrm{g}$ and the desorption $\mathrm{K}_{\mathrm{d}}$ values ranged from 12.3 to $29.8 \mathrm{~mL} / \mathrm{g}$.

A geochemical process that describes strongly sorbing iodine is iodine partitioning to sediment OM. Xu et al. (2015) recently conducted studies related to this issue (Table A.4). Using three composite 
PNNL-24709, Rev. 2

RPT-DVZ-AFRI-030, Rev. 2

sediments recovered from the 200 West Area, iodate $K_{d}$ values were on average $89 \%$ greater than iodide $\mathrm{K}_{\mathrm{d}}$ values. These studies showed greater sorption in the sediments with higher OC and greater sorption of iodate than iodide to these sediments. It is especially noteworthy that this trend existed at the very low OC concentrations that naturally exist in the Hanford sediments (0.04 to $0.15 \mathrm{wt} \%$ OC). Additional measurements are needed to confirm this trend of $K_{d}$ values with the extremely low OC levels existing at Hanford.

Table A.4. Iodide and iodate $K_{d}$ values for composite sediments recovered from 200 West Area borehole cores (Xu et al. 2015).

\begin{tabular}{|c|c|c|c|c|c|c|}
\hline $\begin{array}{l}\text { Composite } \\
\text { Sediment }^{(a)}\end{array}$ & $\begin{array}{c}\text { Organic } \\
\text { Carbon } \\
(\%) \\
\end{array}$ & $\begin{array}{c}\text { Inorganic } \\
\text { Carbon } \\
(\%) \\
\end{array}$ & $\begin{array}{c}\text { Total Sediment } \\
\text { lodine } \\
(\mu \mathrm{g} / \mathrm{g})\end{array}$ & $\begin{array}{c}\text { Total DOC } \\
\left(_{(\mu \mathrm{M}){ }^{(\mathrm{b})}}\right.\end{array}$ & $\begin{array}{l}\text { lodide- } \\
\text { Spiked } \mathrm{K}_{\mathrm{d}} \\
(\mathrm{mL} / \mathrm{g})^{(c)}\end{array}$ & $\begin{array}{c}\begin{array}{c}\text { lodate- } \\
\text { Spiked } \mathrm{K}_{\mathrm{d}} \\
(\mathrm{mL} / \mathrm{g})^{(\mathrm{c})}\end{array} \\
\end{array}$ \\
\hline $\mathrm{H} 3$ & 0.15 & 0.18 & 2.10 & $94 \pm 17$ & 3.38 & 3.94 \\
\hline $\mathrm{H} 1$ & 0.12 & 0.92 & 4.79 & $284 \pm 33$ & 0.08 & 1.78 \\
\hline $\mathrm{H} 2$ & 0.04 & 0.01 & 0.68 & 0 & 0.00 & 0.83 \\
\hline
\end{tabular}

(a) $\mathrm{H} 1$ - composite of fine-grained sediments, mostly silt, from the vadose zone of borehole cores 299W11-92 and 299-W15-226. Natural calcium carbonate cementation of the sediment was apparent. $\mathrm{H} 2$ - composite from different depths within one well (299-W11-92).

$\underline{\mathrm{H} 3}$ - composite of saturated zone sediments of two different wells: 299-W11-92 and 299-W15-226.

(b) Total DOC is the total OC released from the sediment to the aqueous phase $(<0.45 \mu \mathrm{m})$ after 21 days of contact during the sediment/groundwater batch iodine uptake experiment.

(c) Suspensions were spiked with either iodide or iodate ( $\operatorname{ss}^{125} \mathrm{I}$ ), but during contact period the spiked species transformed to other species. Consequently, these are not species-specific $\mathrm{K}_{d}$ values.

Another geochemical process that may result in the strong sorption of radioiodine to sediments is the co-precipitation of $\mathrm{IO}_{3}{ }^{-}$as a trace impurity in $\mathrm{CaCO}_{3}$ phases. Carbonate minerals in subsurface systems are constantly forming and dissolving. The size of the $\mathrm{IO}_{3}{ }^{-}$ion is the same as the $\mathrm{CO}_{3}{ }^{2-}$ ion and can substitute for it in carbonate phases. It was shown that recently precipitated carbonate phases (formed by degassing $\mathrm{CO}_{2}$ from Hanford groundwater samples) scrubbed iodine from the aqueous phase and incorporated the iodate into the precipitated phase (Zhang et al. 2013) (Table A.5). The implications of this finding may provide a mechanism by which iodine is strongly bound to Hanford sediments, explaining why desorption is often found to be much slower than sorption (i.e., why desorption $\mathrm{K}_{\mathrm{d}}$ values are greater than sorption $\mathrm{K}_{\mathrm{d}}$ values). 
PNNL-24709, Rev. 2

RPT-DVZ-AFRI-030, Rev. 2

Table A.5. Suspended particles formed by $\mathrm{CO}_{2}$ degassing from 200 West

Area groundwater samples (Zhang et al. 2013).

\begin{tabular}{|c|c|c|c|c|c|c|}
\hline Wells & $\begin{array}{c}\text { Particle } \\
\text { concentration } \\
\text { (mg/L) }\end{array}$ & $\begin{array}{c}\text { Total } \\
\text { carbon } \\
\text { (wt\%) }\end{array}$ & $\begin{array}{c}\text { Total } \\
127 \mathrm{I} \\
(\mu \mathrm{g} / \mathrm{g})\end{array}$ & $\begin{array}{l}\text { Total } \\
129 \mathrm{I} \\
(\mu \mathrm{g} / \mathrm{g})\end{array}$ & $\begin{array}{l}\text { Particulate } \\
\quad(w t \%)^{(a)}\end{array}$ & $\begin{array}{l}\text { Particulate } \\
\quad(w t \%)^{(a)}\end{array}$ \\
\hline 299-W14-11 & 113.0 & 7.62 & 96.67 & 0.14 & 12.7 & 6.8 \\
\hline 299-W14-13 & 114.3 & 6.69 & 80.68 & 0.20 & 13.3 & 10.0 \\
\hline 299-W14-15 & 99.5 & 6.5 & 88.84 & 0.18 & 18.6 & 11.8 \\
\hline 299-W11-43 & 133.5 & 7.99 & 54.64 & 0.08 & 42.7 & 37.5 \\
\hline 299-W11-88 & 85.7 & 8.56 & 84.97 & 0.17 & 43.8 & 41.2 \\
\hline 699-36-70B & 87.1 & 7.44 & 63.57 & 0.18 & 39.8 & 24.9 \\
\hline 699-38-70B & 120.2 & 7.81 & 48.59 & 0.07 & 38.7 & 35.4 \\
\hline Average & 107.6 & 7.5 & 74.0 & 0.15 & 29.9 & 23.9 \\
\hline
\end{tabular}

(a) Particulate iodine percentage is defined as the percentage of iodine in particles vs. that the bulk groundwater (particulate \& dissolved), expressed as:

[particle concentration] $\times \mathrm{TI}($ particle $) /($ [particle concentration] $\times \mathrm{TI}($ particle $)+\mathrm{TI}($ dissolved/filtered $))$

Iodine speciation changed once the spike solution came into contact with the sediments, indicating that Table A.4 is not reporting species-specific $K_{d}$ values, but instead represents $K_{d}$ of a suite of iodine species. The importance of evaluating a species-specific approach to describing radioiodine speciation is that it may provide an ${ }^{129}$ I fraction that is nearly irreversibly bound to the sediment and may provide a more accurate representation of ${ }^{129}$ I transport.

The significance of the data in Table A.5 is that iodate typically sorbs to sediments greater than iodide. No sorption testing has been conducted with Organo-I, but it too may sorb appreciably more than iodide to sediments. These findings bring into question whether the present Hanford ${ }^{129} \mathrm{I} \mathrm{K}_{\mathrm{d}}$ values, albeit conservative, adequately represent the sorption anticipated by the more strongly sorbing iodate and Organo-I species. The presence of multiple iodine species would not influence the expected extent of a Hanford plume, as the presence of the fastest moving species, iodide, would not change. However, the presence of iodate or Organo-I would be expected to move slower, thereby changing the distribution of the total ${ }^{129}$ I concentrations within the plume.

Chang et al. (2014) developed an integrated model describing multiple physiochemical and enzyme catalyzed reactions based on detailed iodine speciation data obtained from laboratory experiments using organic-rich and organic-poor soils from SRS. The model accounted for iodine speciation, interconversion kinetics ( $\mathrm{I}^{-}, \mathrm{IO}_{3}^{-}$, Organo-I, and colloidal-I), reversible partitioning to SOM and mineral surfaces, irreversible covalent bonding to SOM, and abiotic and biotic (enzymatic/catalyst-type) reactions. Modeling results strongly supported the assertion that iodine-SOM interactions dominate iodine geochemistry; the iodine uptake coefficient for SOM $\left(\mathrm{K}_{\mathrm{d}}\right)$ was an order-of-magnitude greater than that for mineral surfaces. The proposed model simulated well the iodine partitioning among the soil, colloid, and solution phases. The model revealed that during the first 14 days of contact, most iodine in soil was comprised of $\mathrm{I}^{-}$or $\mathrm{IO}_{3}{ }^{-}$associated with mineral surfaces and reversibly bound to SOM. After 14 days, the continued uptake of iodine by soil was attributed primarily to the irreversible bonding of Organo-I to SOM. Finally, the model was successfully validated using an independent experimental data set. This biogeochemical modeling study underscores the importance of capturing the dynamic nature of 
iodine speciation transformations and the importance of treating SOM as a sink (irreversible covalent bonding) and a source (colloidal- and Organo-I mobile species) for subsurface iodine.

\section{A.4 Biological lodine Conversion}

\section{A.4.1 Overview}

Biological cycling of iodine is an important process that likely affects fate and transport of iodine in the Hanford subsurface. Iodine can be present in the environment in the form of iodide $\left(\mathrm{I}^{-}\right)$, molecular iodine $\left(\mathrm{I}_{2}\right)$, iodate $\left(\mathrm{IO}_{3}{ }^{-}\right)$, and organic iodine compounds, including volatile compounds, such as methyl iodide $\left(\mathrm{CH}_{3} \mathrm{I}\right)$. Understanding the different biological processes involved in cycling of iodine between the different species will allow for (1) better prediction of biogeochemical impacts related to transport, (2) development of better informed bioremediation strategies to control transport, and (3) processes driving current speciation in Hanford groundwater.

Microorganisms are important catalysts for the cycling of iodine in the environment, and can affect partitioning of iodine between water, soil, and air through redox transformations. Much of the existing knowledge about iodine biogeochemistry in the environment has been generated from studies looking at cycling of iodine, both ${ }^{127} \mathrm{I}$ and ${ }^{129} \mathrm{I}$, in marine and freshwater environments (Gilfedder et al. 2009). Speciation of iodine in marine systems depends on geographical location, as well as depth in the water column (Chance et al. 2014). These differences are postulated to be related to the presence of oxygen and effects of redox on iodine oxidation and reduction. In oxic seawater, iodine speciation is dependent on where in the water column the samples are taken. Water from deep in the ocean contain low levels of $\mathrm{I}^{-}$ ( $\sim 10 \mathrm{nM}$ ), while $\mathrm{IO}_{3}{ }^{-}$dominates, accounting for greater than $95 \%$ of the iodine present (Žic et al. 2008). Water samples at the surface and in some shelf seas have roughly equal distribution of $\mathrm{I}^{-}$and $\mathrm{IO}_{3}{ }^{-}$. Reduction of $\mathrm{IO}_{3}{ }^{-}$near the surface has been hypothesized to occur in association with primary productivity, which is defined as the conversion of inorganic carbon to organic carbon by photosynthetic single (prokaryotes) and multicellular (algae) organisms (Finkel 2014). Many phototrophs have been characterized for their ability to reduce $\mathrm{IO}_{3}{ }^{-}$in these oxic environments through the activity of nitrate reductase enzymes. These enzymes are typically responsible for reduction of nitrate to nitrite by microorganisms. Concentrations of organic iodine can approach $100 \mathrm{~nm}$ in near-shore environments. In contrast, in anoxic ocean environments, such as deep sea trenches, oxygen minimum zones, and the Black Sea, $\mathrm{I}^{-}$is the dominant form and $\mathrm{IO}_{3}{ }^{-}$is absent. These results suggest that where oxygen is present, $\mathrm{I}^{-}$ oxidation to $\mathrm{IO}_{3}{ }^{-}$occurs, and in the absence of oxygen, $\mathrm{IO}_{3}{ }^{-}$reduction to $\mathrm{I}^{-}$is the dominant process.

More recently, due to accidents like Fukushima and subsurface contamination at DOE sites, such as Hanford, increased interest in understanding the effects of microbial transformation of radioiodine on fate and transport has been established (Hou et al. 2013; Kincaid et al. 2006; Zhang et al. 2013). Major pathways of iodine cycling affected by microbes, include volatilization of organic iodine compounds into the gas phase, oxidation and reduction of inorganic iodine species, accumulation of iodine species by microorganisms, and microbially mediated sorption of iodine into SOM (Amachi et al. 2005a, 2008; Hu et al. 2009, 2012; Kaplan et al. 2013; Küpper et al. 2011). While these processes are discussed individually, there is often connectivity between the processes (e.g., iodide oxidation leading to volatilization and formation of organic iodine compounds). In addition, there are microbially catalyzed processes, such as iron and sulfate reduction, that indirectly influence iodine speciation. 
PNNL-24709, Rev. 2

RPT-DVZ-AFRI-030, Rev. 2

The iodine cycle as proposed for the subsurface is shown in Figure A.2. One primary difference between the iodine cycle in the subsurface and in a marine system would be the absence of iodine conversion reactions catalyzed by phototrophs, as well as photo-oxidation of volatile iodine species in the atmosphere. Speciation of iodine, especially radioiodine, is important because speciation of iodine will affect interaction with geological media, which will in turn affect fate and transport.

When considering ex situ treatment strategies for iodine-contaminated groundwater, the complete iodine cycle, including phototrophs and photooxidation of volatile organic iodine species, must also be considered. Interconversion between iodine species will affect interaction with sorption technologies.

This section looks at biotransformation on iodine speciation, in a broad sense, and proposed effects on iodine fate and transport. While iodine species in the Hanford subsurface are predominantly iodate and organic iodine, understanding all aspects of iodine cycling is important and will help to determine how this species distribution was formed. Since both in situ and ex situ processes are relevant for remediation of iodine, all aspects of iodine cycling are discussed.

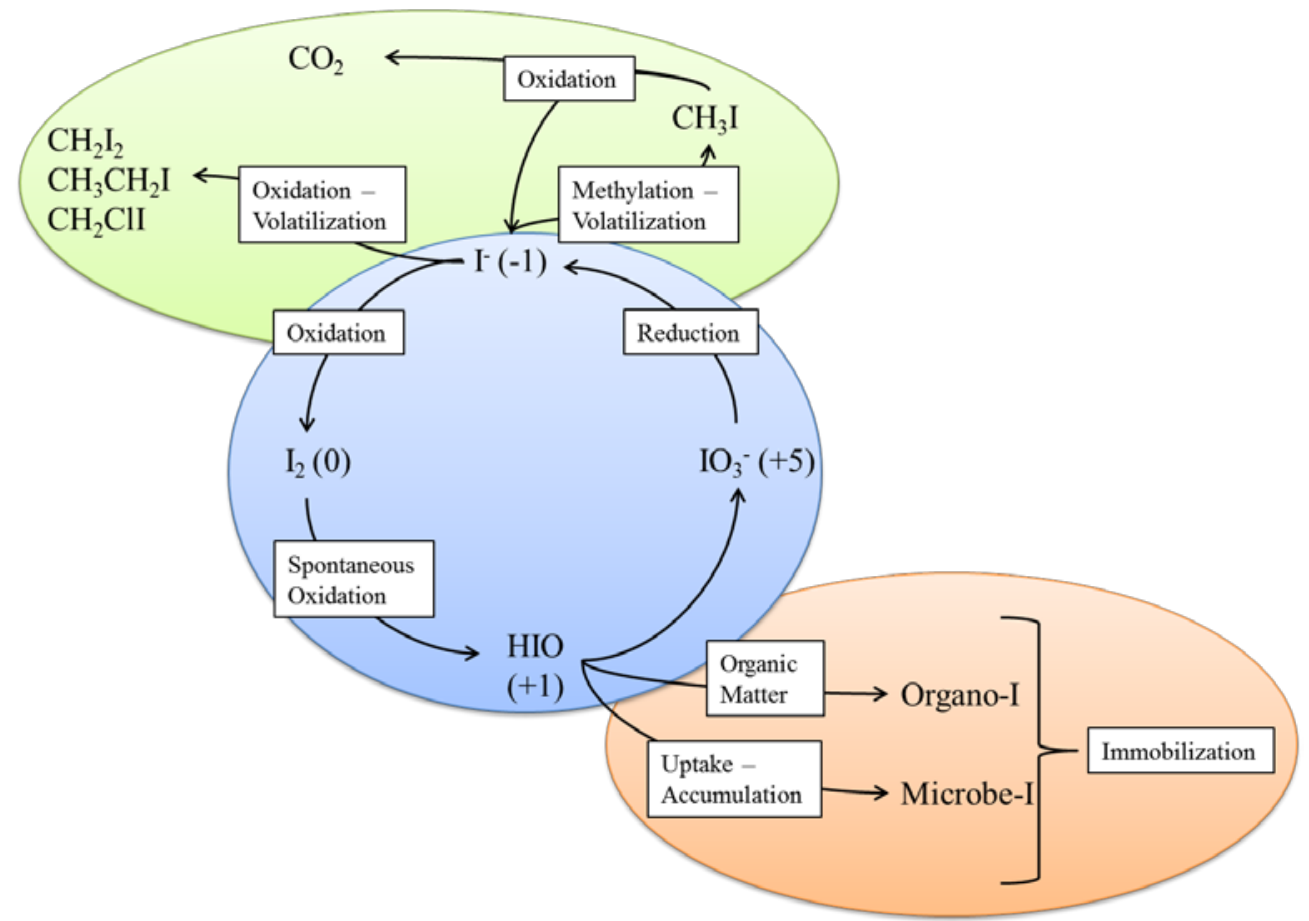

Figure A.2. Biological transformations associated with iodine cycling in the environment. The blue ellipse represents predominantly aqueous-phase iodine species. The orange ellipse represents predominantly solid-phase species of iodine associated with organic compounds (Organo-I) or accumulated in microbial biomass (Microbe-I). Some types of Organo-I may also be mobile in the aqueous phase. The green ellipse represents predominantly gas-phase volatile Organo-I compounds.

\section{A.4.2 lodide Oxidation}

While iodide concentrations in Hanford groundwater are below 5\% of the total iodine, waste knowledge indicates most iodine in the liquid waste should be in the form of iodide. For this reason, 
understanding oxidation of iodide is important to understanding the current species distribution in the Hanford groundwater. Bacterial oxidation of iodide has been recognized as an important part of the iodine cycle in marine environments for decades (Tsunogai and Sase 1969). Elucidation of an iodide oxidation mechanism based on an extracellular oxidative enzyme produced by Pseudomonas iodooxidans was first discussed in the 1970s (Gozlan and Margalith 1973, 1974). Iodide in an aquarium was oxidized to iodine, causing fish mortality; an extracellular peroxidase system, in the presence of polysaccharides, was shown to catalyze the reaction.

Two environments in which iodide-oxidizing bacteria have been found include natural gas brines and marine environments (Amachi et al. 2005b; Arakawa et al. 2012; Žic et al. 2008). Iodine-oxidizing bacteria have also been isolated from corroding pipes at an iodine production facility in China (Wakai et al. 2014). Roseovarius tolerans is an iodide-oxidizing bacterium that was isolated from natural gas brines, where populations of iodide-oxidizing bacteria were up to $10^{5}$ colony forming units per milliliter of water (Amachi et al. 2005b). The oxidation of iodide to molecular iodine was catalyzed by an extracellular enzyme that required oxygen. Two bacteria closely related to $R$. tolerans have also been isolated from marine samples, and were able to produce free iodine from iodide (Fuse et al. 2003). Three Roseovarius species capable of iodide oxidation to iodine were also isolated from water and biofilms collected from a natural gas plant. The marine bacterium Roseobacter species AzwK-3Gb, which has been characterized as a manganese-oxidizing bacterium, has also been shown to oxidize iodide to iodine (Li et al. 2014). Iodide oxidation was catalyzed by production of superoxides in the growth medium.

A number of bacteria from the Firmicute family, isolated from the F Area at SRS, were also shown to oxidize iodide to iodine ( $\mathrm{Li}$ et al. 2012b). Hydrogen peroxide-dependent iodide oxidation was enhanced by the addition of organic acids, indicating that peroxy carboxylic acids were a strong oxidant for iodide oxidation. The effect of acids on iodide oxidation improved as the $\mathrm{pH}$ of the growth medium decreased from 9 to 4 .

Production of the enzyme laccase, or other laccase-like multicopper oxidase (LMCO) enzymes produced by fungi and bacteria, has also been shown to catalyze the oxidation of iodide (Ihssen et al. 2014; Kulys et al. 2005; Suzuki et al. 2012). Iodide oxidation by Roseovarius species discussed above is thought to be catalyzed by a LMCO enzyme (Amachi et al. 2005b; Arakawa et al. 2012). An $\alpha$-Proteobacteria designated strain Q-1 that was isolated from iodide-rich natural gas brine water was shown to oxidize iodide to iodine using an oxidase-like enzyme (Suzuki et al. 2012). Characterization of the enzyme showed similarity to multicopper oxidase enzymes. Laccases and other LMCO enzymes have also been shown to catalyze addition of iodine to organic matter during the iodide oxidation process, yielding volatile Organo-I species or more complex Organo-I species. This function is discussed in a later section.

Microbial oxidation of $\mathrm{I}^{-}$to $\mathrm{I}_{2}$ and $\mathrm{IO}_{3}{ }^{-}$is another important process that could affect iodine speciation in the Hanford groundwater. While $\mathrm{I}^{-}$concentrations in Hanford groundwater are below $5 \%$ of the total iodine, the potential for biological $\mathrm{I}^{-}$oxidation will provide insight into current speciation, and prevalence of $\mathrm{IO}_{3}{ }^{-}$, in the 200 West Area groundwater. A number of bacterial isolates from the Hanford groundwater have been shown to oxidize to $\mathrm{I}^{-}$to $\mathrm{I}_{2}$ (Figure A.3 and Table A.6). While not all bacterial species tested were able to oxidize I', most species tested appeared to have this physiological ability. Analyses are currently being performed to determine whether complete conversion to $\mathrm{IO}_{3}{ }^{-}$is occurring. 
PNNL-24709, Rev. 2

RPT-DVZ-AFRI-030, Rev. 2

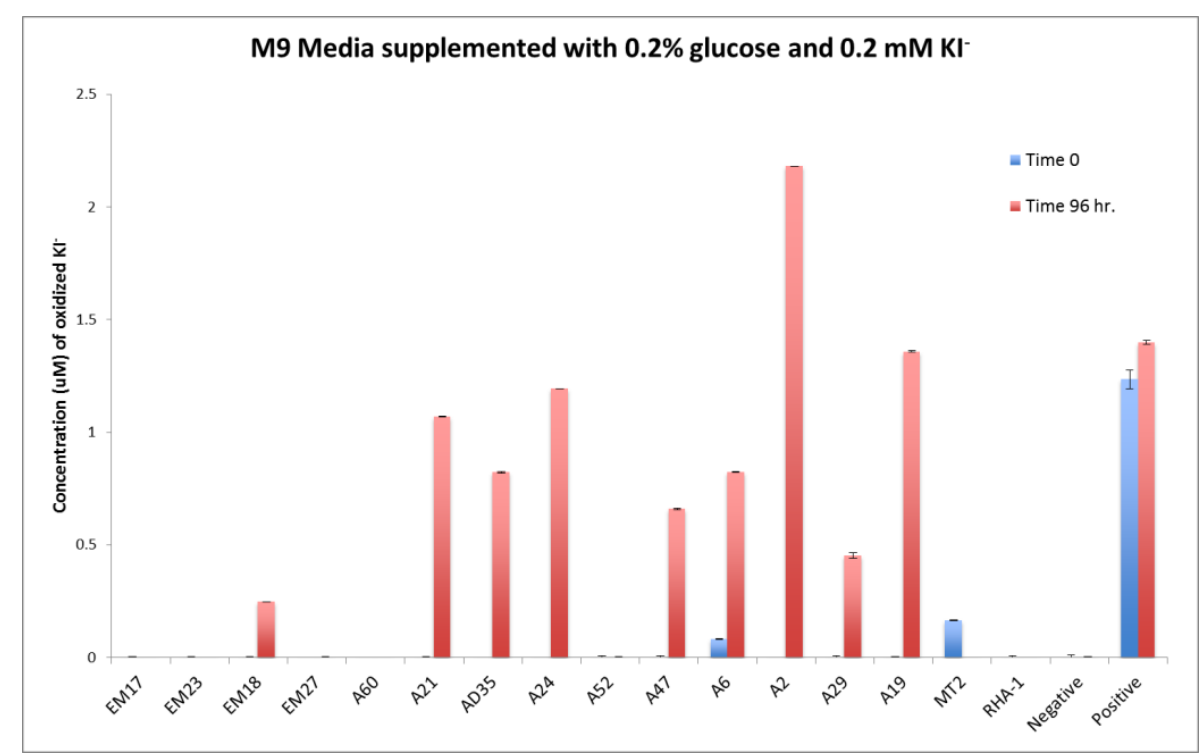

Figure A.3. Hanford isolates capable of oxidizing I- (see Table A.6 for identity).

Table A.6. Identity of bacterial species isolated from Hanford groundwater that were tested for the ability to oxidize $\mathrm{I}^{-}$to $\mathrm{I}_{2}$ and $\mathrm{IO}_{3}{ }^{-}$.

\begin{tabular}{ll}
\hline Strain & Affiliation (accession number) \\
\hline EM17 & Ralstonia sp. PNP11 (DQ887520.1) \\
EM23 & Pseudomonas frederiksbergensis strain DSM 13022 (NR_117177.1) \\
EM18 & Pseudomonas sp. PAMC 26822 (KF011696.1) \\
EM27 & Pseudomonas mandelii strain NF22-1 (KF151354.1) \\
A60 & Cupriavidus necator strain N-1 (NR_028766.1) \\
21 & Arthrobacter ilicis strain ICMP 2608 (NR_104950.1) \\
AD35 & Agrobacterium tumefaciens strain IAM 12048 (NR_041396.1) \\
A24 & Pseudomonas mosselii strain CFML 90-83 (NR_024924.1) \\
A52 & Lysobacter niastensis strain GH41-7 (NR_043868.1) \\
A47 & Shinella kummerowiae strain CCBAU 25048 (NR_044066.1) \\
A6 & Pseudomonas mosselii strain CFML 90-83 (NR_024924.1) \\
A2 & Bacillus thuringiensis strain IAM 12077 (NR_043403.1) \\
A29 & Enterobacter hormaechei strain 0992-77 (NR_042154.1) \\
A19 & Microbacterium invictum strain DC-200 (NR_042708.1) \\
MT2 & Pseudomonas putida \\
RHA1 & Rhodococcus jostii \\
\hline
\end{tabular}

\section{A.4.3 lodine Bioaccumulation}

Iodine is an element that accumulates in biological material, including vertebrates, algae, coral, sponges, lobworms, and shellfish. Accumulation of iodine is important from a health perspective because radioiodine concentrates in the thyroid gland in mammals. Most studies of iodine accumulation have 
been performed on thyroid tissue and in brown algae. More recently, iodine accumulation by bacteria, as well as other phototrophs, has been studied.

Laminaria digitata is a brown algae (kelp) that has been shown to accumulate iodine to levels ranging from $0.4 \%$ to $4.7 \%$ of the organism's dry weight, depending on the stage of growth (Küpper et al. 1998). This yields an accumulation of 30,000 times the iodine levels found in seawater (Colin et al. 2003; Küpper et al. 1998). X-ray absorption spectroscopy studies have shown that the accumulated form of iodine in L. digitata is iodide and that the purpose of iodide in this organism is to act as an inorganic antioxidant (Küpper et al. 2008). In this function, iodide scavenges reactive oxygen species, leading to efflux of the iodide into the external environment in the form of iodide and volatile iodocarbons (discussed in a later section). Iodine uptake and formation of iodo-organic compounds has been shown to be catalyzed by vanadium-dependent haloperoxidases, specifically iodoperoxidases (Colin et al. 2003; La Barre et al. 2010). These enzymes oxidize iodide to iodine $\left(\mathrm{I}_{2}\right)$, hypoiodous acid (HIO), which is then taken up into the cell, where it spontaneously reverts to iodide, which can be associated with cellular material (Verhaeghe et al. 2008).

Accumulation of iodine in other algal species and diatoms has also been demonstrated (Manley 2009; Osterc and Stibilj 2012; Shimura et al. 2012; Thorenz et al. 2014; van Bergeijk et al. 2013). Regardless of the species, uptake appears to occur through the mechanism of a haloperoxidase, with or without hydrogen peroxide.

Until recently, only a few instances of bacterial accumulation of iodine could be found. More recently, a number of aerobic bacteria have been found that are able to accumulate iodine (Amachi et al. 2005c, d; Fournier et al. 2014; Li et al. 2011; MacLean et al. 2004). Similar uptake of iodine has not been demonstrated in anaerobic bacteria, indicating that iodide uptake in bacteria may occur through oxidative processes. A vanadium iodoperoxidase from Zobella galactanivorans has been demonstrated (Fournier et al. 2014). Amachi et al. (2005c) demonstrated iodine uptake in a number of bacteria common to marine and terrestrial environments. One bacterium, Arenibacter troitsensis strain C-21, was able to accumulate $80 \%$ of a $0.1 \mu \mathrm{M}$ iodide solution. Uptake by this bacterium appeared to be catalyzed by hydrogen peroxide produced by a glucose oxidase enzyme (Amachi et al. 2007a). A proposed haloperoxidase enzyme then oxidizes the iodide using hydrogen peroxide as the oxidant, yielding iodine or hypoiodous acid, which then diffuses into the cell. These two species of bacteria are of particular interest because they are both members of the family Flavobacteriaceae, which have been found in groundwater at Hanford. Iodine accumulation by bacteria is more pertinent to the subsurface of Hanford, where bacteria are the dominant organism that may possess this ability.

Experiments have not been performed to understand the ability of Hanford bacteria to accumulate stable or radioiodine.

\section{A.4.4 lodine Volatilization}

Methyl iodide is a volatile iodine compound that plays a large role in carrying iodine from terrestrial and marine environments to the atmosphere. Many examples of iodine volatilization can once again come from looking at the activity of algae and microalgae in oceans and other freshwater bodies of water. Likewise, some terrestrial environments harbor bacteria that catalyze methylation of iodide, yielding volatile iodine species. As mentioned previously, organic iodine compounds are commonly produced during the oxidation of iodide to iodine, while in other bacteria, iodide is directly methylated by the enzymatic activity of microbes. During oxidation of iodide to iodine, a range of organic compounds are 
produced, while direct methylation produces methyl iodide. Once in the atmosphere, methyl iodide is broken down by sunlight and the iodine produced is deposited back to terrestrial or marine environments with precipitation. While there is potential for volatilization of iodine in the subsurface, photolysis would not be expected.

On a global level, phototrophs in marine environments have been shown to produce up to $10^{6}$ to $10^{10} \mathrm{~g}$ of methyl iodide $\left(\mathrm{CH}_{3} \mathrm{I}\right)$ per year (Stemmler et al. 2014). In addition, $\mathrm{CH}_{3} \mathrm{I}$ is known to play a significant role in the global iodine cycle (Klick and Abrahamsson 1992). $\mathrm{CH}_{3} \mathrm{I}$ has been demonstrated by microalgae, phytoplankton, and cyanobacteria (Hughes et al. 2011; Karlsson et al. 2008; La Barre et al. 2010; Thorenz et al. 2014). In most cases, methylation of iodide is thought to be catalyzed by the activity of the enzyme S-adenosyl-L-methionine (SAM) methyltransferase (Ohsawa et al. 2001; Toda and Itoh 2011).

In-depth analysis of bacterial involvement in volatilization of iodine from soil was part of a study looking at cycling of iodine in rice paddy soil (Muramatsu et al. 1996). Likewise, volatile iodine production was noted in soil, seawater, and bacterial cell suspensions (Amachi et al. 2000). Analysis of volatile fractions recovered in silver mesh or granular activated carbon indicated that volatile species were primarily Organo-I, rather than volatile $\mathrm{I}_{2}$. Involvement of soil bacteria in the volatilization of iodine was further supported in a study comparing iodine emissions from rice paddy, upland field, forest, and wetland soil (Amachi et al. 2003). Microbial catalysis of volatile iodine species was further supported when iodine emissions ceased when soils were autoclaved or when antibiotics were added to inhibit bacterial activity. Interestingly, iodine emission was not affected when fungal inhibitors were added, showing the prevalence of bacteria in iodine volatilization from soils. Molecular characterization of bacteria isolated from the soil showed that iodine-volatilizing bacteria are widespread and not confined to a specific group of bacteria. Bacteria were distributed in Proteobacteria ( $\alpha, \beta$, and $\gamma$ subdivisions), Cytophaga-Flexibacter-Bacteriodes (CFB) Group, and high G+C Gram-positive bacteria. $\mathrm{CH}_{3} \mathrm{I}$ was the primary volatile iodine species found during these studies.

A similar study was performed using samples of seawater to determine whether bacteria were involved in volatilization of iodine in marine environments (Amachi et al. 2004). Similar groups of bacteria, $\alpha$ - and $\gamma$-Proteobacteria, and the CFB group were isolated and shown to volatilize iodide to $\mathrm{CH}_{3}$ I. Experiments also showed that iodate was not converted to $\mathrm{CH}_{3} \mathrm{I}$. When samples were autoclaved, filtered to remove bacteria, or antibiotics were added, little volatilization of iodide was shown. One of the bacteria isolated during these experiments was able to volatilize up to $2 \%$ of the total iodine added to the growth medium to $\mathrm{CH}_{3} \mathrm{I}$.

Bacteria isolated from brackish water were shown to methylate a range of halides, including iodide (Fujimori et al. 2012). Five genetically distinct species belonging to the genera Erythrobacter or Pseudomonas were able to produce $\mathrm{CH}_{3} \mathrm{I}$ when grown in the presence of iodide. These bacteria represent species of $\alpha$ - and $\gamma$-Proteobacteria. Analysis of the headspace of the vials showed primarily $\mathrm{CH}_{3} \mathrm{I}$ and not other iodinated volatiles.

Recent research has shown that a wide variety of marine and terrestrial bacteria also volatilize iodine through the methylation of iodide (Amachi et al. 2001). Six out of ten terrestrial bacteria tested were shown to methylate iodide, while seven out of ten marine bacteria were shown to methylate iodide. In these same studies, anaerobic bacteria (Clostridia and methanogens) did not appear to methylate iodide. The cell extract from a Rhizobium species was shown to methylate iodide when SAM was used as the methyl donor, indicating that bacteria may use a similar mechanism to phototrophs. 
Along with $\mathrm{CH}_{3} \mathrm{I}$, a number of other volatile Organo-I compounds can be formed during oxidation of iodide. Two bacterial species closely related to Roseovarious tolerans that were isolated from marine samples were able to produce $\mathrm{CH}_{2} \mathrm{I}_{2}$ and $\mathrm{CH}_{2} \mathrm{ClI}$ from constituents in the growth medium (Fuse et al. 2003). Molecular iodine was also a product of iodide oxidation by these bacteria. Bacteria that produced the volatile organic compounds were grown in media containing yeast extract and peptone.

Since volatilization of iodine has been shown to be linked to I' oxidation, this process may occur in Hanford groundwater since I' oxidation was demonstrated by Hanford bacterial isolates. Formation of volatile Organo-I species during the $\mathrm{I}^{-}$oxidation process is currently being tested.

\section{A.4.5 Iodination of Organic Material}

In addition to volatile organic compounds, oxidation of iodide can also lead to the generation of more complex organic iodine compounds, including iodinated SOM. This process becomes very important for soils that contain large amounts of organic material. Some of the peroxidase enzymes discussed in the iodide oxidation section also catalyze iodination of other organic compounds. Laccases are involved in a process called "humification," in which polyaromatic humic acid structures become linked through phenoxy-free radical catalyzed polymerization (Chefetz et al. 1998). In terrestrial ecosystems, such as peatlands, this process is thought to be key in storage of iodine in these environments (Keppler et al. 2003). Iodine bound to the humic fraction of peat material can be stable for thousands of years.

In a study using nine organic soils, experiments showed that iodide removal was increased in soils with microbial activity (Koch et al. 1989). In soils that were fed with glucose, iodide decreased, while in soils that had been treated with thymol or gamma irradiation, iodide removal was depressed. While microbial iodide removal was thought to be the dominant process in these soils, some residual iodide removal activity occurred, indicating some abiotic factors may have been responsible. Specific mechanisms of iodine removal were not determined, only iodide removal with organic containing soil and microbial activity was determined.

A microbial enzyme that is responsible for the breakdown of lignin and other aromatic-containing compounds has also been shown to catalyze iodination of SOM. These enzymes are copper oxidase enzymes commonly known as laccases. Laccases are produced by fungi and bacteria and are commonly found in many soil microorganisms. As discussed above, laccases have also been implicated in the oxidation of iodide. Formation of Organo-I is thought to occur when iodide is transformed into more reactive species such as $\mathrm{I}_{2}$, $\mathrm{HIO}$, or $\mathrm{I}_{3}{ }^{-}$(Moulin et al. 2001). Similar results were demonstrated using the radioactive iodide tracer ${ }^{125} \mathrm{I}^{-}$. Soils with high laccase activity showed positive correlation to enhanced sorption of iodide (Seki et al. 2012). Treatment of soil by autoclaving, gamma-irradiation, or heat significantly inhibited iodide sorption. Likewise, the addition of laccase to autoclaved soils partially restored iodide sorption to the soils. Laccase oxidation to $\mathrm{I}_{2}$ or $\mathrm{HIO}$ was thought to drive iodide sorption to the soils.

A study of soils from Chiba, Japan, indicated that in the soil column, pore-water contained Organo-I and iodide species, while analysis of the soil fraction indicated only Organo-I (Shimamoto et al. 2011). As with previous studies, laccase activity in these soils was high and was likely driving the process.

Similar results have been demonstrated in organic-rich soils at SRS. Analysis of ${ }^{127} \mathrm{I}$ and ${ }^{129} \mathrm{I}$ in surface soils near the F Area of SRS indicated that the humic acid fraction of the SOM accounted for up to $56 \%$ of the iodine in the soil (Xu et al. 2011b). Iodination of the soils appeared to be affected by 
molecular size of the SOM fraction, composition, and availability of iodine binding sites. In soil resuspension experiments, to simulate surface runoff and stormwater flow, newly added iodide and iodate appeared to be irreversibly bound to organic-rich riparian soil (Xu et al. 2011a). The remainder of the iodine appeared to form complexes that represent a truly mobile Organo-I fraction. Soils from a wetland zone adjacent to the F Area was enriched for microbes capable of iodide oxidation (Li et al. 2012a). Results showed that when microbes were active in some soils, Organo-I was the dominant species, with iodide being the second most abundant. As demonstrated in other studies, removing microbial activity by autoclaving stopped the Organo-I formation process.

Since iodination of organic material has been shown to be linked to $\mathrm{I}^{-}$oxidation, this process may occur in Hanford groundwater since I' oxidation was demonstrated by Hanford bacterial isolates. Understanding this process will be important since approximately $25 \%$ of the iodine species in Hanford groundwater is Organo-I.

\section{A.4.6 lodate Reduction}

Iodate can be used as an alternate electron acceptor for growth, and is converted to iodide under anaerobic or microaerobic conditions. To date, nitrate-reducing, iron-reducing, and sulfate-reducing bacteria have been found to reduce iodate. Likewise, a number of phototrophs, such as diatoms and algae, have been shown to reduce iodate (Bluhm et al. 2010; Chance et al. 2007, 2009; Hung et al. 2005). Few studies have demonstrated the bacterial reduction of iodate. Amachi et al. (2007b) demonstrated the dissimilatory iodate reduction by Pseudomonas sp. SCT, isolated from marine sediment slurry, in the presence of nitrate under anaerobic conditions. During these experiments, cells pre-grown without iodate did not reduce it, nor could they reduce iodate aerobically (Amachi et al. 2007b). The iodate-reducing enzyme, which was called an iodate reductase, was found in the periplasmic space, which is located between the inner and outer membranes of this bacterium.

Tsunogai and Sase (1969) reported several marine laboratory strains of nitrate-reducing bacteria to reduce iodate aerobically, concluding that iodate is reduced in a coupled mechanism by nitrate reductases (Tsunogai and Sase 1969). Other studies have shown microbial reduction of iodate with anaerobic cell suspensions of Desulfovibrio desulfuricans and marine bacterium Shewanella putrefaciens (Councell et al. 1997). In addition to these two bacterial species being able to directly reduce iodate to iodine, soluble ferrous iron and sulfide, as well as iron monosulfide produced by the metabolism of these microbes, were shown to abiotically reduce iodate to iodide. Likewise, $S$. putrefaciens strain MR-4 was shown to reduce iodate to iodide (Farrenkopf et al. 1997).

Reduction of $\mathrm{IO}_{3}{ }^{-}$has also been demonstrated by the perchlorate respiring bacterium strain GR1 (Kengen et al. 1999). An enzyme that was isolated from the periplasm of this bacterium was shown to reduce perchlorate, chlorate, nitrate, iodate, and bromate.

Sediments from traps incubated in iodine-contaminated groundwater at the Hanford Site have yielded a number of bacterial isolates that can oxidize or reduce different iodine species. Since the dominant iodine species in 200-UP-1 groundwater has been shown to be $\mathrm{IO}_{3}{ }^{-}$, experiments were performed to determine the ability of various Hanford isolates to reduce $\mathrm{IO}_{3}{ }^{-}$in the presence of nitrate, a common cocontaminant in the 200-UP-1 groundwater. One isolate designated AD35, which is most closely related to Agrobacterium tumefaciens, has been shown to reduce $\mathrm{IO}_{3}^{-}$to $\mathrm{I}^{-}$in the presence of nitrate (Figure A.4). 
PNNL-24709, Rev. 2

RPT-DVZ-AFRI-030, Rev. 2

Iodate reduction occurred under both anaerobic and microaerobic conditions. When the culture was spiked with nitrate, $\mathrm{IO}_{3}{ }^{-}$concentrations continued to decrease in the culture medium.

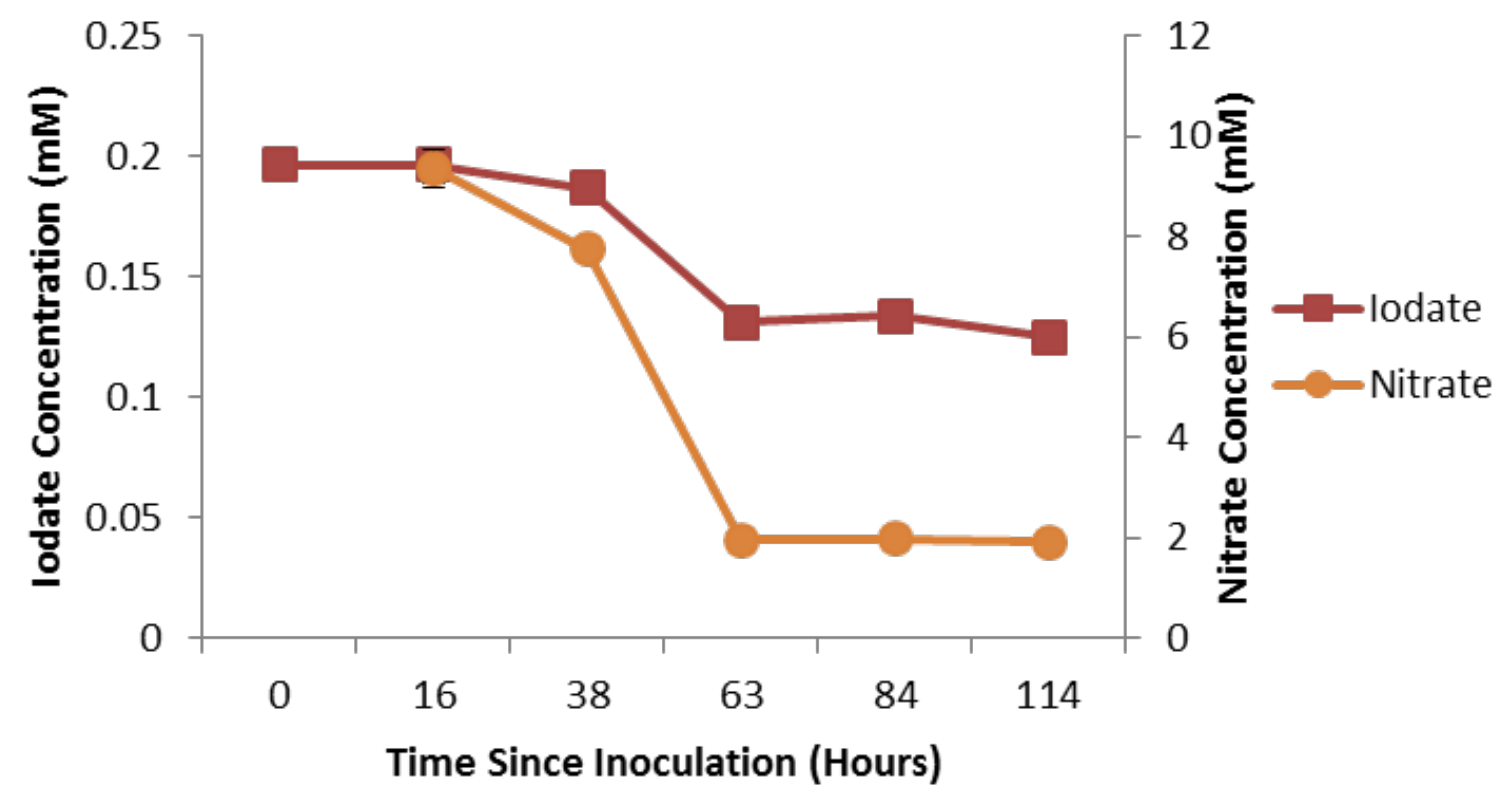

Figure A.4. Iodate reduction in the presence of nitrate by an Agrobacterium species isolated from sediment traps that were incubated within an iodine plume in the 200 West Area.

\section{A.5 References}

Amachi, S. 2008. "Microbial Contribution to Global Iodine Cycling: Volatilization, Accumulation, Reduction, Oxidation, and Sorption of Iodine.” Microbes and Environments, 23(4):269-276.

Amachi, S., Muramatsu, Y., and Kamagata, Y. 2000. "Radioanalytical Determination of Biogenic Volatile Iodine Emitted from Aqueous Environmental Samples.” J. Radioanalytical and Nuclear Chemistry, 246(2):337-341.

Amachi, S., Kamagata, Y., Kanagawa, T., and Muramatsu, Y. 2001. "Bacteria Mediate Methylation of Iodine in Marine and Terrestrial Environments.” Applied and Environmental Microbiology, 67(6):2718-2722.

Amachi, S., Kasahara, M., Hanada, S., Kamagata, Y., Shinoyama, H., Fujii, T., and Muramatsu, Y. 2003. "Microbial Participation in Iodine Volatilization from Soils.” Environ. Sci. Tech., 37(17):3885-3890.

Amachi, S., Kasahara, M., Fujii, T., Shinoyama, H., Hanada, S., Kamagata, Y., Ban-Nai, T., and Muramatsu, Y. 2004. "Radiotracer Experiments on Biological Volatilization of Organic Iodine from Coastal Seawaters.” Geomicrobiology J., 21(7):481-488. 
PNNL-24709, Rev. 2

RPT-DVZ-AFRI-030, Rev. 2

Amachi, S., Fujii, T., Shinoyama, H., and Muramatsu, Y. 2005a. "Microbial Influences on the Mobility and Transformation of Radioactive Iodine in the Environment." J. Nuclear and Radiochemical Sciences, 6(1):21-24.

Amachi, S., Muramatsu, Y., Akiyama, Y., Miyazaki, K., Yoshiki, S., Hanada, S., Kamagata, Y., Ban-nai, T., Shinoyama, H., and Fujii, T. 2005b. "Isolation of Iodide-Oxidizing Bacteria from Iodide-Rich Natural Gas Brines and Seawaters.” Microbial Ecology, 49(4):547-557.

Amachi, S., Mishima, Y., Shinoyama, H., Muramatsu, Y., and Fujii, T. 2005c. “Active Transport and Accumulation of Iodide by Newly Isolated Marine Bacteria.” Applied and Environmental Microbiology, 71(2):741-745.

Amachi, S., Muramatsu, Y., Shinoyama, H., and Fujii, T. 2005d. “Application of Autoradiography and a Radiotracer Method for the Isolation of Iodine-Accumulating Bacteria.” $J$. Radioanalytical and Nuclear Chemistry, 266(2):229-234.

Amachi, S., Kimura, K., Muramatsu, Y., Shinoyama, H., and Fujii, T. 2007a. "Hydrogen PeroxideDependent Uptake of Iodine by Marine Flavobacteriaceae Bacterium Strain C-21.” Applied and Environmental Microbiology, 73(23):7536-7541.

Amachi, S., Kawaguchi, N., and Muramatsu, Y. 2007b. "Dissimilatory Iodate Reduction by Marine Pseudomonas sp. Strain SCT.” Appl. Environ. Microbiol., 73(18):5725-5730.

Arah, J.R.M., and Kirk, G.J.D. 2000. “Modeling Rice Plant-Mediated Methane Emission.” Nutrient Cycling in Agroecosystems, 58(1-3):221-230.

Arakawa, Y., Akiyama, Y., Furukawa, H., Suda, W., and Amachi, S. 2012. “Growth Stimulation of Iodide-Oxidizing $\alpha$-Proteobacteria in Iodide-Rich Environments.” Microbial Ecology, 63(3):522-531.

Ashworth, D.J., and Shaw, G. 2006. "Effects of Moisture Content and Redox Potential on In Situ $\mathrm{K}_{\mathrm{d}}$ Values for Radioiodine in Soil.” Science of The Total Environment, 359(1-3):244-254.

Ashworth, D.J., Shaw, G., Butler, A.P., and Ciciani, L. 2003. “Soil Transport and Plant Uptake of Radio-Iodine from Near-Surface Groundwater.” J. Environmental Radioactivity, 70(1-2):99-114.

Assemi, S., and Erten, H.N. 1994. "Sorption of Radioiodine on Organic Rich Soil, Clay Minerals, and Alumina.” J. Radioanalytical and Nuclear Chemistry, 178:193-204.

Baas-Becking, L.G.M., Kaplan, I.R., and Moore, D. 1960. "Limits of the natural environment in terms of $\mathrm{pH}$ and oxidation-reduction potentials.” J. Geology, 68:243-284.

Baker, J.M., Sturges, W.T., Sugier, J., Sunnenberg, G., Lovett, A.A., Nightingale, P.D., and Penkett, S.A. 2001. "Emissions of CH3Br, Organochlorines, and Organoiodines from Temperate Macroalgae.” Chemosphere Global Change Science, 3(1):93-106.

Bethke, C.M., and Yeakel, S. 2013. The Geochemist's Workbench Release 9.0 - Reference Manual. Aqueous Solutions LLC, Champaign, Illinois. 
PNNL-24709, Rev. 2

RPT-DVZ-AFRI-030, Rev. 2

Bird, G.A., and Schwartz, W. 1997. "Distribution Coefficients, $\mathrm{K}_{\mathrm{d}} \mathrm{s}$, for Iodide in Canadian Shield Lake Sediments under Oxic and Anoxic Conditions.” J. Environmental Radioactivity, 35(3):261-279.

Bluhm, K., Croot, P., Wuttig, K., and Lochte, K. 2010. “Transformation of Iodate to Iodide in Marine Phytoplankton Driven by Cell Senescence.” Aquatic Biology, 11(1):1-15.

Bors, J., Martens, R., and Kuhn, W. 1988. "Studies on the Role of Natural and Anthropogenic Organic Substances in the Mobility of Radioiodine in Soils.” Radiochimica Acta, 44/45:201-206.

Bors, J., Gorny, A., and Dultz, D. 1994. "Some Factors Affecting the Interactions of Organophilic Clay Minerals with Radioiodine.” Radiochimica Acta, 66/67:309-313.

Cantrell, K.J., Serne, R.J., and Last, G.V. 2003. Hanford Contaminant Distribution Coefficient Database and Users Guide. PNNL-13895, Rev. 1, Pacific Northwest National Laboratory, Richland, Washington.

Chance, R., Malin, G., Jickells, T., and Baker, A.R. 2007. "Reduction of Iodate to Iodide by Cold Water Diatom Cultures.” Marine Chemistry, 105(1):169-180.

Chance, R., Baker, A.R., Küpper, F.C., Hughes, C., Kloareg, B., and Malin, G. 2009. "Release and Transformations of Inorganic Iodine by Marine Macroalgae.” Estuarine, Coastal and Shelf Science, 82(3):406-414.

Chance, R., Baker, A.R., Carpenter, L., and Jickells, T.D. 2014. “The Distribution of Iodide at the Sea Surface.” Environmental Science: Processes \& Impacts, 16(8):1841-1859.

Chang, H.S., Xu, C., Schwehr, K.A., Zhang, S., Kaplan, D.I., Seaman, J.C., Yeager, C., and Santschi, P.H. 2014. "Model of Radioiodine Speciation and Partitioning in Organic-Rich and Organic-Poor Soils from the Savannah River Site.” J. Environmental Chemical Engineering, 2:1321-1330.

Chefetz, B., Kerem, Z., Chen, Y., and Hadar, Y. 1998. "Isolation and Partial Characterization of Laccase from a Thermophilic Composted Municipal Solid Waste.” Soil Biology and Biochemistry, 30(8):1091-1098.

Colin, C., Leblanc, C., Wagner, E., Delage, L., Leize-Wagner, E., Van Dorsselaer, A., Kloareg, B., and Potin, P. 2003. “The Brown Algal Kelp Laminaria digitata Features Distinct Bromoperoxidase and Iodoperoxidase Activities.” J. Biological Chemistry, 278(26):23545-23552.

Councell, T.B., Landa, E.R., and Lovley, D.R. 1997. “Microbial Reduction of Iodate.” Water, Air, Soil Pollution, 100(1-2):99-106.

Couture, R.A., and Seitz, M.G. 1983. "Sorption of anions of iodine by iron oxides and kaolinite.” Nuclear Chemical Waste Management, 4:301-306.

Dai, J.L., Zhang, M., and Zhu, Y.G. 2004. “Adsorption and Desorption of Iodine by Various Chinese Soils: I. Iodate.” Environment International, 30(4):525-530. 
Dai, J.L., Zhang, M., Hu, Q.H., Huang, Y.Z., Wang, R.Q., and Zhu, Y.G. 2009. “Adsorption and Desorption of Iodine by Various Chinese Soils: II. Iodide and Iodate.” Geoderma, 153(1-2):130-135.

Emerson, H.P., Xu, C., Feng, Y., Lilley, M., Kaplan, D.I., Santschi, P.H., and Powell, B.A. 2014. "Geochemical Controls of Iodine Transport in Savannah River Site Subsurface Sediments.” Chemical Geology, 45:105-113.

Farrenkopf, A.M., Dollhopf, M.E., Chadhain, S.N., Luther Iii, G.W., and Nealson, K.H. 1997. "Reduction of Iodate in Seawater During Arabian Sea Shipboard Incubations and in Laboratory Cultures of the Marine Bacterium Shewanella putrefaciens Strain MR-4.” Marine Chemistry, 57(3-4):347-354.

Finkel, Z.V. 2014. “Marine Net Primary Production.” In: Global Environmental Change., B. Freedman, ed. Springer, Dordrecht, The Netherlands. pp. 117-124.

Fournier, J.-B., Rebuffet, E., Delage, L., Grijol, R., Meslet-Cladière, L., Rzonca, J., Potin, P., Michel, G., Czjzek, M., and Leblanc, C. 2014. "The Vanadium Iodoperoxidase from the Marine Flavobacteriaceae Species Zobellia galactanivorans Reveals Novel Molecular and Evolutionary Features of Halide Specificity in the Vanadium Haloperoxidase Enzyme Family.” Applied and Environmental Microbiology, 80(24):7561-7573.

Fuhrmann, M., Bajt, S., and Schoonen, M.A. 1998. "Sorption of Iodine on Minerals Investigated by X-ray Absorption Near Edge Structure (XANES) and ${ }^{125}$ I Tracer Sorption Experiments.” Applied Geochemistry, 13(2):127-141.

Fujimori, T., Yoneyama, Y., Taniai, G., Kurihara, M., Tamegai, H., and Hashimoto, S. 2012. "Methyl Halide Production by Cultures of Marine Proteobacteria Erythrobacter and Pseudomonas and Isolated Bacteria from Brackish Water.” Limnol. Oceanogr., 57(1):154-162.

Fukui, M., Fujikawa, Y., and Satta, N. 1996. "Factors Affecting Interaction of Radioiodide and Iodate Species with Soil.” J. Environmental Radioactivity, 31(2):199-216.

Fuse, H., Inoue, H., Murakami, K., Takimura, O., and Yamaoka, Y. 2003. "Production of Free and Organic Iodine by Roseovarius spp.” FEMS Microbiology Letters, 229(2):189-194.

Gee, G.W., and Campbell, A.C. 1980. Monitoring and Physical Characterization of Unsaturated Zone Transport - Laboratory Analysis. PNL-3304, Pacific Northwest Laboratory, Richland, Washington.

Gilfedder, B.S., Petri, M., and Biester, H. 2008. "Iodine Speciation and Cycling in Limnic Systems: Observations from a Humic Rich Headwater Lake(Mummelsee).” Biogeosciences Discussions, 5:25-64.

Gilfedder, B.S., Petri, M., and Biester, H. 2009. "Iodine Speciation and Cycling in Fresh Waters: A Case Study from a Humic Rich Headwater Lake (Mummelsee).” J. Limnology, 68(2):396-408.

Gozlan, R.S., and Margalith, P. 1973. “Iodide Oxidation by a Marine Bacterium.” J. Applied Bacteriology, 36(3):407-417. 
PNNL-24709, Rev. 2

RPT-DVZ-AFRI-030, Rev. 2

Gozlan, R.S., and Margalith, P. 1974. “Iodide Oxidation by Pseudomonas iodooxidans.” J. Applied Bacteriology, 37(4):493-499.

Hou, X.L., Fogh, C.L., Kucera, J., Andersson, K.G., Dahlgaard, H., and Nielsen, S.P. 2003. "Iodine-129 and Caesium-137 in Chernobyl Contaminated Soil and Their Chemical Fractionation.” The Science of the Total Environment, 308:97-109.

Hou, X., Hansen, V., Aldahan, A., Possnert, G., Lind, O.C., and Lujaniene, G. 2009. “A Review on Speciation of Iodine-129 in the Environmental and Biological Samples.” Analytica Chimica Acta, 632(2):181-196.

Hou, X., Povinec, P.P., Zhang, L., Shi, K., Biddulph, D., Chang, C.-C., Fan, Y., Golser, R., Hou, Y., Ješkovský, M., Jull, A.J.T., Liu, Q., Luo, M., Steier, P., and Zhou, W. 2013. “Iodine-129 in Seawater Offshore Fukushima: Distribution, Inorganic Speciation, Sources, and Budget.” Environ. Sci. Tech., 47(7):3091-3098.

Hu, Q., Zhao, P., Moran, J.E., and Seaman, J.C. 2005. “Sorption and transport of iodine species in sediments from the Savannah River and Hanford Sites.” J. Contaminant Hydrology, 78(3):185-205.

Hu, Q., Moran, J., and Blackwood, V. 2009. “Geochemical Cycling of Iodine Species in Soils.” In: Comprehensive Handbook of Iodine: Nutritional, Biochemical, Pathological and Therapeutic Aspects, V.R. Preedy, G.N. Burrow, and R.R. Watson (eds.). Academic Press, Oxford.

Hu, Q., Moran, J., and Gan, J. 2012. "Sorption, Degradation, and Transport of Methyl Iodide and Other Iodine Species in Geologic Media.” Applied Geochemistry, 27(3):774-781.

Hughes, C., Franklin, D.J., and Malin, G. 2011. "Iodomethane Production by Two Important Marine Cyanobacteria: Prochlorococcus marinus (CCMP 2389) and Synechococcus sp. (CCMP 2370).” Marine Chemistry, 125(1-4):19-25.

Hung, C.-C., Wong, G.T.F., and Dunstan, W.M. 2005. "Iodate Reduction Activity in Nitrate Reductase Extracts from Marine Phytoplankton.” Bulletin of Marine Science, 76(1):61-72.

Ihssen, J., Schubert, M., Thöny-Meyer, L., and Richter, M. 2014. "Laccase Catalyzed Synthesis of Iodinated Phenolic Compounds with Antifungal Activity.” PLoS ONE, 9(3):e89924.

Kaplan, D.I. 2003. "Influence of Surface Charge of an Fe-Oxide and an Organic Matter Dominated Soil on Iodide and Pertechnetate Sorption.” Radiochimica Acta, 91(3):173-178.

Kaplan, D.I., Serne, R.J., Owen, A.T., Conca, J.A., Wietsma, T.W., and Gervais, T.L. 1996. Radionuclide Adsorption Distribution Coefficients Measured in Hanford Sediments for the Low-Level Waste Performance Assessment Project. PNNL-11485, Pacific Northwest National Laboratory, Richland, Washington.

Kaplan, D.I., Parker, K.E., and Orr, R.D. 1998. Effects of High-pH and High-Ionic-Strength Groundwater on Iodide, Pertechnetate, and Selenate Sorption to Hanford Sediments: Final Report for Subtask 3a. PNNL-11964, Pacific Northwest National Laboratory, Richland, Washington. 
PNNL-24709, Rev. 2

RPT-DVZ-AFRI-030, Rev. 2

Kaplan, D.I., Mattigod, S.V., Parker, K., and Iversen, G. 2000. I-129 Test and Research to Support Disposal Decisions. WSRC-TR-2000-00283, Rev. 0, Savannah River National Laboratory, Aiken, South Carolina.

Kaplan, D.I., Roberts, K.A., Schwehr, K.A., Lilley, M.S., Brinkmeyer, R., Denham, M.E., Diprete, D., Li, H.P., Powell, B.A., Xu, C., Yeager, C.M., Zhang, S.J., and Santschi, P.H. 2011. "Evaluation of a radioiodine plume increasing in concentration at the Savannah River Site.” Environmental Science Technology, 45(2):489-495.

Kaplan, D.I., Yeager, C., Denham, M.E., Zhang, S., Xu, C., Schwehr, K.A., and Santschi, P.H. 2012. Biogeochemical Considerations Related To The Remediation Of I-129 Plumes. SRNL-STI-2012-00425, Savannah River Site, Aiken, South Carolina.

Kaplan, D.I., Zhang, S., Roberts, K.A., Schwehr, K., Xu, C., Creeley, D., Ho, Y.F., Li, H.P., Yeager, C.M., and Santschi, P.H. 2013. "Radioiodine Concentrated in a Wetland." J. Environmental Radioactivity, 131:57-61.

Kaplan, D.I., Denham, M.E., Zhang, S., Yeager, C., Xu, C., Schwehr, K.A., Li, H.P., Ho, Y.F., Wellman, D., and Santschi, P.H. 2014. "Radioiodine Biogeochemistry and Prevalence in Groundwater.” Critical Reviews Environ. Sci. Tech., 44(20):2287-2335.

Karlsson, A., Auer, N., Schulz-Bull, D., and Abrahamsson, K. 2008. "Cyanobacterial Blooms in the Baltic-A Source of Halocarbons.” Marine Chemistry, 110(3):129-139.

Kengen, S.W., Rikken, G.B., Hagen, W.R., Van Ginkel, C.G., and Stams, A.J. 1999. "Purification and Characterization of (Per)chlorate Reductase from the Chlorate-respiring Strain GR-1.” J. Bacteriology, 181(21):6706-6711.

Keppler, F., Biester, H., Putschew, A., Silk, P.J., Schöler, H.F., and Müller, G. 2003. “Organoiodine Formation during Humification in Peatlands.” Environ. Chem. Letters, 1(4):219-223.

Kincaid, C.T., Eslinger, P.W., Aaberg, R.L., Miley, T.B., Nelson, I.C., Strenge, D.L., and Evans, J.C. 2006. Inventory Data Package for Hanford Assessments. PNNL-15829, Pacific Northwest National Laboratory, Richland, Washington.

Klick, S., and Abrahamsson, K. 1992. "Biogenic Volatile Iodated Hydrocarbons in the Ocean.” J. Geophysical Research: Oceans, 97(C8):12683-12687.

Koch, J., Rachar, D., and Kay, B. 1989. "Microbial Participation in Iodide Removal from Solution by Organic Soils.” Canadian J. Soil Science, 69(1):127-135.

Kodama, S., Takahashi, Y, Okumura, K., and Uruga, T. 2006. “Speciation of Iodine in Solid Environmental Samples by Iodine K-Edge XANES: Application to Soils and Ferromanganese Oxides.” Science of The Total Environment, 363:275-284.

Kulys, J., Bratkovskaja, I., and Vidziunaite, R. 2005. "Laccase-catalysed Iodide Oxidation in Presence of Methyl Syringate.” Biotechnology and Bioengineering, 92(1):124-128.

Küpper, F., Schweigert, N., Gall, E.A., Legendre, J.-M., Vilter, H., and Kloareg, B. 1998. “Iodine Uptake in Laminariales Involves Extracellular, Haloperoxidase-Mediated Oxidation of Iodide.” Planta, 207(2):163-171. 
Küpper, F.C., Carpenter, L.J., McFiggans, G.B., Palmer, C.J., Waite, T.J., Boneberg, E.-M., Woitsch, S., Weiller, M., Abela, R., and Grolimund, D. 2008. "Iodide Accumulation Provides Kelp with an Inorganic Antioxidant Impacting Atmospheric Chemistry.” Proceedings of the National Academy of Sciences, 105(19):6954-6958.

Küpper, F.C., Feiters, M.C., Olofsson, B., Kaiho, T., Yanagida, S., Zimmermann, M.B., Carpenter, L.J., Luther, G.W., Lu, Z., Jonsson, M., and Kloo, L. 2011. “Commemorating Two Centuries of Iodine Research: An Interdisciplinary Overview of Current Research.” Angewandte Chemie International Edition, 50(49):11598-11620.

La Barre, S., Potin, P., Leblanc, C., and Delage, L. 2010. “The Halogenated Metabolism of Brown Algae (Phaeophyta), Its Biological Importance and Its Environmental Significance.” Marine Drugs, 8(4):988-1010.

Lauterbach, A., and Ober, G. 1996. Encyclopedia of Chemical Technology, Vol. 14. Kirk-Othmer (ed). John Wiley \& Sons, Boston. pp. 709-737.

Li, H-P., Brinkmeyer, R., Jones, W.L., Zhang, S., Xu, C., Schwehr, K.A., Santschi, P.H., Kaplan, D.I., and Yeager, C.M. 2011. "Iodide Accumulation by Aerobic Bacteria Isolated from Subsurface Sediments of a ${ }^{129}$ I-Contaminated Aquifer at the Savannah River Site, South Carolina.” Applied and Environmental Microbiology, 77(6):2153-2160.

Li, H-P., Brinkmeyer, R., Jones, W.L., Zhang, S., Xu, C., Ho, Y-F., Schwehr, K.A., Kaplan, D.I., Santschi, P.H., and Yeager, C.M. 2012a. "Iodide Oxidizing Activity of Bacteria from Subsurface Sediments of the Savannah River Site, SC, USA.” Interdisciplinary Studies on Environmental Chemistry, 6:89-97.

Li, H-P., Yeager, C.M., Brinkmeyer, R., Zhang, S., Ho, Y-F., Xu, C., Jones, W.L., Schwehr, K.A., Otosaka, S., Roberts, K.A., Kaplan, D.I., and Santschi, P.H. 2012b. "Bacterial Production of Organic Acids Enhances $\mathrm{H}_{2} \mathrm{O}_{2}$-Dependent Iodide Oxidation.” Environmental Science Technology, 46(9):4837-4844.

Li, H-P., Daniel, B., Creeley, D., Grandbois, R., Zhang, S., Xu, C., Ho, Y-F., Schwehr, K.A., Kaplan, D.I., Santschi, P.H., Hansel, C.M., and Yeager, C.M. 2014. "Superoxide Production by a Manganese-Oxidizing Bacterium Facilitates Iodide Oxidation.” Applied and Environmental Microbiology, 80(9):2693-2699.

MacLean, L.C., Martinez, R.E., and Fowle, D.A. 2004. “Experimental Studies of Bacteria-Iodide Adsorption Interactions.” Chemical Geology, 212(3):229-238.

Maillant, S., Sheppard, M.I., Echevarria, G., Denys, S., Villemin, G., Tekely, P., Leclerc-Cessac, E., and Morel, J.L. 2007. “Aged Anthropogenic Iodine in a Boreal Peat Bog.” Applied Geochemistry, 22(5):873-887.

Malinauskas, A.P., and Bell, J.T. 1987. "The Chemistry of Fission-Product Iodine under Nuclear Reactor Accident Conditions.” Nuclear Safety, 28:505-514.

Manley, S.L. 2009. "Iodine Assimilation by Marine Diatoms and Other Phytoplankton in NitrateReplete Conditions.” Limnology and Oceanography, 54(5):1653-1664. 
Mishra, S.P., and Srinivasu, N. 1992. "Radiotracer Technique in Adsorption Study - IX. Adsorption of Iodide Ions on Titanium(IV) Oxide Powder.” Applied Radiation and Isotopes, 43:789-793.

Moulin, V., Reiller, P., Amekraz, B., and Moulin, C. 2001. "Direct Characterization of Iodine Covalently Bound to Fulvic Acids by Electrospray Mass Spectrometry.” Rapid Communications in Mass Spectrometry, 15(24):2488-2496.

Muramatsu, Y., Uchida, S., Sumiya, M., Ohmomo, Y., and Obata, H. 1989. “Tracer Experiments on Transfer of Radio-Iodine in the Soil-Rice Plant System.” Water, Air, Soil Pollution, 45(1):157-171.

Muramatsu, Y., Uchida, S., and Ohmomo, Y. 1990a. "Determination of I-129 and I-127 in Soil and Tracer Experiments on the Adsorption of Iodine on Soil.” J. Radioanalytical and Nuclear Chemistry, 138:377-384.

Muramatsu, Y., Uchida, S., Sriyotha, P., and Sriyotha, K. 1990b. "Some Consideration on the Sorption and Desorption Phenomena of Iodide and Iodate on Soil." Water, Air, Soil Pollution, 49(1-2):125-138.

Muramatsu, Y., Yoshida, S., Uchida, S., and Hasebe, A. 1996. "Iodine Desorption from Rice Paddy Soil.” Water, Air, Soil Pollution, 86(1-4):359-371.

Musić, S., Šipalo-Žuljerić, J., and Wolf, R.H.H. 1979. "Radiochemical Study of the Sorption of Iodide and Iodate on Aluminum(III) Hydroxide Precipitate.” Isotopenpraxis, 15:93-96.

Neal, C., and Truesdale, V.W. 1976. "Sorption of Iodate and Iodide by Riverine Sediments - Its Implications to Dilution Gauging and Hydrochemistry of Iodine.” J. Hydrology, 31(3-4):281-291.

Nirel, P.M.V., and Morel, F.M.M. 1990. "Pitfalls of Sequential Extractions.” Water Research, 24:1055-1056.

Nishimaki, K., Satta, N., and Maeda, M. 1994. "Sorption and Migration of Radioiodine in Saturated Sandy Soil.” J. Nuclear Science and Technology, 31(8):828-838.

Ohsawa, N., Tsujita, M., Morikawa, S., and Itoh, N. 2001. "Purification and Characterization of a Monohalomethane-Producing Enzyme S-Adenosyl-L-Methionine: Halide Ion Methyltransferase from a Marine Microalga, Pavlova pinguis.” Bioscience, Biotechnology, and Biochemistry, 65(11):2397-2404.

Osterc, A., and Stibilj, V. 2012. "Influence of Releases of I-129 from Reprocessing Plants on the Marine Environment of the North Adriatic Sea.” Chemosphere, 86(10):1020-1027.

Otosaka, S., Schwehr, K.A., Kaplan, D.I., Roberts, D.A., Zhang, S., Xu, C., Li, H.-P., Ho, Y.-F., Brinkmeyer, R., Yeager, C.M., and Santschi, P.H. 2011. "Factors Controlling Mobility of ${ }^{127}$ I and ${ }^{129}$ I Species in an Acidic Groundwater Plume at the Savannah River Site.” The Science of the Total Environment, 409(19):3857-3865.

Paquette, J., Wren, D.J., Ford, B.L., and Toth, L.M. 1986. Iodine Chemistry. American Chemical Society, Washington, D.C. 
PNNL-24709, Rev. 2

RPT-DVZ-AFRI-030, Rev. 2

Parsly, L.F. 1970. Design Considerations of Reactor Containment Spray Systems - Part IV. Calculation of Iodine-Water Partition Coefficients. Oak Ridge National Laboratory, Oak Ridge, Tennessee.

Santschi, P.H., and Schwehr, K.A. 2004. "I-129/I-127 as a New Environmental Tracer or Geochronometer for Biogeochemical or Hydrodynamic Processes in the Hydrosphere and Geosphere: The Central Role of Organo-Iodine.” The Science of the Total Environment, 321:257-271.

Santschi, P.H., Xu, C., Zhang, S., Ho, Y.F., Li, H.P., Schwehr, K.A., and Kaplan, D.I. 2012. Laboratory Results on Iodine $\left({ }^{129}\right.$ I and ${ }^{127}$ I) Speciation, Transformation and Mobility in Hanford Groundwater, Suspended Particles, and Sediments. SRNL-STI-2012-00592, Savannah River National Laboratory, Aiken, South Carolina.

Sazarashi, M., Ikeda, Y., Seki, R., and Yoshikawa, H. 1994. “Adsorption of I- Ions on Minerals for ${ }^{129}$ I Waste Management.” J. Nuclear Science and Technology, 31:620-622.

Scheckel, K.G., Impellitteri, C.A., Ryan, J.A., and McEvoy, T. 2003. “Assessment of a Sequential Extraction Procedure for Perturbed Lead-Contaminated Samples with and Without Phosphorus Amendments.” Environ. Sci. Technol., 37:1892-1898.

Schlegel, M.L., Reiller, P., Mercier-Bion, F., Barre, N., and Moulin, V. 2006. "Molecular Environment of Iodine in Naturally Iodinated Humic Substances: Insight from X-ray Absorption Spectroscopy.” Geochimica, 70:5536-5551.

Schmitz, K., and Aumann, D.C. 1995. "A Study on the Association of Two Iodine Isotopes of Natural I-127 and of the Fission Product I-129, with Soil Components using a Sequential Extraction Procedure.” J. Radioanalytical Nuclear Chemistry, 198:229-236.

Schwehr, K.A., Santschi, P.H., and Elmore, D. 2005. "The dissolved organic iodine species of the isotopic ratio of (129)I/(127)I: A novel tool for tracing terrestrial organic carbon in the estuarine surface waters of Galveston Bay, Texas.” Limnology and OceanographyMethods, 3:326-337.

Schwehr, K.A., Santschi, P.H., Kaplan, D.I., Yeager, C.M., and Brinkmeyer, R. 2009. “Organo-Iodine Formation in Soils and Aquifer Sediments at Ambient Concentrations.” Environmental Science Technology, 43(19):7258-7264.

Seki, M., Oikawa, J.-i., Taguchi, T., Ohnuki, T., Muramatsu, Y., Sakamoto, K., and Amachi, S. 2012. "Laccase-Catalyzed Oxidation of Iodide and Formation of Organically Bound Iodine in Soils.” Environmental Science Technology, 47(1):390-397.

Serne, R.J., Conca, J.L., LeGore, V.L., Cantrell, K.J., Lindenmeier, C.W., Campbell, J.A., Amonette, J.E., and Wood, M.I. 1993. Solid-Waste Leach Characteristics and Contaminant-Sediment Interactions. Volume 1: Batch Leach and Adsorption Tests and Sediment Characterization. PNL-8889, Vol. 1, Pacific Northwest Laboratory, Richland, Washington.

Sheppard, M.I., and Hawkins, J.L. 1995. “Iodine and microbial interactions in an organic soil.” Radioactivity, 29:91-109. 
PNNL-24709, Rev. 2

RPT-DVZ-AFRI-030, Rev. 2

Sheppard, M.I., and Thibault, D.H. 1991. “A 4-Year Mobility Study of Selected Trace-Elements and Heavy-Metals.” J. Environmental Quality, 20(1):101-114.

Sheppard, M. I., Thibault, D.H., and Smith, P.A. 1989. "Iodine Dispersion and Effects on Groundwater Chemistry Following a Release to a Peat Bog, Manitoba, Canada.” Applied Geochemistry, 4(4):423-432.

Shimamoto, Y.S., and Takahashi, Y. 2008. "Superiority of K-Edge XANES over L-III-edge XANES in the Speciation of Iodine in Natural Soils.” Analytical Sciences, 24(3):405-409.

Shimamoto, Y.S., Takahashi, Y., and Terada, Y. 2011. "Formation of Organic Iodine Supplied as Iodide in a Soil-Water System in Chiba, Japan.” Environmental Science Technology, 45(6):2086-2092.

Shimura, H., Itoh, K., Sugiyama, A., Ichijo, S., Ichijo, M., Furuya, F., Nakamura, Y., Kitahara, K., Kobayashi, K., and Yukawa, Y. 2012. "Absorption of Radionuclides from the Fukushima Nuclear Accident by a Novel Algal Strain.” PLoS ONE, 7(9):e44200.

Skulski, L. 2000. “Organic iodine (I, III, and V) chemistry: 10 years of development at the Medical University of Warsaw, Poland.” Molecules, 5:1331-1371.

Stang, P.J. 2003. “Polyvalent Iodine Organic Chemistry.” J. Organic Chemistry, 68:2997-3008.

Stemmler, I., Hense, I., Quack, B., and Maier-Reimer, E. 2014. "Methyl Iodide Production in the Open Ocean.” Biogeosciences, 11:4459-4476.

Stutz, J., Hebestreit, K., Alicke, B., and Platt, U. 1999. "Chemistry of Halogen Oxides in the Troposphere: Comparison of Model Calculations with Recent Field Data.” J. Atmospheric Chemistry, 34:65-85.

Suzuki, M., Eda, Y., Ohsawa, S., Kanesaki, Y., Yoshikawa, H., Tanaka, K., Muramatsu, Y., Yoshikawa, J., Sato, I., Fujii, T., and Amachi, S. 2012. "Iodide Oxidation by a Novel Multicopper Oxidase from the Alphaproteobacterium Strain Q-1.” Applied and Environmental Microbiology, 78(11):3941-3949.

Taghipour, F., and Evans, G.J. 2002. "Modeling of Iodine Radiation Chemistry in the Presence of Organic Compounds.” Radiation Physics and Chemistry, 64:203-213.

Tessier, A., and Campbell, P.G.C. 1988. Metal Speciation: Theory, Analysis, and Application. Kramer, J.R., and Allen, H.E. (eds). Lewis Publishers, Inc., Chelsea, Michigan. pp. 183-217.

Thorenz, U., Carpenter, L., Huang, R-J., Kundel, M., Bosle, J., and Hoffmann, T. 2014. "Emission of Iodine-Containing Volatiles by Selected Microalgae Species.” Atmospheric Chemistry and Physics, 14(23):13327-13335.

Ticknor, K.V., and Cho, Y.H. 1990. "Interaction of Iodide and Iodate with Granitic Fracture-Filling Minerals.” J. Radioanalytical and Nuclear Chemistry, 140:75-90. 
PNNL-24709, Rev. 2

RPT-DVZ-AFRI-030, Rev. 2

Toda, H., and Itoh, N. 2011. "Isolation and Characterization of a Gene Encoding a S-adenosyl-lmethionine-dependent Halide/thiol Methyltransferase (HTMT) from the Marine Diatom Phaeodactylum tricornutum: Biogenic Mechanism of $\mathrm{CH}_{3}$ I Emissions in Oceans.” Phytochemistry, 72(4):337-343.

Tsunogai, S., and Sase, T. 1969. "Formation of Iodide-Iodine in the Ocean.” Deep Sea Research and Oceanographic Abstracts, 16(5):489-496.

Um, W., Serne, R.J., and Krupka, K.M. 2004. "Linearity and Reversibility of Iodide Adsorption on Sediments from Hanford, Washington under Water Saturated Conditions.” Water Research, 38(8):2009-2016.

van Bergeijk, S.A., Javier, L.H., Heyland, A., Manchado, M., and Canavate, J.P. 2013. "Uptake of Iodide in the Marine Haptophyte Isochrysis sp.(T. ISO) Driven by Iodine Oxidation.” $J$. Phycol., 49:640-647.

Verhaeghe, E.F., Fraysse, A., Guerquin-Kern, J.-L., Wu, T.-D., Devès, G., Mioskowski, C., Leblanc, C., Ortega, R., Ambroise, Y., and Potin, P. 2008. "Microchemical Imaging of Iodine Distribution in the Brown Alga Laminaria digitata Suggests a New Mechanism for Its Accumulation.” J. Biological Inorganic Chemistry, 13(2):257-269.

Wakai, S., Ito, K., Iino, T., Tomoe, Y., Mori, K., and Harayama, S. 2014. "Corrosion of Iron by IodideOxidizing Bacteria Isolated from Brine in an Iodine Production Facility.” Microbial Ecology, 68(3):519-527.

Whitehead, D.C. 1973. “The Sorption of Iodide by Soils as Influenced by Equilibrium Conditions and Soil Properties.” J. the Science of Food and Agriculture, 24:547-556.

Whitehead, D.C. 1974. “The Sorption of Iodide by Soil Components.” J. the Science of Food and Agriculture, 25:73-79.

Wren, J.C., and Ball, J.M. 2001. "LIRIC 3.2: An Updated Model for Iodine Behavior in the Presence of Organic Impurities.” Radiation Physics and Chemistry, 60:577-596.

Xu, C., Miller, E.J., Zhang, S., Li, H.-P., Ho, Y.-F., Schwehr, K.A., Kaplan, D.I., Otosaka, S., Roberts, K.A., Brinkmeyer, R., Yeager, C.M., and Santschi, P.H. 2011a. "Sequestration and Remobilization of Radioiodine $\left({ }^{129} \mathrm{I}\right)$ by Soil Organic Matter and Possible Consequences of the Remedial Action at Savannah River Site.” Environmental Science Technology, 45(23):9975-9983.

Xu, C., Zhang, S., Ho, Y.-F., Miller, E.J., Roberts, K.A., Li, H.-P., Schwehr, K.A., Otosaka, S., Kaplan, D.I., Brinkmeyer, R., Yeager, C.M., and Santschi, P.H. 2011b. "Is Soil Natural Organic Matter a Sink or Source for Mobile Radioiodine $\left({ }^{129} \mathrm{I}\right)$ at the Savannah River Site?” Geochimica Et Cosmochimica Acta, 75(19):5716-5735.

Xu, C., Zhong, J., Hatcher, P.G., Zhang, S., Li, H.-P., Ho, Y.-F., Schwehr, K.A., Kaplan, D.I., Roberts, K.A., Brinkmeyer, R., Yeager, C.M., and Santschi, P.H. 2012. "Molecular Environment of Stable Iodine and Radioiodine $\left({ }^{129} \mathrm{I}\right)$ in Natural Organic Matter: Evidence Inferred from NMR and Binding Experiments at Environmentally Relevant Concentrations.” Geochimica Et Cosmochimica Acta, 97:166-182. 
PNNL-24709, Rev. 2

RPT-DVZ-AFRI-030, Rev. 2

Xu, C., Kaplan, D.I., Zhang, S., Athon, M., Ho, Y.-F., Li, H.-P., Yeager, C.M., Schwehr, K.A., Grandbois, R., Wellman, D., and Santschi, P.H. 2015. "Radioiodine Sorption/Desorption and Speciation Transformation by Subsurface Sediments from the Hanford Site.” J. Environ. Radioact., 139:43-55.

Yoshida, S., Muramatsu, Y., and Uchida, S. 1992. "Studies on the Sorption of I" (iodide) and $\mathrm{IO}_{3}{ }^{-}$ (iodate) onto Andosols.” Water Air and Soil Pollution, 63(3-4):321-329.

Yu, Z., Warner, J.A., Dahlgren, R.A., and Casey, W.H. 1996. "Reactivity of Iodine in Volcanic Soils and Noncrystalline Soil Constituents.” Geochim. Cosmochim. Acta, 60:4945-4956.

Yuita, K. 1992. "Dynamics of Iodine, Bromine, and Chlorine in Soil II. Chemical Forms of Iodine in Soil Solutions.” Soil Science and Plant Nutrition, 38(2):281-287.

Yuita, K., and Kihou, N. 2005. "Behavior of Iodine in a Forest Plot, an Upland Field, and a Paddy Field in the Upland Area of Tsukuba, Japan: Vertical Distribution of Iodine in Soil Horizons and Layers to a Depth of 50 m.” Soil Science and Plant Nutrition, 51(4):455-467.

Zhang, S., Schwehr, K.A., Ho, Y-F., Xu, C., Roberts, K., Kaplan, D.I., Brinkmeyer, R., Yeager, C.M., and Santschi, P.H. 2010. "Determination of ${ }^{127} \mathrm{I}$ and ${ }^{129} \mathrm{I}$ Speciation in Environmental Waters Using a Novel Gas Chromatography-Mass Spectrometry Method.” Environmental Science Technology, 44(23):9042-9048.

Zhang, S., Du, J., Xu, C., Schwehr, K.A., Ho, Y.F., Li, H.P., Roberts, K.A., Kaplan, D.I., Brinkmeyer, R., Yeager, C.M., Chang, H.S., and Santschi, P.H. 2011. "Concentration-Dependent Mobility, Retardation, and Speciation of Iodine in Surface Sediment from the Savannah River Site.” Environmental Science Technology, 45(13):5543-5549.

Zhang, S., Xu, C., Creeley, D., Ho, Y-F., Li, H-P., Grandbois, R., Schwehr, K.A., Kaplan, D.I., Yeager, C.M., Wellman, D., and Santschi, P.H. 2013. "Iodine-129 and Iodine-127 Speciation in Groundwater at the Hanford Site, U.S.: Iodate Incorporation into Calcite.” Environ. Sci. Tech., 47(17):9635-9642.

Zhdankin, V.V., and Stang, P.J. 2002. "Recent Developments in the Chemistry of Polyvalent Iodine Compounds.” Chemical Reviews, 102:2523-2584.

Žic, V., Truesdale, V.W., and Cukrov, N. 2008. "The Distribution of Iodide and Iodate in Anchialine Cave Waters-Evidence for Sustained Localised Oxidation of Iodide to Iodate in Marine Water.” Marine Chemistry, 112(3):168-178. 
PNNL-24709, Rev. 2

RPT-DVZ-AFRI-030, Rev. 2

\section{Appendix B}

\section{0-UP-1 Operable Unit ${ }^{129}$ I Disposal Site Information}




\section{Appendix B}

\section{0-UP-1 Operable Unit ${ }^{129}$ I Disposal Site Information}

\section{B.1 216-S-7 Crib}

The 216-S-7 crib is located in southern 200 West Area, about $230 \mathrm{~m}$ (750 ft) northwest of the 202-S Building (a.k.a. S-Plant; REDOX), and 290 m (950 ft) east of Waste Management Area (WMA) S-SX (Figure B.1).

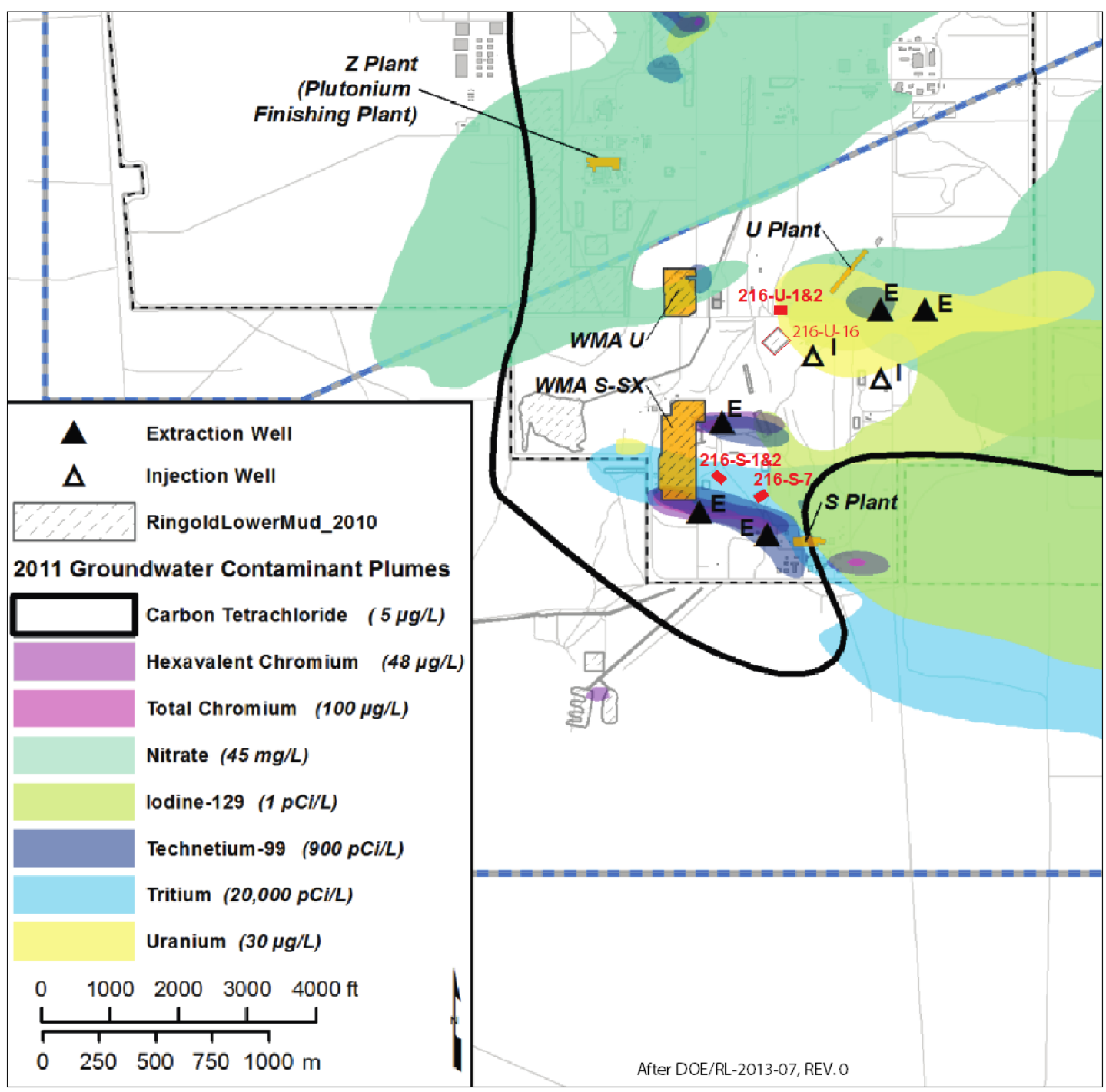

Figure B.1. Location of the 216-S-7 crib and other key facilities (modified after CHPRC 2013). 
PNNL-24709, Rev. 2

RPT-DVZ-AFRI-030, Rev. 2

\section{B.1.1 Facility Design}

The 216-S-7 crib was built to replace the 216-S-1\&2 cribs (Shearer 2013, p. 1144). It consists of two

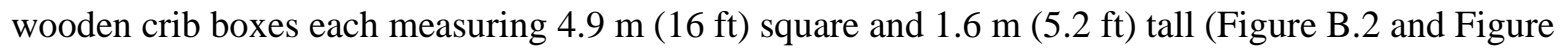
B.3). The crib boxes are set $15.2 \mathrm{~m}$ (50 ft) apart, center-to-center, in one excavation (Shearer 2013, p. 1144) with bottom dimensions of 15.2 x $30.5 \mathrm{~m}(50 \times 100 \mathrm{ft})$. The crib boxes were set in gravel and covered with backfill. The two crib boxes are connected in parallel by a pipe, allowing the flow to be equally distributed to both cribs (Shearer 2013, p. 1144). Each crib box had two risers that extended to the surface.

The excavation is approximately $6.6 \mathrm{~m}$ (22 ft) deep, with the original ground surface at about $205.4 \mathrm{~m}$

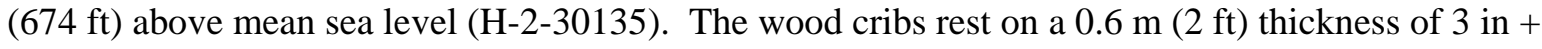
washed gravel, which also filled the excavation around the cribs to a depth of at least $1.5 \mathrm{~m}(5 \mathrm{ft})$. This gravel is capped by a $10 \mathrm{~cm}$ (4 in) thickness of 0.75 to 1.5 in gravel that, in turn, is covered with a $5 \mathrm{~cm}$ (2 in) thickness of 0.6 to $1.9 \mathrm{~cm}$ ( 0.25 to $0.75 \mathrm{in})$ pea gravel, that is then covered with a vapor barrier, composed of two layers of heavy Sisalkraft construction paper (DOE 2004 |DOE-RL-2000-60, Rev. 1, Re-issue|). Soil excavated from the trench was most likely used as backfill over the Sisalkraft barrier.

At least one episode of collapse of the wooden crib boxes is known to have occurred and stabilized with available fill, in addition, at least one $0.61 \mathrm{~m}$ (2 ft) thickness of clean soil was placed over the waste site in 1992 (DOE 2004 |DOE-RL-2000-60, Rev. 1, Re-issue|). The aboveground risers are believed to have been removed before August 1975. 
PNNL-24709, Rev. 2

RPT-DVZ-AFRI-030, Rev. 2

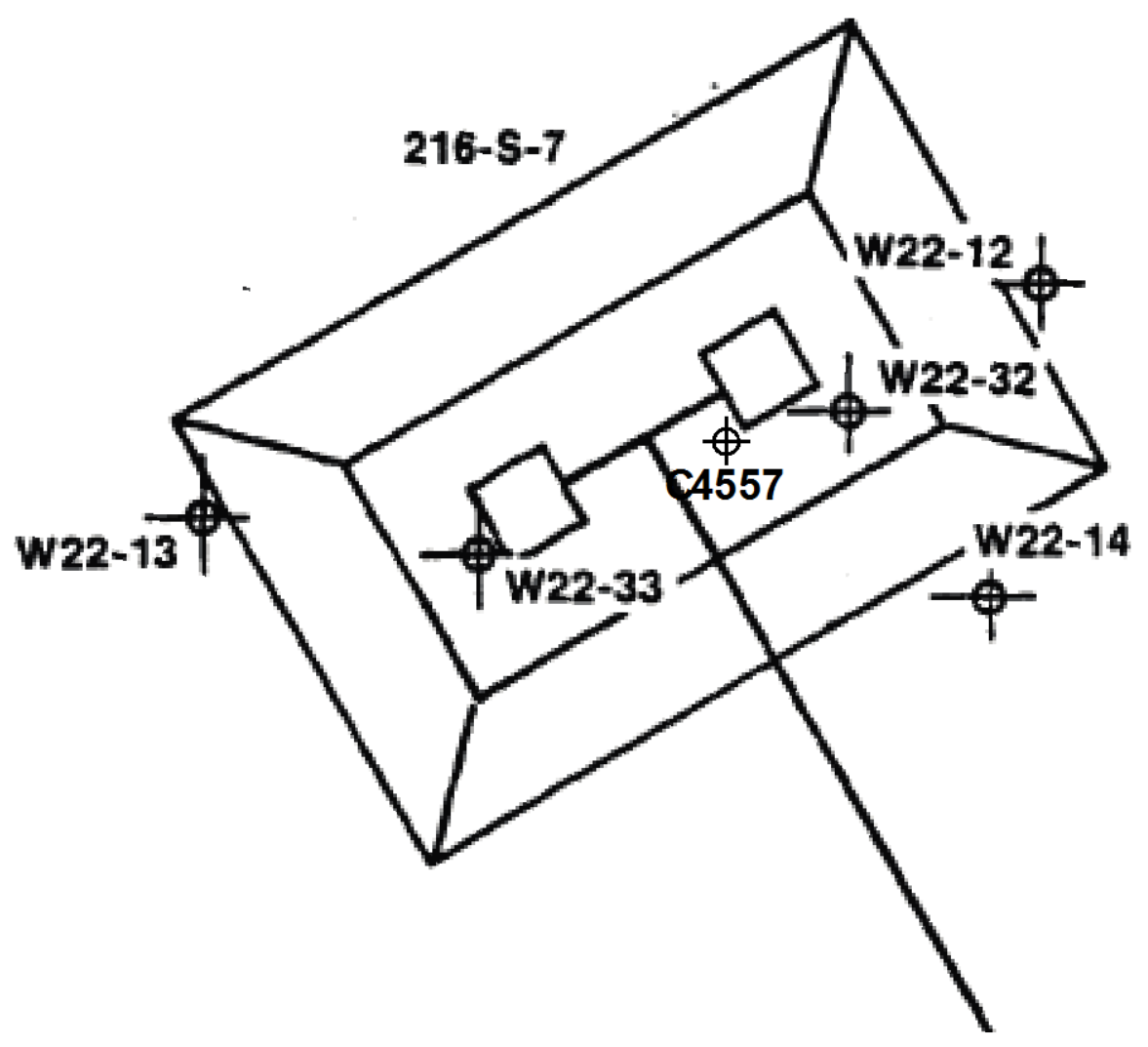

Figure B.2. Plan view of the 216-S-7 crib design (after Fecht et al. 1977). 


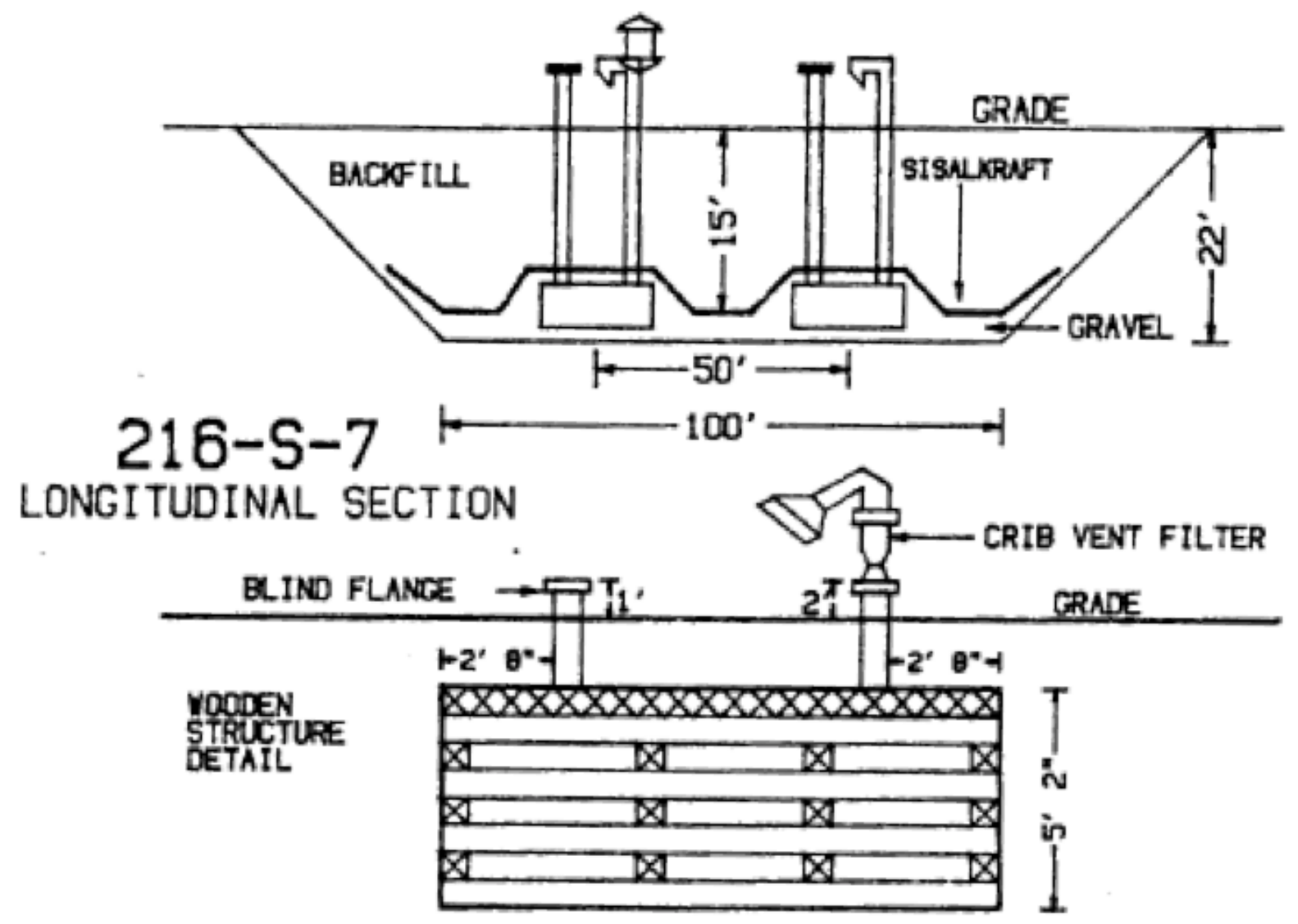

Figure B.3. Longitudinal section through the $216-\mathrm{S}-7$ crib. ${ }^{1}$

Approximate center coordinates for the crib is based on extrapolation from QMAP geospatial map portal (available at hgis.rl.gov/qmap/).

- 216-S-7 - N134176; E567168 (State Plane, m)

Trench Bottom Area $=15.2$ by $30.5 \mathrm{~m}=464.5 \mathrm{~m}^{2}$

Graveled Side Slope Area=2@32.8 m²+2@65.7 m²=197.1 m²

Total Infiltration Area $=661.5 \mathrm{~m}^{2}$

\footnotetext{
${ }^{1}$ Downloaded from Hanford's Integrated Data Management System (IDMS) via the Enterprise application; 216-S7/05 Sketches, Drawings and Maps

(http://idmsweb.rl.gov/idms/livelink.exe?func=ll\&objId=151728765\&objAction=Open\&nexturl=\%2Fidms\%2Flivel ink\%2Eexe\%3Ffunc\%3Dll\%26objId\%3D149106046\%26objAction\%3Dbrowse\%26viewType\%3D1 ). Accessed on December 29, 2015.
} 
PNNL-24709, Rev. 2

RPT-DVZ-AFRI-030, Rev. 2

\section{B.1.2 Operational History:}

The crib operated from January 12, 1956 to July 1965 (Shearer 2013, p. 1144). From January 12, 1956 to April 12, 1959, the crib receive REDOX cell drainage from the D-1 Receiver Tank, process condensate from the D-2 receiver tank, and condensate from the H-6 condenser in 202-S Building (Shearer 2013, p. 1144). A buildup of beta activity in the crib prompted the rerouting of H-6 waste material to the underground waste storage tanks on April 12, 1959 (Shearer 2013, p. 1144). The crib continued to receive waste from D-1 and D-2 vessels until July 1965. The chemicals disposed at the site included nitrate, aluminum nitrate, nitric acid, and sodium (Shearer 2013, p. 1144) and methyl iso-butyl ketone (MIBK, hexone, or 4-nethyl-2-pentanone; used as solvent for solvent extraction of uranium and plutonium from fission products in REDOX and present in process drainage and possibly in process condensates (DOE 2004 |DOE-RL-2000-60, Rev. 1, Re-issue|).

PNL (1975 |PNL-MA-588|), Anderson (1976), and Maxfield (1979) indicate that a total of $3.9 \times 10^{8}$ liters were discharged to the crib (Table B.1). DOE (2004) suggested that the discharged waste was acidic (as low as $\mathrm{pH}=2$ ), at least at the start of 216-S-7 crib operations. They also estimated that $3 \%$ by volume of the waste from the D-1and D-2 tanks was settleable solids, and that the temperature of the waste sent to the crib ranged up to $60^{\circ} \mathrm{C}\left(140^{\circ} \mathrm{F}\right)$. Figure B.4 illustrates the annual mean discharge volumes and mean ${ }^{129}$ I concentrations (taken from Corbin et al. 2005). 
PNNL-24709, Rev. 2 RPT-DVZ-AFRI-030, Rev. 2

Table B.1. Annual inventory of waste discharged to the 216-S-7 crib.

\begin{tabular}{|c|c|c|c|c|c|c|c|c|c|c|c|c|c|}
\hline Constituent & Units & Source & 1956 & 1957 & 1958 & 1959 & 1960 & 1961 & 1962 & 1963 & 1964 & 1965 & Sum \\
\hline \multirow[t]{4}{*}{ Volume } & $\mathrm{L}$ & Anderson (1976) & $5.58 \mathrm{E}+07$ & $4.95 \mathrm{E}+07$ & $4.62 \mathrm{E}+07$ & $3.48 \mathrm{E}+07$ & $3.23 \mathrm{E}+07$ & $3.34 \mathrm{E}+07$ & $3.40 \mathrm{E}+07$ & $4.10 \mathrm{E}+07$ & $4.54 \mathrm{E}+07$ & $1.75 \mathrm{E}+07$ & $3.90 \mathrm{E}+08$ \\
\hline & & SIM Mean & $5.58 \mathrm{E}+07$ & $4.95 \mathrm{E}+07$ & $4.62 \mathrm{E}+07$ & $3.48 \mathrm{E}+07$ & $3.23 E+07$ & $3.34 \mathrm{E}+07$ & $3.40 E+07$ & $4.10 \mathrm{E}+07$ & $4.54 \mathrm{E}+07$ & $1.75 E+07$ & $3.90 \mathrm{E}+08$ \\
\hline & & SIM StdDev & $5.61 \mathrm{E}+06$ & $4.98 E+06$ & $4.65 E+06$ & $3.50 E+06$ & $3.25 E+06$ & $3.36 \mathrm{E}+06$ & $3.42 E+06$ & $4.12 E+06$ & $4.56 \mathrm{E}+06$ & $1.76 \mathrm{E}+06$ & NA \\
\hline & & VL & $5.58 \mathrm{E}+07$ & $4.95 E+07$ & $4.62 \mathrm{E}+07$ & $3.48 \mathrm{E}+07$ & $3.23 E+07$ & $3.34 \mathrm{E}+07$ & $3.40 E+07$ & $4.10 \mathrm{E}+07$ & $4.54 \mathrm{E}+07$ & $1.75 \mathrm{E}+07$ & $3.90 \mathrm{E}+08$ \\
\hline Beta & $\mathrm{Ci}$ & Anderson (1976) & $7.93 E+04$ & $6.70 E+04$ & $1.13 E+05$ & $4.27 \mathrm{E}+03$ & $2.00 E+03$ & $2.17 \mathrm{E}+03$ & $1.43 E+03$ & $2.74 E+03$ & $4.31 \mathrm{E}+03$ & $4.30 \mathrm{E}+03$ & $2.81 E+05$ \\
\hline \multirow[t]{3}{*}{ Sr-90 } & $\mathrm{Ci}$ & Anderson (1976) & $1.05 E+03$ & $1.08 \mathrm{E}+03$ & $6.88 \mathrm{E}+02$ & $3.00 \mathrm{E}+00$ & & & $5.60 \mathrm{E}+01$ & $1.03 E+02$ & $1.60 \mathrm{E}+01$ & $1.02 \mathrm{E}+02$ & $3.10 E+03$ \\
\hline & & SIM Mean & $3.44 \mathrm{E}+02$ & $3.05 E+02$ & $1.33 E+02$ & $1.01 E+02$ & $9.33 \mathrm{E}+01$ & $9.64 \mathrm{E}+01$ & $9.83 E+01$ & $1.18 \mathrm{E}+02$ & $1.31 \mathrm{E}+02$ & $5.06 \mathrm{E}+01$ & $1.47 \mathrm{E}+03$ \\
\hline & & SIM StdDev & $1.39 E+02$ & $1.24 \mathrm{E}+02$ & $8.95 E+01$ & $6.69 E+01$ & $6.21 \mathrm{E}+01$ & $6.42 \mathrm{E}+01$ & $6.54 \mathrm{E}+01$ & $7.86 \mathrm{E}+01$ & $8.74 \mathrm{E}+01$ & $3.37 E+01$ & $2.74 \mathrm{E}+02$ \\
\hline \multirow[t]{3}{*}{ Cs-137 } & $\mathrm{Ci}$ & Anderson (1976) & 4.47E+02 & 4.62E+02 & $2.94 \mathrm{E}+02$ & $1.80 \mathrm{E}+01$ & $9.00 \mathrm{E}+00$ & & $1.60 \mathrm{E}+01$ & $3.60 E+01$ & $8.60 E+01$ & $1.02 \mathrm{E}+02$ & $1.47 \mathrm{E}+03$ \\
\hline & & SIM Mean & $2.97 \mathrm{E}+02$ & $2.63 E+02$ & $6.79 E+01$ & $5.11 \mathrm{E}+01$ & $4.75 E+01$ & $4.92 \mathrm{E}+01$ & $5.00 E+01$ & $6.03 E+01$ & $6.68 \mathrm{E}+01$ & $2.57 \mathrm{E}+01$ & $9.79 \mathrm{E}+02$ \\
\hline & & SIM StdDev & $1.22 \mathrm{E}+02$ & $1.08 \mathrm{E}+02$ & $4.52 \mathrm{E}+01$ & $3.39 \mathrm{E}+01$ & $3.14 \mathrm{E}+01$ & $3.25 E+01$ & $3.31 E+01$ & $4.00 \mathrm{E}+01$ & $4.43 E+01$ & $1.71 \mathrm{E}+01$ & $1.92 \mathrm{E}+02$ \\
\hline \multirow[t]{3}{*}{ Ru-106 } & $\mathrm{Ci}$ & Anderson (1976) & $4.23 \mathrm{E}+02$ & $3.57 \mathrm{E}+02$ & $6.06 \mathrm{E}+02$ & $2.30 \mathrm{E}+01$ & $1.10 \mathrm{E}+01$ & $1.10 \mathrm{E}+01$ & $8.00 \mathrm{E}+00$ & $1.50 \mathrm{E}+01$ & $2.30 \mathrm{E}+01$ & $2.30 \mathrm{E}+01$ & $1.50 \mathrm{E}+03$ \\
\hline & & SIM Mean & $7.47 \mathrm{E}-12$ & $6.63 \mathrm{E}-12$ & $3.20 \mathrm{E}-10$ & $2.41 \mathrm{E}-10$ & $2.24 \mathrm{E}-10$ & $2.32 \mathrm{E}-10$ & $2.36 \mathrm{E}-10$ & $2.84 \mathrm{E}-10$ & 3.15E-10 & $1.21 \mathrm{E}-10$ & $1.99 \mathrm{E}-09$ \\
\hline & & SIM StdDev & $6.94 \mathrm{E}-12$ & $6.11 \mathrm{E}-12$ & 4.00E-10 & $3.02 \mathrm{E}-10$ & $2.78 \mathrm{E}-10$ & 2.90E-10 & $2.94 \mathrm{E}-10$ & $3.54 \mathrm{E}-10$ & 3.93E-10 & $1.52 \mathrm{E}-10$ & $9.00 \mathrm{E}-10$ \\
\hline \multirow[t]{3}{*}{ Co-60 } & $\mathrm{Ci}$ & Anderson (1976) & $7.00 \mathrm{E}+00$ & $6.00 \mathrm{E}+00$ & $1.00 \mathrm{E}+01$ & 4.00E-01 & $2.00 \mathrm{E}-01$ & $2.00 \mathrm{E}-01$ & $1.00 \mathrm{E}-01$ & $2.00 \mathrm{E}-01$ & $5.00 \mathrm{E}-01$ & 4.00E-01 & $2.50 \mathrm{E}+01$ \\
\hline & & SIM Mean & 7.25E-03 & $6.44 \mathrm{E}-03$ & 1.26E-02 & $9.51 \mathrm{E}-03$ & 8.83E-03 & $9.13 \mathrm{E}-03$ & $9.30 \mathrm{E}-03$ & 1.12E-02 & 1.24E-02 & 4.79E-03 & $9.15 \mathrm{E}-02$ \\
\hline & & SIM StdDev & 3.25E-03 & $2.87 \mathrm{E}-03$ & $9.40 \mathrm{E}-03$ & 7.06E-03 & $6.59 \mathrm{E}-03$ & $6.79 \mathrm{E}-03$ & $6.89 \mathrm{E}-03$ & $8.35 \mathrm{E}-03$ & $9.25 \mathrm{E}-03$ & $3.54 \mathrm{E}-03$ & $2.15 \mathrm{E}-02$ \\
\hline $\mathrm{Pu}$ & $\mathrm{g}$ & Anderson (1976) & $1.56 \mathrm{E}+02$ & $8.27 E+01$ & $5.68 \mathrm{E}+01$ & $3.30 \mathrm{E}+00$ & $1.01 \mathrm{E}+02$ & $9.90 \mathrm{E}+00$ & $1.32 \mathrm{E}+01$ & $1.22 \mathrm{E}+01$ & $3.50 \mathrm{E}+00$ & $2.00 \mathrm{E}+00$ & $4.40 \mathrm{E}+02$ \\
\hline U & $\mathrm{kg}$ & Anderson (1976) & $1.93 \mathrm{E}+03$ & $9.05 \mathrm{E}+01$ & $1.13 \mathrm{E}+02$ & $7.90 \mathrm{E}+00$ & $1.70 \mathrm{E}+02$ & $8.75 \mathrm{E}+01$ & $1.19 \mathrm{E}+02$ & $2.38 \mathrm{E}+01$ & $3.04 \mathrm{E}+01$ & $1.67 \mathrm{E}+01$ & $2.60 \mathrm{E}+03$ \\
\hline \multirow[t]{2}{*}{ I-129 } & $\mathrm{Ci}$ & SIM Mean & 5.03E-02 & 4.46E-02 & 4.16E-02 & 3.14E-02 & 2.91E-02 & 3.01E-02 & 3.07E-02 & 3.70E-02 & 4.09E-02 & $1.58 \mathrm{E}-02$ & 3.51E-01 \\
\hline & & SIM StdDev & $2.99 \mathrm{E}-02$ & $2.64 \mathrm{E}-02$ & 3.80E-02 & $2.86 \mathrm{E}-02$ & $2.65 \mathrm{E}-02$ & $2.74 \mathrm{E}-02$ & $2.80 \mathrm{E}-02$ & 3.37E-02 & 3.73E-02 & $1.44 \mathrm{E}-02$ & $9.43 \mathrm{E}-02$ \\
\hline \multirow[t]{2}{*}{ TC-99 } & $\mathrm{Ci}$ & SIM Mean & $9.33 \mathrm{E}-01$ & 8.28E-01 & 1.16E-01 & 8.78E-02 & $8.15 \mathrm{E}-02$ & 8.43E-02 & $8.58 \mathrm{E}-02$ & 1.03E-01 & 1.15E-01 & 4.41E-02 & $2.48 \mathrm{E}+00$ \\
\hline & & SIM StdDev & 3.80E-01 & 3.37E-01 & $7.52 \mathrm{E}-02$ & 5.69E-02 & $5.26 \mathrm{E}-02$ & $5.45 \mathrm{E}-02$ & $5.58 \mathrm{E}-02$ & $6.74 \mathrm{E}-02$ & 7.43E-02 & 2.87E-02 & 5.37E-01 \\
\hline \multirow[t]{2}{*}{ NO3 } & $\mathrm{kg}$ & SIM Mean & $7.57 \mathrm{E}+04$ & $6.71 \mathrm{E}+04$ & $4.70 \mathrm{E}+04$ & $3.54 \mathrm{E}+04$ & $3.28 \mathrm{E}+04$ & $3.40 \mathrm{E}+04$ & $3.46 \mathrm{E}+04$ & 4.17E+04 & $4.62 \mathrm{E}+04$ & $1.78 \mathrm{E}+04$ & $4.32 \mathrm{E}+05$ \\
\hline & & SIM StdDev & $9.04 \mathrm{E}+03$ & $7.98 \mathrm{E}+03$ & $4.31 \mathrm{E}+03$ & $3.24 \mathrm{E}+03$ & $2.99 \mathrm{E}+03$ & $3.13 E+03$ & $3.15 E+03$ & $3.85 E+03$ & $4.22 \mathrm{E}+03$ & $1.64 \mathrm{E}+03$ & $1.54 \mathrm{E}+04$ \\
\hline
\end{tabular}




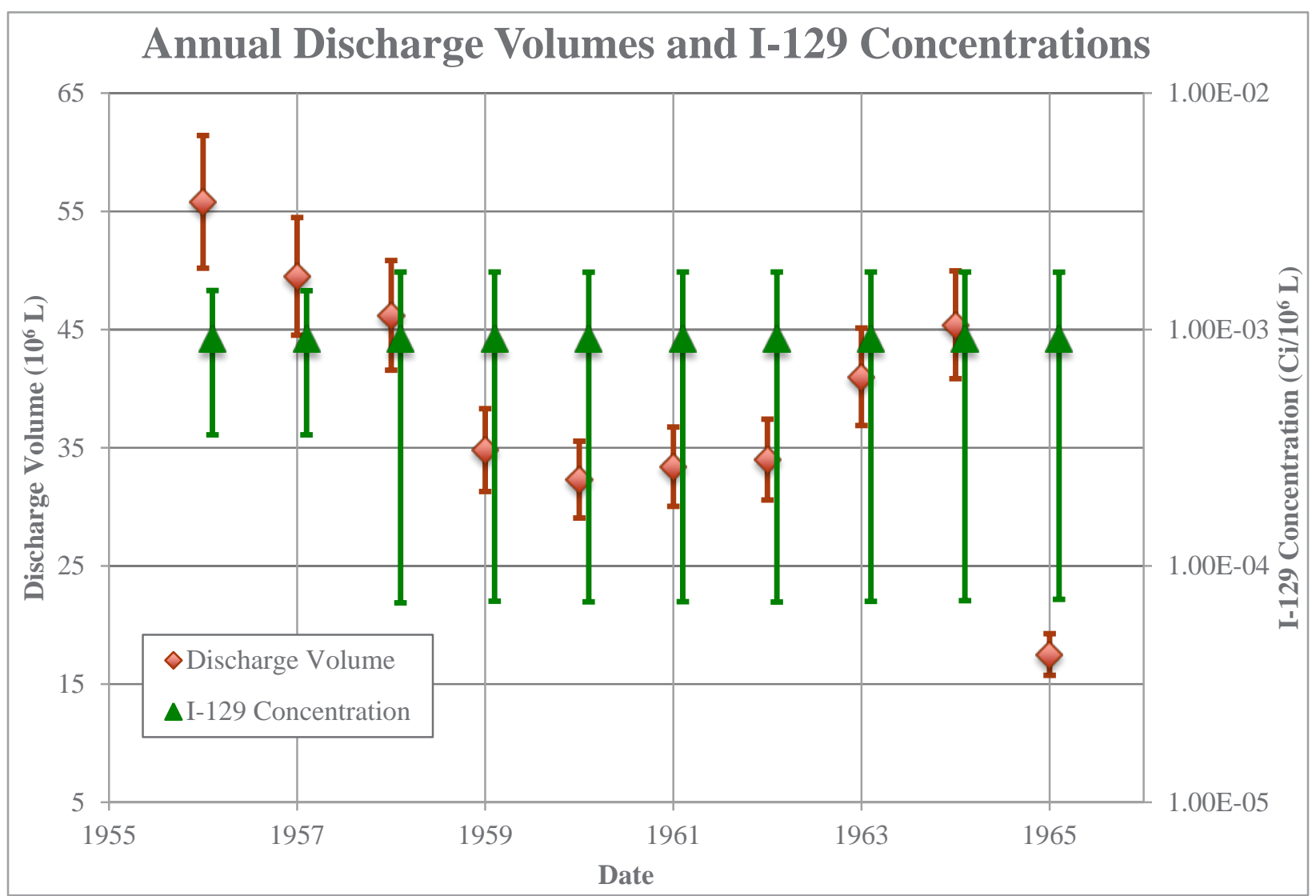

Figure B.4. Mean annual discharge volumes and ${ }^{129} \mathrm{I}$ concentrations (from Corbin et al. 2005).

\section{B.1.3 Site Characterization and Monitoring}

In 1956, just prior to crib operation, three wells (299-W22-12, 299-W22-13, and 299-W22-14) were installed around the perimeter of the crib to monitor radionuclide movement through the soil column during crib operations (Figure B.2).

In 1966, following the cessation of waste discharges to the crib, two new wells (299-W22-32 and 299-W22-33) were installed through the center of the crib, to evaluate the distribution of radionuclides in the soil column. Analyses of core samples indicated that Cs-137 concentrations reached $13 \mu \mathrm{Ci} / \mathrm{g}$ at 6.4 m (21 ft) bgs) (Maxfield 1979), but at a depth of $10.7 \mathrm{~m}$ (35 ft), had dropped to $3 \times 10^{-4} \mu \mathrm{Ci} / \mathrm{g}$, with concentrations remaining relatively uniform to a depth of $39.6 \mathrm{~m}(130 \mathrm{ft})$ bgs. Below that depth, Cs-137 concentrations declined to $2 \times 10^{-6} \mu \mathrm{Ci} / \mathrm{g}$. Strontium-90 concentrations also peaked at $6.4 \mathrm{~m}(21 \mathrm{ft})$ with concentrations of $2.70 \mu \mathrm{Ci} / \mathrm{g}$. Concentrations then decreased to below detection levels $2 \times 10-5 \mu \mathrm{Ci} / \mathrm{g}$

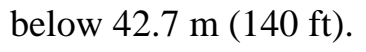

Geophysical logging using a scintillation probe was conducted on all five wells. Fecht et al. (1979, |RHO-LD-29|) present logs covering the years 1958, 1959, 1968, and 1976. The logs are off scale for the first 10 to $30 \mathrm{~m}$ below the crib for all logging events. A second peak is seen at a depth 55 to $58 \mathrm{~m}$ (180 to $190 \mathrm{ft}$ ) in the 1968 and 1976 data, which may be associated with a change in lithology. Radioactivity 
PNNL-24709, Rev. 2

RPT-DVZ-AFRI-030, Rev. 2

levels detected in the 1968 surveys are typically over an order of magnitude higher than those recorded in 1976, most likely due to decay of Ru-106.

The WIDS Report for this site (http://idmsweb.rl.gov/idms) cites the Radiation Monitoring Monthly Report for August 1975 as stating that the above ground piping was removed, the remaining piping blanked below ground level, sink holes filled in, and the ground surface leveled. In 1979, all wells were reconfigured to prevent preferential migration of liquids along the outside of the casing, and in 1992, the site was surface stabilized with an additional $0.61 \mathrm{~m}$ (2 ft) of clean dirt (WIDS Report, http://idmsweb.rl.gov/idms).

DOE (2004) suggested that the effluent volume discharged $(390,000,000 \mathrm{~L})$ at this site is 47 times greater than the soil pore volume $(8,361,000 \mathrm{~L})$, and that there has been impact to the groundwater at this site. In 2004, borehole C4557 was drilled through the center of the crib. Figure B.5 illustrates the vertical distribution of Cs-137 interpreted from geophysical logs and the moisture content determined in core samples taken from this borehole. Note that all ${ }^{129} \mathrm{I}$ concentrations were below detection limits. The Cs-137 appears to be held up fairly high in the soil column, in the Hanford formation, above the Cold Creek Unit. 
PNNL-24709, Rev. 2

RPT-DVZ-AFRI-030, Rev. 2

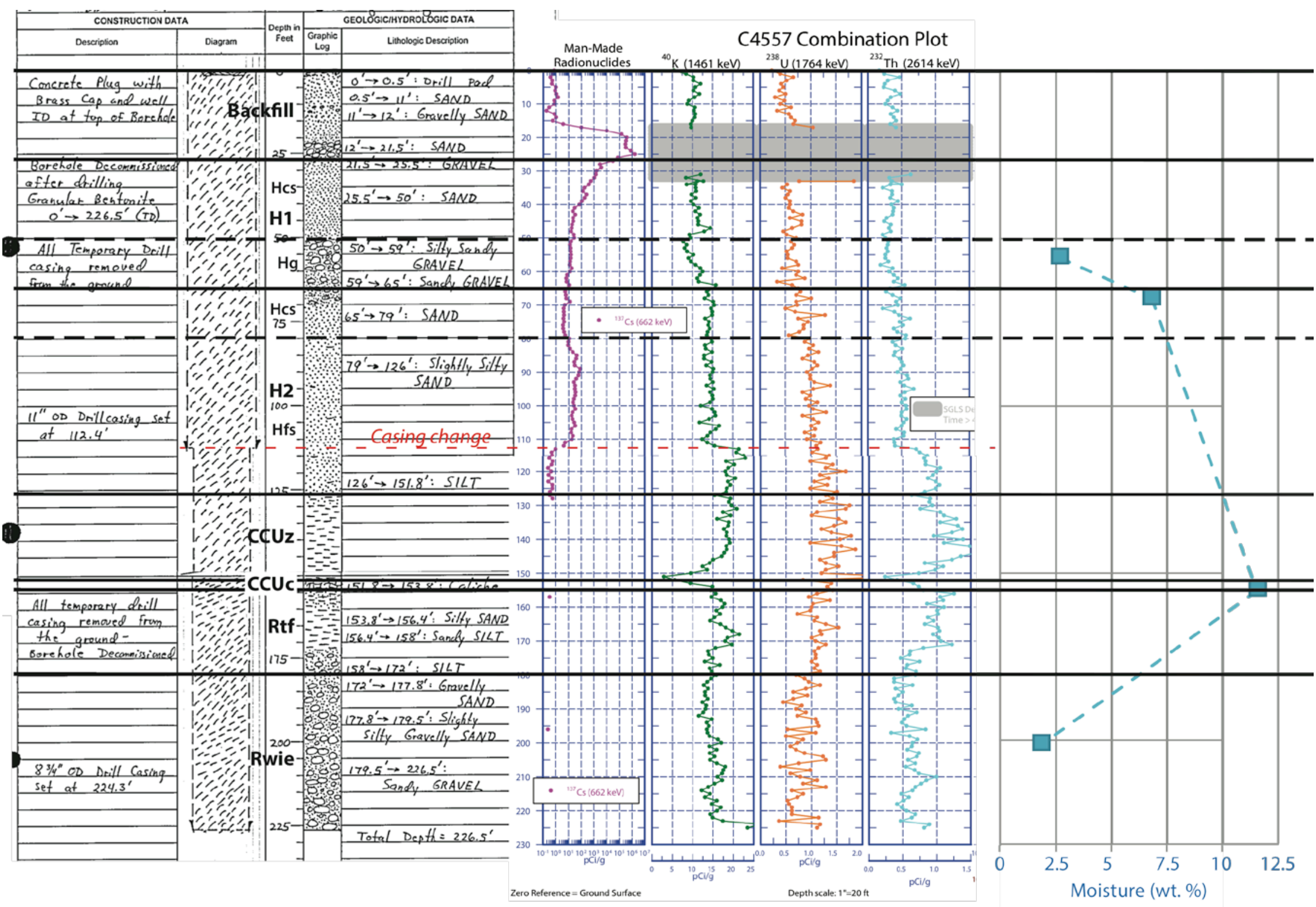

Figure B.5. Composite log for borehole C4557. 
PNNL-24709, Rev. 2

RPT-DVZ-AFRI-030, Rev. 2

\section{B.1.4 Hydrogeology}

Figure B.6 illustrates a hydrograph of the water table beneath the crib. The pre-Hanford water table is believed to have been at an elevation of about $122.5 \mathrm{~m}$. During operations in 1956 and 1965, the water table was at an elevation of about 140 to $143.5 \mathrm{~m}$ (67.9 to $64.4 \mathrm{~m}$ below ground surface). Water levels reached a peak of about $144.9 \mathrm{~m}$ in 1977, and have since dropped, reaching a low of about $131.8 \mathrm{~m}$ in October 2015. Thus, the vadose zone thickness has generally ranged from 63 to over $76 \mathrm{~m}$ since crib operations.

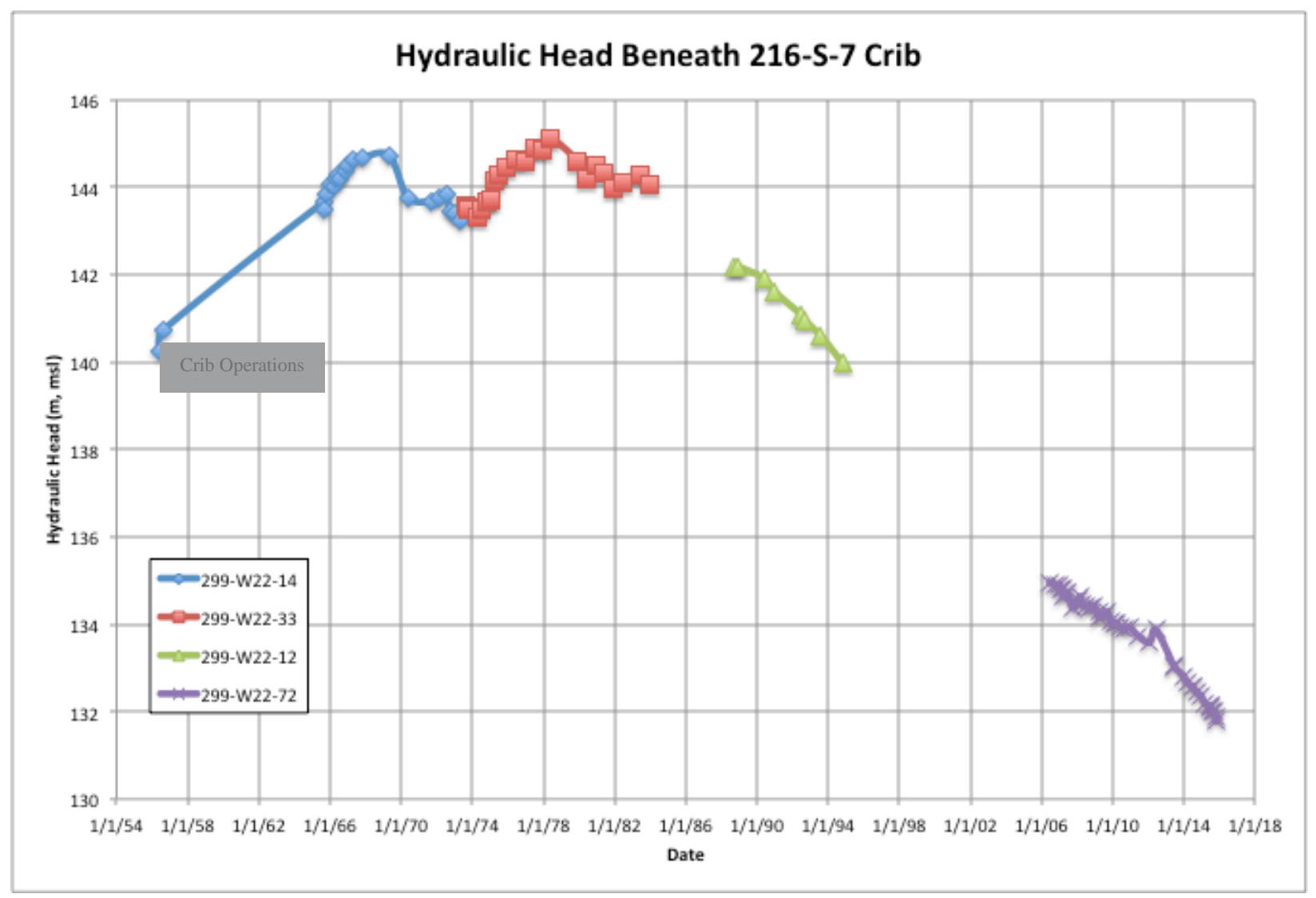

Figure B.6. Hydrograph of the water table beneath the 216-S-7 crib.

The hydrostratigraphy beneath the crib is illustrated in Figure B.5. Table B.2 lists the average contact elevations and thickness of the major hydrostratigraphic units. 
PNNL-24709, Rev. 2

RPT-DVZ-AFRI-030, Rev. 2

Table B.2. Elevation and thickness of major stratigraphic units (based on borehole logs from C4557).

\begin{tabular}{|c|c|c|c|c|}
\hline $\begin{array}{l}\text { Hydrogeologic } \\
\text { Unit }\end{array}$ & Description & $\begin{array}{l}\text { Sediment } \\
\text { Class (after } \\
\text { Last et al. } \\
\text { 2009) }\end{array}$ & $\begin{array}{l}\text { Top } \\
\text { Contact } \\
\text { Elevation } \\
\text { (m MSL) }\end{array}$ & $\begin{array}{l}\text { Unit } \\
\text { Thickness } \\
\text { (m) }\end{array}$ \\
\hline Backfill & Backfill (includes crib gravel) & $\mathrm{Bf}$ & $\begin{array}{l}207.3 \\
\text { (ground } \\
\text { surface, } \\
\text { assumed) }\end{array}$ & 6.6 \\
\hline \multirow[t]{2}{*}{ Hanford H1 } & $\begin{array}{l}\text { SAND; fine to coarse, alternating } \\
\text { between fine-medium sand and } \\
\text { coarse sand. Some thin silt layers } \\
<0.5 \mathrm{~cm} \text { thick. Moist. }\end{array}$ & $\mathrm{Hcs}$ & 200.7 & 8.7 \\
\hline & $\begin{array}{l}\text { Silty Sandy GRAVEL to Sandy } \\
\text { GRAVEL; } 40-50 \% \text { medium to very } \\
\text { coarse pebble (with a some of small } \\
\text { cobble, } 30-60 \% \text { coarse to very } \\
\text { coarse sand, up to } 20 \% \text { silt } \\
\text { (decreasing with depth). Dry to } \\
\text { slightly moist. }\end{array}$ & $\mathrm{Hg}$ & 192.1 & 4.6 \\
\hline \multirow[t]{2}{*}{ Hanford H2 } & $\begin{array}{l}\text { SAND; coarse to medium, trace of } \\
\text { silt. A thin }(1 \mathrm{~cm} \text { thick) bed of silt at } \\
67.5 \mathrm{ft} \text {. Slightly moist. }\end{array}$ & $\mathrm{Hcs}$ & 187.5 & 4.3 \\
\hline & $\begin{array}{l}\text { Slightly Silty SAND; } 85-90 \% \text { medium } \\
\text { to fine sand, } 10-15 \% \text { silt. Slightly } \\
\text { moist. }\end{array}$ & Hfs & 183.2 & 14.3 \\
\hline Cold Creek Silt & $\begin{array}{l}\text { SILT; } \geq 80 \% \text { silt, }<20 \% \text { very fine } \\
\text { sand, with some thickly laminated } \\
\text { dark brown silty clay layers. Moist. }\end{array}$ & CCUz & 168.9 & 7.9 \\
\hline $\begin{array}{l}\text { Cold Creek } \\
\text { Carbonate }\end{array}$ & $\begin{array}{l}\text { CALICHE; well cemented medium to } \\
\text { fine sand; } 70 \% \text { sand, } 30 \% \text { silt }\end{array}$ & CCUc & 161.0 & 0.6 \\
\hline $\begin{array}{l}\text { Ringold Formation, } \\
\text { member of Taylor } \\
\text { Flats }\end{array}$ & $\begin{array}{l}\text { Silty SAND, Sandy SILT and SILT; } \\
\text { with very fine sand and a few } \\
\text { cobbles increasing with depth. }\end{array}$ & CCUz & 160.4 & 5.5 \\
\hline $\begin{array}{l}\text { Ringold - Wooded } \\
\text { Island Unit e }\end{array}$ & $\begin{array}{l}\text { Silty sandy medium to fine pebble to } \\
\text { sandy very coarse to fine pebble }\end{array}$ & Rg (gravel) & 154.9 & NA \\
\hline
\end{tabular}

\section{B.1.5 Physical and Hydraulic Properties}

Best estimate physical and hydraulic properties for each of the sediment classes listed in Table B.2 are shown in Table B.3, based on those of Last et al. (2006a, 2009). 
PNNL-24709, Rev. 2

RPT-DVZ-AFRI-030, Rev. 2

Table B.3. Best estimate physical and hydraulic properties.

\begin{tabular}{|c|c|c|c|c|c|c|c|c|c|c|}
\hline $\begin{array}{c}\text { Hydraulic } \\
\text { Property } \\
\text { Class }\end{array}$ & count & $\begin{array}{c}a \\
(1 / \mathrm{cm})\end{array}$ & $n$ & $\begin{array}{c}q_{R} \\
\left(\mathrm{~cm}^{3} / \mathrm{cm}^{3}\right)\end{array}$ & $\begin{array}{c}q_{s} \\
\left(\mathrm{~cm}^{3} / \mathrm{cm}^{3}\right)\end{array}$ & $\begin{array}{c}K_{\mathrm{s}} \\
(\mathrm{cm} / \mathrm{sec})\end{array}$ & $S_{r}$ & $\begin{array}{l}\text { gravel } \\
\text { wt. } \%\end{array}$ & $\begin{array}{c}\text { Bulk } \\
\text { Density } \\
\left(\mathrm{g} / \mathrm{cm}^{3}\right)\end{array}$ & Porosity \\
\hline $\mathrm{Bf}$ & 6 & 0.019 & 1.400 & 0.030 & 0.262 & 5.98E-04 & 0.103 & 33.5 & 1.94 & 0.21 \\
\hline $\mathrm{Hg}$ & 3 & 0.011 & 1.845 & 0.029 & 0.150 & 2.88E-04 & 0.204 & 57.1 & 2.09 & 0.23 \\
\hline Hcs & 7 & 0.038 & 1.945 & 0.035 & 0.317 & 1.09E-03 & 0.099 & 2.1 & 1.65 & 0.38 \\
\hline $\mathrm{Hfs}$ & 4 & 0.013 & 2.451 & 0.042 & 0.347 & $1.71 \mathrm{E}-05$ & 0.122 & 0.0 & 1.72 & 0.34 \\
\hline CCUz & 5 & 0.004 & 2.285 & 0.047 & 0.395 & 7.27E-06 & 0.117 & 0.1 & 1.71 & 0.35 \\
\hline CCUC & 14 & 0.011 & 1.740 & 0.054 & 0.281 & 8.45E-04 & 0.185 & 19.1 & 1.72 & 0.34 \\
\hline $\begin{array}{l}\mathrm{Rg} \\
\text { (gravel) }\end{array}$ & 2 & 0.018 & 1.654 & 0.005 & 0.114 & 2.60E-04 & 0.055 & 66.0 & 1.96 & 0.17 \\
\hline
\end{tabular}

Best estimate values after Last et al. 2006a and 2009.

\section{B.1.6 Recharge Estimates}

Recharge estimates are based on assumptions regarding the surface soil conditions and deep drainage (recharge) rates derived from field data and computer simulation results that were assembled into a suite of recharge classes described by Last et al. (2006a). The soil conditions and recharge estimates have been defined for 216-S-7 crib, for two different time intervals: (1) Pre-Operations and (2) Operations/Post Operations (Table B.4).

Table B.4. Estimated recharge rates for the 216-S-7 crib based on those from Last et al. (2006a, b).

\begin{tabular}{|c|c|c|c|c|c|}
\hline Time Interval & $\begin{array}{c}\text { Soil } \\
\text { Conditions }\end{array}$ & $\begin{array}{c}\text { Best } \\
\text { Estimate } \\
\text { (mm/yr) }\end{array}$ & $\begin{array}{c}\text { Estimated } \\
\text { Standard } \\
\text { Deviation } \\
\text { (mm/yr) }\end{array}$ & $\begin{array}{c}\text { Minimum } \\
(\mathrm{mm} / \mathrm{yr})\end{array}$ & $\underset{(\mathrm{mm} / \mathrm{yr})}{\operatorname{Maximum}}$ \\
\hline $\begin{array}{l}\text { Pre-Operations (As late as } 9 / 30 / 1955 \\
\text { - assumes construction started } 3 \\
\text { months prior to initial discharge). } \\
\text { Note that the structural drawings for } \\
\text { the cribs, } \mathrm{H}-2-30135 \text {, were signed as } \\
\text { late as Oct. } 21,1955 \text {, and reviewed } \\
\text { for As-Built as early as } 1 / 13 / 1956) \text {. }\end{array}$ & Rp-s & 4.0 & 2.0 & 2.0 & 8.0 \\
\hline $\begin{array}{l}\text { Operations and Post-Operations } \\
\text { (10/1/1955 to present - assumes soil } \\
\text { cover was cleared and grubbed and } \\
\text { maintained in a non-vegetated state } \\
\text { from construction through the } \\
\text { present). Note that the WIDS Report, } \\
\text { dated } 6 / 21 / 2010 \text {, describes at least } \\
\text { two surface stabilization efforts } \\
\text { (http://idmsweb.rl.gov/idms). }\end{array}$ & Rp-dn & 44.0 & 22.0 & 22.0 & 88.0 \\
\hline
\end{tabular}


PNNL-24709, Rev. 2

RPT-DVZ-AFRI-030, Rev. 2

\section{B.2 216-S-1\&2 Cribs}

The 216-S-1\&2 cribs are located east of WMA S-SX in southern 200 West Area (Figure B.7).

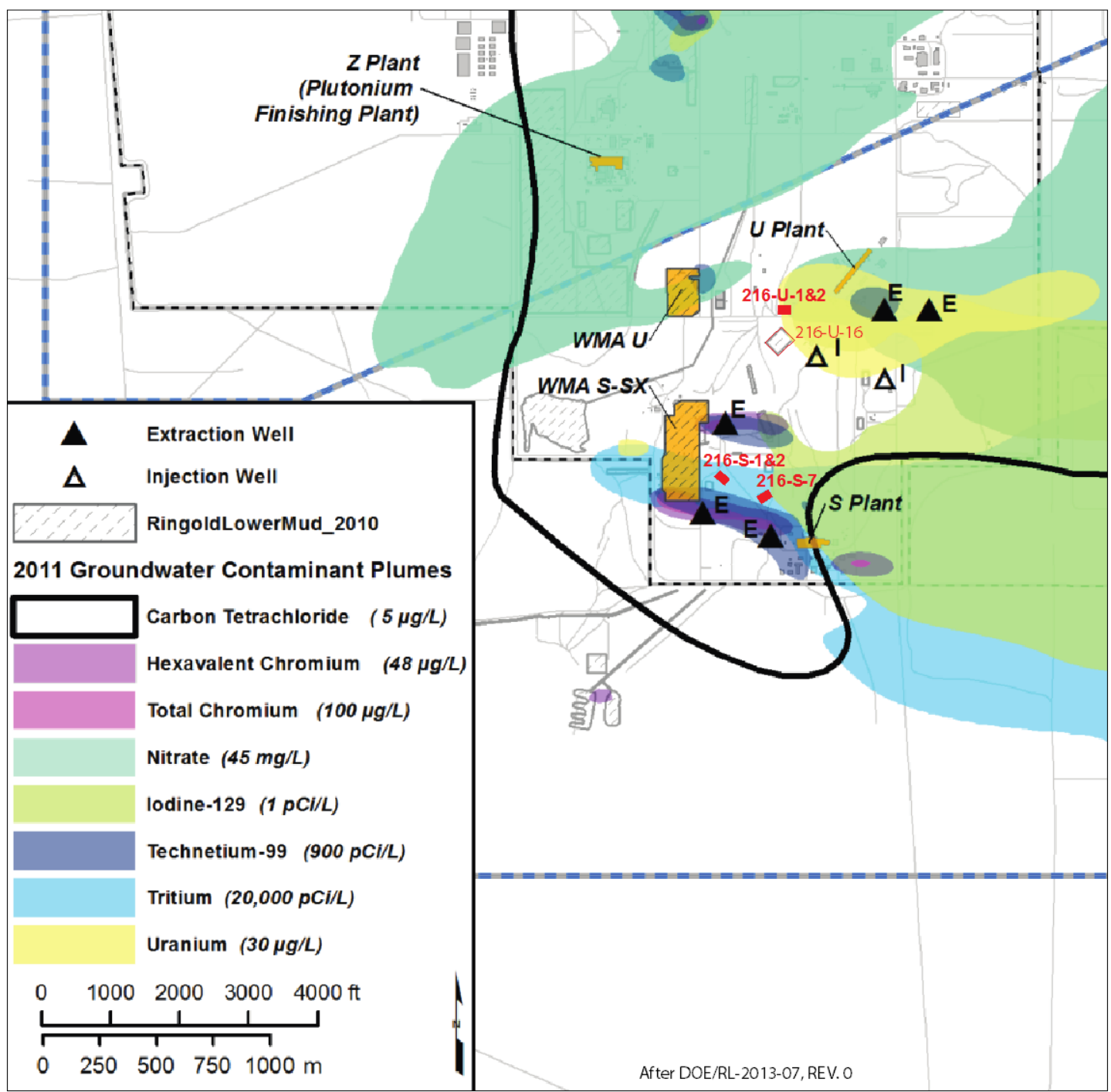

Figure B.7. Location of the 216-S-1\&2 cribs and other key facilities (modified after CHPRC 2013).

\section{B.2.1 Facility Design}

This site consists of two open-bottomed crib boxes set in a gravel-lined trench. The cribs are connected in series where overflow from the crib box S-1 flows into crib box S-2 via an underground pipe

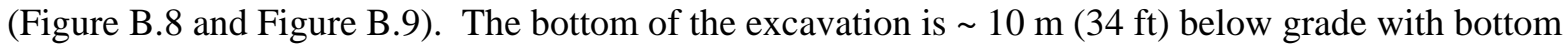
dimensions of 12.2 by $27.4 \mathrm{~m}$ (90 by $40 \mathrm{ft}$ ) and 45-degree side slopes (Van Luik and Smith 1982; Maxfield 1979). The bottom $3 \mathrm{~m}$ were filled with screened, crushed stone greater than $1.3 \mathrm{~cm}$ diameter.

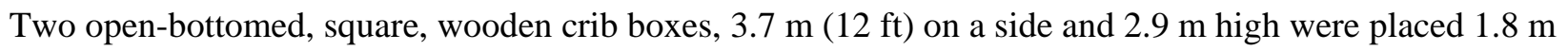
in to the gravel layer. The crib boxes were constructed with 15 - by 20 -cm timbers and cross braces. 


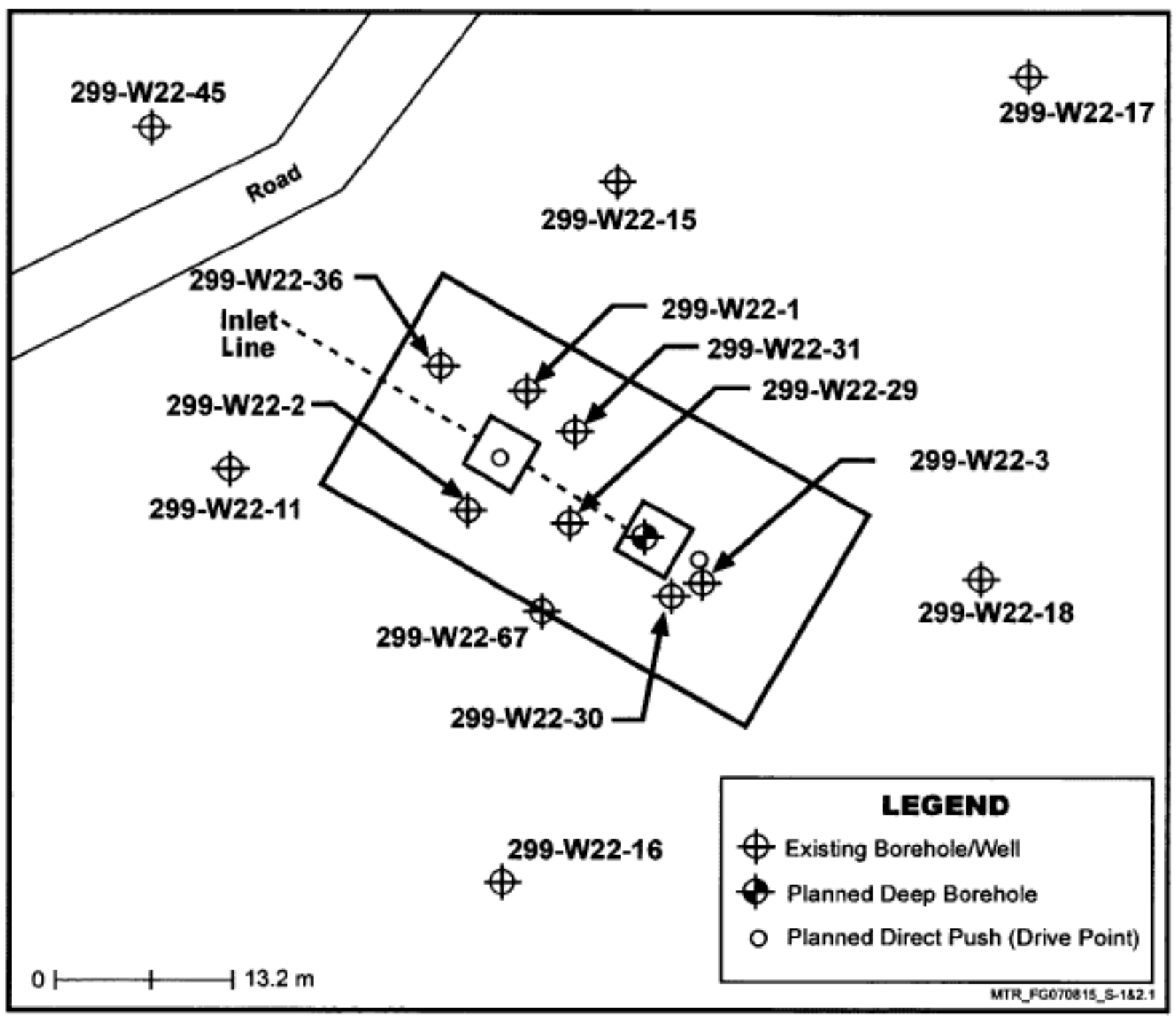

Figure B.8. Map view of the 216-S-1\&2 cribs (after DOE 2008 |DOE/RL-2007-02-VOL II-ADD 5 REV. 0|). 
PNNL-24709, Rev. 2

RPT-DVZ-AFRI-030, Rev. 2
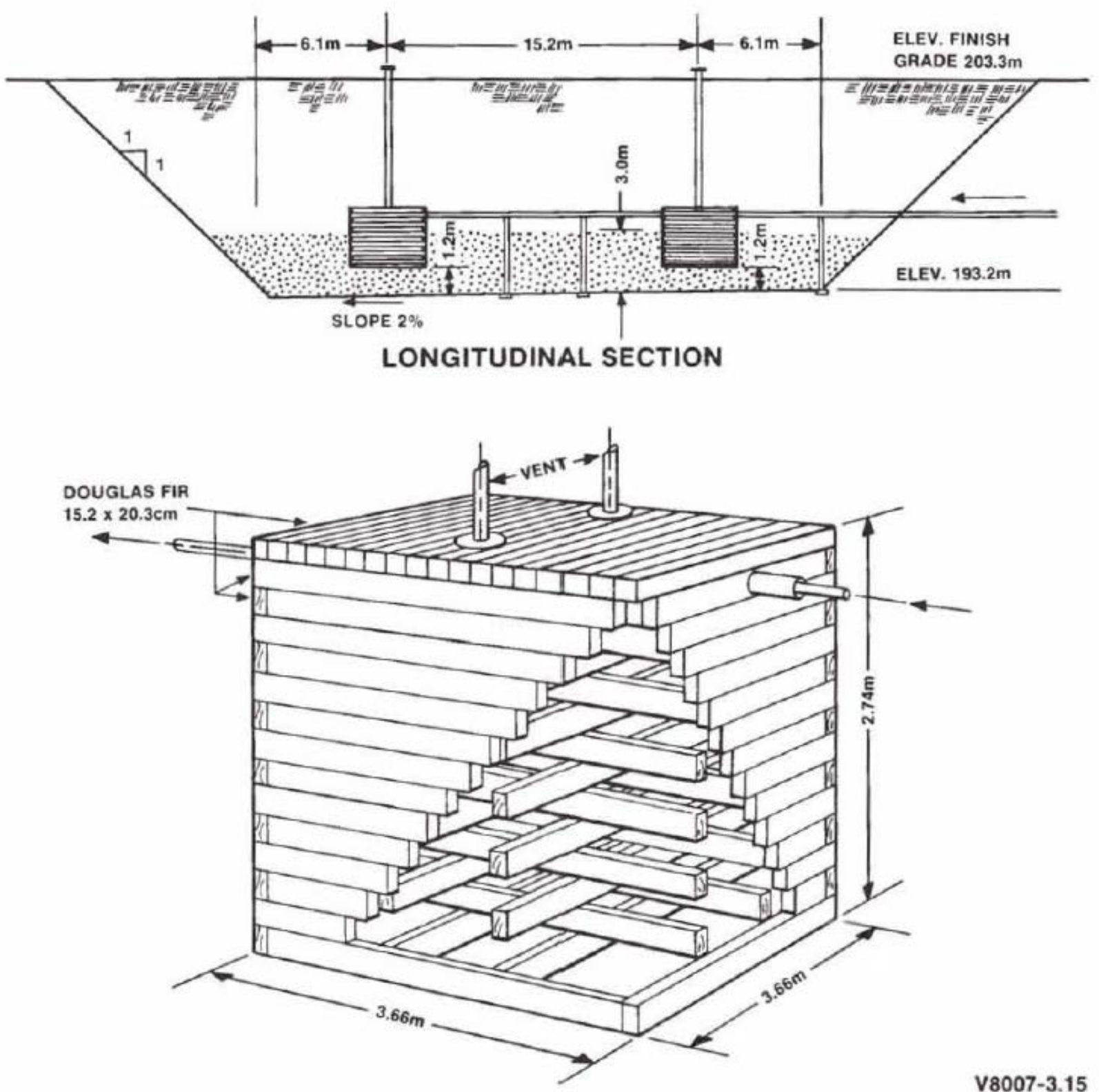

V8007-3.15

Figure B.9. Construction details (after Van Luik and Smith 1982).

Approximate center coordinates for each crib (shown below) are based on extrapolation from QMAP geospatial map portal (available at hgis.rl.gov/qmap/).

- 216-S-1 - N134265; E566973 (State Plane, m)

• 216-S-2 - N134258.5; E566983.5 (State Plane, m)

Trench Bottom Area $=12.2$ by $27.4 \mathrm{~m}=334.4 \mathrm{~m}^{2}$

Graveled Side Slope Area=2@52.5 m²+2@118.2 m²=341.6 m²

Total Infiltration Area $=676.0 \mathrm{~m}^{2}$ 
PNNL-24709, Rev. 2

RPT-DVZ-AFRI-030, Rev. 2

\section{B.2.2 Operational History}

The 216-S-1\&2 cribs were used as a subsurface liquid distribution system for cell drainage and process condensate from the REDOX facility (Shearer 2013, p. 1141). The waste had a pH of 2.1 and was discharged to the cribs in batches of about 19,000 liters (Van Luik and Smith 1982; Haney and Linderoth 1959), with an average of 10 batches discharged each day (DOE 2008).

The site was deactivated in January 1956 when the acid waste corroded though monitoring well casings (299-W22-3) and penetrated sediments near the water table. This release is now called UPR-200W-36 (DOE 2008). The WIDS Report states ...

On August 2, 1955, process vapors were smelled near the 216-S-1 \& 2 cribs. A Radiation Monitor investigated the area and found the well cap on test well 207-S-Il1 (alias 299-W22-3) to have a dose rate of 4 rad per hour on the well cap. A water sample was collected from the well on August 4, 1955 that resulted in a personnel contamination incident. The sampler also reported a gurgling sound coming from the well. It was concluded that the well casing had failed or ruptured. The rupture was apparently allowing process waste to by pass the crib soil column and flow directly into the groundwater. The well was promptly backfilled with sand.

DOE (2004 |DOE/RL-2000-60, Rev.1, Reissue, p. D-2|) noted that a release of hexone-rich concentrator wastes to the 216-S-1\&2 cribs was documented as an unplanned release (UPR-200-W-36) in August 1955.

Table B.5 provides the annual inventory estimates. Table B.6 provides the estimated monthly discharge volumes, ${ }^{129}$ I release inventories, and concentrations, based on the mean annual estimates from the Soil Inventory Model (Corbin et al. 2005 |RPP-26744/ Appendix C|), and normalized to monthly discharges and beta inventories reported in Hanford Works documents by Rupert and Heid (1954), Pass and Heid (1955), and Heid (1956). Figure B.10 provides a graphical representation of these estimates.

Table B.5. Annual inventory of waste discharged to the 216-S-1\&2 cribs.

\begin{tabular}{|c|c|c|c|c|c|c|c|c|}
\hline Constituent & Units & Source & 1952 & 1953 & 1954 & 1955 & 1956 & Sum \\
\hline Discharge Volume & $\mathrm{L}$ & $\begin{array}{l}\text { Van Luik and Smith } \\
\text { 1982) }\end{array}$ & $1.43 E+07$ & $4.69 \mathrm{E}+07$ & $4.92 \mathrm{E}+07$ & $4.96 \mathrm{E}+07$ & $2.60 \mathrm{E}+04$ & $1.60 \mathrm{E}+08$ \\
\hline \multirow[t]{3}{*}{ Volume } & L & VL & $1.43 \mathrm{E}+07$ & $4.69 \mathrm{E}+07$ & $4.92 \mathrm{E}+07$ & $4.96 \mathrm{E}+07$ & $2.60 \mathrm{E}+04$ & $1.60 \mathrm{E}+08$ \\
\hline & & SIM Mean & $1.43 \mathrm{E}+07$ & $4.69 \mathrm{E}+07$ & $4.96 \mathrm{E}+07$ & $4.96 \mathrm{E}+07$ & $2.60 \mathrm{E}+04$ & $1.60 E+08$ \\
\hline & & SIM StdDev & $1.45 E+06$ & $4.73 \mathrm{E}+06$ & $4.97 \mathrm{E}+06$ & $5.00 \mathrm{E}+06$ & $2.00 \mathrm{E}+03$ & NA \\
\hline Beta & $\mathrm{Ci}$ & $\begin{array}{l}\text { Van Luik and Smith } \\
\text { 1982) }\end{array}$ & $5.56 \mathrm{E}+02$ & $4.53 E+04$ & $3.08 E+05$ & $3.96 \mathrm{E}+05$ & $1.16 \mathrm{E}+02$ & $7.50 \mathrm{E}+05$ \\
\hline \multirow[t]{3}{*}{ Sr-90 } & $\mathrm{Ci}$ & $\begin{array}{l}\text { Van Luik and Smith } \\
\text { 1982) }\end{array}$ & $2.00 \mathrm{E}+00$ & $1.81 \mathrm{E}+02$ & $1.23 \mathrm{E}+03$ & $1.58 \mathrm{E}+03$ & $1.00 \mathrm{E}+00$ & $3.00 E+03$ \\
\hline & & SIM Mean & $6.18 \mathrm{E}+01$ & $2.62 \mathrm{E}+02$ & $3.48 \mathrm{E}+02$ & $2.85 E+02$ & $1.77 \mathrm{E}+00$ & $9.59 E+02$ \\
\hline & & SIM StdDev & $2.70 \mathrm{E}+01$ & $1.07 \mathrm{E}+02$ & $1.42 \mathrm{E}+02$ & $1.16 \mathrm{E}+02$ & $9.76 \mathrm{E}-01$ & $2.14 \mathrm{E}+02$ \\
\hline \multirow[t]{3}{*}{ Cs-137 } & $\mathrm{Ci}$ & $\begin{array}{l}\text { Van Luik and Smith } \\
\text { 1982) }\end{array}$ & $2.00 \mathrm{E}+00$ & $1.51 E+02$ & 1.03E+03 & $1.32 \mathrm{E}+03$ & -- & $2.50 \mathrm{E}+03$ \\
\hline & & SIM Mean & $5.33 \mathrm{E}+01$ & $2.26 \mathrm{E}+02$ & $3.00 \mathrm{E}+02$ & $2.46 \mathrm{E}+02$ & $1.52 \mathrm{E}+00$ & 8.27E+02 \\
\hline & & SIM StdDev & $2.37 \mathrm{E}+01$ & $9.38 \mathrm{E}+01$ & $1.25 \mathrm{E}+02$ & $1.01 \mathrm{E}+02$ & 8.62E-01 & $1.88 \mathrm{E}+02$ \\
\hline \multirow[t]{3}{*}{ Ru-106 } & $\mathrm{Ci}$ & $\begin{array}{l}\text { Van Luik and Smith } \\
\text { 1982) }\end{array}$ & $2.00 \mathrm{E}+00$ & $1.81 E+02$ & $1.23 \mathrm{E}+03$ & $1.59 E+03$ & $3.00 \mathrm{E}+03$ & $3.00 E+00$ \\
\hline & & SIM Mean & 1.34E-12 & $5.70 \mathrm{E}-12$ & $7.56 \mathrm{E}-12$ & $6.20 \mathrm{E}-12$ & 3.84E-14 & $2.08 \mathrm{E}-11$ \\
\hline & & SIM StdDev & 1.34E-12 & $5.25 E-12$ & $7.02 \mathrm{E}-12$ & $5.70 \mathrm{E}-12$ & 4.86E-14 & $1.05 \mathrm{E}-11$ \\
\hline Co-60 & $\mathrm{Ci}$ & $\begin{array}{l}\text { Van Luik and Smith } \\
\text { 1982) }\end{array}$ & -- & 6.00E-01 & 4.10E+00 & $5.30 E+00$ & -- & 3.24E-01 \\
\hline
\end{tabular}


PNNL-24709, Rev. 2

RPT-DVZ-AFRI-030, Rev. 2

\begin{tabular}{|c|c|c|c|c|c|c|c|c|}
\hline Constituent & Units & Source & 1952 & 1953 & 1954 & 1955 & 1956 & Sum \\
\hline & & SIM Mean & $1.30 \mathrm{E}-03$ & $5.53 \mathrm{E}-03$ & $7.33 \mathrm{E}-03$ & $6.01 \mathrm{E}-03$ & $3.72 \mathrm{E}-05$ & $2.02 \mathrm{E}-02$ \\
\hline & & SIM StdDev & $6.30 \mathrm{E}-04$ & $2.48 \mathrm{E}-03$ & 3.33E-03 & $2.69 \mathrm{E}-03$ & $2.29 \mathrm{E}-05$ & 4.98E-03 \\
\hline $\mathrm{Pu}$ & g & $\begin{array}{l}\text { Van Luik and Smith } \\
\text { 1982) }\end{array}$ & $8.00 \mathrm{E}+00$ & $4.90 \mathrm{E}+01$ & $4.44 \mathrm{E}+02$ & $6.97 \mathrm{E}+02$ & $2.00 \mathrm{E}+00$ & $1.20 \mathrm{E}+03$ \\
\hline U-238 & $\mathrm{kg}$ & $\begin{array}{l}\text { Van Luik and Smith } \\
\text { 1982) }\end{array}$ & $1.50 \mathrm{E}+01$ & $9.30 \mathrm{E}+01$ & $8.39 E+02$ & $1.32 \mathrm{E}+03$ & $4.00 \mathrm{E}+00$ & $2.27 E+02$ \\
\hline \multirow[t]{2}{*}{ I-129 } & $\mathrm{Ci}$ & $\begin{array}{l}\text { Van Luik and Smith } \\
\text { 1982) }\end{array}$ & 5.23E-03 & 3.45E-02 & 5.69E-02 & 3.87E-02 & 4.91E-04 & 1.36E-01 \\
\hline & & SIM StdDev & $3.11 \mathrm{E}-03$ & 2.05E-02 & 3.38E-02 & 2.30E-02 & 2.92E-04 & 4.61E-02 \\
\hline \multirow[t]{2}{*}{ Tc-99 } & $\mathrm{Ci}$ & SIM Mean & $1.68 \mathrm{E}-01$ & 7.12E-01 & 9.43E-01 & 7.74E-01 & $4.80 \mathrm{E}-03$ & $2.60 E+00$ \\
\hline & & SIM StdDev & 7.33E-02 & 2.90E-01 & $3.85 E-01$ & 3.15E-01 & 2.67E-03 & 5.84E-01 \\
\hline \multirow[t]{2}{*}{$\mathrm{NO}_{3}$} & $\mathrm{~kg}$ & SIM Mean & $1.36 \mathrm{E}+04$ & $5.77 \mathrm{E}+04$ & $7.65 E+04$ & $6.27 E+04$ & $3.89 E+02$ & $2.11 E+05$ \\
\hline & & SIM StdDev & $1.74 \mathrm{E}+03$ & $6.94 \mathrm{E}+03$ & $9.16 \mathrm{E}+03$ & $7.50 \mathrm{E}+03$ & $6.37 \mathrm{E}+01$ & $1.38 \mathrm{E}+04$ \\
\hline $\begin{array}{l}\text { Radionuclide InV } \\
\text { VL =m Virtual Li } \\
\text { SIM = Soil Inven }\end{array}$ & Model & $\begin{array}{l}\text { ste Discharged to } t \\
\text { module } \\
\text { orbin et al. 2005) }\end{array}$ & & & & h 1982;). & & \\
\hline
\end{tabular}

Table B.6. Monthly estimated discharge volume, ${ }^{129}$ I releases, and ${ }^{129}$ I concentrations (based on the mean annual estimates from Corbin et al. 2005).

\begin{tabular}{ccccc}
\hline Month End Date & $\begin{array}{c}\text { Normalized SIM } \\
\text { Volume Per Month } \\
\left(\mathbf{1 0 ^ { 6 }} \text { Liters) }\right.\end{array}$ & $\begin{array}{c}\text { Normalized SIM } \\
\text { Mean Annual I-129 } \\
\text { Inventory } \\
\text { (Ci) }\end{array}$ & $\begin{array}{c}\text { Normalized SIM } \\
\text { Monthly I-129 } \\
\text { Concentration } \\
\text { (Ci/106) }\end{array}$ & $\begin{array}{c}\text { SIM I-129 } \\
\text { Concentration } \\
\text { Std. Dev. }\end{array}$ \\
\hline $1 / 31 / 52$ & 1.00 & $4.55 \mathrm{E}-05$ & $4.56 \mathrm{E}-05$ & $2.245 \mathrm{E}-04$ \\
$2 / 29 / 52$ & 1.00 & $4.55 \mathrm{E}-05$ & $4.56 \mathrm{E}-05$ & $2.245 \mathrm{E}-04$ \\
$3 / 31 / 52$ & 1.00 & $4.55 \mathrm{E}-05$ & $4.56 \mathrm{E}-05$ & $2.245 \mathrm{E}-04$ \\
$4 / 30 / 52$ & 1.00 & $4.55 \mathrm{E}-05$ & $4.56 \mathrm{E}-05$ & $2.245 \mathrm{E}-04$ \\
$5 / 31 / 52$ & 1.00 & $4.55 \mathrm{E}-05$ & $4.56 \mathrm{E}-05$ & $2.245 \mathrm{E}-04$ \\
$6 / 30 / 52$ & 1.00 & $4.55 \mathrm{E}-05$ & $4.56 \mathrm{E}-05$ & $2.245 \mathrm{E}-04$ \\
$7 / 31 / 52$ & 1.48 & $2.81 \mathrm{E}-06$ & $1.90 \mathrm{E}-06$ & $2.245 \mathrm{E}-04$ \\
$8 / 31 / 52$ & 1.19 & $9.37 \mathrm{E}-06$ & $7.90 \mathrm{E}-06$ & $2.245 \mathrm{E}-04$ \\
$9 / 30 / 52$ & 1.35 & $7.50 \mathrm{E}-06$ & $5.54 \mathrm{E}-06$ & $2.245 \mathrm{E}-04$ \\
$10 / 31 / 52$ & 1.19 & $9.37 \mathrm{E}-07$ & $7.90 \mathrm{E}-07$ & $2.245 \mathrm{E}-04$ \\
$11 / 30 / 52$ & 1.65 & $4.93 \mathrm{E}-03$ & $2.99 \mathrm{E}-03$ & $2.245 \mathrm{E}-04$ \\
$12 / 31 / 52$ & 1.47 & $4.69 \mathrm{E}-06$ & $3.19 \mathrm{E}-06$ & $2.245 \mathrm{E}-04$ \\
$1 / 31 / 53$ & 4.20 & $3.78 \mathrm{E}-06$ & $9.02 \mathrm{E}-07$ & $4.492 \mathrm{E}-04$ \\
$2 / 28 / 53$ & 1.70 & $2.80 \mathrm{E}-05$ & $1.65 \mathrm{E}-05$ & $4.492 \mathrm{E}-04$ \\
$3 / 31 / 53$ & 2.96 & $1.82 \mathrm{E}-03$ & $6.14 \mathrm{E}-04$ & $4.492 \mathrm{E}-04$ \\
$4 / 30 / 53$ & 2.77 & $6.13 \mathrm{E}-04$ & $2.21 \mathrm{E}-04$ & $4.492 \mathrm{E}-04$ \\
$5 / 31 / 53$ & 3.51 & $4.80 \mathrm{E}-03$ & $1.37 \mathrm{E}-03$ & $4.492 \mathrm{E}-04$ \\
$6 / 30 / 53$ & 2.33 & $1.65 \mathrm{E}-03$ & $7.07 \mathrm{E}-04$ & $4.492 \mathrm{E}-04$ \\
$7 / 31 / 53$ & 3.66 & $6.33 \mathrm{E}-03$ & $1.73 \mathrm{E}-03$ & $4.492 \mathrm{E}-04$ \\
$8 / 31 / 53$ & 4.16 & $3.49 \mathrm{E}-03$ & $8.39 \mathrm{E}-04$ & $4.492 \mathrm{E}-04$ \\
$9 / 30 / 53$ & 4.16 & $2.07 \mathrm{E}-03$ & $4.98 \mathrm{E}-04$ & $4.492 \mathrm{E}-04$ \\
$10 / 31 / 53$ & 5.35 & $2.23 \mathrm{E}-03$ & $4.16 \mathrm{E}-04$ & $4.492 \mathrm{E}-04$ \\
$11 / 30 / 53$ & 6.24 & $2.86 \mathrm{E}-03$ & $4.59 \mathrm{E}-04$ & $4.492 \mathrm{E}-04$ \\
$12 / 31 / 53$ & 5.86 & $1.46 \mathrm{E}-03$ & $4.492 \mathrm{E}-04$ \\
\hline
\end{tabular}


PNNL-24709, Rev. 2 RPT-DVZ-AFRI-030, Rev. 2

\begin{tabular}{|c|c|c|c|c|}
\hline Month End Date & $\begin{array}{c}\text { Normalized SIM } \\
\text { Volume Per Month } \\
\left(10^{6} \text { Liters }\right)\end{array}$ & $\begin{array}{l}\text { Normalized SIM } \\
\text { Mean Annual I-129 } \\
\text { Inventory } \\
\text { (Ci) }\end{array}$ & $\begin{array}{c}\text { Normalized SIM } \\
\text { Monthly I-129 } \\
\text { Concentration } \\
\left(\text { Ci } / 10^{6} \mathrm{~L}\right) \\
\end{array}$ & $\begin{array}{l}\text { SIM I-129 } \\
\text { Concentration } \\
\text { Std. Dev. }\end{array}$ \\
\hline $1 / 31 / 54$ & 3.44 & $2.30 \mathrm{E}-03$ & $6.70 \mathrm{E}-04$ & 7.030E-04 \\
\hline $2 / 28 / 54$ & 3.03 & $2.25 \mathrm{E}-03$ & 7.43E-04 & 7.030E-04 \\
\hline $3 / 31 / 54$ & 5.08 & 1.16E-02 & $2.28 \mathrm{E}-03$ & 7.030E-04 \\
\hline $4 / 30 / 54$ & 4.09 & $2.94 \mathrm{E}-03$ & 7.18E-04 & 7.030E-04 \\
\hline $5 / 31 / 54$ & 5.21 & 1.60E-03 & 3.07E-04 & 7.030E-04 \\
\hline $6 / 30 / 54$ & 1.84 & 1.31E-03 & 7.15E-04 & 7.030E-04 \\
\hline $7 / 31 / 54$ & 2.80 & $8.62 \mathrm{E}-03$ & 3.08E-03 & 7.030E-04 \\
\hline $8 / 31 / 54$ & 4.12 & $9.28 \mathrm{E}-03$ & $2.25 \mathrm{E}-03$ & 7.030E-04 \\
\hline $9 / 30 / 54$ & 4.50 & 6.66E-03 & $1.48 \mathrm{E}-03$ & 7.030E-04 \\
\hline $10 / 31 / 54$ & 4.50 & $9.14 \mathrm{E}-04$ & 2.03E-04 & 7.030E-04 \\
\hline $11 / 30 / 54$ & 5.14 & 8.05E-04 & 1.57E-04 & 7.030E-04 \\
\hline $12 / 31 / 54$ & 5.86 & 8.63E-03 & 1.47E-03 & 7.030E-04 \\
\hline $1 / 31 / 55$ & 1.81 & 2.97E-03 & $1.64 \mathrm{E}-03$ & 4.771E-04 \\
\hline $2 / 28 / 55$ & 4.28 & $1.21 \mathrm{E}-03$ & $2.82 \mathrm{E}-04$ & 4.771E-04 \\
\hline 3/31/55 & 5.18 & 2.47E-04 & 4.77E-05 & 4.771E-04 \\
\hline $4 / 30 / 55$ & 0.47 & $1.15 E-04$ & $2.46 \mathrm{E}-04$ & 4.771E-04 \\
\hline $5 / 31 / 55$ & 5.25 & 7.56E-04 & $1.44 \mathrm{E}-04$ & 4.771E-04 \\
\hline $6 / 30 / 55$ & 3.69 & 6.27E-04 & 1.70E-04 & 4.771E-04 \\
\hline $7 / 31 / 55$ & 4.11 & 2.40E-05 & 5.83E-06 & 4.771E-04 \\
\hline $8 / 31 / 55$ & 5.06 & $1.51 \mathrm{E}-03$ & 2.98E-04 & 4.771E-04 \\
\hline $9 / 30 / 55$ & 5.74 & 1.18E-03 & 2.05E-04 & 4.771E-04 \\
\hline $10 / 31 / 55$ & 5.36 & 1.62E-02 & 3.03E-03 & 4.771E-04 \\
\hline $11 / 30 / 55$ & 4.84 & 1.27E-02 & 2.62E-03 & 4.771E-04 \\
\hline $12 / 31 / 55$ & 3.80 & 1.12E-03 & $2.95 E-04$ & 4.771E-04 \\
\hline $1 / 31 / 56$ & 0.03 & 4.91E-04 & 1.89E-02 & 1.126E-02 \\
\hline
\end{tabular}


PNNL-24709, Rev. 2

RPT-DVZ-AFRI-030, Rev. 2

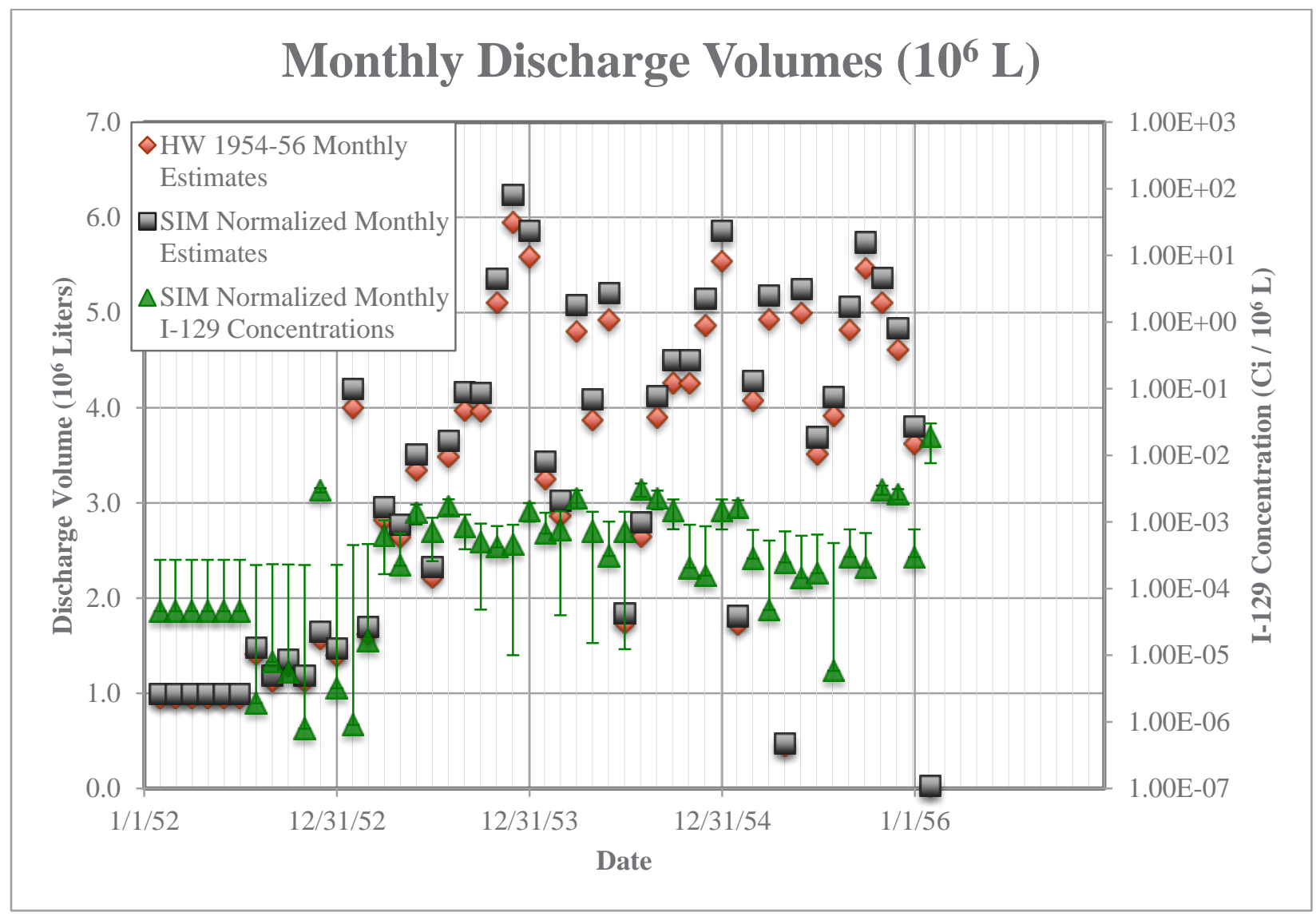

Figure B.10. Estimated monthly discharge volume and ${ }^{129}$ I concentrations.

\section{B.2.3 Site Characterization and Monitoring}

In January 1955, one of the three original vadose zone monitoring wells (dry wells), installed before operations, well 299-W22-3, was deepened from 45 to $93 \mathrm{~m}$ and perforated from 63 to $93 \mathrm{~m}$ to provide a ground-water monitoring well (Van Luik and Smith 1982). In June 1955, the well was found to be filled with liquid waste to within $15 \mathrm{~m}$ of the ground surface (Van Luik and Smith 1982). The well casing is believed to have failed near the bottom of the crib, with waste flowing down the well and out into the saturated sediments through the well perforations. It is believed that the leak into the well was due to failure of a weld in the casing, and probably not due to the acidic waste corroding the casing (Van Luik and Smith 1982). In early August 1955, the well was filled with sand, and within 6 months, the crib was removed from service. This well is listed as a candidate for decommissioning. ${ }^{1}$ Haney and Linderoth (1959) noted that approximately 1 year after the cribs were abandoned, ${ }^{90} \mathrm{Sr}$ was detected in the groundwater beneath the facility.

Figure B.11 and Figure B.12 illustrate the subsurface distribution of ${ }^{90} \mathrm{Sr}$ and ${ }^{137} \mathrm{Cs}$ from previous studies in 1956, 1966, and 1982.

\footnotetext{
${ }^{1}$ Well Information and Document Lookup (WIDL), accessed at prc.chprc.rl.gov/widl/, on 2016-03-24.
} 
PNNL-24709, Rev. 2

RPT-DVZ-AFRI-030, Rev. 2

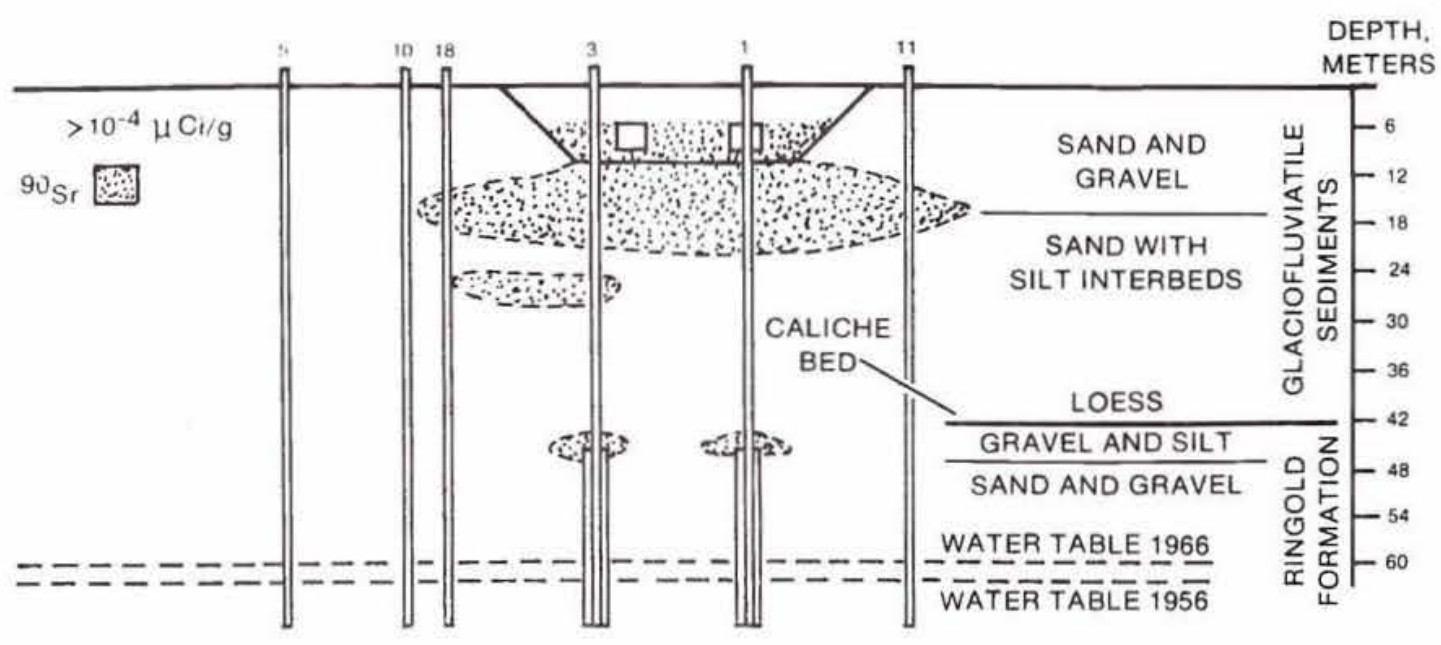

1956 FIELD EVALUATION
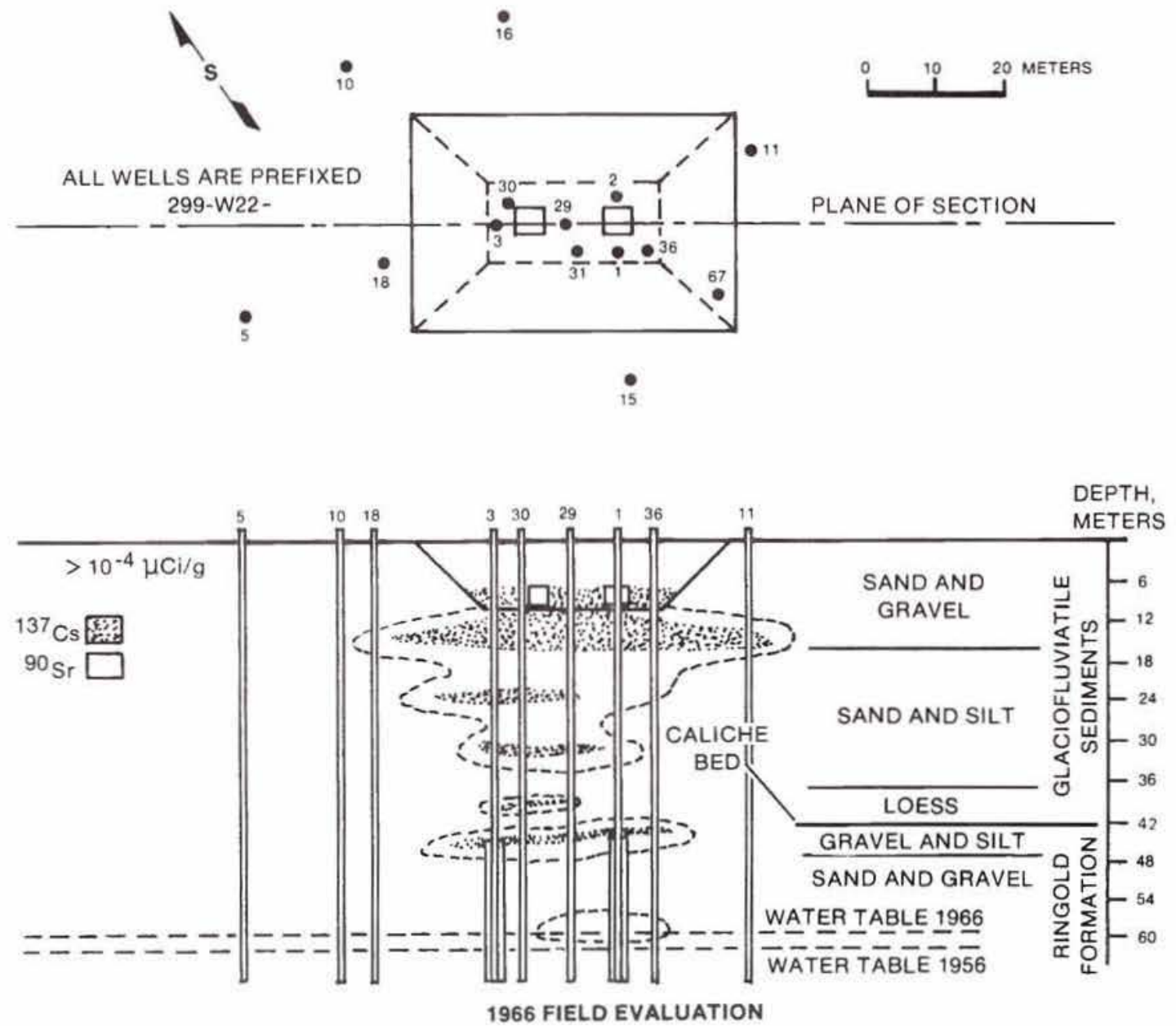

V8103-8.6

Figure B.11. Subsurface distribution of ${ }^{90} \mathrm{Sr}$ and ${ }^{137} \mathrm{Cs}$ in 1956 (top) and 1966 (bottom), taken from Van Luik and Smith 1982. 
PNNL-24709, Rev. 2

RPT-DVZ-AFRI-030, Rev. 2

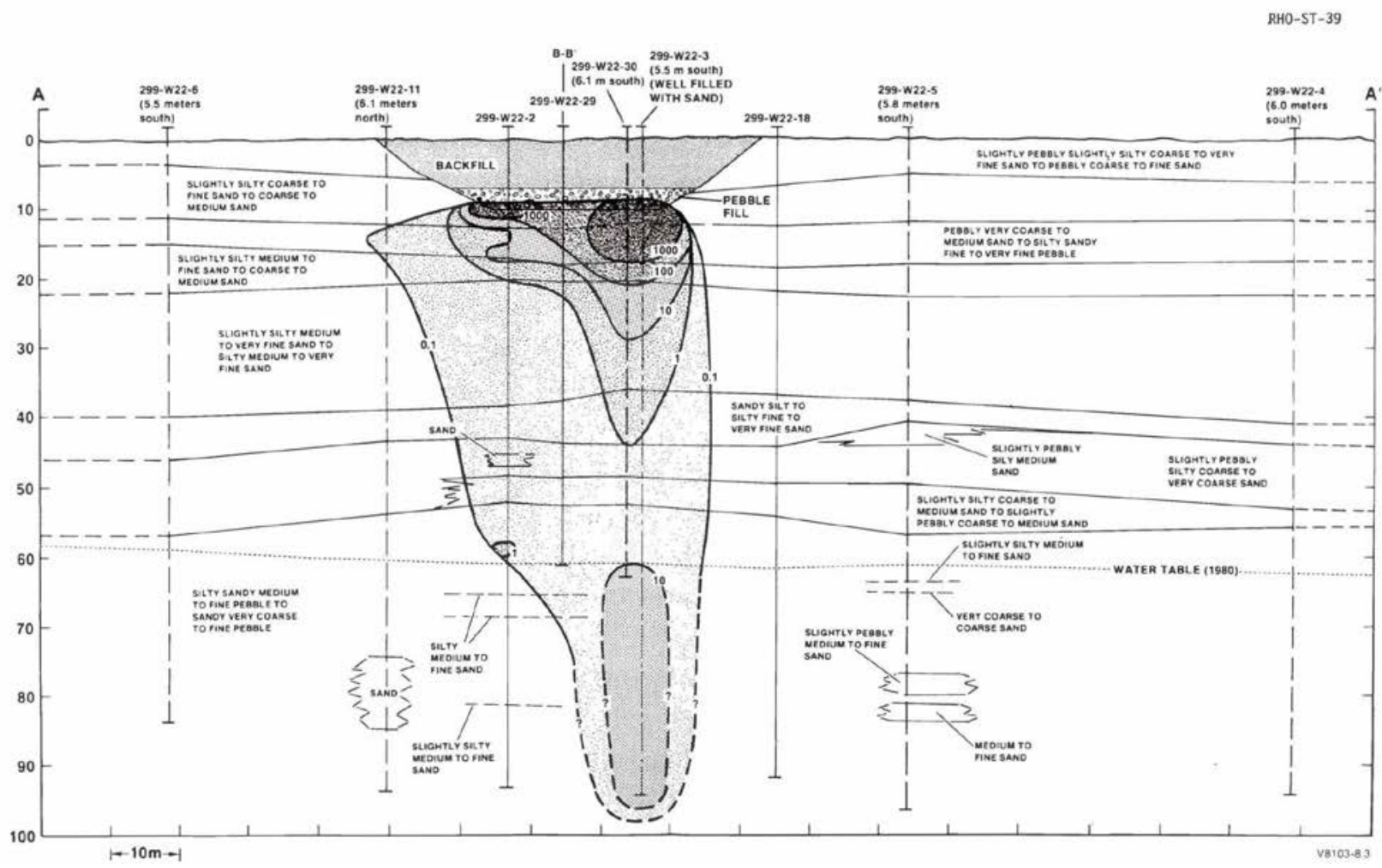

Figure B.12. Subsurface distribution of ${ }^{137}$ Cs in 1982 (taken from Van Luik and Smith 1982).

\section{B.2.4 Hydrogeology}

Figure B.13 illustrates a hydrograph of the water table beneath the crib. The pre-Hanford water table is believed to have been at an elevation of about $122.5 \mathrm{~m}$ (Kipp and Mud 1974). During operations in 1952 through 1955, the water table was at an elevation of about 135 to $140 \mathrm{~m}$ (69 to $64 \mathrm{~m}$ below ground surface). Water levels reached a peak of about $146 \mathrm{~m}$ in 1977/1978, and have since dropped, reaching a low of about $132.5 \mathrm{~m}$ in October 2015. Thus, the vadose zone thickness has generally ranged from about 64 to over $80 \mathrm{~m}$ since crib operations. 
PNNL-24709, Rev. 2

RPT-DVZ-AFRI-030, Rev. 2

Hydraulic Head Beneath 216-S-1\&2 Crib

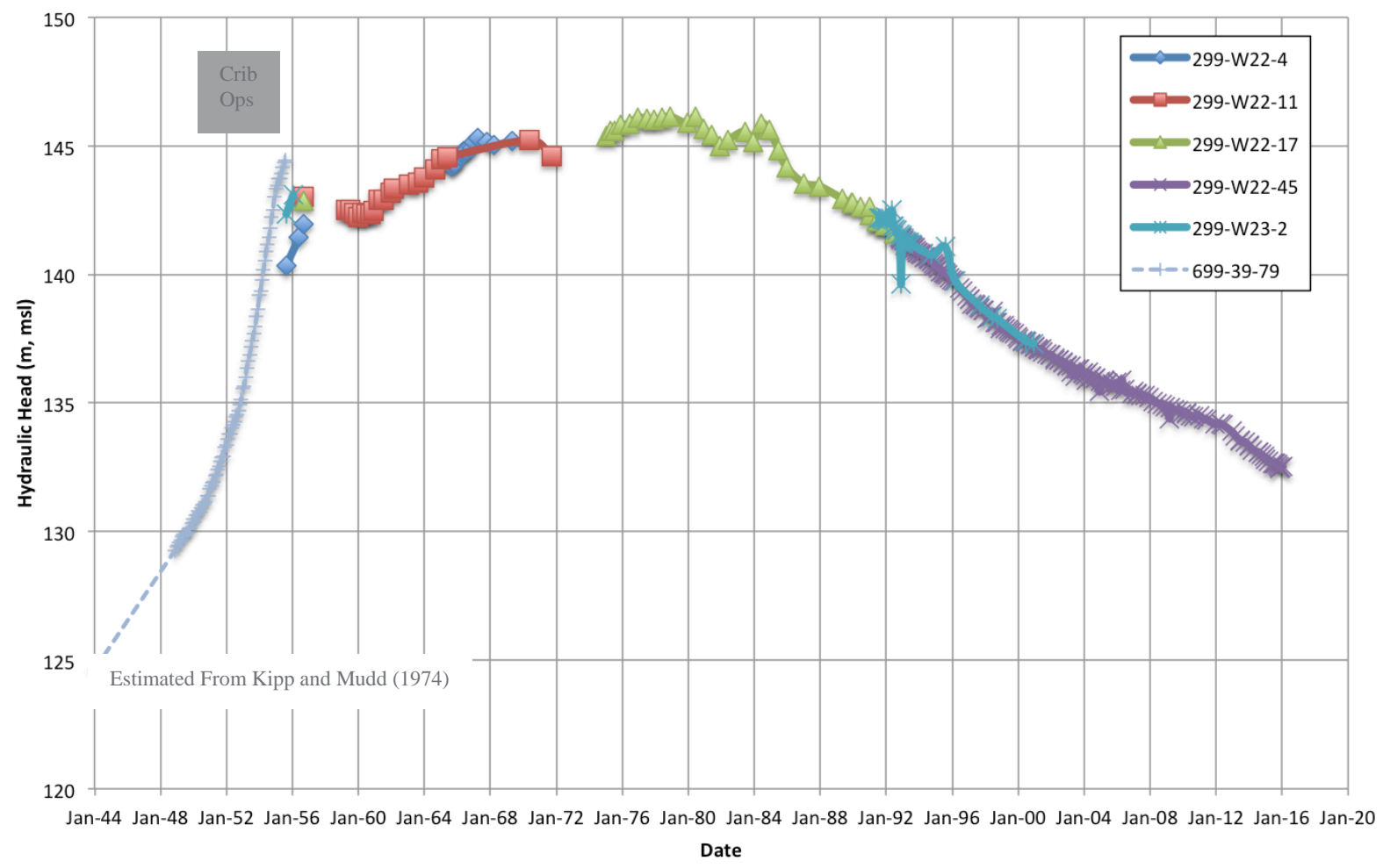

Figure B.13. Hydrograph of the water table beneath the 216-S-1\&2 cribs.

The geology underlying the 216-S-1\&2 cribs, and its physical and geochemical properties, control moisture and contaminant movement through the vadose zone to groundwater. Of particular interest are the interrelationships between the coarser and finer-grained facies, and the degree of contrast in their physical and geochemical properties. Information on the hydrogeologic stratigraphy comes primarily from the interpretation of borehole data. There are 35 borings and wells within about $100 \mathrm{~m}$ of the 216-S$1 \& 2$ cribs. Twenty of these have at least some geologic contact information (mostly taken from the geologic contacts database dated 12/31/2010 or interpreted from Van Luik and Smith 1982).

Figure B.14 illustrates the general stratigraphy through the cribs. Table B.7 provides that average geologic contact elevation and thicknesses for each of the major stratigraphic units. 
PNNL-24709, Rev. 2

RPT-DVZ-AFRI-030, Rev. 2

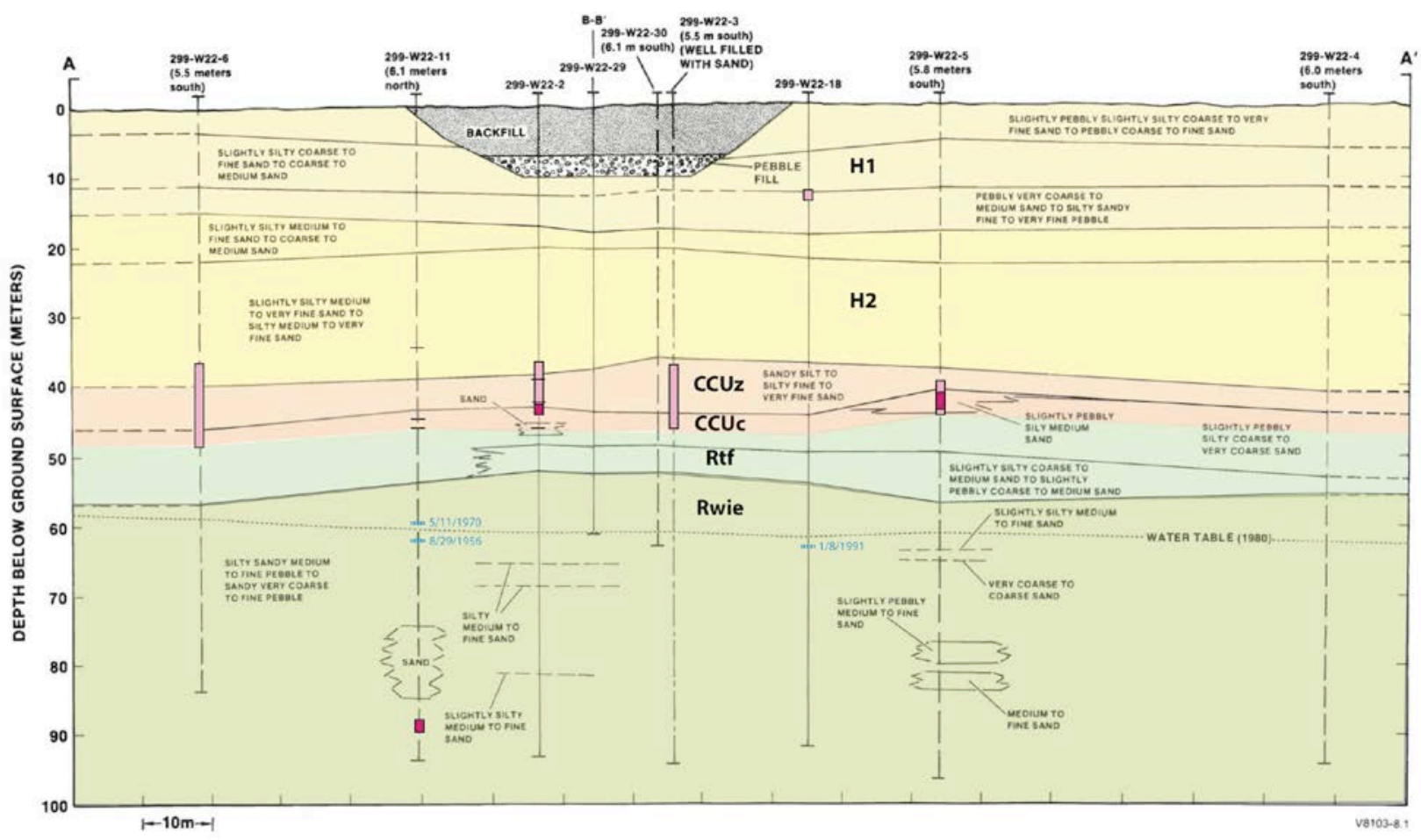

Figure B.14. General stratigraphy beneath the 216-S-1\&2 cribs, modified from Van Luik and Smith (1982).

Table B.7. Elevation and thickness of major stratigraphic units (based on geologic contacts compiled for this report).

\begin{tabular}{|c|c|c|c|c|c|c|c|c|}
\hline $\begin{array}{c}\text { Hydrogeologic } \\
\text { Unit }\end{array}$ & $\begin{array}{l}\text { Description } \\
\text { (from Van } \\
\text { Luik and } \\
\text { Smith 1982) }\end{array}$ & $\begin{array}{l}\text { Sediment } \\
\text { Class } \\
\text { (after } \\
\text { Last et al. } \\
\text { 2009) }\end{array}$ & $\begin{array}{c}\text { Number } \\
\text { of } \\
\text { Contacts }\end{array}$ & $\begin{array}{l}\text { Range in } \\
\text { Contact } \\
\text { Elevation } \\
\text { (m MSL) }\end{array}$ & $\begin{array}{c}\text { Average } \\
\text { Contact } \\
\text { Elevation } \\
\text { (m MSL) }\end{array}$ & $\begin{array}{l}\text { Number } \\
\text { used for } \\
\text { Thickness }\end{array}$ & $\begin{array}{l}\text { Range in } \\
\text { Thickness } \\
\text { (m) }\end{array}$ & $\begin{array}{l}\text { Average } \\
\text { Thickness } \\
\text { (m) }\end{array}$ \\
\hline Backfill & $\begin{array}{c}\text { Backfill } \\
\text { (includes } \\
\text { pebble fill) }\end{array}$ & $\mathrm{Bf}$ & 8 & $\begin{array}{c}204.7- \\
203.1\end{array}$ & 204.2 & 8 & $10.1^{*}-1.5$ & 7.8 \\
\hline \multirow[t]{3}{*}{$\begin{array}{l}\text { Hanford H1 } \\
\text { (assume equal } \\
\text { thicknesses of } \\
\text { each sediment } \\
\text { class) }\end{array}$} & $\begin{array}{l}\text { Slightly pebbly, } \\
\text { slightly silty } \\
\text { coarse to fine } \\
\text { sand, to pebbly } \\
\text { coarse to fine } \\
\text { sand }\end{array}$ & Hgs & 19 & $\begin{array}{c}206.1- \\
194.2\end{array}$ & $201.3^{*}$ & 19 & $19.2-7.3$ & 14.2 \\
\hline & $\begin{array}{l}\text { Slightly silty } \\
\text { coarse sand to } \\
\text { fine sand to } \\
\text { coarse to } \\
\text { medium sand }\end{array}$ & $\mathrm{Hcs}$ & & & & & & \\
\hline & $\begin{array}{l}\text { Pebbly very } \\
\text { coarse to } \\
\text { medium sand } \\
\text { to silty sandy } \\
\text { fine to very fine } \\
\text { pebble }\end{array}$ & Hgs & & & & & & \\
\hline
\end{tabular}


PNNL-24709, Rev. 2

RPT-DVZ-AFRI-030, Rev. 2

\begin{tabular}{|c|c|c|c|c|c|c|c|c|}
\hline $\begin{array}{c}\text { Hydrogeologic } \\
\text { Unit }\end{array}$ & $\begin{array}{l}\text { Description } \\
\text { (from Van } \\
\text { Luik and } \\
\text { Smith 1982) }\end{array}$ & $\begin{array}{l}\text { Sediment } \\
\text { Class } \\
\text { (after } \\
\text { Last et al. } \\
\text { 2009) }\end{array}$ & $\begin{array}{l}\text { Number } \\
\text { of } \\
\text { Contacts }\end{array}$ & $\begin{array}{l}\text { Range in } \\
\text { Contact } \\
\text { Elevation } \\
\text { (m MSL) }\end{array}$ & $\begin{array}{c}\text { Average } \\
\text { Contact } \\
\text { Elevation } \\
\text { (m MSL) }\end{array}$ & $\begin{array}{l}\text { Number } \\
\text { used for } \\
\text { Thickness }\end{array}$ & $\begin{array}{l}\text { Range in } \\
\text { Thickness } \\
\text { (m) }\end{array}$ & $\begin{array}{c}\text { Average } \\
\text { Thickness } \\
\text { (m) }\end{array}$ \\
\hline \multirow[t]{2}{*}{$\begin{array}{l}\text { Hanford } \mathrm{H} 2 \\
\text { (assume Hfs = } \\
2 / 3 \text { and Hss = } \\
1 / 3 \text { of total } \\
\text { thickness) }\end{array}$} & $\begin{array}{l}\text { Slightly silty } \\
\text { medium to fine } \\
\text { sand to coarse } \\
\text { to medium } \\
\text { sand }\end{array}$ & $\mathrm{Hfs}$ & 20 & $\begin{array}{c}188.8- \\
185.5\end{array}$ & 187 & 20 & $\begin{array}{c}25.9- \\
16.5\end{array}$ & 20.9 \\
\hline & $\begin{array}{l}\text { Slightly silty } \\
\text { medium to } \\
\text { very fine sand } \\
\text { to silty medium } \\
\text { to very fine } \\
\text { sand }\end{array}$ & Hss & & & & & & \\
\hline $\begin{array}{l}\text { Cold Creek Unit } \\
\text { Silt; CCUz }\end{array}$ & $\begin{array}{l}\text { Sandy silt to } \\
\text { silty very fine } \\
\text { sand }\end{array}$ & CCUz & 19 & $\begin{array}{c}169.4- \\
163.1\end{array}$ & 166.4 & 18 & $9.8-3.0$ & 6.1 \\
\hline $\begin{array}{l}\text { Cold Creek Unit } \\
\text { Carbonate; } \\
\text { ccuz }\end{array}$ & $\begin{array}{l}\text { Slightly pebbly } \\
\text { silty medium to } \\
\text { very coarse } \\
\text { sand }\end{array}$ & CCUc & 19 & $\begin{array}{c}164.7- \\
157.0\end{array}$ & 160.4 & 7 & $3.7-0.3$ & 2.3 \\
\hline $\begin{array}{l}\text { Ringold unit of } \\
\text { Taylor Flats; Rtf }\end{array}$ & $\begin{array}{l}\text { Slightly pebbly } \\
\text { silty coarse to } \\
\text { very coarse } \\
\text { sand } \\
\text { Slightly silty } \\
\text { coarse to } \\
\text { medium sand } \\
\text { to slightly } \\
\text { pebbly coarse } \\
\text { to medium } \\
\text { sand }\end{array}$ & $\mathrm{Rg}$ (sand) & 7 & $\begin{array}{c}160.5- \\
154.2\end{array}$ & 157.4 & 11 & $12.8-0^{\wedge}$ & $4.4^{\wedge}$ \\
\hline $\begin{array}{l}\text { Ringold - } \\
\text { Wooded Island } \\
\text { Unit e; Rwie }\end{array}$ & $\begin{array}{l}\text { Silty sandy } \\
\text { medium to fine } \\
\text { pebble to } \\
\text { sandy very } \\
\text { coarse to fine } \\
\text { pebble }\end{array}$ & $\begin{array}{c}\mathrm{Rg} \\
\text { (gravel) }\end{array}$ & 19 & $\begin{array}{c}161.0- \\
146.7\end{array}$ & 152.2 & NA & NA & NA \\
\hline $\begin{array}{l}\text { Water Table } \\
\text { (Date) }\end{array}$ & NA & NA & NA & $\begin{array}{c}124 \\
(1944)^{1} \\
140.3 \\
(1955)^{2} \\
141.5 \\
(1992)^{3} \\
132.5 \\
(2015)^{4}\end{array}$ & NA & NA & NA & NA \\
\hline \multicolumn{9}{|c|}{$\begin{array}{l}\text { * Thickness of the backfill over the cri } \\
\text { A This unit is missing in } 3 \text { of the } 11 \text { bo } \\
{ }^{1} \text { Based on Kipp and Mud }(1974) . \\
{ }^{2} \text { Well } 299-W 22-4 \text { (August 18, 1955). } \\
{ }^{3} \text { Well 299-W22-45 (12/17/1992). } \\
{ }^{4} \text { Well 299-W22-45 (11/06/2015). }\end{array}$} \\
\hline
\end{tabular}


PNNL-24709, Rev. 2

RPT-DVZ-AFRI-030, Rev. 2

\section{B.2.5 Physical and Hydraulic Properties}

Best estimate physical and hydraulic properties for each of the sediment classes listed in Table B.7 are shown in Table B.8, based on those of Last et al. (2006a, 2009).

Table B.8. Best estimate physical and hydraulic properties.

\begin{tabular}{|c|c|c|c|c|c|c|c|c|c|c|}
\hline $\begin{array}{c}\text { Hydraulic } \\
\text { Property } \\
\text { Class }\end{array}$ & count & $\begin{array}{c}a \\
(1 / \mathrm{cm})\end{array}$ & $N$ & $\begin{array}{c}q_{R} \\
\left(\mathrm{~cm}^{3} / \mathrm{cm}^{3}\right)\end{array}$ & $\begin{array}{c}q_{s} \\
\left(\mathrm{~cm}^{3} / \mathrm{cm}^{3}\right)\end{array}$ & $\begin{array}{c}K_{s} \\
(\mathrm{~cm} / \mathrm{sec})\end{array}$ & $S_{r}$ & $\begin{array}{l}\text { gravel } \\
\text { wt. } \%\end{array}$ & $\begin{array}{c}\text { Bulk } \\
\text { Density } \\
\left(\mathrm{g} / \mathrm{cm}^{3}\right)\end{array}$ & Porosity \\
\hline $\mathrm{Bf}$ & 6 & 0.019 & 1.400 & 0.030 & 0.262 & $5.98 \mathrm{E}-04$ & 0.103 & 33.5 & 1.94 & 0.21 \\
\hline Hgs & 2 & 0.008 & 2.223 & 0.030 & 0.273 & $2.35 \mathrm{E}-04$ & 0.133 & 24.0 & 1.81 & 0.34 \\
\hline HCS & 7 & 0.038 & 1.945 & 0.035 & 0.317 & 1.09E-03 & 0.099 & 2.1 & 1.65 & 0.38 \\
\hline Hss & 6 & 0.007 & 2.347 & 0.066 & 0.437 & $2.49 \mathrm{E}-05$ & 0.147 & 0.0 & 1.58 & 0.39 \\
\hline Hfs & 4 & 0.013 & 2.451 & 0.042 & 0.347 & 1.71E-05 & 0.122 & 0.0 & 1.72 & 0.34 \\
\hline Hfs & 8 & 0.010 & 2.177 & 0.042 & 0.356 & 3.67E-05 & 0.118 & 0.4 & 1.70 & 0.32 \\
\hline CCUz & 5 & 0.004 & 2.285 & 0.047 & 0.395 & 7.27E-06 & 0.117 & 0.1 & 1.71 & 0.35 \\
\hline CCUc & 14 & 0.011 & 1.740 & 0.054 & 0.281 & $8.45 \mathrm{E}-04$ & 0.185 & 19.1 & 1.72 & 0.34 \\
\hline $\mathrm{Rg}$ (sand) & 6 & 0.012 & 1.677 & 0.054 & 0.354 & 7.83E-05 & 0.142 & 7.6 & 1.80 & 0.34 \\
\hline $\begin{array}{l}\mathrm{Rg} \\
\text { (gravel) }\end{array}$ & 2 & 0.018 & 1.654 & 0.005 & 0.114 & 2.60E-04 & 0.055 & 66.0 & 1.96 & 0.17 \\
\hline
\end{tabular}

\section{B.2.6 Recharge Estimates}

Recharge estimates are based on assumptions regarding the surface soil conditions and deep drainage (recharge) rates derived from field data and computer simulation results that were assembled into a suite of recharge classes described by Last et al. (2006a). The soil conditions and recharge estimates have been defined for two different time intervals: (1) Pre-Operations and (2) Operations/Post Operations (Table B.9).

Table B.9. Estimated recharge rates based on those from Last et al. (2006a, b).

\begin{tabular}{|c|c|c|c|c|c|}
\hline Time Interval & $\begin{array}{c}\text { Soil } \\
\text { Conditions }\end{array}$ & $\begin{array}{c}\text { Best } \\
\text { Estimate } \\
(\mathrm{mm} / \mathrm{yr})\end{array}$ & $\begin{array}{c}\text { Estimated } \\
\text { Standard } \\
\text { Deviation } \\
(\mathrm{mm} / \mathrm{yr})\end{array}$ & $\underset{(\mathrm{mm} / \mathrm{yr})}{\text { Minimum }}$ & $\begin{array}{c}\text { Maximum } \\
(\mathrm{mm} / \mathrm{yr})\end{array}$ \\
\hline $\begin{array}{l}\text { Pre-Operations (As late as } 12 / 31 / 1950 \\
\text { - assumes construction started } 1 \text { year } \\
\text { prior to initial discharge). Note that the } \\
\text { structural drawings for the cribs, } \mathrm{H}-2- \\
1813 \text {, were signed Oct. } 27,1949 .\end{array}$ & Rp-s & 4.0 & 2.0 & 2.0 & 8.0 \\
\hline $\begin{array}{l}\text { Operations and Post-Operations } \\
\text { (1/1/1951 to present - assumes soil } \\
\text { cover maintained in a non-vegetated } \\
\text { state). Note that the WIDS Report, } \\
\text { dated } 5 / 24 / 2010, \text { states "The surface is } \\
\text { free of vegetation" } \\
\text { (http://idmsweb.rl.gov/idms). }\end{array}$ & Rp-dn & 44.0 & 22.0 & 22.0 & 88.0 \\
\hline
\end{tabular}


PNNL-24709, Rev. 2

RPT-DVZ-AFRI-030, Rev. 2

\section{B.3 216-U-1\&2 Cribs}

The 216-U-1\&2 cribs are located between U Plant and of WMA U in southern 200 West Area (Figure B.15). Located just to the south lies the 216-U-16 crib, which is known to have impacted the contaminant plume beneath the $216-\mathrm{U}-1 \& 2$ cribs.

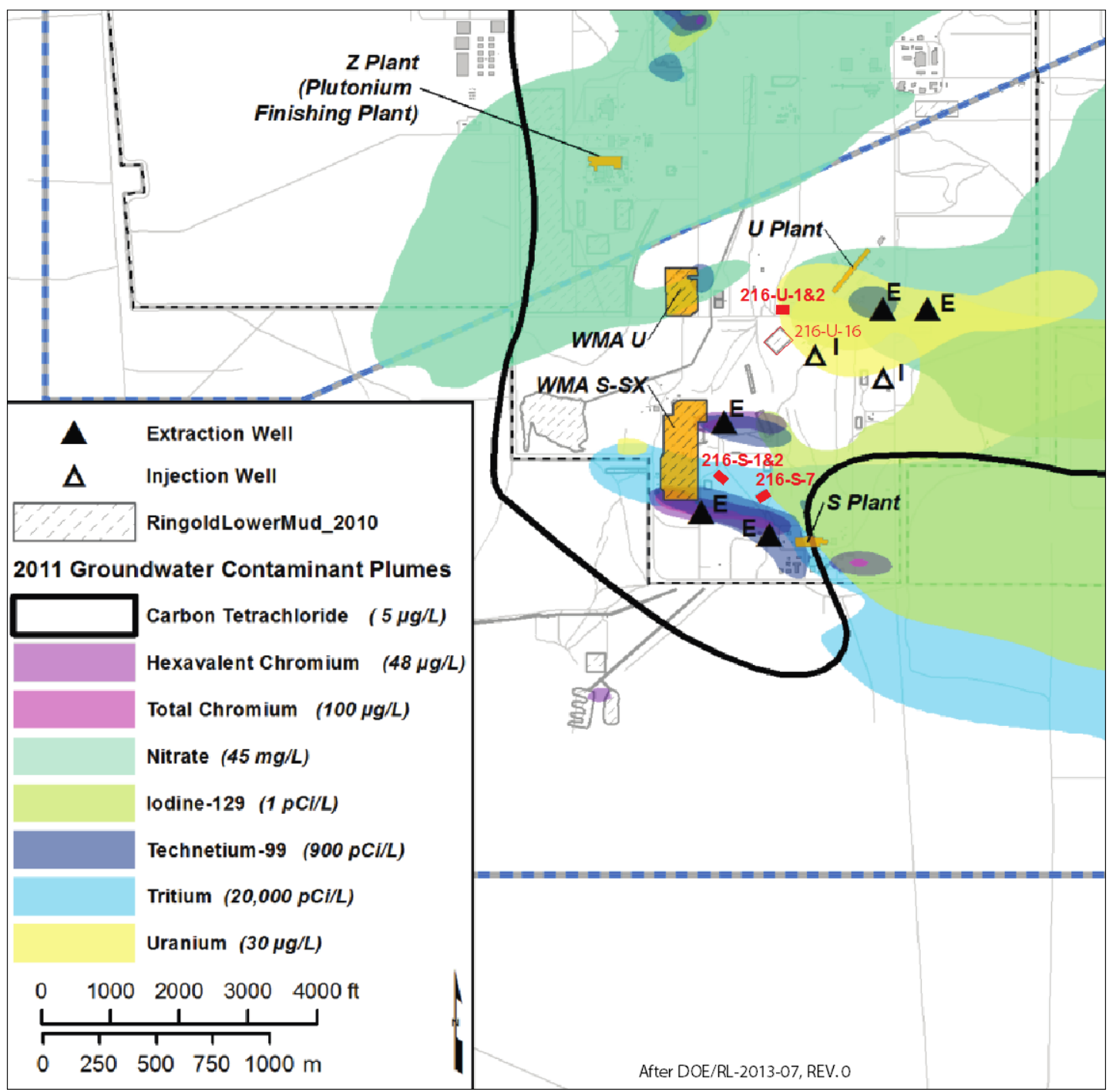

Figure B.15. Location of the 216-U-1\&2 cribs, 216-U-16 crib, and other key facilities (modified after CHPRC 2013).

\section{B.3.1 Facility Design}

\section{B.3.1.1 216-U-1\&2 Cribs}

The 216-U-1\&2 cribs consist of two timbered cribs that operated in series, receiving overflow from the 241-U-361 settling tank, via underground pipeline (Figure B.16). Each crib consisted of a $3.7 \mathrm{~m} \times 3.7$ $\mathrm{m}(12 \mathrm{ft}$ x $12 \mathrm{ft})$ timbered crib box set in a $4.3 \mathrm{~m}$ x $4.3 \mathrm{~m}(14 \mathrm{ft}$ x $14 \mathrm{ft})$ excavation set $6.1 \mathrm{~m}$ (20 ft; H-2- 
PNNL-24709, Rev. 2

RPT-DVZ-AFRI-030, Rev. 2

56601) to $7.3 \mathrm{~m}$ (24 ft; Maxfield 1979) to below ground surface with 1:1 (45-degree) side slopes (Figure B.16). There is no mention of gravel fill being used. It appears the crib box was set directly on the bottom of the excavation, and the excavation backfilled (most likely with the native soils removed during excavation). Borehole 299-W19-96 was drilled through the 216-C-1 crib, next to the timbered crib box, and backfill was composed of sand, gravelly sand, and silty sand from the surface to a depth of $25.5 \mathrm{ft}$ (Kelty et al. 1995).

Center coordinates for each crib are taken from H-2-831024.

- 216-U-1 - N135001.73; E567242.89 (State Plane, m)

• 216-U-2 - N135001.78; E567265.76 (State Plane, m)

The effective infiltration area is believed to be limited to the base area of the two crib boxes themselves $(2 \times 3.7 \mathrm{~m} \times 3.7 \mathrm{~m}=26.8 \mathrm{~m})$ or to the base area of the two excavation areas $(2 \times 4.3 \mathrm{~m} \times 4.3$ $\mathrm{m}=36.4 \mathrm{~m}^{2}$ ), assuming there are no gravel side-slopes available for infiltration.

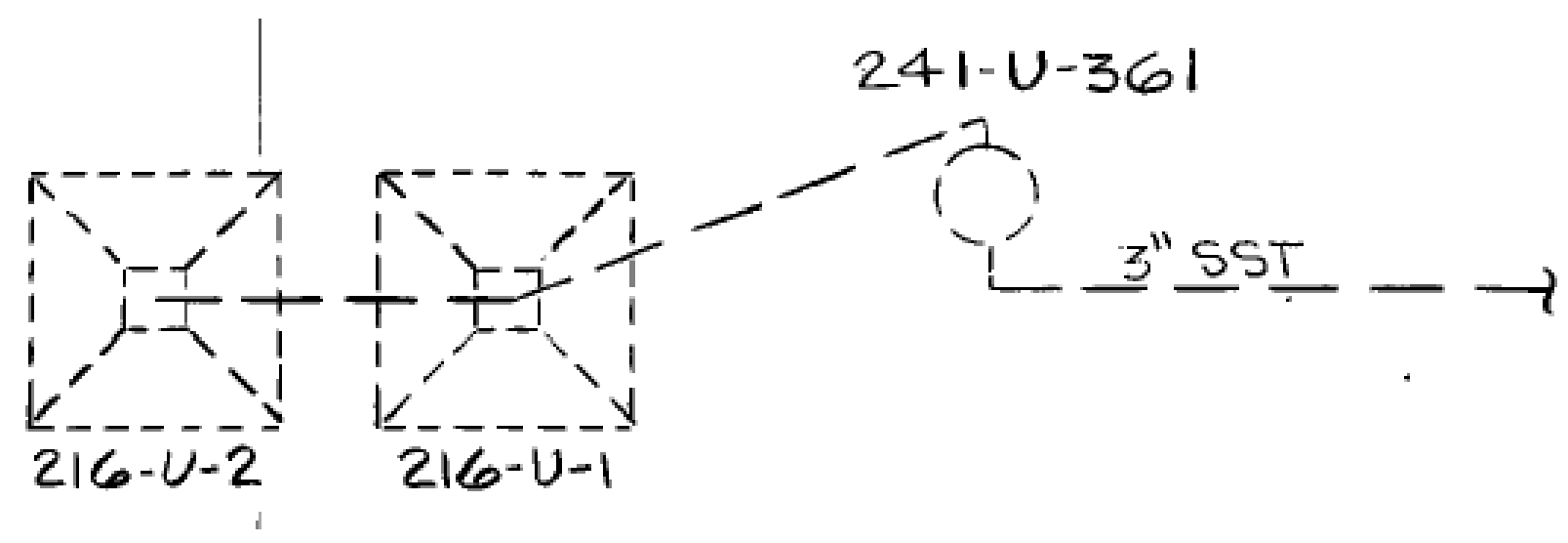

Figure B.16. Plan view of the 216-U-1\&2 facility (taken from H-2-74442).

\section{B.3.1.2 216-U-16 Crib}

The 216-U-16 crib was built to receive waste from the 224-Uranium Oxide Processing Facility. The crib was constructed in a $5.2 \mathrm{~m}$ (17 ft) deep rectangular excavation with bottom dimensions of $58.2 \mathrm{~m} \mathrm{x}$ $79.5 \mathrm{~m}$ (191 ft x $261 \mathrm{ft}$ ) (H-2-94256, Rev. 1; WIDS Summary Sheet) and 1.5:1 side slopes. The crib

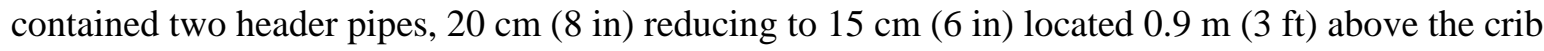
bottom, running the length of the unit, one on each side. Twenty-two $10 \mathrm{~cm}$ (4 in) perforated pipes connect the two header pipes, running the width of the unit, equally spaced, $0.9 \mathrm{~m}$ ( $3 \mathrm{ft}$ ) above the bottom.

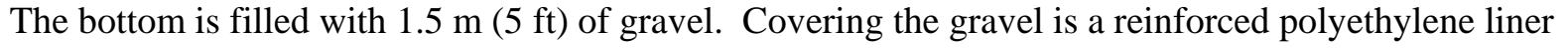
extending $2.4 \mathrm{~m}(8 \mathrm{ft})$ up the sides of the excavation. The crib structure has been backfilled over to grade. A $15 \mathrm{~cm}$ (6 in) subdrainage pipe runs the width of the unit at the west side.

Center coordinates for the crib are N134861; E567238 (State Plane, m), estimated from the QMAP geospatial map portal (available at hgis.rl.gov/qmap/).

The effective infiltration area is believed be the excavation area as well as the graveled side slopes:

- Crib Bottom Area $=58.2 \mathrm{~m}$ x $79.5 \mathrm{~m}=4631 \mathrm{~m}^{2}$ 
PNNL-24709, Rev. 2

RPT-DVZ-AFRI-030, Rev. 2

- Graveled Side Slope Area=2@166.2 m² + 2@224.8 m²= $782 \mathrm{~m}^{2}$

- Total Maximum Infiltration Area $=5413 \mathrm{~m}^{2}$

The proposed infiltration design for the $216-\mathrm{U}-16$ crib was $815 \mathrm{l} / \mathrm{m}^{2} /$ day $\left(20 \mathrm{gal} / \mathrm{ft}^{2} / \text { day }\right)^{1}$. This was adjusted from field data that ranged from 1426 to $3260 \mathrm{l} / \mathrm{m}^{2} /$ day (35 to $80 \mathrm{gal} / \mathrm{ft}^{2} / \mathrm{day}$ ) from two injectiondrainage tests and an infiltration test. The adjustment was made to reduce the infiltration rate to account for spreading of infiltrating water on less permeable layers.

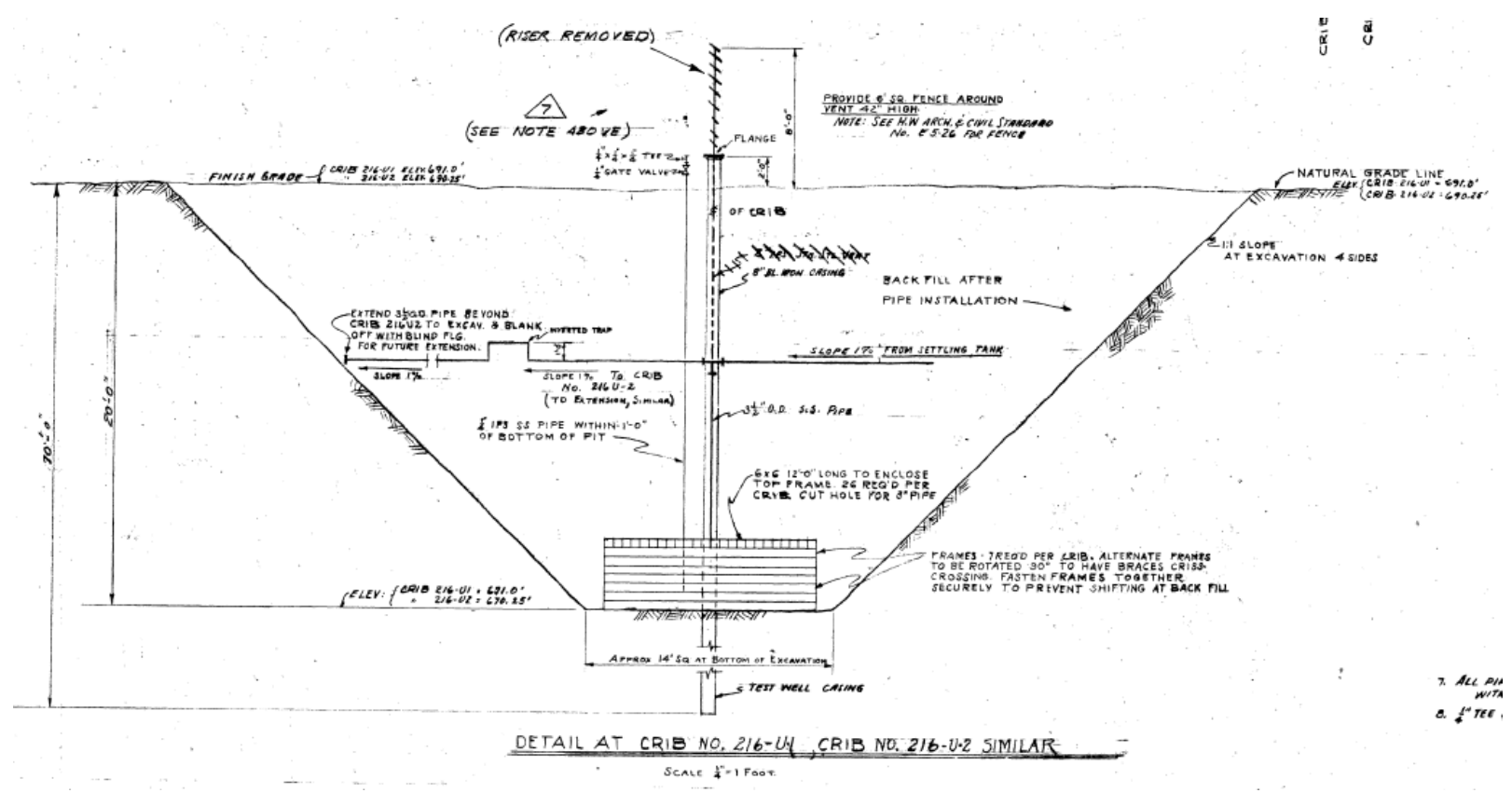

Figure B.17. Typical cross section view through the 216-U-1\&2 cribs (taken from H-2-50061).

\section{B.3.2 Operational History and Inventory}

Descriptions of the operational history of the $216-\mathrm{U}-1 \& 2$ cribs as well as other nearby facilities that may have impacted the $216-\mathrm{U}-1 \& 2$ cribs are presented below.

\section{B.3.2.1 216-U-1 and -2 Cribs}

Maxfield (1979) indicates that waste disposal to the 216-U-1 crib started in November 1951 and ended in June 1967, while discharges to the 216-U-2 crib are listed as starting in March 1952 and ending in May 1967).

Stenner et al. (1988, p. 570) summarized the service history of the site as follows:

From 3/52 to 6/57 the site received cell drainage from tank 5-6 in the 221-U building and waste from the 224-U building via the overflow from the 241-U-361 settling tank.

\footnotetext{
${ }^{1}$ Internal Letter No. 72710-82-081, from J. B. Sisson/M. J. Graham to W. F. Heine, dated May 17, 1982.
} 
PNNL-24709, Rev. 2

RPT-DVZ-AFRI-030, Rev. 2

From 6/57 to 7/57 the site received waste from the 224-U building via the overflow from the 241-U-361 settling tank and contaminated solvent from the 276-U settling tank solvent storage area. The discharge of 221-U waste was discontinued during the shutdown of Production Operations.

From 7/57 to 5/67 the site received waste from the 224-U building and equipment decontamination and reclamation wastes from CPD Services Operations in the 221-U building canyon. The site was deactivated in 5/67.

Liquid waste from the 216-U-16 crib migrated to the north and flushed through the soil column beneath the $216-U-1$ \& 2 cribs. This action carried uranium contamination into the ground water at that site. Remedial action consisted of pumping out 8 million gallons of groundwater which was processed to recover the uranium.

Annual inventory estimates are provided in Table B.10. Figure B.18 illustrates the annual discharge volumes and estimated ${ }^{129}$ I concentrations from Corbin et al. (2005). 
PNNL-24709, Rev. 2

RPT-DVZ-AFRI-030, Rev. 2

Table B.10. Annual inventory of waste discharged to the $216-\mathrm{U}-1 \& 2$ cribs.

\begin{tabular}{|c|c|c|c|c|c|c|c|c|c|c|c|c|c|}
\hline Constituent & Source & 1951 & 1952 & 1953 & 1954 & 1955 & 1956 & 1958 & 1959 & 1960 & 1966 & 1967 & Sum \\
\hline \multirow[t]{3}{*}{ Volume (L) } & $\begin{array}{l}\text { Anderson } \\
(1976)\end{array}$ & $1.40 \mathrm{E}+05$ & $2.35 E+06$ & $5.00 \mathrm{E}+06$ & $4.21 E+06$ & $6.30 \mathrm{E}+05$ & $6.00 \mathrm{E}+03$ & $7.27 \mathrm{E}+05$ & $1.21 \mathrm{E}+06$ & $4.43 E+05$ & $5.30 \mathrm{E}+04$ & $1.13 \mathrm{E}+06$ & $1.59 \mathrm{E}+07$ \\
\hline & SIM Mean & $1.40 \mathrm{E}+05$ & $2.35 \mathrm{E}+06$ & $5.00 \mathrm{E}+06$ & $4.21 \mathrm{E}+06$ & $6.30 \mathrm{E}+05$ & $6.00 \mathrm{E}+03$ & 7.27E+05 & $1.24 \mathrm{E}+06$ & $4.43 \mathrm{E}+05$ & $5.30 \mathrm{E}+04$ & $1.13 \mathrm{E}+06$ & $1.59 \mathrm{E}+07$ \\
\hline & SIM StdDev & $1.43 \mathrm{E}+04$ & $1.56 \mathrm{E}+05$ & $3.23 \mathrm{E}+05$ & $3.18 \mathrm{E}+05$ & $4.76 \mathrm{E}+04$ & $6.12 \mathrm{E}+02$ & $5.09 E+04$ & $1.17 \mathrm{E}+05$ & $4.17 \mathrm{E}+04$ & $4.02 \mathrm{E}+03$ & 8.87E+04 & NA \\
\hline Beta (Ci) & $\begin{array}{l}\text { Anderson } \\
\text { (1976) }\end{array}$ & $0.00 \mathrm{E}+00$ & $1.30 \mathrm{E}+01$ & $5.60 \mathrm{E}+02$ & $2.30 \mathrm{E}+02$ & $1.59 \mathrm{E}+02$ & $0.00 \mathrm{E}+00$ & 4.70E+01 & $6.40 \mathrm{E}+01$ & $1.27 \mathrm{E}+02$ & $0.00 \mathrm{E}+00$ & $1.70 \mathrm{E}+01$ & $1.22 E+03$ \\
\hline \multirow[t]{3}{*}{ Sr-90 (Ci) } & $\begin{array}{l}\text { Anderson } \\
\text { (1976) }\end{array}$ & $0.00 E+00$ & $0.00 E+00$ & $2.00 E+00$ & $1.00 \mathrm{E}+00$ & $1.00 \mathrm{E}+00$ & $0.00 \mathrm{E}+00$ & $0.00 E+00$ & $0.00 E+00$ & $1.00 \mathrm{E}+00$ & $0.00 \mathrm{E}+00$ & $0.00 \mathrm{E}+00$ & $5.00 E+00$ \\
\hline & SIM Mean & 3.09E-02 & 2.89E-01 & 5.82E-01 & 2.10E-01 & 3.13E-02 & $0.00 \mathrm{E}+00$ & 2.41E-02 & 4.10E-03 & 1.47E-03 & 3.16E-09 & $2.55 \mathrm{E}-08$ & 1.17E+00 \\
\hline & SIM StdDev & 1.52E-02 & $1.42 \mathrm{E}-01$ & 2.86E-01 & 1.03E-01 & 1.54E-02 & $0.00 \mathrm{E}+00$ & 1.18E-02 & $2.02 \mathrm{E}-03$ & 7.19E-04 & 2.98E-09 & $2.40 \mathrm{E}-08$ & 3.37E-01 \\
\hline \multirow[t]{3}{*}{ Cs-137 (Ci) } & $\begin{array}{l}\text { Anderson } \\
\text { (1976) }\end{array}$ & $0.00 \mathrm{E}+00$ & $0.00 \mathrm{E}+00$ & $6.00 \mathrm{E}+00$ & $2.00 E+00$ & $1.00 \mathrm{E}+00$ & $0.00 \mathrm{E}+00$ & $0.00 E+00$ & $0.00 E+00$ & $1.00 \mathrm{E}+00$ & $0.00 \mathrm{E}+00$ & $0.00 E+00$ & $1.00 \mathrm{E}+01$ \\
\hline & SIM Mean & 4.76E-02 & 4.46E-01 & 8.98E-01 & 3.24E-01 & $4.82 \mathrm{E}-02$ & $0.00 \mathrm{E}+00$ & $3.71 \mathrm{E}-02$ & 6.32E-03 & $2.26 \mathrm{E}-03$ & $0.00 \mathrm{E}+00$ & $0.00 \mathrm{E}+00$ & $1.81 \mathrm{E}+00$ \\
\hline & SIM StdDev & 2.32E-02 & 2.18E-01 & 4.38E-01 & 1.58E-01 & 2.35E-02 & $0.00 \mathrm{E}+00$ & 1.80E-02 & 3.08E-03 & 1.10E-03 & $0.00 \mathrm{E}+00$ & $0.00 \mathrm{E}+00$ & 5.15E-01 \\
\hline \multirow[t]{3}{*}{ Ru-106 (Ci) } & $\begin{array}{l}\text { Anderson } \\
\text { (1976) }\end{array}$ & $0.00 E+00$ & $5.00 \mathrm{E}+00$ & $2.28 \mathrm{E}+02$ & $9.60 \mathrm{E}+01$ & $6.60 \mathrm{E}+01$ & $0.00 \mathrm{E}+00$ & $2.00 E+01$ & $2.70 E+01$ & $5.30 \mathrm{E}+01$ & $0.00 \mathrm{E}+00$ & $5.00 \mathrm{E}+00$ & $5.00 E+02$ \\
\hline & SIM Mean & 3.95E-17 & $3.70 \mathrm{E}-16$ & $7.45 \mathrm{E}-16$ & $2.68 \mathrm{E}-16$ & $4.00 \mathrm{E}-17$ & $0.00 \mathrm{E}+00$ & $3.08 \mathrm{E}-17$ & $5.25 \mathrm{E}-18$ & 1.87E-18 & $0.00 E+00$ & $0.00 \mathrm{E}+00$ & $1.50 \mathrm{E}-15$ \\
\hline & SIM StdDev & 5.74E-17 & 5.36E-16 & 1.08E-15 & 3.88E-16 & 5.78E-17 & $0.00 \mathrm{E}+00$ & 4.48E-17 & 7.63E-18 & 2.71E-18 & $0.00 \mathrm{E}+00$ & $0.00 \mathrm{E}+00$ & 1.27E-15 \\
\hline \multirow[t]{3}{*}{ Co-60 (Ci) } & $\begin{array}{l}\text { Anderson } \\
\text { (1976) }\end{array}$ & $0.00 E+00$ & $0.00 \mathrm{E}+00$ & $0.00 E+00$ & $1.00 \mathrm{E}-01$ & $0.00 \mathrm{E}+00$ & $0.00 E+00$ & $0.00 E+00$ & $0.00 E+00$ & $0.00 E+00$ & $0.00 \mathrm{E}+00$ & $0.00 \mathrm{E}+00$ & $1.00 \mathrm{E}-01$ \\
\hline & SIM Mean & 2.30E-06 & 2.15E-05 & 4.34E-05 & 1.57E-05 & 2.33E-06 & $0.00 \mathrm{E}+00$ & $1.82 \mathrm{E}-06$ & 3.57E-07 & $1.28 \mathrm{E}-07$ & 1.45E-08 & 1.17E-07 & 8.76E-05 \\
\hline & SIM StdDev & $1.41 \mathrm{E}-06$ & 1.32E-05 & 2.66E-05 & $9.60 \mathrm{E}-06$ & 1.43E-06 & $0.00 \mathrm{E}+00$ & 1.09E-06 & 1.96E-07 & $6.99 \mathrm{E}-08$ & 1.53E-08 & 1.23E-07 & 3.12E-05 \\
\hline $\mathrm{Pu}(\mathrm{g})$ & $\begin{array}{l}\text { Anderson } \\
\text { (1976) }\end{array}$ & $0.00 E+00$ & $2.50 \mathrm{E}+00$ & $2.68 \mathrm{E}+01$ & $5.70 E+00$ & $3.00 \mathrm{E}+00$ & $0.00 E+00$ & $1.40 \mathrm{E}+00$ & $1.40 \mathrm{E}+00$ & $1.20 \mathrm{E}+00$ & $0.00 E+00$ & $6.00 \mathrm{E}-01$ & $4.26 \mathrm{E}+01$ \\
\hline \multirow[t]{3}{*}{ U (kg) } & $\begin{array}{l}\text { Anderson } \\
(1976)\end{array}$ & $1.20 \mathrm{E}+02$ & $8.81 E+02$ & $1.57 \mathrm{E}+03$ & $4.83 E+02$ & $5.17 \mathrm{E}+02$ & $5.90 \mathrm{E}+01$ & $1.59 E+02$ & $2.23 E+01$ & $0.00 \mathrm{E}+00$ & $1.82 \mathrm{E}+02$ & $2.86 \mathrm{E}+01$ & $4.04 \mathrm{E}+03$ \\
\hline & SIM Mean & $5.25 \mathrm{E}+01$ & $7.81 \mathrm{E}+02$ & $1.74 \mathrm{E}+03$ & $6.27 \mathrm{E}+02$ & $4.35 \mathrm{E}+02$ & $5.20 \mathrm{E}+00$ & 1.35E+02 & $2.31 \mathrm{E}+01$ & $8.27 \mathrm{E}+00$ & $3.08 \mathrm{E}+01$ & $1.22 \mathrm{E}+02$ & $3.96 \mathrm{E}+03$ \\
\hline & SIM StdDev & $4.01 \mathrm{E}+01$ & $4.51 \mathrm{E}+02$ & $9.96 \mathrm{E}+02$ & $3.58 \mathrm{E}+02$ & $3.34 \mathrm{E}+02$ & $4.51 \mathrm{E}+00$ & $8.76 \mathrm{E}+01$ & $1.50 \mathrm{E}+01$ & $5.33 \mathrm{E}+00$ & $5.19 \mathrm{E}+01$ & $2.07 \mathrm{E}+02$ & $1.22 \mathrm{E}+03$ \\
\hline \multirow[t]{2}{*}{ I-129 (Ci) } & SIM Mean & 5.96E-08 & 5.59E-07 & 1.12E-06 & 4.06E-07 & 6.04E-08 & $0.00 \mathrm{E}+00$ & 4.65E-08 & 7.92E-09 & 2.83E-09 & $0.00 \mathrm{E}+00$ & $0.00 \mathrm{E}+00$ & 2.27E-06 \\
\hline & SIM StdDev & 2.81E-08 & 2.63E-07 & 5.30E-07 & 1.91E-07 & 2.84E-08 & $0.00 \mathrm{E}+00$ & 2.19E-08 & 3.73E-09 & 1.33E-09 & $0.00 \mathrm{E}+00$ & $0.00 \mathrm{E}+00$ & 6.26E-07 \\
\hline \multirow[t]{2}{*}{ Tc-99 (Ci) } & SIM Mean & 1.86E-01 & $1.77 \mathrm{E}+00$ & $3.59 \mathrm{E}+00$ & $1.29 \mathrm{E}+00$ & 2.29E-01 & 5.52E-04 & 1.55E-01 & 2.64E-02 & $9.44 \mathrm{E}-03$ & 2.91E-03 & 1.16E-02 & 7.27E+00 \\
\hline & SIM StdDev & 8.80E-02 & 8.23E-01 & $1.66 \mathrm{E}+00$ & 5.99E-01 & $9.16 \mathrm{E}-02$ & $2.72 \mathrm{E}-04$ & 6.87E-02 & 1.17E-02 & 4.19E-03 & $3.18 \mathrm{E}-03$ & 1.27E-02 & $1.95 \mathrm{E}+00$ \\
\hline \multirow[t]{2}{*}{$\mathrm{NO}_{3}(\mathrm{~kg})$} & SIM Mean & $1.63 \mathrm{E}+02$ & $1.74 \mathrm{E}+04$ & $3.92 \mathrm{E}+04$ & $5.10 \mathrm{E}+04$ & $7.61 \mathrm{E}+03$ & $9.15 \mathrm{E}+01$ & $9.37 E+03$ & 1.84E+04 & $6.56 \mathrm{E}+03$ & $7.12 \mathrm{E}+02$ & 1.65E+04 & 1.67E+05 \\
\hline & SIM StdDev & $9.89 \mathrm{E}+01$ & $5.63 \mathrm{E}+03$ & $1.22 \mathrm{E}+04$ & $2.24 \mathrm{E}+04$ & $1.97 \mathrm{E}+03$ & $2.64 \mathrm{E}+01$ & $3.59 E+03$ & $8.62 \mathrm{E}+03$ & $3.07 \mathrm{E}+03$ & $1.95 \mathrm{E}+02$ & $6.46 \mathrm{E}+03$ & $2.87 E+04$ \\
\hline
\end{tabular}


PNNL-24709, Rev. 2

RPT-DVZ-AFRI-030, Rev. 2

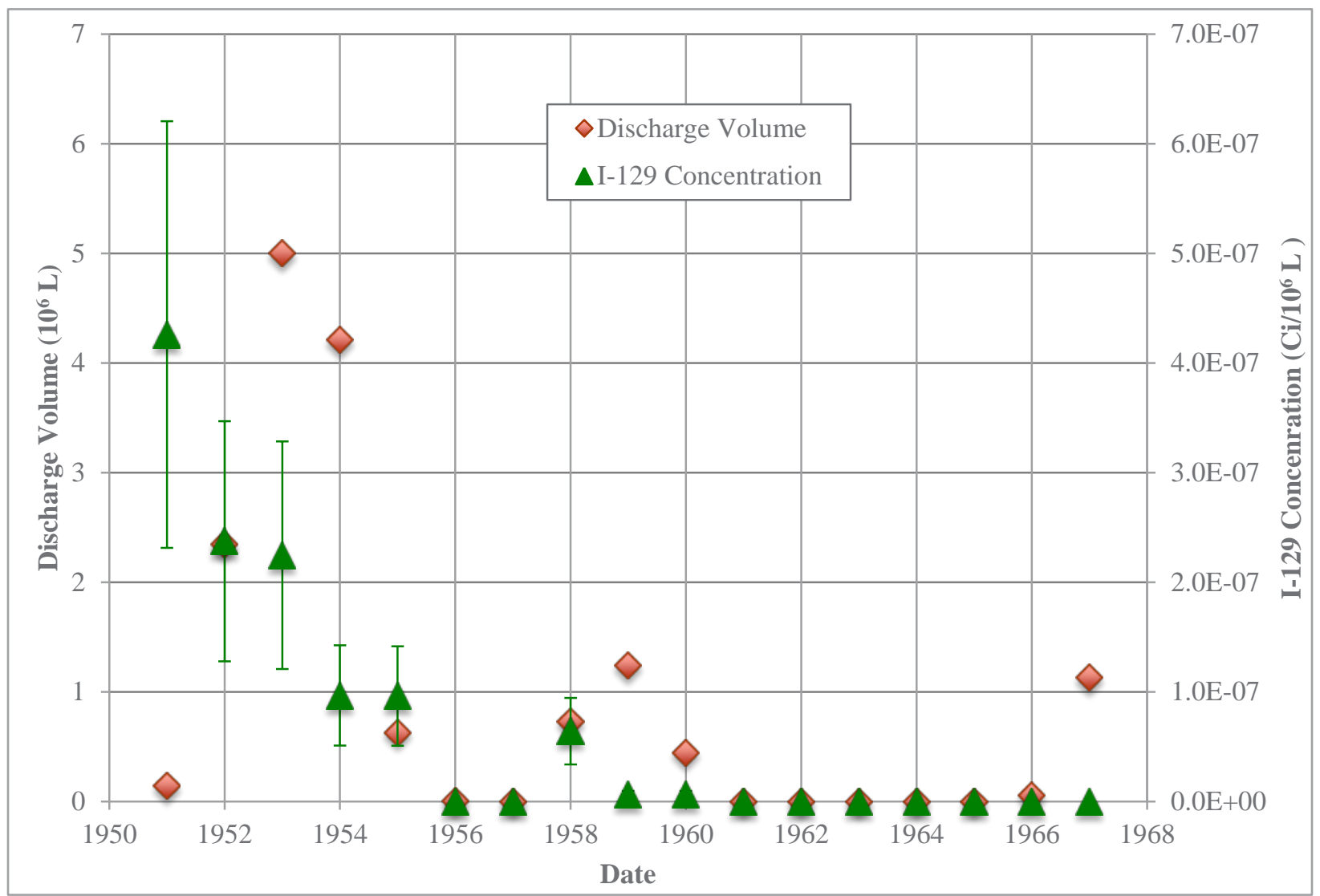

Figure B.18. Estimated discharge volumes and ${ }^{129}$ I concentrations (after Corbin et al 2005).

\section{B.3.2.2 216-U-16 Crib}

The 216-U-16 crib is located approximately $145 \mathrm{~m}$ (475 ft) south of the $216-\mathrm{U}-1 \&-2$ cribs. It operated from July 20, 1984 to about June 1985 (when pump and treat started), receiving liquid waste from the 224-U Uranium Oxide Processing Facility. A total of 409,000,000 liters were discharged to the crib (WIDS Report, http://idmsweb.rl.gov/idms). Corbin et al. (2005) estimated that volume was split about 2/3 (2.86E+8 L) during 1984 and 1/3 (1.23E+8 L) in 1985 (Table B.11). Table B.11 also provides an estimate of the monthly discharge volumes.

Table B.11. Estimated annual and monthly discharge volumes (after Corbin et al. 2005).

\begin{tabular}{lccccc}
\hline Source & \multicolumn{3}{c}{1984} & \multicolumn{2}{c}{1985} \\
\cline { 2 - 6 } & $\begin{array}{c}\text { Annual } \\
\text { Total }\end{array}$ & $\begin{array}{c}\text { Est. Monthly } \\
\text { Average } \\
\text { July (20-31) }\end{array}$ & $\begin{array}{c}\text { Est. Monthly } \\
\text { Average } \\
\text { Aug. - Dec. }\end{array}$ & Annual Total & $\begin{array}{c}\text { Est. Monthly } \\
\text { Average } \\
\text { Jan. - May }\end{array}$ \\
\hline SIM Mean & $2.86 \mathrm{E}+08$ & $2.07 \mathrm{E}+07$ & $5.31 \mathrm{E}+07$ & $1.23 \mathrm{E}+08$ & $2.46 \mathrm{E}+07$ \\
SIM StdDev & $1.14 \mathrm{E}+07$ & & & $3.55 \mathrm{E}+06$ & \\
\hline SIM = Soil Inventory Model (Corbin et al. 2005). & & & \\
\hline
\end{tabular}


PNNL-24709, Rev. 2

RPT-DVZ-AFRI-030, Rev. 2

\section{B.3.2.3 2607-W5 Septic Tank and Drain Field}

The 2607-W5 septic tank and drain field is located approximately $30.5 \mathrm{~m}$ (100 ft) north of 216-U1\&2 cribs (Smith 1992 |WHC-SD-DD-TI-063, Rev.0|, See Attachment A from Kelty et al. 1995). The site is comprised of an underground concrete septic tank, two distribution boxes, and two drain fields (tile fields). An early, abandoned drain field, with similar dimension to the most recent tile filed, is located to

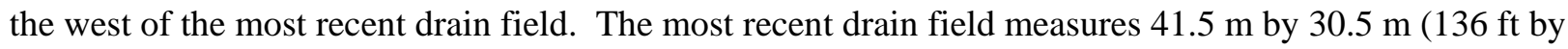
$100 \mathrm{ft}$ ) and is backfilled to approximately $2.5 \mathrm{ft}$ below grade, leaving a large rectangular depression. In 1992, the 2607-W5 septic tank and drain field received approximately 3200 gal per day of sanitary sewage from the U Plant, 222-U Laboratory, and U0 3 Plant (Smith 1992 |WHC-SD-DD-TI-063, Rev.0|).

\section{B.3.3 Site Characterization, Interim Remediation, and Monitoring}

Baker et al. (1988) stated that in February 1985, the concentration of uranium in groundwater beneath the site had abruptly increased to $72,000 \mathrm{pCi} / \mathrm{L}$, and that a subsequent investigation indicated that acid decontamination wastes discharged toward the end of the cribs' service life had partially dissolved the sorbed uranium, and that water from the nearby 216-U-16 crib provided the driving force to transport the uranium to the groundwater. They noted that liquid discharges to the 216-U-16 crib were sufficient to "form a pond" above a caliche layer about $50 \mathrm{~m}$ (165 ft) below ground surface, move laterally below the 216-U-1\&2 cribs, and transport the uranium through holes in the caliche layer to the groundwater. They hypothesized that the holes in the caliche layer were either natural thin spots or due to boreholes. Note that the center of 216-U-16 is located about $145 \mathrm{~m}$ (475 ft) to the south of the $216-\mathrm{U}-1 \& 2$ cribs.

\section{B.3.3.1 1985 Interim Pump-and-Treat}

From June 13, 1985 to November 26, 1985, an interim remedial action was conducted to pump 30 million liters (8 million gallons) of contaminated groundwater from well 299-W19-9 (Delegard 1986 |RHO-RE-SA-116P|, Figure B.19) the site and treat it with an ion exchange column to remove an estimated $687 \mathrm{~kg}$ of uranium and reduce the maximum groundwater concentrations to $17,000 \mathrm{pCi} / \mathrm{g}$ (Baker et al. 1988). The ion exchange system was estimated to be about $90 \%$ efficient in removing the uranium. Discharge from the ion exchange system, containing the residual uranium, went to the 216-S-25 crib. 


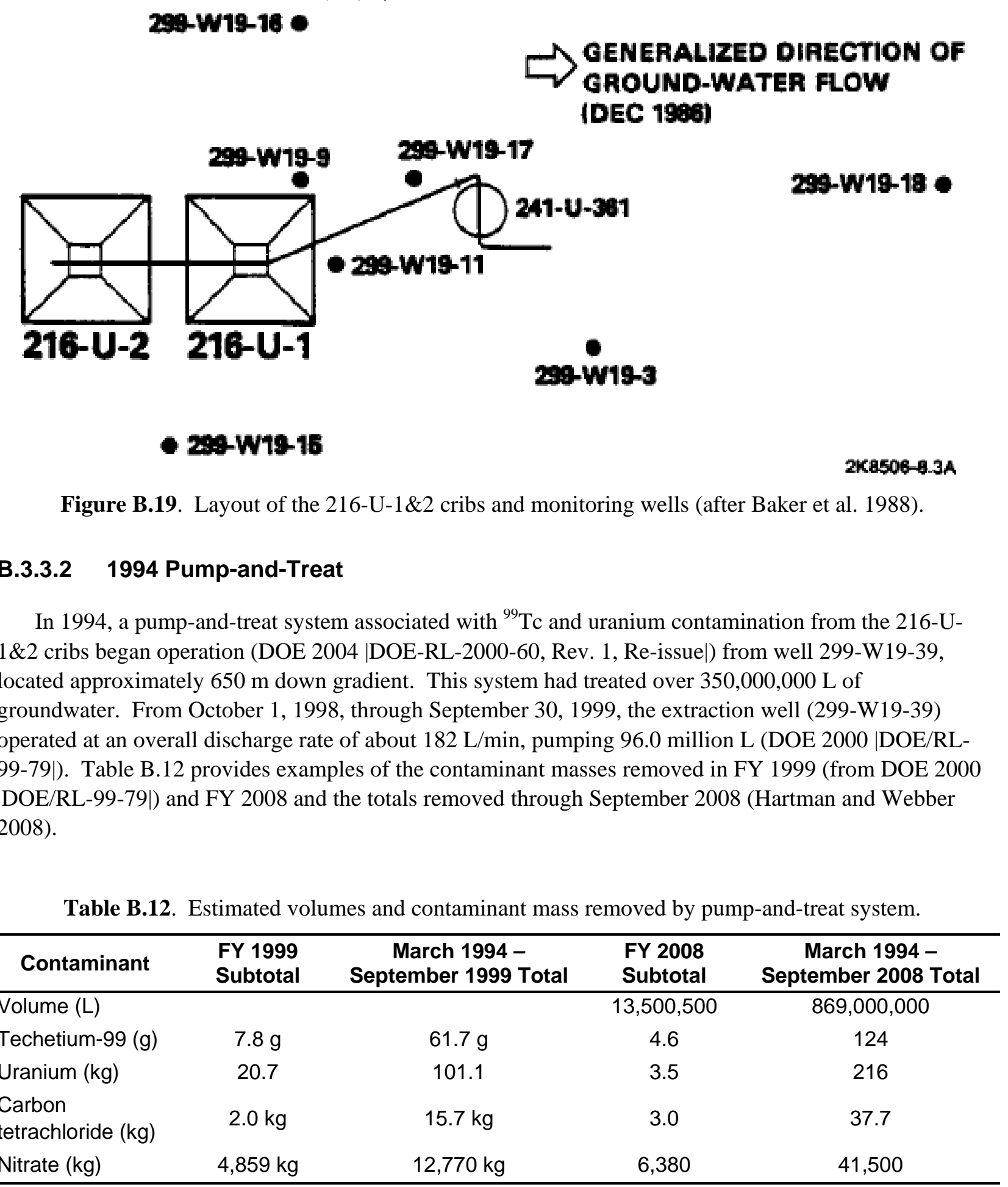

During January 2005, groundwater extraction was terminated (Hartman and Webber (eds.) 2008 |DOE/RL-2008-01, Rev. 0|). A rebound study concluded in January 2006, and groundwater extraction resumed in wells 299-W19-36 and 299-W19-43 on April 19, 2007 (Hartman and Webber (eds.) 2008 |DOE/RL-2008-01, Rev. 0|). As of September 2008, over 869 million L had been treated since startup of remediation activities in FY 1994, removing a total of $216 \mathrm{~kg}$ of uranium, $124 \mathrm{~g}$ of ${ }^{99} \mathrm{TC}, 37.7 \mathrm{~kg}$ of 
PNNL-24709, Rev. 2

RPT-DVZ-AFRI-030, Rev. 2

carbon tetrachloride, and 41,500 kg of nitrate during treatment. The system was shut down in March 2011 (DOE 2013 |DOE/RL-2013-22, Rev. 0|)

\section{B.3.3.3 1995 Site Characterization}

In 1995, three characterization boreholes (299-W19-95, 299-W19-96, and 299-W19-97) were installed near the 216-U-1\&2 cribs, and no lateral movement of contaminants was identified in the vadose zone (WIDS Report). Kelty et al. (1995) identified 12 contaminants within the 216-U-1/2 cribs as potential contaminants of concern; these included americium-241, cobalt- 60, cesium-137, europium-152, neptunium-237, plutonium-239/240, radium-228, strontium-90, thorium-228, and uranium-233/234, -235, -238. They found that contamination extends to a depth of $175 \mathrm{ft}$ beneath the 216-U-1/2 cribs. Cesium137, cobalt-60, europium-152/154, and uranium-235/238 had migrated to a depth of $49 \mathrm{ft}$. Additional uranium-235/238 contamination was identified on top of the low permeable caliche zone at $168 \mathrm{ft} .{ }^{129} \mathrm{I}$ was not detected in any of the borehole samples above limiting criteria (EDA, download on 1/7/2016). It was detected below the estimated detection limit of $1.6 \mathrm{pCi} / \mathrm{g}$ in one sample at a depth of about $37 \mathrm{~m} \mathrm{(121}$ ft) from 299-W19-96.

\section{B.3.4 Hydrogeology}

Figure B.20 illustrates a hydrograph of the water table beneath the cribs. The pre-Hanford water table is believed to have been at an elevation of about $122.5 \mathrm{~m}$. During operations in 1951 through 1967, the water table ranged from an elevation of about 133 to $144.6 \mathrm{~m}$ (79.5 to $68 \mathrm{~m}$ below ground surface). Water levels reached a peak of about $145.7 \mathrm{~m}$ directly beneath the cribs in 1976, and have since dropped, reaching a low of about $131.7 \mathrm{~m}$ in February 2016. Thus, the vadose zone thickness has generally ranged from 68 to over $80.8 \mathrm{~m}$ since crib operations. 
PNNL-24709, Rev. 2

RPT-DVZ-AFRI-030, Rev. 2

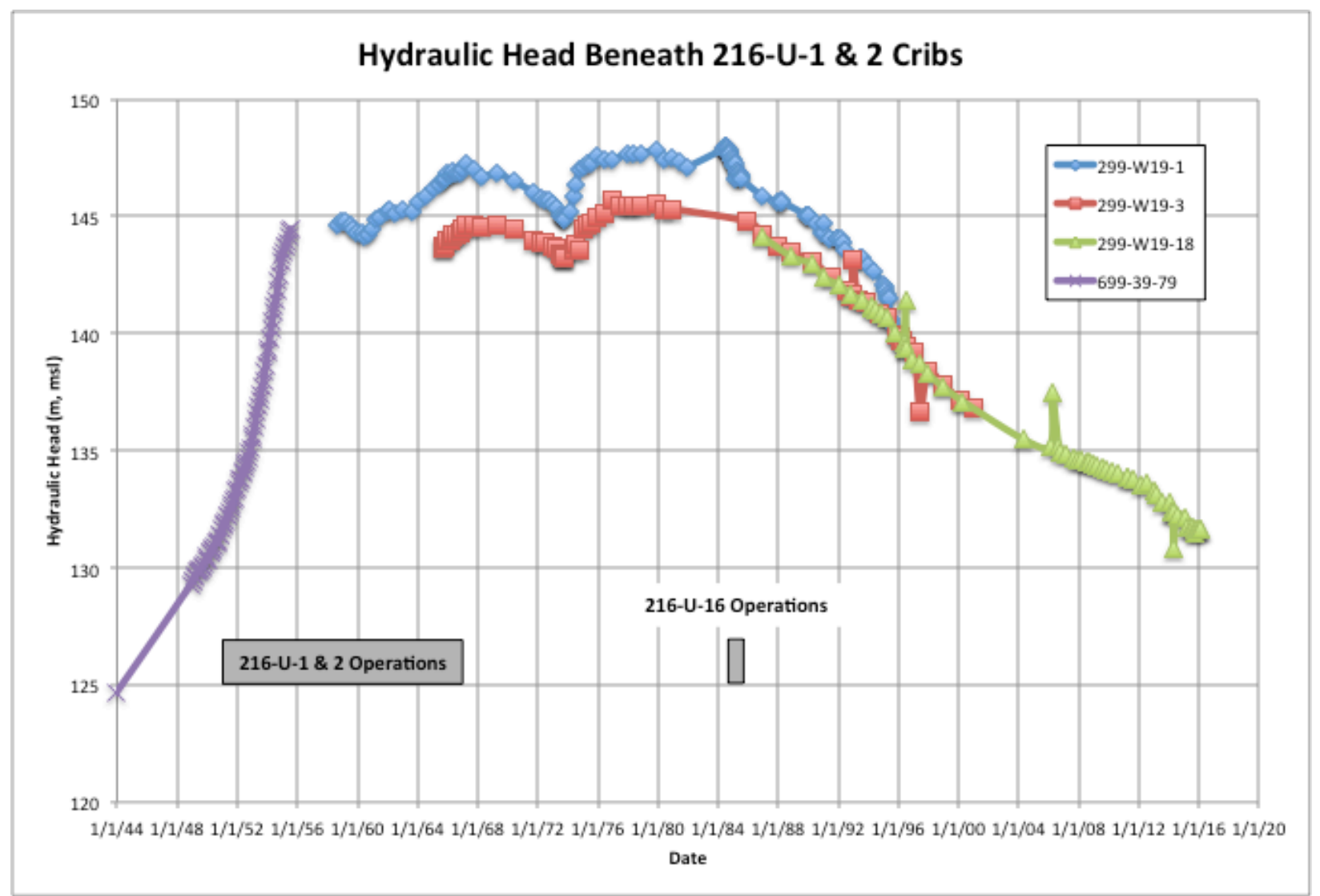

Figure B.20. Hydrograph beneath the $216-\mathrm{U}-1 \& 2$ cribs.

The major hydrostratigraphy is illustrated in Figure B.21, a reproduction of Kelty et al.'s (1995) north-south geologic cross section through the 216-U-1\&2 and 216-U-16 facilities. Table B.13 lists the contact elevations and thickness of the major hydrostratigraphic units penetrated by the 299-W19-96. 
PNNL-24709, Rev. 2

RPT-DVZ-AFRI-030, Rev. 2

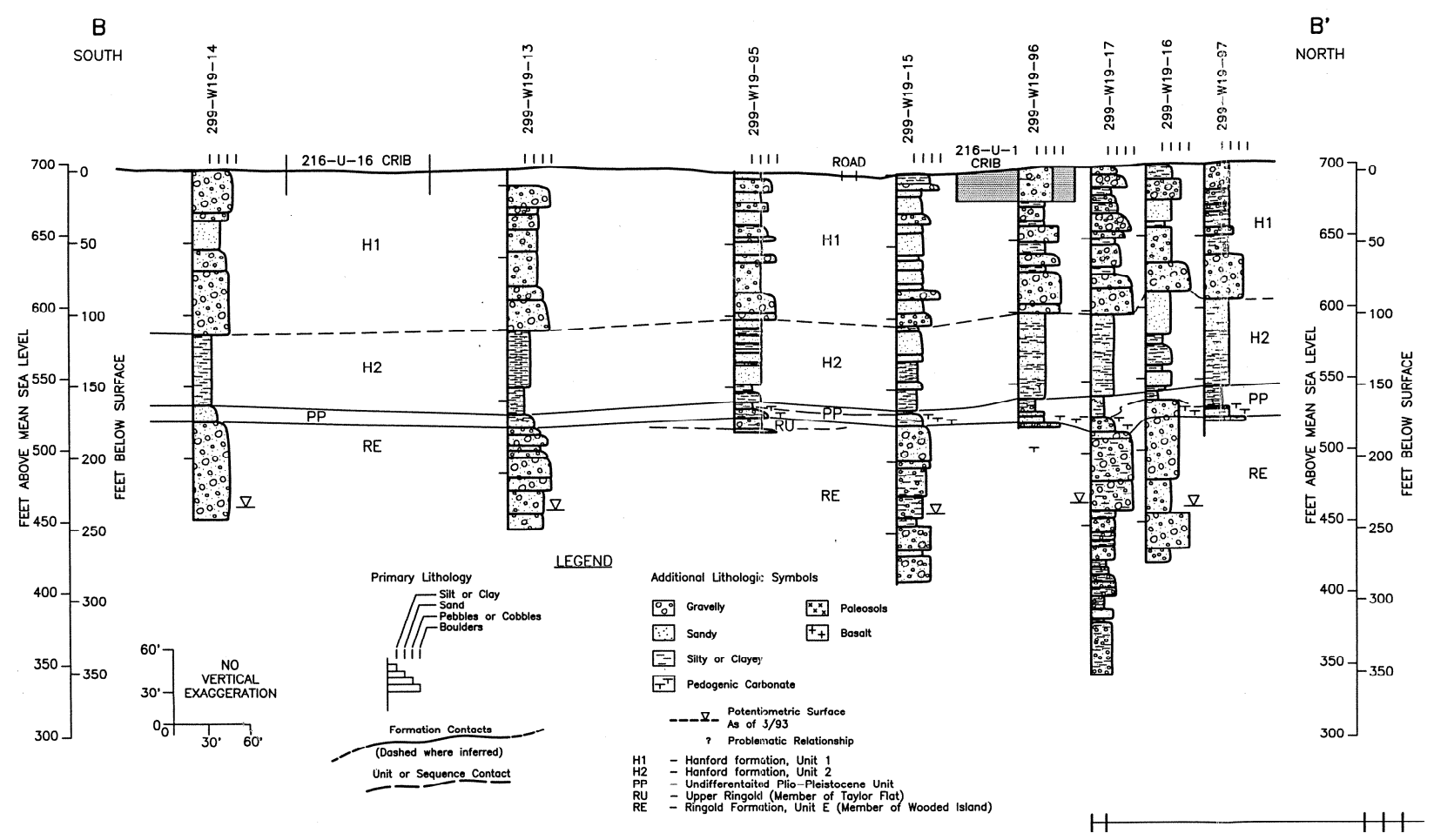

Figure B.21. North-south cross section through the 216-U-1\&2 and 216-U-16 crib facilities (from Kelty et al. 1995).

Table B.13. Elevation and thickness of major stratigraphic units (based on borehole logs from 299-W1996, after Kelty et al. 1995, and geologic the contacts database ${ }^{1}$ ).

\begin{tabular}{|c|c|c|c|c|c|c|c|c|}
\hline $\begin{array}{c}\text { Hydrogeologic } \\
\text { Unit }\end{array}$ & $\begin{array}{c}\text { Description } \\
\text { (Kelty et al. } \\
\text { 1995) }\end{array}$ & $\begin{array}{c}\text { Sediment } \\
\text { Class } \\
\text { (after } \\
\text { Last et al. } \\
\text { 2009) }\end{array}$ & $\begin{array}{c}\text { Number } \\
\text { of } \\
\text { Contacts }\end{array}$ & $\begin{array}{l}\text { Range in } \\
\text { Contact } \\
\text { Elevation } \\
\text { (m MSL) }\end{array}$ & $\begin{array}{l}\text { Average } \\
\text { Contact } \\
\text { Elevation } \\
\text { (m MSL) }\end{array}$ & $\begin{array}{c}\text { Number } \\
\text { used for } \\
\text { Thickness }\end{array}$ & $\begin{array}{c}\text { Range in } \\
\text { Thickness } \\
\text { (m) }\end{array}$ & $\begin{array}{c}\text { Average } \\
\text { Thickness } \\
\text { (m) }\end{array}$ \\
\hline Backfill & $\begin{array}{l}\text { Backfill (sand, } \\
\text { gravelly sand, } \\
\text { and silty sand) }\end{array}$ & $\mathrm{Bf}$ & 2 & $\begin{array}{c}211.2- \\
211.8\end{array}$ & 211.5 & 0 & $1.8-7.9^{\star}$ & $7.6^{\star}$ \\
\hline Hanford H1 & $\begin{array}{c}\text { interbedded } \\
\text { sandy gravel, } \\
\text { sand, and } \\
\text { minor silt }\end{array}$ & Hgs & 6 & $\begin{array}{c}203.9 *- \\
211.8\end{array}$ & $209.9 *$ & 6 & $\begin{array}{c}22.6^{\star}- \\
31.1\end{array}$ & $28.6^{*}$ \\
\hline Hanford H2 & $\begin{array}{l}\text { Sand with } \\
\text { lenses of } \\
\text { sandy silt and } \\
\text { silt }\end{array}$ & $\mathrm{Hfs}$ & 6 & $\begin{array}{c}179.5- \\
183.5\end{array}$ & 181.2 & 6 & $\begin{array}{c}17.4- \\
27.7\end{array}$ & 21.6 \\
\hline Cold Creek Silt & $\begin{array}{l}\text { Silt, calcareous } \\
\text { silt, and } \\
\text { intermittent } \\
\text { sand }\end{array}$ & CCUz & 3 & $\begin{array}{c}162.1- \\
164.9\end{array}$ & 163.2 & 3 & $1.5-6.6$ & 2.5 \\
\hline $\begin{array}{l}\text { Cold Creek } \\
\text { Carbonate }\end{array}$ & $\begin{array}{l}\text { Gravelly silt } \\
\text { with caliche }\end{array}$ & CCUc & 3 & $\begin{array}{c}160.3- \\
160.9\end{array}$ & 160.6 & 3 & $0.6-2.4$ & 1.5 \\
\hline
\end{tabular}

${ }^{1}$ GeoContacts_Hanford_2015-02-24.xlsx (accessed via the Enterprise application to the Integrated Data Management System, IDMS). 
PNNL-24709, Rev. 2

RPT-DVZ-AFRI-030, Rev. 2

\begin{tabular}{|c|c|c|c|c|c|c|c|c|}
\hline $\begin{array}{c}\text { Hydrogeologic } \\
\text { Unit }\end{array}$ & $\begin{array}{c}\text { Description } \\
\text { (Kelty et al. } \\
\text { 1995) }\end{array}$ & $\begin{array}{l}\text { Sediment } \\
\text { Class } \\
\text { (after } \\
\text { Last et al. } \\
\text { 2009) }\end{array}$ & $\begin{array}{l}\text { Number } \\
\text { of } \\
\text { Contacts }\end{array}$ & $\begin{array}{l}\text { Range in } \\
\text { Contact } \\
\text { Elevation } \\
\text { (m MSL) }\end{array}$ & $\begin{array}{c}\text { Average } \\
\text { Contact } \\
\text { Elevation } \\
\text { (m MSL) }\end{array}$ & $\begin{array}{l}\text { Number } \\
\text { used for } \\
\text { Thickness }\end{array}$ & $\begin{array}{l}\text { Range in } \\
\text { Thickness } \\
\text { (m) }\end{array}$ & $\begin{array}{c}\text { Average } \\
\text { Thickness } \\
\text { (m) }\end{array}$ \\
\hline & development & & & & & & & \\
\hline $\begin{array}{l}\text { Ringold unit of } \\
\text { Taylor Flats }\end{array}$ & Sand & Rg (sand) & 3 & $\begin{array}{c}158.2- \\
159.7\end{array}$ & 159.1 & 3 & $0.9-2.1$ & 1.5 \\
\hline $\begin{array}{l}\text { Ringold - } \\
\text { Wooded Island } \\
\text { Unit e }\end{array}$ & Sandy gravel & $\begin{array}{c}\mathrm{Rg} \\
\text { (gravel) }\end{array}$ & 6 & $\begin{array}{c}152.4- \\
160.3\end{array}$ & 156.8 & NA & NA & NA \\
\hline
\end{tabular}

\section{B.3.5 Physical and Hydraulic Properties}

Best estimate physical and hydraulic properties for each of the sediment classes listed in Table B.11 are shown in Table B.14, based on those of Last et al. (2006a, 2009).

Table B.14. Best estimate physical and hydraulic properties.

\begin{tabular}{|c|c|c|c|c|c|c|c|c|c|c|}
\hline $\begin{array}{c}\text { Hydraulic } \\
\text { Property } \\
\text { Class }\end{array}$ & count & $\begin{array}{c}a \\
(1 / \mathrm{cm}) \\
\end{array}$ & $n$ & $\begin{array}{c}q_{R} \\
\left(\mathrm{~cm}^{3} / \mathrm{cm}^{3}\right)\end{array}$ & $\begin{array}{c}q_{s} \\
\left(\mathrm{~cm}^{3} / \mathrm{cm}^{3}\right)\end{array}$ & $\begin{array}{c}K_{s} \\
(\mathrm{~cm} / \mathrm{sec})\end{array}$ & $s_{r}$ & $\begin{array}{l}\text { gravel } \\
\text { wt. } \%\end{array}$ & $\begin{array}{c}\text { Bulk } \\
\text { Density } \\
\left(\mathrm{g} / \mathrm{cm}^{3}\right)\end{array}$ & Porosity \\
\hline $\mathrm{Bf}$ & 6 & 0.019 & 1.400 & 0.030 & 0.262 & 5.98E-04 & 0.103 & 33.5 & 1.94 & 0.21 \\
\hline Hgs & 2 & 0.008 & 2.223 & 0.030 & 0.273 & 2.35E-04 & 0.133 & 24.0 & 1.81 & 0.34 \\
\hline $\mathrm{Hfs}$ & 4 & 0.013 & 2.451 & 0.042 & 0.347 & 1.71E-05 & 0.122 & 0.0 & 1.72 & 0.34 \\
\hline CCUz & 5 & 0.004 & 2.285 & 0.047 & 0.395 & 7.27E-06 & 0.117 & 0.1 & 1.71 & 0.35 \\
\hline CCUC & 14 & 0.011 & 1.740 & 0.054 & 0.281 & 8.45E-04 & 0.185 & 19.1 & 1.72 & 0.34 \\
\hline $\mathrm{Rg}$ (sand) & 6 & 0.012 & 1.677 & 0.054 & 0.354 & 7.83E-05 & 0.142 & 7.6 & 1.80 & 0.34 \\
\hline $\begin{array}{l}\mathrm{Rg} \\
\text { (gravel) }\end{array}$ & 2 & 0.018 & 1.654 & 0.005 & 0.114 & 2.60E-04 & 0.055 & 66.0 & 1.96 & 0.17 \\
\hline
\end{tabular}

\section{B.3.6 Recharge Estimates}

Estimates of natural recharge (deep drainage from precipitation events) are based on assumptions regarding the surface soil conditions and deep drainage (recharge) rates derived from field data and computer simulation results that were assembled into a suite of recharge classes described by Last et al. (2006a). The soil conditions and recharge estimates have been defined for $216-\mathrm{U}-1 \& 2$ cribs, for two different time intervals: (1) Pre-Operations and (2) Operations/Post Operations (Table B.15). 
PNNL-24709, Rev. 2

RPT-DVZ-AFRI-030, Rev. 2

Table B.15. Estimated recharge rates for the 216-U-1\&2 cribs based on those from Last et al. 2006a and $b$.

\begin{tabular}{|c|c|c|c|c|c|}
\hline Time Interval & $\begin{array}{c}\text { Soil } \\
\text { Conditions }\end{array}$ & $\begin{array}{c}\text { Best } \\
\text { Estimate } \\
(\mathrm{mm} / \mathrm{yr})\end{array}$ & $\begin{array}{c}\text { Estimated } \\
\text { Standard } \\
\text { Deviation } \\
(\mathrm{mm} / \mathrm{yr})\end{array}$ & $\underset{(\mathrm{mm} / \mathrm{yr})}{\text { Minimum }}$ & $\underset{(\mathrm{mm} / \mathrm{yr})}{\operatorname{Maximum}}$ \\
\hline $\begin{array}{l}\text { Pre-Operations (Before } 8 / 30 / 1951- \\
\text { assumes construction started } 3 \\
\text { months prior to initial discharge, } \\
\text { 11/1951). Note that structural } \\
\text { drawing H-2-50060, was signed } \\
\text { 1/30/51, and noted "As-Built" on } \\
\text { 12/4/1951). }\end{array}$ & Rp-s & 4.0 & 2.0 & 2.0 & 8.0 \\
\hline $\begin{array}{l}\text { Operations and Post-Operations } \\
\text { ( } 9 / 1 / 1951 \text { to present - assumes soil } \\
\text { cover was cleared and grubbed and } \\
\text { maintained in a non-vegetated state } \\
\text { from construction through the } \\
\text { present). Note that the WIDS Report, } \\
\text { dated } 5 / 24 / 2010, \text { states that in } 1992 \\
\text { the site was "surface stabilized with } \\
\text { clean dirt" } \\
\text { (http://idmsweb.rl.gov/idms). }\end{array}$ & Rp-dn & 44.0 & 22.0 & 22.0 & 88.0 \\
\hline
\end{tabular}

Note that the $216-\mathrm{U}-1 \& 2$ cribs are also known to have been impacted by lateral flow of anthropogenic water from the 216-U-16 crib. Another site that may have impacted the site is the 2607W5 septic tank and drain field, which lies approximately $50 \mathrm{~m}$ to the northeast of 216-U-1. Shearer (2013) lists this site as operating from 1944 to the present (currently active), and estimated the rate of discharge at 12.2 cubic meters (431 cubic feet) per day in 1987 and 1741 liters (460 gallons) per day in 1995.

\section{B.4 References}

Anderson, J.D. 1976. Input and Decayed Values of Radioactive Liquid Wastes Discharged to the Ground in the 200 Areas Through 1975. ARH-CD-745. Atlantic Richfield Hanford Company, Richland, Washington.

Baker, S.M., Devary, J.L., Elmore, RP., Lorang, R.F., Rossi, A.J., and Freshley, M.D. 1988. U1/U2 Uranium Plume Characterization, Remedial Action Review and Recommendation for Future Action. WHC-EP-0133, Westinghouse Hanford Company, Richland, Washington.

CHPRC. 2013. 200-UP-1 Groundwater Operable Unit Remedial Design/Remedial Action Work Plan. DOE/RL-2013-07, CH2M Hill Plateau Remediation Company, Richland, Washington.

Corbin R.A., Simpson, B.C., Anderson, M.J., Danielson, W.F. III, Field, J.G., Jones, T.E., and Kincaid, C.T. 2005. Hanford Soil Inventory Model, Rev. 1., RPP-26744/Appendix C. CH2M Hill, Hanford Group, Inc., Richland, Washington. 
PNNL-24709, Rev. 2

RPT-DVZ-AFRI-030, Rev. 2

Delegard, C.H., Weiss, R.L., Kimura, R.T., Law, A.G., and Routson, R.C. 1986. Characterization and Anion Exchange Removal of Uranium From Hanford Ground Water. RHO-RE-SA-116, Rockwell Hanford Operations, Richland, Washington.

DOE. 2000. Fiscal Year 1999 Annual Summary Report for the 200-UP-1, 200-ZP-1, and 100-NR-2 Pump-and-Treat Operations and Operable Units. DOE/RL-99-79, Rev. 0, U.S. Department of Energy, Richland, Washington.

DOE. 2004. Uranium-Rich/General Process Condensate \& Process Waste Group OU RI/FS Work Plan \& RCRA TSD Unit Sampling Plan, Includes 200-PW-2 \& 200-PW-4 OU. DOE-RL2000-60, Rev. 1, Re-issue. U.S. Department of Energy, Richland, Washington.

DOE. 2008. Site-Specific Field-Sampling Plans for 216-A-5 Crib and 216-S-I \& 2 Cribs, 200-PW-2/4 Operable Unit (Addendum 5). DOE/RL-2007-02-VOLII-ADD5, Rev. 0, U.S. Department of Energy, Richland, Washington.

DOE. 2013. Hanford Site Groundwater Monitoring Report for 2012. DOE/RL-2013-22, Rev. 0, U.S. Department of Energy, Richland, Washington.

Fecht, K.R., Last, G.V., and B. Price. 1979. Scintillation Probe Profiles 200-West Area Crib Monitoring Wells. RHO-LD-29. Rockwell Hanford Operations, Richland, Washington.

Haney, W.A., and Linderoth, C.E. 1959. Exploratory Field Study of a Ground Waste Disposal Facility. HW-60l15. General Electric Company, Richland, Washington.

Hartman, M.J., and Webber, W.D. (eds.) 2008. Hanford Site Groundwater Monitoring for Fiscal Year 2007. DOE/RL-2008-01, Rev. 0, U. S. Department of Energy, Richland, Washington.

Heid, K.R. 1956. Radioactive Contamination in liquid Wastes Discharged to Ground at Separations Facilities Through June, 1956. HW-44784, General Electric Company, Richland, Washington.

Kelty, G.G., Lindsey, K.A., Kos, S.E., and Price, R.E. 1995. Borehole Summary Report for the 200-UP2 Operable Unit, 200 West Area. BHI-00034, Rev. 01, Bechtel Hanford, Inc., Richland, Washington.

Kipp, K.L., and Mudd, R.D. 1974. Selected Water Table Contour Maps and Well Hydrographs For the Hanford Reservation, 1944-1973. BNWL-B-360, Pacific Northwest Laboratories, Richland, Washington.

Last G.V., Nichols, W.E., and Kincaid, C.T. 2006b. Geographic and Operational Site Parameters List (GOSPL) for Hanford Assessments. PNNL-14725, Rev. 1, Pacific Northwest National Laboratory, Richland, Washington.

Last, G.V., Freeman, E.J., Cantrell, K.J., Fayer, M.J., Gee, G.W., Nichols, W.E., Bjornstad, B.N., and Horton, D.G. 2006a. Vadose Zone Hydrogeology Data Package for Hanford Assessments. PNNL-14702, Rev. 1, Pacific Northwest National Laboratory, Richland, Washington. 
PNNL-24709, Rev. 2

RPT-DVZ-AFRI-030, Rev. 2

Last, G.V., Rockhold, M.L., Murray, C.J., and Cantrell, K.L. 2009. Selection and Traceability of Parameters To Support Hanford-Specific RESRAD Analyses - Fiscal Year 2008 Status Report. PNNL-18564, Pacific Northwest National Laboratory, Richland, Washington.

Maxfield, H.L. 1979. Handbook, 200 Areas Waste Sites. RHO-CD-673, Volume II. Rockwell Hanford Operations, Richland, Washington.

Paas, H.J., and Heid, K.R. 1955. Radioactive Contamination in liquid Waste Discharged to Ground at Separations Facilities Through June, 1955. HW-38562, General Electric Company, Richland, Washington.

PNL. 1975. Energy Systems Department. Resource Book-Decommissioning of Contaminated Facilities at Hanford. PNL-MA-588, Pacific Northwest Laboratory, Richland, Washington.

Rupert, H.G., and Heid, K.R. 1954. Summary of Liquid Radioactive Wastes Discharged to the Ground200 Areas, July 1952 through June 1954. HW-33591, General Electric Company, Richland, Washington.

Shearer, J.P. 2013. Hanford Site Waste Management Units Report. DOE/RL-88-30, Rev. 22, U.S. Department of Energy, Richland Operations Office, Richland, Washington.

Smith, D.L. 1992. 216-U-1 and 216-U-2 Cribs Interim Stabilization Final Report. WHC-SD-DD-TI063, Rev. 0, Westinghouse Hanford Company, Richland, Washington.

Stenner, R.D., Cramer, K.H., Higley, K.A., Jette, S.J., Lamar, D.A., McLaughlin, T.J., Sherwood, D.R., and Van Houten, N.C. 1988. Hazard Ranking System Evaluation of CERCLA Inactive Waste Sites at Hanford. Volume 2 - Engineered-Facility Sites (HISS Data Base). PNL6456, Vol. 2, Pacific Northwest Laboratory, Richland, Washington.

Van Luik, A.E., and Smith, R.M. 1982. 216-S-1 and S-2 Mixed Fission Product Crib Characterization Study. RHO-ST-39, Rockwell Hanford Operations, Richland, Washington. 


\section{Distribution}

No. of

Copies

1 U.S. Department of Energy Richland Operations Office

Mike Cline

(PDF)

1 Savannah River National Laboratory

DI Kaplan

(PDF)
No. of

\section{Copies}

7 Pacific Northwest National Laboratory MJ Truex

BD Lee

CD Johnson

NP Qafoku

MH Lee

MD Freshley

JE Szecsody

JE Kyle

M Tfaily

MMV Snyder

G Tartakovsky

II Leavy

EM McElroy

R Sahajpal

MM Carroll

D Appriou
(PDF)

(PDF)

(PDF)

(PDF)

(PDF)

(PDF)

(PDF)

(PDF)

(PDF)

(PDF)

(PDF)

(PDF)

(PDF)

(PDF)

(PDF)

(PDF) 


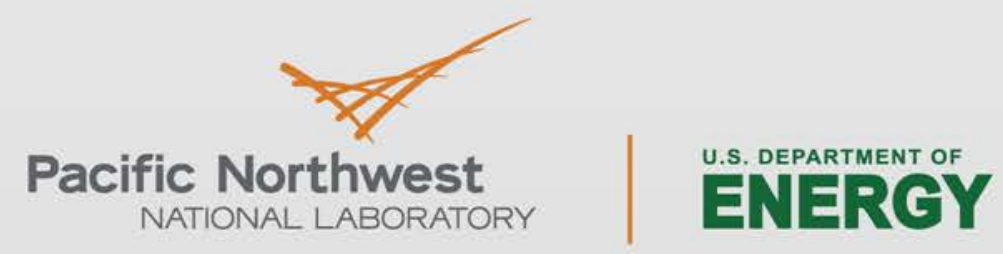

Proudly Operated by Battelle Since 1965

902 Battelle Boulevard

P.O. Box 999

Richland, WA 99352

1-888-375-PNNL (7665)

www.pnnl.gov 